\title{
The geochemistry of antimony in hydrothermal solutions
}

\author{
By \\ Nellie J. Olsen
}

\begin{abstract}
A thesis
submitted to the Victoria University of Wellington in partial fulfillment of the requirements for the degree of Doctor of Philosophy
\end{abstract}

School of Geography, Environment and Earth Sciences

Victoria University of Wellington

Wellington, New Zealand

November 2016 



\section{Abstract}

In this thesis, $30^{\circ} \mathrm{C}$ stibnite solubility experiments, ambient temperature $\mathrm{X}$-ray absorption spectroscopic measurements of antimony in solution, and high temperature ( 70 to $400^{\circ} \mathrm{C}$ ) stibnite solubility experiments were carried out in order to determine the aqueous antimony species present in equilibrium with stibnite in hydrosulfide solutions from $\mathrm{pH}=3.5$ to 12 and reduced sulfur concentrations from 0.001 to $0.1 \mathrm{~mol} \mathrm{~kg}^{-1}$. Both ambient and elevated temperature solubility studies were conducted using a flow-through apparatus containing a column of stibnite grains though which solutions were pumped. Above $100^{\circ} \mathrm{C}$, solubility experiments were conducted at slightly above saturated water vapour pressure to pressures of 300 bar.

At $30^{\circ} \mathrm{C}$, the stibnite solubility curve was best reproduced by a scheme of five species: $\mathrm{Sb}_{2} \mathrm{~S}_{4}{ }^{2-}$, $\mathrm{HSb}_{2} \mathrm{~S}_{4}^{-}, \mathrm{H}_{2} \mathrm{Sb}_{2} \mathrm{~S}_{5}{ }^{2-}, \mathrm{H}_{3} \mathrm{SbS}_{2} \mathrm{O}$, and $\mathrm{Sb}(\mathrm{OH})_{3}$. At higher temperatures $\left(\geq 70{ }^{\circ} \mathrm{C}\right)$, stibnite solubility at the conditions of the experiments was due to the following four species: $\mathrm{Sb}_{2} \mathrm{~S}_{4}{ }^{2-}, \mathrm{HSb}_{2} \mathrm{~S}_{4}-\mathrm{H}_{3} \mathrm{SbS}_{2} \mathrm{O}$, and $\mathrm{Sb}(\mathrm{OH})_{3}$. Equilibrium constants were determined for the following five heterogeneous solubility reactions for the temperature ranges listed:

$$
\begin{gathered}
S b_{2} S_{3}+2 H S^{-}<=>H_{2} S_{2} S_{5}^{2-} \\
S b_{2} S_{3}+H S^{-}<=>S_{2} S_{4}^{2-}+H^{+} \\
S b_{2} S_{3}+H S^{-}<=>\mathrm{HSb}_{2} S_{4}^{-} \\
0.5 \mathrm{Sb}_{2} S_{3}+0.5 H S^{-}+1.5 H^{+}+H_{2} O<=>H_{3} S b S_{2} O \\
0.5 \mathrm{Sb}_{2} S_{3}+3 H_{2} O<=>S b(O H)_{3}+1.5 H S^{-}+1.5 H^{+}
\end{gathered}
$$

Stibnite solubility was independent of pressure at $\leq 350^{\circ} \mathrm{C}$. At $\sim 400^{\circ} \mathrm{C}$, the solubility of stibnite was strongly dependent on pressure and decreased from $\mathrm{Sb}_{\text {total }}=0.015$ to $0.0003 \mathrm{~mol} \mathrm{~kg}^{-1}$ ( 2000 to 40 ppm) with a pressure decrease from 300 to 160 bars.

The Sb K-edge X-ray absorption spectroscopic (XAS) measurements of antimony in alkaline $(\mathrm{pH}=10.9$ to 12$)$ hydrosulfide solutions gave average first shell coordination environments that were consistent with the speciation model derived from solubility experiments for strongly alkaline solutions (i.e., $\mathrm{Sb}_{2} \mathrm{~S}_{4}{ }^{2-}$ and $\mathrm{Sb}(\mathrm{OH})_{3}$ ). XAS data enable the elimination of a speciation model involving only monomeric antimony complexes at strongly alkaline $\mathrm{pH}$.

Antimony speciation in near neutral to strongly alkaline $\mathrm{pH}$ 's is dominated by dimeric antimony-sulfide complexes at $30^{\circ} \mathrm{C}$ and sulfide concentrations $>0.001 \mathrm{~mol} \mathrm{~kg}^{-1}$. With increasing temperature, antimony speciation becomes increasingly dominated by $\mathrm{Sb}(\mathrm{OH})_{3}$. For hydrothermal solutions with sulfide concentrations between 0.0001 and $0.01 \mathrm{~mol} \mathrm{~kg}^{-1}$, antimony-sulfide complexes are predominant at $<100^{\circ} \mathrm{C}$, whereas antimonous acid, $\mathrm{Sb}(\mathrm{OH})_{3}$, is the main aqueous species at contributing to stibnite solubility at $>200^{\circ} \mathrm{C}$ with the speciation in the intervening temperature range 
being dependent on the $\mathrm{pH}$ and sulfide concentration of the solution. For higher sulfide concentrations (i.e., $\sim 0.1 \mathrm{~mol} \mathrm{~kg}^{-1}$ ), $\mathrm{HSb}_{2} \mathrm{~S}_{4}^{-}$and $\mathrm{Sb}_{2} \mathrm{~S}_{4}{ }^{2-}$ control stibnite solubility to higher temperatures. 


\section{Acknowledgements}

This $\mathrm{PhD}$ was supported by a Victoria University of Wellington PhD Scholarship. The research expenses and additional $\mathrm{PhD}$ support was provided by the Geothermal Resources Program at GNS Science. Measurements at the Australian Synchrotron were made possible by the New Zealand Synchrotron Group Limited (Projects AS132/XAS/6413 and AS142/XAS/7621) and the Royal Society of New Zealand. Additional support came from the Irene Memorial Scholarship, an extraordinarily well-targeted scholarship.

This research would have been impossible without the help and understanding of the excellent staff of the NZGAL (New Zealand Geothermal Analytical Laboratory) and the scientists and technical staff at the Wairakei Research Centre, in particular the irreplaceable Marshall Muller (a walking reference book for multiple analytical techniques), Dave Keen (a master of all electronic paraphernalia accompanying experimental apparati), and Ed Mroczek (without whom the VBA codes would have required much more sweat and pain).

Embarking on a $\mathrm{PhD}$ in a foreign country based at a research institution introduces its own challenges, and these acknowledgements would be incomplete without thanking my collegues at GNS and the community of Taupo. Thanks to the Wairakei Student Group, the Exphiles, and the Thursday Journal Club for coffee and chocolate and a university-y community away from a university. Special thanks must go to Kevin Lee, my ex-officemate of multiple years, for cat videos, wide-ranging conversations, and for putting up with pithy responses to grammatical questions. I have very much enjoyed my time in this community on the edge of a massive caldera and this is in large part due to the people I have shared it with: Renee and her zoo, St. Andrews, the members of the most flippant home group ever, the members of the least formal Frisbee club ever, the Edge Rock Wall, the (usually) Tuesday International Dinning Extravaganza, random beautiful people I have met skiing, and a few wonderful bad influences who have gotten me out on tramping, skiing, climbing, rowing, and mountain biking adventures (you know who you are). Finances in the last year have been greatly helped by the privilege of caring for multiple well-loved animal companions: so thanks to the people belonging to Phoenix, Charlie, Einstein, Moby, Remu, Urban, Afie, TK, and Pihanga, and to chickens 1, 2, and Fluffball. And finally, thanks to my parents for being who they are and letting me keep playing in the dirt.

Lastly, thanks to my two supervisors, Prof. Terry Seward and Dr. Bruce Mountain, who have provided invaluable help in formulating, accomplishing, and presenting this body of research. 


\section{Table of contents}

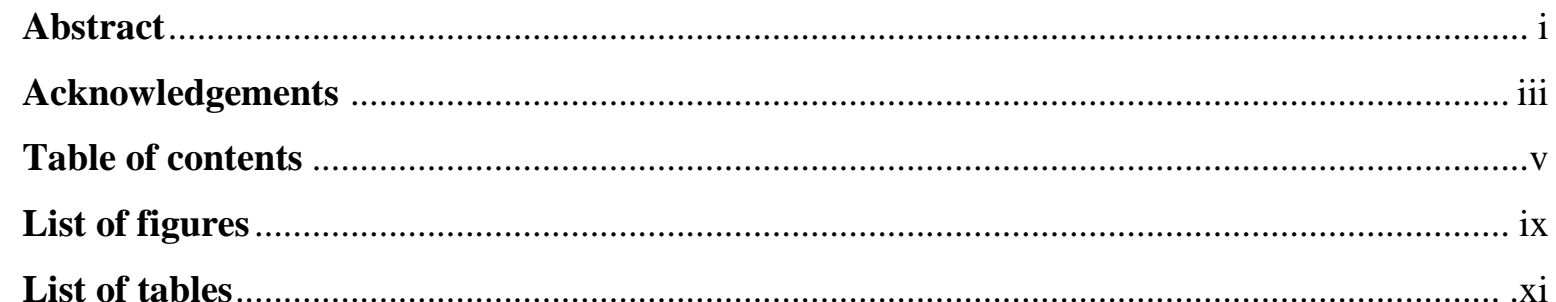

Chapter (1): Antimony geochemistry in hydrothermal solutions: Research context and experimental approach 1

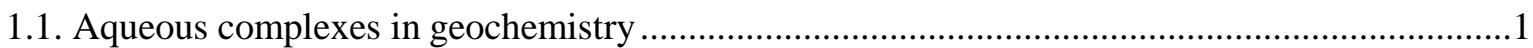

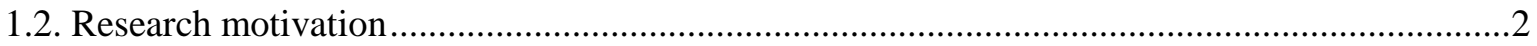

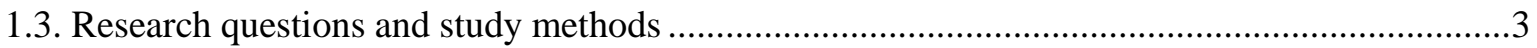

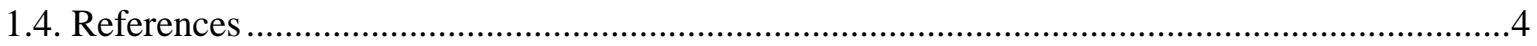

Chapter (2): Stibnite solubility and antimony speciation in aqueous sulfide solutions at $30^{\circ} \mathrm{C} \ldots \ldots . .5$

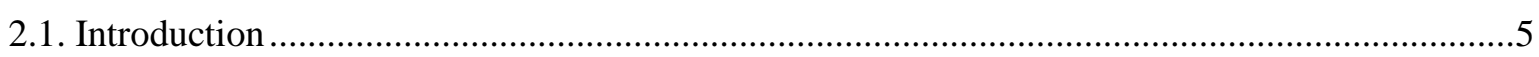

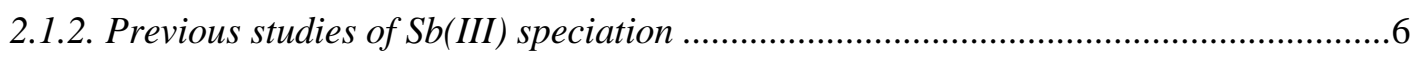

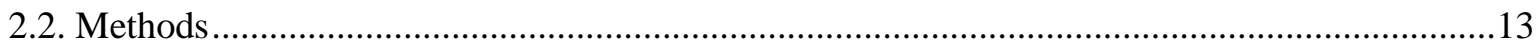

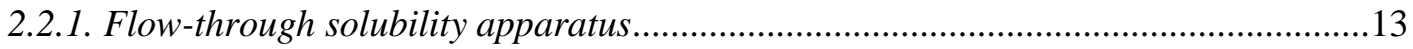

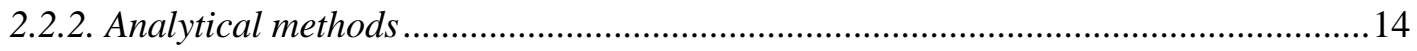

2.2.3. Selection of aqueous complexes and nonlinear least-squares fitting ..........................14

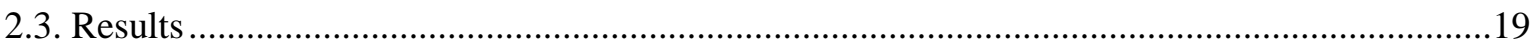

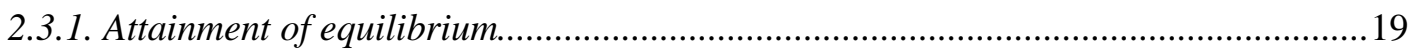

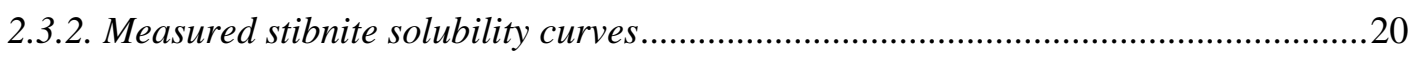

2.3.3. Determining equilibrium constants for antimony-sulfide complexes.........................22

2.3.4. Estimating an equilibrium constant for antimonous acid .........................................26

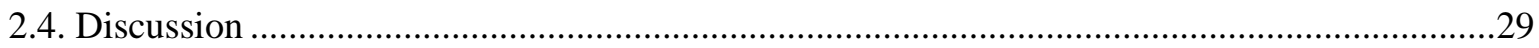

2.4.1. Comparison of $S b(I I I)-S(I I)$ speciation model with previous studies ........................29

2.4.2. Influence of sulfide concentration on aqueous antimony speciation............................32

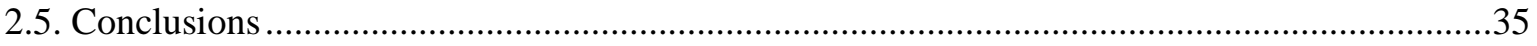

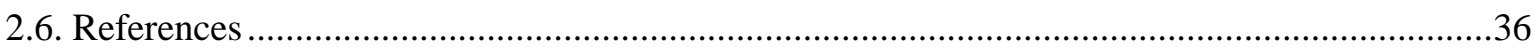

Chapter (3) X-ray absorption spectroscopy measurements of antimony-sulfide and -hydroxide complexes at stibnite saturation 
3.1. Introduction

3.1.2. Previous XAS studies of antimony in aqueous solutions .

3.1.3. X-ray near edge fine structure (XANES) at the Sb K-edge..................................... 43

3.2. Methods

3.3. Results

3.3.2. X-ray absorption spectra of solutions containing sufficient sulfide to complex antimony 48

3.3.3. X-ray absorption spectra of solutions containing insufficient sulfide to complex

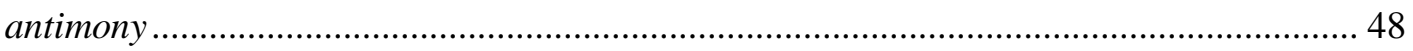

3.3.4. X-ray near edge fine structure of aqueous antimony complexes ............................. 49

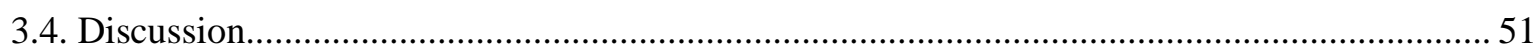

3.4.1. Motivation for combining solubility and spectroscopic approaches....................... 52

3.4.2. Antimony first coordination shells measured by EXAFS and predicted by stibnite solubility studies.

3.4.3. Re-evaluation of previous $S b(I I I)-S(I I) X A S$ studies and future research directions ....

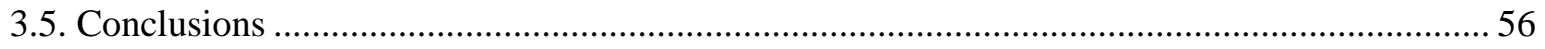

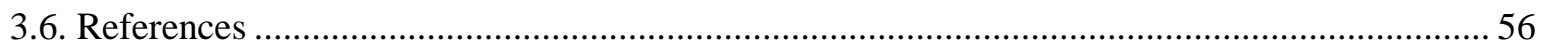

Chapter (4) Stibnite solubility and antimony speciation in hydrosulfide solutions from 70 to $400^{\circ} \mathrm{C}$

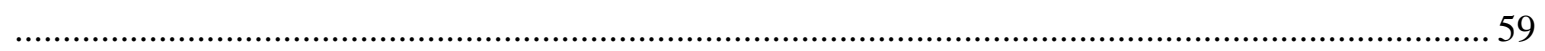

4.1. Introduction

4.1.2. Previous studies of antimony speciation in hydrosulfide solutions at elevated temperatures

4.1.3. Interpretations of the change in stibnite solubility's dependence on sulfide

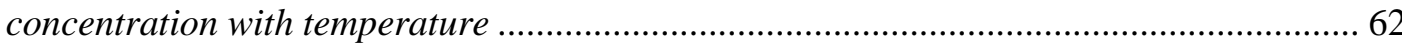

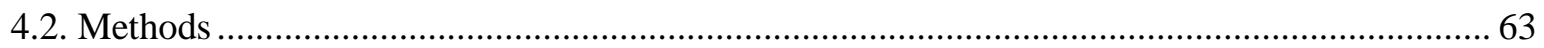

4.2.1. High pressure-temperature flow-through reaction system solution preparation...... 63

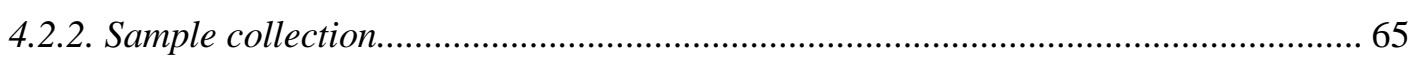

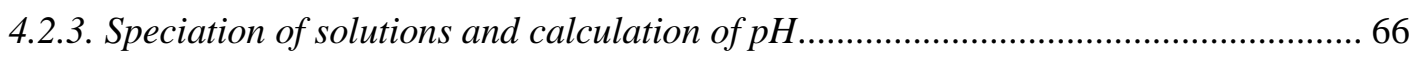

4.2.4. Fitting of heterogeneous solubility constants ...................................................... 68

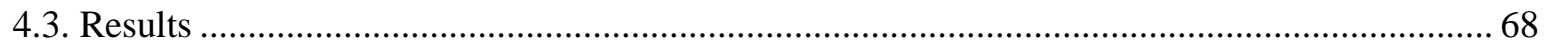

4.3.1. Attainment of equilibrium.......................................................................... 68

4.3.2. Pressure dependence of stibnite solubility from 100 to $350^{\circ} \mathrm{C}$.............................. 69

4.3.3. General changes in stibnite solubility with temperature ..................................... 70

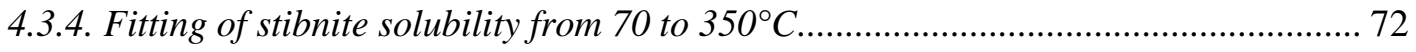

4.3.5. Stibnite solubility at $400^{\circ} \mathrm{C}$ in supercritical fluids and in fluids with vapour-like densities 
4.4. Discussion ....

4.4.1. Temperature dependence of equilibrium constants for $\mathrm{Sb}_{2} \mathrm{~S}_{4}{ }^{2-}, \mathrm{HSb} \mathrm{S}_{4} \mathrm{~S}_{4}$, and $\mathrm{Sb}(\mathrm{OH})_{3}$.

4.4.2. Evidence for changes in antimony speciation at elevated temperatures from previous spectroscopic studies.

4.4.3. Stibnite solubility and antimony speciation applied in natural hydrothermal fluids .....

4.5. Conclusions .91

4.6. References.

Chapter (5): Antimony geochemistry in hydrothermal solutions: Concluding remarks .97

5.1. Summary of results.

5.2. Scope of current study and avenues for future research. .99

5.2.2. Ruminations on the value of combining solubility and spectroscopic experimental techniques. 102

5.3. Implications for antimony transport by hydrothermal fluids in the Earth's crust 102

5.5. References. 104

Appendix (A) 107 


\section{List of figures}

Figure (2.1) Schematic of the occurrence and intensity of Raman spectral features in sodium sulfide solutions .10

Figure (2.2) Flow-through experimental setup at $30^{\circ} \mathrm{C}$ 13

Figure (2.3) Schematic of possible stibnite solubility versus $\mathrm{pH}$ at constant sulfide (A) or versus sulfide (B) for selected monomers and dimers.

Figure (2.4) Solubility of stibnite at different flow rates in solutions with constant $\mathrm{pH}$ and sulfide concentration

Figure (2.5) Stibnite solubility versus $\mathrm{pH}$ (A) and versus sulfide concentration (B through E) ..... 21

Figure (2.6) Comparison of the preferred speciation model (Fit $30-\mathrm{G}, \mathrm{A}$ ) and the $30^{\circ} \mathrm{C}$ solubility data (B) from the current study and models and solubility from previous solubility studies at ambient temperature.

Figure (2.7) Distribution of $\mathrm{Sb}(\mathrm{III})$ species at $30^{\circ} \mathrm{C}$ from $\mathrm{pH}=3$ to 12

Figure (2.8) Calculated stibnite solubility at $30^{\circ} \mathrm{C}$ from $\mathrm{pH}=3$ to 12 at constant total sulfide concentrations

Figure (3.1) Antimony K-edge XANES and first derivative spectra for representative mineral and solution samples from the current study.

Figure (3.2) The background subtracted EXAFS (A) and Fourier transforms (B) 48

Figure (3.3) Antimony K-edge energies for solid reference samples and experimental solutions...50 Figure (3.4) Local coordination of antimony within stibnite, an antimony(III)-sulfide monomer (represented by $\mathrm{H}_{3} \mathrm{SbS}_{3}$ ), and an antimony(III)-sulfide dimer (represented by $\mathrm{Sb}_{2} \mathrm{~S}_{4}{ }^{2-}$ )..... .53

Figure (3.5) First coordination shells of antimony(III) complexes at different sulfide concentrations

Figure (4.1) Previously published values of equilibrium constants for stibnite solubility in terms of $\mathrm{Sb}(\mathrm{OH})_{3}$ (Equation 4.2), $\mathrm{Sb}_{2} \mathrm{~S}_{4}{ }^{2-}$, and $\mathrm{HSb}_{2} \mathrm{~S}_{4}^{-}$(Equation 4.1)

Figure (4.2) Diagram of the flow-through autoclave reactor

Figure (4.3) Stibnite solubility at different flow rates at $150^{\circ} \mathrm{C}$ (A) and $200^{\circ} \mathrm{C}$ (B)

Figure (4.4) Variation in stibnite solubility with pressure at constant temperature input fluid conditions for five experiments from 100 to $350^{\circ} \mathrm{C}$.

Figure (4.5) Measured stibnite solubility from 70 to $350^{\circ} \mathrm{C}$ plotted with respect to $\mathrm{pH}$ (left) and sulfide concentration (right).

Figure (4.6) Stibnite solubility between 390 and $406^{\circ} \mathrm{C}$ versus input solution $\mathrm{pH}$ 80

Figure (4.7) Stibnite solubility at $\sim 400^{\circ} \mathrm{C}$ versus pressure (A) and fluid density (B) 81 
Figure (4.8) Stibnite solubility (A) and $\mathrm{K}_{1033}$ (B) between 390 and $406^{\circ} \mathrm{C}$ as a function of fluid density

Figure (4.9) Temperature dependence of logarithms of the equilibrium constants for heterogeneous stibnite solubility reactions involving $\mathrm{Sb}(\mathrm{OH})_{3}(\mathrm{~A}), \mathrm{Sb}_{2} \mathrm{~S}_{4}{ }^{2-}(\mathrm{B}), \mathrm{HSb}_{2} \mathrm{Sb}_{4}^{-}(\mathrm{C})$.

Figure (4.10) Previously published EXAFS results for antimony in sodium sulfide solutions at elevated temperature.

Figure (4.11) Stibnite solubility at $250^{\circ} \mathrm{C}$ for $\mathrm{S}^{2-}$ total $=0.0001,0.001,0.01$, and $0.1 \mathrm{~mol} \mathrm{~kg}^{-1}$

Figure (4.12) Stibnite solubility and reported antimony concentrations for fluids in the Rotokawa (A) and Ngawha (B) power stations.

Figure (4.13) Stibnite solubility and aqueous antimony speciation from $\mathrm{pH}=4$ to 9 for a $70^{\circ} \mathrm{C}$ fluid with $\sim 15$ ppm sulfide

Figure (5.1) Stibnite solubility and antimony species distribution from 300 to $80^{\circ} \mathrm{C}$ at $\mathrm{pH}=8$ and a sulfide concentration of $0.02 \mathrm{~mol} \mathrm{~kg}^{-1}$ at swvp. 100

Figure (5.2) Stibnite solubility and antimony species distribution from 270 to $70^{\circ} \mathrm{C}$ at $\mathrm{pH}=5.5(\mathrm{~A}, \mathrm{~B}$, and $\mathrm{C}$ ) and at $\mathrm{pH}=6.5$ for sulfide concentrations of $0.01,0.001$, and $0.0001 \mathrm{~mol} \mathrm{~kg}^{-1}$. 103

Figure (A.1) XRD of Chinese stibnite used in experiments. 107

Figure (A.2) SEM images of reacted stibnite from high temperature experiments 122 


\section{List of tables}

Table (2.1) Summary of experimental studies of aqueous $\mathrm{Sb}$ (III) speciation at $<100^{\circ} \mathrm{C}$..................7

Table (2.2) Heterogeneous solubility reactions used in nonlinear fitting ........................................17

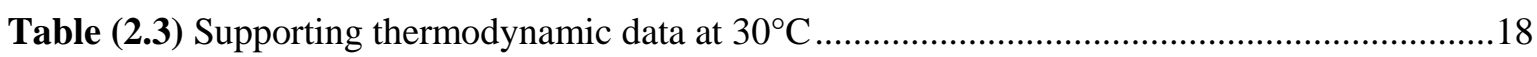

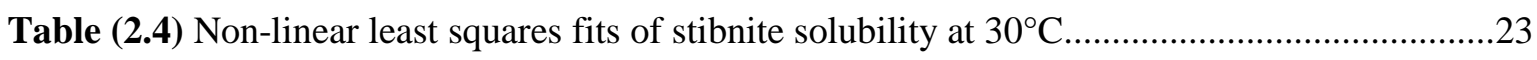

Table (2.5) Speciation models that failed to fit stibnite solubility at near neutral $\mathrm{pH}$ at $30^{\circ} \mathrm{C} \ldots \ldots \ldots .25$

Table (2.6) Non-linear fits of stibnite solubility at $30^{\circ} \mathrm{C}$ including deionized water experiments ...27

Table (2.7) Previously published values for $\mathrm{K}_{1033}$ 28

Table (2.8) Summary of proposed heterogeneous stibnite solubility reactions and the logarithms

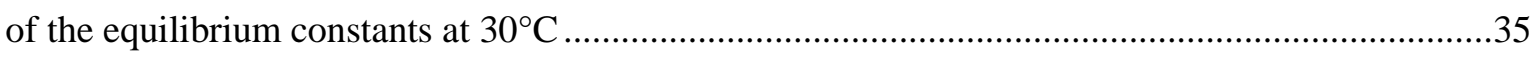

Table (3.1) Summary of previous EXAFS studies of antimony speciation in solution.....................41

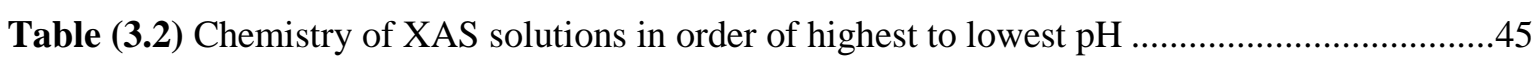

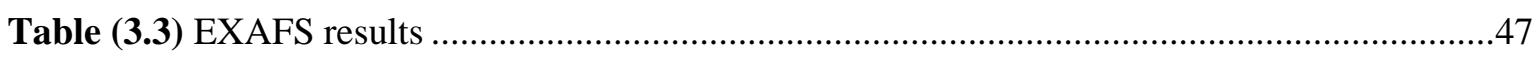

Table (3.4) Comparison of the average first shell coordination numbers in strongly alkaline solutions measured with EXAFS with those predicted by different speciation models derived from stibnite

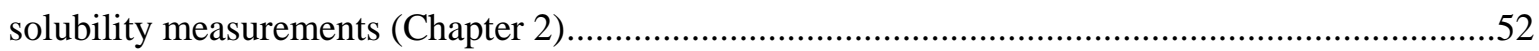

Table (4.1) Input fluid conditions for high temperature experiments...........................................65

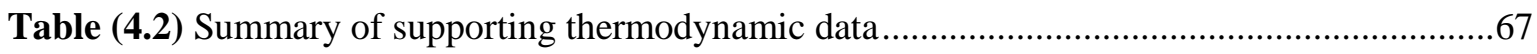

Table (4.3) Summary of heterogeneous stibnite solubility reactions ..........................................72

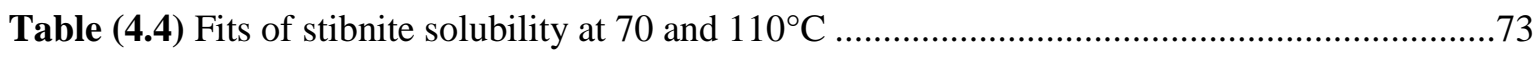

Table (4.5) Preferred fit of stibnite solubility at $150^{\circ} \mathrm{C}(150-\mathrm{A})$ and fits demonstrating misfit of

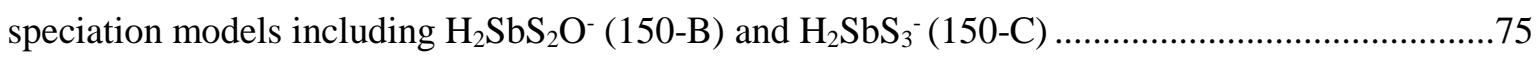

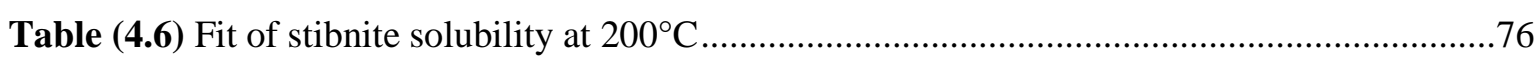

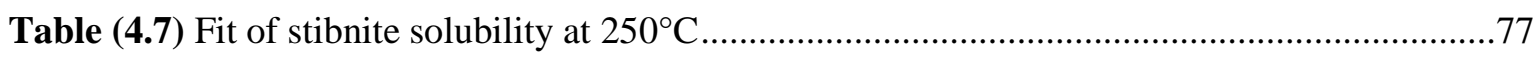

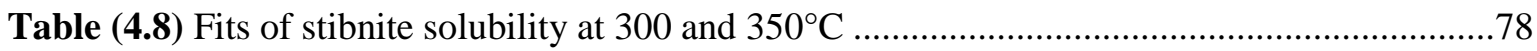

Table (4.9) Experimentally derived logarithms of equilibrium constants for heterogeneous stibnite

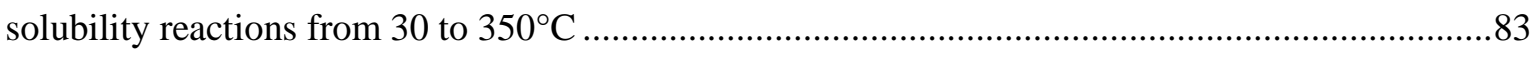

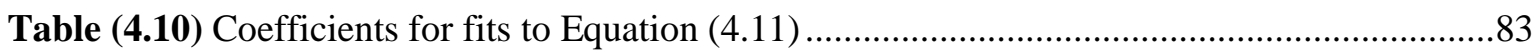

Table (A.1) Calculation of detection limits for antimony analyses by inductively-coupled plasmaoptical spectroscopy (ICP-OES) and hydride-generation atomic absorption spectroscopy (HG-AAS) 
Table (A.2) Stibnite solubility data at $30^{\circ} \mathrm{C}$.

Table (A.3) Stibnite solubility data from 70 to $400^{\circ} \mathrm{C}$. 


\section{Chapter (1):}

\section{Antimony geochemistry in hydrothermal solutions: Research context and experimental approach}

\subsection{Aqueous complexes in geochemistry}

The transport of elements by aqueous fluids is one of the main processes responsible for variably distributing metals within the Earth's crust. Within these fluids, metals and metalloids exist as metal-ligand complexes, in which anions or anionic molecules bind to one or more metal atoms to form a stable aqueous complex or an aqueous species. It is the stability of these complexes relative to that of possible mineral phases which determines the solubility of a given element in a given fluid. Since coordination complexes were first proposed in the late 1800s (Werner, 1893), detailed studies of the stability, stoichiometry, and geometry of metal complexes has enabled the prediction of metal solubility over a wide range of temperature, pressure, and chemical conditions.

The ability to predict metal behavior to high temperatures for different fluid chemical compositions is instrumental to understanding the formation of ore deposits from hydrothermal fluids, the behavior of metals during high-temperature industrial processes (particularly of interest for this study are mineral precipitation/dissolution reactions inside geothermal power stations), and the environmental and biological impacts of discharging high-temperature, metal-bearing solutions into the Earth's surface environment. Aqueous complexes may be studied using either solubility experiments, in which all physiochemical variables other than a metal's solubility are either carefully controlled or measured, or by a variety of other experimental methods including spectroscopy (e.g., visible/ultraviolet, Raman, and synchrotron X-ray absorption), potentiometry, and mass spectrometry as well as modern quantum chemical $a b$ initio methods. Unlike solubility studies, many of these other techniques probe the geometric and/or stoichiometric characteristics of the aqueous complexes directly. The goal of experimental studies is to identify the complexes in solution (i.e., the type and number of coordinating ligands complexed with the metal atoms), to quantify the stability of those complexes, and enable geochemical modeling by the derivation of equilibrium constants.

Both the stoichiometry of complexes and thermodynamic equilibrium constants can be derived from solubility data by nonlinear regression fitting of the data with equations defined by possible combinations of aqueous species. The speciation model that is best able to reproduce the measured solubility can then be used to predict solubility outside the range of the chemical conditions of the experiments. However, depending on the system being studied, several different complexes may produce mathematically identical solubility curves and therefore speciation models may in some 
situations be non-unique. Additionally, multiple different combinations of aqueous species may produce statistically indistinguishable fits given the uncertainty or scatter present in real solubility data. In contrast, spectroscopic techniques directly measure the complexes actually present in a solution at the time of analysis. Of importance to the current study, the average first shell coordination of dissolved metals in solutions can be determined by X-ray absorption spectroscopy (XAS) and these data may compliment and reinforce conclusions drawn from the solubility measurements.

Hydroxide $\left(\mathrm{OH}^{-}\right)$, sulfide $\left(\mathrm{HS}^{-}\right)$, chloride $\left(\mathrm{Cl}^{-}\right)$, and fluoride $\left(\mathrm{F}^{-}\right)$ligands are important inorganic ligands in natural aqueous fluids within the Earth's crust. For hydroxide and sulfide ligands, reaction with metal cations can result in deprotonation of the bound ligand to form negatively charged complexes. Obtaining accurate thermodynamic data for the interactions of metal cations with each of these ligands under the conditions of natural fluids is the prerequisite being able to model the transport and precipitation of metals in natural systems. The importance of different metal-ligand complexes can be predicted using the qualitative divisions of "hard" and "soft" ligands and metals, which were referred to as, respectively, "acids" and "bases" when the terminology was proposed by Pearson (1963). Hard metals and ligands tend to be small, strongly charged, and form ionic bonds by electron transfer. In contrast, soft metals and ligands are larger ions that are likely to be more weakly charged and form covalent bonds by the sharing of electrons. In general, hard metals will preferentially form complexes with hard ligands. Likewise, soft metals will form complexes with soft ligands. Of the common inorganic ligands mentioned above, $\mathrm{OH}^{-}$and $\mathrm{F}^{-}$are hard bases, $\mathrm{Cl}^{-}$is borderline between hard and soft bases, and sulfide is a soft base. The $3+$ valence state of antimony ( $\mathrm{Sb}^{3+}$ or $\mathrm{Sb}(\mathrm{III})$ ) is a borderline acid and so may be expected to have significant interactions with both hard and soft ligands. Additionally, chemical bonding in aqueous solutions becomes increasing ionic in character with increasing temperature in response to changes in the structure of water. Thus, the preference of antimony for $\mathrm{HS}^{-}$versus $\mathrm{OH}^{-}$ligands may be expected to change significantly over the temperature range from ambient temperatures in surface and groundwaters to elevated temperatures in hydrothermal fluids.

\subsection{Research motivation}

This current study combines solubility and X-ray absorption spectroscopic approaches to investigate the interaction of antimony $(\mathrm{Sb})$ with hydroxide $\left(\mathrm{OH}^{-}\right)$and sulfide $\left(\mathrm{HS}^{-}\right)$ligands in reduced fluids from ambient temperatures to $400^{\circ} \mathrm{C}$. Antimony is a trace element that is of geological interest because it can be strongly associated with precious metals, particularly gold ( $\mathrm{Au})$, in many hydrothermal ore deposits (Boyle and Jonasson, 1984; Dill, 1998; Goldfarb et al., 2005; Nevia et al., 2006). The element is of economic importance because it is currently used in semiconductors, batteries, metal alloys, flame retardants, and as an additive to some ceramic and glass (Filella et al., 2002), and it may have applications thin-film solar cell technology (e.g., Sinsermsuksakul et al., 2012; Suehiro et al., 2015). Finally, antimony is of environmental concern because it is toxic to aquatic and 
terrestrial life and because it forms stable aqueous antimony-hydroxide complexes at ambient temperature in near neutral $\mathrm{pH}$ fluids, a chemical property that can make antimony soluble, and therefore mobile, in surface and groundwaters (Wilson et al., 2010). Antimony's interactions with sulfide ligands are the focus of this study because antimony-sulfide complexes are known to be present in natural hydrothermal fluids and reliable thermodynamic data for antimony-sulfide complexes necessary to model antimony chemistry in these fluids is currently unavailable.

\subsection{Research questions and study methods}

The purpose of the current endeavor has been to determine antimony speciation present in reducing sulfide-containing (i.e., $\mathrm{H}_{2} \mathrm{~S}$ and $\mathrm{HS}^{-}$) solutions and to measure stibnite solubility in these solutions from ambient temperature to supercritical conditions along the liquid-vapor saturation line. Two complementary techniques have been employed to gain insight into antimony-sulfide interactions (speciation): (1) the solubility of stibnite was measured using flow-through reactors from 30 to $400^{\circ} \mathrm{C}$ and (2) the synchrotron X-ray absorption spectra (both XANES and EXAFS) of dissolved antimony in solutions at stibnite saturation were measured at ambient temperature. The results from these studies are presented in the following chapters and are briefly summarized below.

\section{Chapter (2): Stibnite solubility and antimony speciation in aqueous sulfide solutions at $30^{\circ} \mathrm{C}$}

The results of $30^{\circ} \mathrm{C}$ stibnite solubility studies conducted using a flow-through experimental setup are presented in this chapter. Experimental fluids contained sulfide concentrations from 0.008 to $0.1 \mathrm{~mol} \mathrm{~kg}^{-1} \mathrm{~S}^{2-}{ }_{\text {total }}$ and the $\mathrm{pH}$ was varied from $\mathrm{pH}=4$ to 12 . In addition, previous studies of antimony speciation in hydrosulfide solutions using batch solubility experiments, potentiometric studies, spectroscopic measurements, ab initio calculations, and ion chromatography methods are summarized, including attempts to determine antimony speciation in fluids from hot springs. The computational approach used to determine complex stoichiometries from solubility data is also developed.

\section{Chapter (3): X-ray absorption spectroscopy measurements of antimony-sulfide and-}

\section{hydroxide complexes at stibnite saturation}

The results from XAS measurements of the $\mathrm{Sb} \mathrm{K}$-edge from fluids equivalent to those studied in Chapter (2) are presented and the complimentary aspects and apparent discrepancies between the spectroscopic and solubility data are considered in detail.

Chapter (4): Stibnite solubility and antimony speciation in hydrosulfide solutions from 70 to $400^{\circ} \mathrm{C}$

This chapter builds on the low temperature experiments presented in Chapter (2), beginning with a summary of previous high temperature studies and finishing with new high-temperature stibnite solubility experiments conducted in a flow-through autoclave reactor. Experiments were conducted 
from 70 to $400^{\circ} \mathrm{C}$ at slightly above saturated water vapor pressure (swvp) using fluids with sulfide concentrations between 0.003 to $0.05 \mathrm{~mol} \mathrm{~kg}^{-1} \mathrm{~S}^{2-}$ total and $\mathrm{pH}$ from $\mathrm{pH}=3.5$ to 8.5 .

The thesis ends with concluding remarks presented after Chapter (4). Expanded background for each topic, methodologies, and references are included in each chapter. An appendix follows Chapter (5). Additionally, two manuscripts presenting the research in this thesis are in preparation for publication. The first manuscript combines Chapters (2) and (3), and the second manuscript covers the higher temperature solubility experiments.

\subsection{References}

Boyle, R.W., Jonasson, I.R., 1984. The geochemistry of antimony and its use as an indicator element in geochemical prospecting. J. Geochem. Explor. 20, 233-302.

Dill, H.G., 1998. Evolution of Sb mineralisation in modern fold belts: a comparison of the $\mathrm{Sb}$ mineralisation in the Central Andes (Bolivia) and Western Carpathians (Slovakia). Min. Dep. 33, 359-378.

Filella, M., Belzile, N., Chen, Y.-W., 2002. Antimony in the environment: a review focused on natural waters I. Occurence. Earth-Science Reviews 57, 125-176.

Goldfarb, R.J., Baker, T., Dubé, B., Groves, D.I., Hart, C.J.R., Gosselin, P., 2005. Distribution, character, and genesis of gold deposits in metamorphic terranes. Econ. Geol. 100, 407-450.

Nevia, A.M.R., Andras, P., Ramos, J.M.F., 2006. Antimony quartz and antimony-gold quartz veins from nothern Portugal. Goldschmidt Conference Abstracts A442.

Pearson, R.G., 1963. Hard and soft acids and bases. J. Am. Chem Soc. 85, 3533-3539.

Sinsermsuksakul, P., Chakraborty, R., Kim, S.B., Heald, S.M., Buonassisi, T., Gordon, R.G., 2012. Antimony-doped tin(II) sulfide thin films. Chemistry of Materials 24, 4556-4562.

Suehiro, S., Horita, K., Yuasa, M., Tanaka, T., Fujita, K., Ishiwata, Y., Shimanoe, K., Kida, T., 2015. Synthesis of copper-antimony-sulfide nanocrystals for solution-processed solar cells. Inorganic Chemistry 54, 7840-7845.

Werner, A., 1893. Beitrag zur Konstitution anorganischer Verbindungen. Zeitschrift fur anorganische Chemie 267-330.

Wilson, S.C., Lockwood, P.V., Ashley, P.M., Tighe, M., 2010. The chemistry and behaviour of antimony in the soil environment with comparisons to arsenic: a critical review. Environ. Pollut. 158, 1169-1181. 


\section{Chapter (2):}

\section{Stibnite solubility and antimony speciation in aqueous sulfide solutions at $30^{\circ} \mathrm{C}$}

\subsection{Introduction}

Antimony is a metalloid that is widely distributed in natural fluids in trace amounts and is of environmental and regulatory concern because of its toxic and carcinogenic properties. The maximum contaminant level set by the United States Environmental Protection Agency for antimony in drinking water is $6 \mathrm{ppb}$ (EPA, 2009). In unpolluted ground and surface waters, the antimony concentration is rarely $>10 \mathrm{ppb}\left(\sim 10^{-7} \mathrm{~mol} \mathrm{~kg}^{-1} \mathrm{Sb}\right)$ and usually $<1 \mathrm{ppb}$ (Filella et al., 2002; Wilson and WebsterBrown, 2009). However in geothermal fluids, the antimony concentration is frequently $>10 \mathrm{ppb}$ and can be as high as 1000 ppb (Smith, 1987; Wilson et al., 2007; Landrum et al., 2009; Wilson et al., 2012; Hannington et al., 2016). In natural waters, antimony occurs as complexes with chloride $\left(\mathrm{Cl}^{-}\right)$, hydroxide $\left(\mathrm{OH}^{-}\right)$, and sulfide or thio ( $\left.\mathrm{HS}^{-}\right)$ligands. Antimony complexed with organic ligands may also contribute a significant portion of the dissolved antimony in natural settings where the concentrations of the organic ligands are at mol kg-1 concentrations (Tella and Pokrovski, 2009). Antimony(III)-chloride complexes are limited to acidic, strongly saline conditions (Belevantsev et al., 1998a; Pokrovski et al., 2006). The neutral antimony(III)-hydroxide complex, $\mathrm{Sb}(\mathrm{OH})_{3}$ (i.e., antimonous acid) is the stable antimony(III)-hydroxide complex in all but the most acidic or alkaline fluids from ambient to near supercritical conditions (Zakaznova-Herzog and Seward, 2006). However at ambient temperatures, when moderate concentrations of sulfide are present $\left(>0.0001 \mathrm{~mol} \mathrm{~kg}^{-1} \mathrm{~S}^{2-}\right.$ total), stibnite solubility due to $\mathrm{Sb}(\mathrm{OH})_{3}$ is limited to only a few tens of ppb except at moderately to strongly alkaline $\mathrm{pH}$. In such reducing, sulfidic natural waters, antimony also forms stable complexes with sulfide ligands, and these antimony-sulfide complexes can enhance stibnite solubility by multiple orders of magnitude above that due to $\mathrm{Sb}(\mathrm{OH})_{3}$ alone.

Despite numerous, previous experimental and theoretical studies, there is still appreciable disagreement concerning the stoichiometry and stability of antimony(III)-sulfide species at ambient conditions (see Table 2.1 and associated references). The aim of this current study was therefore to determine the stoichiometry and stability of antimony(III)-sulfide and -hydroxide-sulfide complexes in aqueous solutions at $30^{\circ} \mathrm{C}$ by measuring the solubility of stibnite over a range of $\mathrm{pH}$ and total reduced sulfur concentration. The solubility data have been complemented by X-ray absorption spectroscopic measurements of antimony(III) coordination in solutions equilibrated with stibnite. 
Since the 1950s, the speciation of antimony and the solubility of stibnite $\left(\mathrm{Sb}_{2} \mathrm{~S}_{3}\right)$ in the presence of reduced sulfur has been studied using a variety of methods. Most solubility studies indicate the presence of an antimony-sulfide dimer, while many spectroscopy studies fail to find evidence for a dimer and, along with chromatography studies, have been interpreted in terms of antimony-sulfide monomers. As summarised in Table (2.1), multiple stoichiometries for antimony and sulfide atoms in antimony-sulfide complexes have been proposed in the $\mathrm{Sb}$ (III)-S(II)- $\mathrm{H}_{2} \mathrm{O}$ system. Additionally, a solubility study in which both sulfide $\left(\mathrm{H}_{2} \mathrm{~S}+\mathrm{HS}^{-}\right)$and elemental sulfur $\left(\mathrm{S}^{0}\right)$ were present introduced the possibility of a mixed valence $\mathrm{Sb}(\mathrm{III}, \mathrm{V})$ dimers (Helz, 2002), which then prompted theoretical calculations of the stability of such mixed valence complexes and use of these complexes to interpret spectroscopic data (Tossell, 2003a; Planer-Friedrich and Scheinost, 2011). The unresolved contradictions in antimony(III) speciation displayed in Table (2.1) and the possibility of complicated changes in speciation during oxidation, have highlighted the need for further study of antimony in the $\mathrm{Sb}$ (III)-S(II)- $\mathrm{H}_{2} \mathrm{O}$ system.

To determine the solubility of stibnite and the speciation of $\mathrm{Sb}$ (III) in the presence of sulfide, solubility experiments have been conducted using natural stibnite in a flow-through apparatus at $30^{\circ} \mathrm{C}$ over the $\mathrm{pH}$ range from $\mathrm{pH}=4$ to 12 and with sulfide concentrations from 0.008 to $0.1 \mathrm{~mol} \mathrm{~kg}^{-1} \mathrm{~S}^{2-}$ total. From the dependence of stibnite solubility on sulfide concentration and $\mathrm{pH}$, the stoichiometries of possible complexes were constrained. The speciation model which best fitted the data was chosen using nonlinear least squares regression fitting of the solubility data. The average first shell coordination environment around antimony derived from X-ray absorption spectroscopy measurements, which are described in Chapter (3), proved useful in selecting the solubility model in alkaline solutions with low sulfide concentrations. The equilibrium constants presented here can be used to predict stibnite solubility and $\mathrm{Sb}(\mathrm{III})$ speciation at ambient temperatures at reducing conditions in which the sulfide concentration is $>\sim 0.005 \mathrm{~mol} \mathrm{~kg}^{-1} \mathrm{~S}^{2-}$ total. In the presence of sufficient concentrations of sulfide, it was found that dissolved antimony forms negatively charged antimonysulfide dimers in circumneutral and alkaline fluids. These dimers transition to $\mathrm{Sb}(\mathrm{OH})_{3}$, and possibly mixed-ligand antimony monomers, as the sulfide concentration decreases.

\subsubsection{Previous studies of $S b(I I I)$ speciation}

Antimony complexation in the $\mathrm{Sb}(\mathrm{III})-\mathrm{S}(\mathrm{II})-\mathrm{H}_{2} \mathrm{O}$ system at ambient temperature has been studied using a variety of methods, including batch solubility experiments (Babko and Lisetskaya, 1956; Arnston et al., 1966; Learned, 1966; Kolpakova, 1982; Krupp, 1988; Akinifiyev et al., 1994; Belevantsev et al., 1998b; Shikina and Zotov, 1999), potentiometric and spectroscopic measurements (Shestitko and Demina, 1971; Wood, 1989; Gushchina et al., 2000; Mosselmans et al., 2000; Sherman et al., 2000; Planer-Friedrich and Scheinost, 2011), ab initio calculations (Tossell, 1994, 2003a, b), and ion chromatography techniques (Planer-Friedrich and Scheinost, 2011; Planer-Friedrich and Wilson, 2012). Antimony-sulfide complexes have also been detected in natural solutions using ion 
Table (2.1) Summary of experimental studies of aqueous $\mathrm{Sb}$ (III)-S(II) speciation at $<100^{\circ} \mathrm{C}$.

\begin{tabular}{|c|c|c|c|c|c|}
\hline Species & $\mathbf{p H}$ & $\mathrm{S}\left(\mathrm{mol} \mathrm{kg}{ }^{-1}\right)^{a}$ & S:Sb ratio & Method & Reference \\
\hline $\mathrm{SbS}_{2}^{-}, \mathrm{SbS}_{3}{ }^{3-}, \mathrm{Sb}_{2} \mathrm{~S}_{5}^{4-}$ & alkaline & $0.005-3 \mathrm{Na}_{2} \mathrm{~S}$ & & $\begin{array}{l}\text { solubility and phase } \\
\text { equilibrium }\end{array}$ & Fiala and Konopik (1950) \\
\hline $\mathrm{SbS}_{2}^{-} \cdot \mathrm{SbS}_{3}{ }^{3-}$ & $0.6-12.3$ & $0.005-0.1$ & & solubility $b$ & Akeret (1953) \\
\hline $\mathrm{SbS}_{2}^{-}$ & (a) $8-9$ & (a) 0.04 & $1.5-200$ & solubility $b$ & Babko and Lisetskaya \\
\hline $\mathrm{Sb}(\mathrm{OH})_{2}^{-}$ & (b) $10-11$ & (b) no added sulfide & & & \\
\hline $\mathrm{Sb}_{4} \mathrm{~S}_{7}{ }^{2-}$ & alkaline & $\mathrm{Na}_{2} \mathrm{~S}$ & $4-5$ & solubility & Arnston et al. (1966) \\
\hline $\mathrm{SbS}_{3}{ }^{3-}, \mathrm{Sb}_{4} \mathrm{~S}_{7}{ }^{2-}, \mathrm{Sb}_{2} \mathrm{~S}_{5}{ }^{4-}$ & alkaline & $\begin{array}{l}0.25-2.5 \mathrm{Na}_{2} \mathrm{~S} \text { with } \\
0-0.12 \mathrm{Sb}_{2} \mathrm{~S}_{3}\end{array}$ & $4-60$ & potentiometry & $\begin{array}{l}\text { Shestiko and Demina } \\
\text { (1971) }\end{array}$ \\
\hline $\mathrm{H}_{2} \mathrm{Sb}_{2} \mathrm{~S}_{4}, \mathrm{HSb}_{2} \mathrm{~S}_{4}^{-}, \mathrm{Sb}_{2} \mathrm{~S}_{4}{ }^{2-}$ & $3-9$ & $0.0001-0.006$ & $0.5-10^{4}$ & $\begin{array}{l}\text { solubility and } \\
\text { reinterpretation of Akeret } \\
\text { (1953), Babko and } \\
\text { Lisetskaya (1956) }\end{array}$ & Kolpakova $(1971,1982)$ \\
\hline $\mathrm{H}_{2} \mathrm{Sb}_{2} \mathrm{~S}_{4}, \mathrm{HSb}_{2} \mathrm{~S}_{4}{ }^{-}, \mathrm{Sb}_{2} \mathrm{~S}_{4}{ }^{2-}$ & $3-12$ & $\begin{array}{l}0.0002-0.13, \text { most } \\
\sim 0.01\end{array}$ & $10-10^{6}$ & solubiilty & Krupp (1988) \\
\hline $\begin{array}{l}\mathrm{H}_{2} \mathrm{Sb}_{2} \mathrm{~S}_{4}, \mathrm{HSb}_{2} \mathrm{~S}_{4}^{-}, \mathrm{Sb}_{2} \mathrm{~S}_{4}{ }^{2-} \\
\mathrm{Sb}(\mathrm{OH})_{3}\end{array}$ & & & & $\begin{array}{l}\text { recalc. of published data } \\
\text { with newdata for water } \\
\text { and } \mathrm{H}_{2} \text { S. Does not include } \\
\text { Krupp (1988) }\end{array}$ & Spycher and Reed (1989) \\
\hline $\begin{array}{l}\mathrm{Sb}_{2} \mathrm{~S}_{4}{ }^{2-} \text { or } \mathrm{Sb}_{4} \mathrm{~S}_{7}^{2-} \\
\mathrm{SbS}_{2}{ }^{-} \text {or } \mathrm{SbS}_{3}{ }^{3-}\end{array}$ & alkaline & \multicolumn{2}{|l|}{$\begin{array}{l}\text { (a) } 0.95 \mathrm{Na}_{2} \mathrm{~S}+0.1 \mathrm{Sb} 1 \\
\text { (b) } 0.95 \mathrm{Na}_{2} \mathrm{~S}+0.005- \\
0.05 \mathrm{Sb}\end{array}$} & Raman & Wood (1989) \\
\hline $\mathrm{HSbS}_{3}{ }^{2-}, \mathrm{H}_{2} \mathrm{Sb}_{2} \mathrm{~S}_{4}, \mathrm{SbS}_{2}{ }^{2-}$ & & & & $\begin{array}{l}\text { gas phase quantum } \\
\text { chemical calculations }\end{array}$ & Tossell (1994) \\
\hline $\mathrm{Sb}_{2} \mathrm{~S}_{4}{ }^{2-}$, minor $\mathrm{SbS}_{2-}$ & alkaline & 0.914 & $1-150$ & $\begin{array}{l}\text { Raman, observed similar } \\
\text { spectral features as Wood } \\
\text { (1989) }\end{array}$ & Guschina et al. (2000) \\
\hline First shell CN 3-4 S atoms & $8-13$ & $0.01-1$ & $3-150$ & EXAFS $^{c}$ & Mosselmans et al. (2000) \\
\hline First shell CN 4-5 S atoms & & & & EXAFS $^{c, d}$ & Sherman et al. (2000) \\
\hline $\mathrm{HSb}(\mathrm{III}, \mathrm{V})_{2} \mathrm{~S}_{5}{ }^{-}, \mathrm{Sb}(\mathrm{V})_{2} \mathrm{~S}_{6}{ }^{2-}$ & $7.6-10$ & $0.0002-0.1$ & $2-50$ & solubility and UV-vis ${ }^{e}$ & Helz et al. (2002) \\
\hline $\begin{array}{l}\text { First shell CN } 3-4 \mathrm{~S} \text { atoms } \\
\text { First shell CN } 2 \mathrm{~S}+1 \mathrm{O} \text { aton }\end{array}$ & $\begin{array}{l}\text { alkaline } \\
\mathrm{ms}\end{array}$ & $\begin{array}{l}\text { (a) } 0.1-0.2 \\
\text { (b) } 0.02\end{array}$ & $\begin{array}{l}\text { (a) } 10-20 \\
\text { (b) } 2\end{array}$ & EXAFS $^{d, f}$ & $\begin{array}{l}\text { Planer-Friedrich and } \\
\text { Scheinost (2011) }\end{array}$ \\
\hline
\end{tabular}

$a$ The sulfur concentration is the amount of free sulfur, if reported, or total sulfur including that complexed with antimony if only the starting solution composition was available.

$b$ amorphous $\mathrm{Sb}$-sulfide used

$c$ range in first shell coordination numbers rounded to nearest whole number derived from fits of EXAFS spectra

$d$ polysulfides and $\mathrm{Sb}(\mathrm{V})$ possibly present based upon solution preparation methods

$e$ most experiments in $\mathrm{Sb}(\mathrm{III})-\mathrm{S}(\mathrm{II})-\mathrm{S}(0)-\mathrm{O}-\mathrm{H}$ sy stem, solution equilibrated with elemental sulfur $\left(\mathrm{S}^{0}\right)$

$f$ anoxic and oxic sample preparation methods used in study. Results from anoxic samples reported in the table 
chromatography combined with mass spectrometry (Planer-Friedrich and Scheinost, 2011; PlanerFriedrich and Wilson, 2012; Ullrich et al., 2013). Various authors have also periodically collected previously published equilibrium constants, critically evaluated them, and produced compilations of thermodynamic data (Spycher and Reed, 1989; Akinifiyev et al., 1994; Zotov et al., 2003; Filella and May, 2005; Obolensky et al., 2007). The models for antimony-sulfide speciation proposed in the experimental studies are summarised in Table (2.1).

\section{Solubility studies}

Several of the earlier studies measured stibnite solubility in alkaline sodium sulfide $\left(\mathrm{Na}_{2} \mathrm{~S}\right)$ solutions (Arnston et al., 1966; Learned, 1966), while other studies have considered stibnite or amorphous antimony-sulfide solubility over a wider range of sulfide and $\mathrm{pH}$ conditions (Babko and Lisetskaya, 1956; Kolpakova, 1982; Krupp, 1988). Solubility experiments conducted in $\mathrm{Na}_{2} \mathrm{~S}$ solutions indicated that stibnite solubility increases with increasing sulfide content at least up to $250^{\circ} \mathrm{C}$ in alkaline solutions (Arnston et al., 1966; Learned, 1966). These data require aqueous antimony complexes containing a stoichiometric ratio of $\mathrm{S}: \mathrm{Sb}$ that is greater than 1.5:1 under the high $\mathrm{pH}$ conditions (> pH 11) and generally high sulfide concentrations ( 0.05 to $\left.3 \mathrm{~mol} \mathrm{~kg}^{-1} \mathrm{~S}_{\text {total }}\right)$ of the $\mathrm{Na}_{2} \mathrm{~S}$ solutions. The various studies interpreted their results in terms of $\mathrm{Sb}_{2} \mathrm{~S}_{4}{ }^{2-}, \mathrm{Sb}_{4} \mathrm{~S}_{7}{ }^{2-}, \mathrm{SbS}_{2}{ }^{-}$, or a mixture of these species.

Other solubility studies have investigated antimony complexation over a wider range of sulfide and pH conditions. Babko and Lisetskaya (1956) determined when oversaturation of antimony sulfide occurred, as indicated by the formation of colloidal suspensions, for relatively high $\mathrm{pH}$ solutions with and without added sulfide. Due to this experimental approach, the authors were probably measuring the solubility of an amorphous phase; however the solubilities measured are not dissimilar from later, more carefully controlled studies that indicated the presence of antimony-sulfide species. Kolpakova $(1971,1982)$ conducted stibnite solubility experiments at moderate to low $\mathrm{pH}$ from 25 to $95^{\circ} \mathrm{C}$ and re-evaluated earlier studies to argue for the protonated dimer, $\mathrm{HSb}_{2} \mathrm{~S}_{4}{ }^{-}$,

predominating over a wide range of $\mathrm{pH}$. Krupp (1988) studied stibnite solubility from $\mathrm{pH}=3$ to 12 and 25 to $350^{\circ} \mathrm{C}$ with the majority of his experiments conducted using solutions with $0.01 \mathrm{~mol} \mathrm{~kg}^{-1} \mathrm{~S}^{2-}$ total. Additional solutions with 0.0003 to $0.13 \mathrm{~mol} \mathrm{~kg}^{-1} \mathrm{~S}^{2-}$ total were used by Krupp to determine the relationship between sulfide and stibnite solubility.

At $25^{\circ}$ C, Krupp proposed the same speciation model as Kolpakova $(1971,1982)$ with $\mathrm{H}_{2} \mathrm{Sb}_{2} \mathrm{~S}_{4}$ dominant at $<\mathrm{pH} 4, \mathrm{HSb}_{2} \mathrm{~S}_{4}{ }^{-}$dominant from $\mathrm{pH} \sim 4$ to $\sim 9$, and $\mathrm{Sb}_{2} \mathrm{~S}_{4}{ }^{2-}$ dominant at $>\mathrm{pH}$ 9.5. At temperatures $>\sim 120^{\circ} \mathrm{C}$, stibnite became more soluble with decreasing sulfide concentration when the sulfide concentration was $<\sim 0.01 \mathrm{~mol} \mathrm{~kg}^{-1} \mathrm{~S}^{2-}$ total. Krupp interpreted this change as due to hydroxide ligands replacing the non-bridging sulfurs in $\mathrm{H}_{\mathrm{x}} \mathrm{Sb}_{2} \mathrm{~S}_{4}{ }^{\mathrm{x}-2}$ to form a mixed hydrosulfide dimer (i.e., $\mathrm{Sb}_{2} \mathrm{~S}_{2}(\mathrm{OH})_{2}$ ). More recent studies that investigated stibnite and $\mathrm{Sb}$ (III)-oxide (senarmonite and valentinite) solubility at elevated temperatures and at lower sulfide concentrations than those used by Krupp (1987) have rejected the mixed species $\mathrm{Sb}_{2} \mathrm{~S}_{2}(\mathrm{OH})_{2}$ in favour of increasing stability of $\mathrm{Sb}(\mathrm{OH})_{3}$ with increasing temperature (Akinifiyev et al., 1994; Shikina and Zotov, 1999; Zotov et al., 2003). 


\section{Potentiometric studies}

Shestitko and Demina (1971) investigated the stoichiometry of antimony complexes using an Sb electrode immersed in sodium sulfide solutions with sulfide concentrations from $\sim 0.25$ to $\sim 2.5$ mol kg-1. Their results indicated a change in the slope of the electrode potential's dependence on the sulfide concentration as the sulfide concentration increased. The authors interpreted this slope change as a transition from multiple polynuclear antimony species with a high number of coordinating sulfurs (13 to 18 ) to a single antimony species with three coordinating sulfurs. The existence of a polynuclear species with ten or more sulfur atoms is unique to this study and may be an artifact of the method. No effort was made in the study to account for the impact of complexed sulfur on free sulfide activity or changes in activity coefficients in concentrated alkaline solutions.

\section{Raman spectroscopy}

Raman spectroscopy can identify spectral features of individual species but cannot assign these features to the unique species without additional constraints from measurements of standards or estimates of vibrational spectra from theoretical calculations. The high concentrations of antimony in solution (> $0.005 \mathrm{~mol} \mathrm{~kg}^{-1}$ ) required for Raman spectroscopy require high $\mathrm{pH}$ solutions for $25^{\circ} \mathrm{C}$ experiments. As a result, Raman measurements are most comparable to the solubility studies conducted in $\mathrm{Na}_{2} \mathrm{~S}$ solutions or at high $\mathrm{pH}$. Raman spectroscopic measurements of antimony sulfide complexes were conducted by Wood (1989) and Gushchina et al. (2000) for similar solutions of high sulfide concentrations $\left(\sim 0.9 \mathrm{~mol} \mathrm{~kg}^{-1}\right)$ and antimony concentrations up to $\sim 0.1 \mathrm{~mol} \mathrm{~kg}^{-1}$. Solutions in both studies were prepared by dilution of a $\mathrm{Sb}(\mathrm{III})-\mathrm{Na}_{2} \mathrm{~S}$ solution with a solution of similar $\mathrm{Na}_{2} \mathrm{~S}$ concentration such that antimony was progressively diluted at a constant $\mathrm{Na}_{2} \mathrm{~S}$ concentration. Wood (1989) found four spectral features attributable to antimony species: a broad, weak band at $314 \mathrm{~cm}^{-1}$; a somewhat more intense band at $369 \mathrm{~cm}^{-1}$; a prominent shoulder near $350 \mathrm{~cm}^{-1}$; and a shoulder at 380 $\mathrm{cm}^{-1}$. The number of distinguishable features increased with increasing antimony concentration. Using predicted vibrational frequencies for a variety of species and measured vibrational frequencies for antimony solids and the $\mathrm{SbS}_{4}^{-}$ion, the spectra were interpreted as representing a dimer $\left(\mathrm{Sb}_{2} \mathrm{~S}_{4}{ }^{2-}\right.$ or $\left.\mathrm{Sb}_{4} \mathrm{~S}_{7^{2-}}\right)$ that decomposed to a bent pyramidal species $\left(\mathrm{SbS}_{2}{ }^{-}\right.$or $\left.\mathrm{SbS}_{3}{ }^{3-}\right)$ upon dilution.

Gushchina et al. (2000) observed three spectral features similar to those found by Wood (1989): weak peak at $\sim 318 \mathrm{~cm}^{-1}$; an intense peak at $\sim 366 \mathrm{~cm}^{-1}$; and a shoulder at $380 \mathrm{~cm}^{-1}$. They also found an additional small peak at $280 \mathrm{~cm}^{-1}$ in their solutions that had the highest antimony concentration relative to the sulfide concentration. This solution had seven times more $\mathrm{Sb}$ than the most concentrated solution of Wood (1989) and thus a lower molar S:Sb. The observed changes in intensity for these four peaks with respect to $\mathrm{S}: \mathrm{Sb}$ ratio are shown schematically in Figure (2.1). They did not observe a shoulder at $\sim 350 \mathrm{~cm}^{-1}$ on the main peak at $\sim 370 \mathrm{~cm}^{-1}$. The spectra for two less concentrated solutions were measured up to $250^{\circ} \mathrm{C}$ at $25-50^{\circ} \mathrm{C}$ intervals. With increasing temperature, the peaks at $280 \mathrm{~cm}^{-1}$ and $380 \mathrm{~cm}^{-1}$ became more pronounced, particularly $\geq 175^{\circ} \mathrm{C}$, while all other peaks diminished. As concluded earlier by Wood (1989), Gushchina et al. (2000) resolved that no 
Figure (2.1) Schematic of the occurrence and intensity of Raman spectral features in sodium sulfide solutions. Features observed by Gushchina et al. (2000) and Wood (1989) with (A) increasing S:Sb ratio in solution and (B) increasing temperature for a solution with $\mathrm{S}: \mathrm{Sb} 6: 1$.
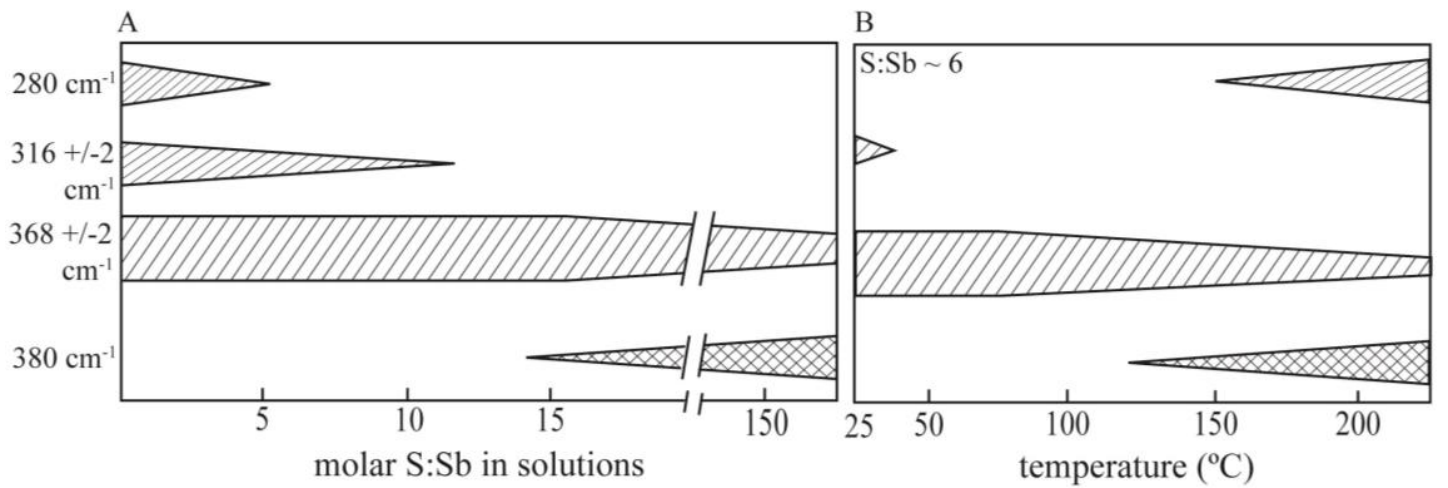

single species could account for the all of the observed peaks shown qualitatively in Figure (2.1), and consequently postulated that more than one antimony species was present.

\section{$X$-ray absorption spectroscopy $(X A S)$}

The extended X-ray absorption fine structure (EXAFS) portion of the XAS spectra probes the average atomic environment around the target element and provides information on the number of neighboring atoms and their distance from the targeted element. EXAFS cannot distinguish between a mixed-ligand sulfide-hydroxide species (e.g., $\mathrm{Sb}_{2} \mathrm{~S}_{4}(\mathrm{OH})_{2}$ ) and mixture of species with sulfide and hydroxide ligands (e.g., $\mathrm{H}_{2} \mathrm{Sb}_{2} \mathrm{~S}_{4}$ and $\mathrm{Sb}(\mathrm{OH})_{3}$ ). Similar to Raman spectroscopy, EXAFS studies have been limited to antimony concentrations $\geq 0.001 \mathrm{~mol} \mathrm{~kg}^{-1}$. Sherman et al. (2000) measured Sb K-edge spectra in $\mathrm{Na}_{2} \mathrm{~S}$ solutions without the exclusion of atmospheric oxygen during sample preparation. At ambient temperatures, the fitting of their spectra showed coordination numbers of $\sim 4$ sulfur atoms and $\mathrm{Sb}-\mathrm{S}$ distances of 2.33 to $2.36 \AA$, which is consistent with an antimony $(\mathrm{V})$-sulfide complex such as $\mathrm{Sb}(\mathrm{V}) \mathrm{S}_{4}{ }^{3-}$. This suggests that antimony(III)-sulfide complexes, or thioantimonites, may be easily oxidised to antimony(V)-sulfide complexes, or thioantimonates, in the presence of oxygen. Later studies summarised in Table (2.1) in which oxygen was apparently excluded found spectra consistent with an $\mathrm{Sb}$ (III) atom surrounded by three sulfurs, although some fits revealed first coordination shells that were intermediate between antimony(III)- and antimony(V)-sulfide species (Mosselmans et al., 2000; Planer-Friedrich and Scheinost, 2011). Oxygen atoms were found within the first coordination shell of antimony when the molar ratio of $\mathrm{S}: \mathrm{Sb}$ in solution was $\leq 2: 1$ (Planer-Friedrich and Scheinost, 2011) and when low sulfide solutions were measured at temperatures above $150^{\circ} \mathrm{C}$ (Mosselmans et al., 2000).

\section{Ab initio}

Tossell (1994) calculated the gas-phase minimum energy geometries and Raman vibrational spectra for a number of antimony-sulfide monomers and oligomers, including $\mathrm{H}_{\mathrm{x}} \mathrm{SbS}_{3}{ }^{\mathrm{x}-3}, \mathrm{H}_{\mathrm{x}} \mathrm{Sb}_{2} \mathrm{~S}_{4}{ }^{\mathrm{x}-2}$, and $\mathrm{H}_{4} \mathrm{Sb}_{2} \mathrm{~S}_{5}$, and for one mixed-ligand complex, $\mathrm{Sb}_{2} \mathrm{~S}_{2}(\mathrm{OH})_{2}$. In addition, the author estimated the effect of the interaction of one water with $\mathrm{SH}^{-}$and the previously mentioned $\mathrm{Sb}$ (III) monomers. The 
calculations produced estimates for $\mathrm{Sb}-\mathrm{S}$ distances, gas-phase vibrational frequencies, hydrated distances, the binding energy of $\mathrm{H}_{2} \mathrm{O}$ complexes, Born hydration energies, and gas-phase and solution phase proton affinities. In the gas phase, the transition from a fully protonated monomer, $\mathrm{H}_{3} \mathrm{SbS}_{3}$, to a fully protonated dimer, $\mathrm{H}_{2} \mathrm{Sb}_{2} \mathrm{~S}_{4}$, was favourable but the progression to neutral trimer, $\mathrm{H}_{3} \mathrm{Sb}_{3} \mathrm{~S}_{6}$, was not. The exchange of $\mathrm{SH}^{-}$ligands for $\mathrm{OH}^{-}$ligands in an $\mathrm{Sb}(\mathrm{III})$ dimer was favoured only above $300^{\circ} \mathrm{C}$.

Tossell later re-evaluated and expanded his calculations from 1994 to include oxidation energetics for $\mathrm{Sb}$ (III) and mixed-valence $\mathrm{Sb}$ (III,V) dimers (Tossell, 2003a), and UV-vis absorbances for $\mathrm{Sb}(\mathrm{III})$ and $\mathrm{Sb}(\mathrm{V})$ monomers and dimers (Tossell, 2003b). Gas-phase calculations in Tossell (2003a) included geometries, Raman active vibrational frequencies, and energies for singly and doubly deprotonated $\mathrm{Sb}(\mathrm{III}), \mathrm{Sb}(\mathrm{V})$, and $\mathrm{Sb}\left(\mathrm{III}, \mathrm{V}\right.$ ) dimers (i.e., $\mathrm{Sb}_{2} \mathrm{~S}_{4}{ }^{2-}, \mathrm{HSb}_{2} \mathrm{~S}_{4}{ }^{-}, \mathrm{Sb}_{2} \mathrm{~S}_{5}{ }^{2-}$, and $\mathrm{Sb}_{2} \mathrm{~S}_{6}{ }^{2-}$ ). Combining these calculations with estimates of hydration energies, the author produced energetics for the oxidation of $\mathrm{Sb}(\mathrm{III})$ dimers to $\mathrm{Sb}(\mathrm{III}, \mathrm{V})$ and $\mathrm{Sb}(\mathrm{V})$ dimers by either polysulfide (modelled as $\mathrm{S}_{4} \mathrm{H}^{-}$) or elemental sulfur (modelled as $\mathrm{S}_{8}$ ) in solution. In terms of aqueous phase energetics, the oxidation of an $\mathrm{Sb}$ (III) dimer to a mixed $\mathrm{Sb}$ (III, V) dimer was favoured but the next step to an $\mathrm{Sb}$ (V) dimer was not. In addition, this oxidation reaction was most favoured when the dimers were doubly rather than singly deprotonated. However, these estimates of aqueous phase energetics were very sensitive to the estimation of hydration energies and are much less accurate than the gas-phase calculations. In one of the complementary papers, these calculations were extended to include estimates of absorbances in the UV-vis wavelengths and estimated pKa's for Sb monomers (Tossell, 2003b). The reported estimates of $\mathrm{pKa}^{\prime}$ 's for $\mathrm{HSbS}_{4}{ }^{-}$and $\mathrm{HSbS}_{3}{ }^{2-}$ were 5.4 and 9.1, respectively. Thus, the author predicted that the last deprotonation step to a fully-deprotonated species, would occur at $\mathrm{pH}=5.4$ for an $\mathrm{Sb}(\mathrm{V})$-sulfide monomer and at $\mathrm{pH}=9.1$ for an $\mathrm{Sb}(\mathrm{III})$-sulfide monomer.

\section{Ion Chromatography}

Ion chromatography (IC) separates aqueous species based upon their retention within a reactive column. When linked with an elemental analysis technique such as mass spectrometry (MS), the combined techniques can determine the relative abundance of, and $\mathrm{Sb}: \mathrm{S}$ ratio within, individual complexes. Within the last five years, IC-ICP-MS has begun to be applied to antimony-sulfide speciation in synthetic and geothermal fluids, as detailed in the following.

In synthetic $\mathrm{Sb}(\mathrm{III})-\mathrm{S}(\mathrm{II})$ aqueous solutions, five antimony species have been detected: $\mathrm{Sb}(\mathrm{OH})_{3}\left(\right.$ as $\mathrm{SbO}_{3}{ }^{3-}$ in the conditions of the reactive column), $\mathrm{Sb}(\mathrm{OH})_{6}{ }^{-}$, two $\mathrm{Sb}(\mathrm{V})$-sulfide species, and an unknown antimony species (Planer-Friedrich and Scheinost, 2011; Planer-Friedrich and Wilson, 2012). The two $\mathrm{Sb}(\mathrm{V})$-sulfide species had $\mathrm{S}: \mathrm{Sb}$ ratio of $3: 1$ and $4: 1$, which are referred to as trithioantimonate and tetrathioantimonate, respectively. Trithioantimonite, e.g., $\mathrm{H}_{\mathrm{x}} \mathrm{SbS}_{3}{ }^{\mathrm{x}-3}$, was not detected by IC-ICP-MS even when a species with this S:Sb ratio was found in nearly identical solutions using X-ray absorption spectroscopy (Planer-Friedrich and Scheinost, 2011). This is in line with two recent ion chromatography studies that failed to directly detect trithioarsenite $\left(\mathrm{H}_{\mathrm{x}} \mathrm{AsS}_{3}{ }^{\mathrm{x}-3}\right)$ in prepared trithioarsenite standards and in reducing geothermal fluids where thioarsenites would be expected (Planer-Friedrich et al., 2010; Keller et al., 2014). With IC-ICP-MS, Planer-Friedrich et al. 
(2010) detected arsenite $\left(\mathrm{AsO}_{3}^{3-}\right)$ instead of trithioarsenite $\left(\mathrm{H}_{\mathrm{x}} \mathrm{AsS}_{3}{ }^{\mathrm{x}-3}\right)$ in synthetic solutions in which $\mathrm{H}_{\mathrm{x}} \mathrm{AsS}_{3}{ }^{\mathrm{x}-3}$ was identified by the same study with X-ray absorption spectroscopy. Keller et al. (2014) noted that samples that should have had $\mathrm{H}_{\mathrm{x}} \mathrm{AsS}_{3}{ }^{\mathrm{x}-3}$ instead had a split arsenite peak when trithioarsenite standards and fluids from the hot springs of the Geysir geothermal area (Iceland) were measured by Ion chromatography-hydride generation-atomic florescence spectrometry (IC-HG-AFS), which suggests that trithioarsenite was changed to arsenite during the analytical process. Both studies attributed the failure to directly detect thioarsenites to differences in the ligand exchange rates of arsenite and arsenate. The exchange rate for $\mathrm{OH}^{-}$ligands in arsenite is on the order of milliseconds, but that for $\mathrm{OH}^{-}$in arsenate is on the order of days (Okumura et al., 1995). Assuming that the exchange rates for $\mathrm{SH}^{-}$ligands behave similarly, the $\mathrm{SH}^{-}$ligands in $\mathrm{As}(\mathrm{HS})_{3}$ will be rapidly replaced by $\mathrm{OH}^{-}$ when a sample is diluted by the alkaline eluent that is used in a chromatographic column, and as a result will be measured as $\mathrm{As}(\mathrm{OH})_{3}$. Accurate speciation of antimony IC-ICP-MS may be limited by a similar instability of antimony-sulfide complexes when diluted by alkaline eluents.

An additional difficulty to the direct measurement of antimony species in solution is the instability of $\mathrm{Sb}$ (III) species during storage, which was noted as part of LC-ICP-MS studies. In synthetic $\mathrm{Sb}$ (III)-S(II) samples prepared or analysed under oxic conditions, tetrathioantimonate, e.g., $\mathrm{SbS}_{4}{ }^{3-}$, was observed instead of the expected $\mathrm{Sb}$ (III)-sulfide complex with three sulfurs when the molar S:Sb ratio in solution was greater than five (Planer-Friedrich and Scheinost, 2011). During storage or upon the addition of an oxidant, there may be a step-wise transformation from $\mathrm{Sb}(\mathrm{HS})_{3}$ to $\mathrm{SbS}_{4}{ }^{3-}$ to $\mathrm{Sb}(\mathrm{OH})_{3}$ and finally to $\mathrm{Sb}(\mathrm{OH})_{6}$. Certain conditions of storage, namely freezing, refrigeration and the exclusion of light, can slow but not entirely stop this oxidation (Planer-Friedrich and Wilson, 2012). Under similar laboratory conditions, antimony-sulfide species appear more sensitive to oxidation than equivalent arsenic species. Thus, due to their instability during storage or in the conditions within a chromatographic column, the ability to infer the presence, absence, or thermodynamic stability of antimony(III)-sulfide species using ion chromatography approaches may be limited.

Within natural hot springs, antimony-sulfide species have been detected by LC-ICP-MS in fluids collected from springs in the U.S.A. (Yellowstone) and in New Zealand (Waiotapu and OrakeiKorako). At Yellowstone, the abundance of $\mathrm{Sb}(\mathrm{V})$ complexed with three or four sulfur atoms increased with $\mathrm{pH}$ and sulfide content and contributed up to $30 \%$ of the dissolved antimony present (Planer-Friedrich and Scheinost, 2011). Antimony-sulfide species were not detected at Steamboat Springs, CO or at Steamboat Springs, NV by the same study, possibly due to competition with arsenic for the available sulfide. Recently, Ullrich et al. (2013) detected arsenite, arsenate, antimonite and a selection of thioarsenates and thioantimonates in hot spring waters in New Zealand using IC-ICP-MS. At Waiotapu, antimonite $\left(\mathrm{SbO}_{3}{ }^{3-}\right)$ was the major species ( 60\%) detected in a slightly acidic sulfidic hot spring, in addition to lesser amounts of antimonate, trithioantimonate, and, in one study, tetrathioantimonate (Planer-Friedrich and Wilson, 2012; Ullrich et al., 2013). With increased distance from the geothermal source, the amount of antimonate increased while all thioantimonates eventually 
disappeared when dissolved sulfide became undetectable (Ullrich et al., 2013). In contrast, fluids from Orakei-Korako, an alkaline hot spring with lower sulfide concentrations, had higher dissolved total antimony but a lower proportion of $\mathrm{Sb}(\mathrm{V})$-sulfide species (Planer-Friedrich and Wilson, 2012).

The high concentrations of antimony measured in reducing fluids discharging from sulfidic hot springs into the earth's surface environment, as summarised above, demonstrate that antimony's behaviour in these types of fluids is critical to how antimony is distributed within the Earth's crust. Because the speciation of antimony in natural systems has proved difficult to study directly, the current and previous experimental studies provide much needed insight into how stibnite solubility and aqueous speciation respond to changes in sulfide concentration and $\mathrm{pH}$. In this Chapter, measurements of stibnite solubility at $30^{\circ} \mathrm{C}$ and antimony speciation models derived from that data are presented. The $30^{\circ} \mathrm{C}$ speciation models developed in this Chapter will also serve as the starting point for interpreting the high temperature data presented in Chapter (4).

\subsection{Methods}

\subsubsection{Flow-through solubility apparatus}

The flow-through apparatus shown schematically in Figure (2.2) was used to conduct solubility experiments. The apparatus consisted of (a) a 21 glass flask in which solutions were prepared, (b) a Teflon-lined HPLC pump with sapphire pistons that transferred solution at a constant flow rate from the flask through the reactive column, and (c) a $30 \mathrm{~cm}$ long glass column containing stibnite that was mounted in an oven which was maintained at constant temperature. Finally, solution samples were collected in a gas-tight syringe from the column outlet located in the oven. The stibnite was natural stibnite from Wuning County in the Jianxi Province, China (XRD pattern in Figure A.1), and was crushed, cleaned with deionised water, and sieved to achieve a grain size of 0.5 to $1 \mathrm{~mm}$ prior to use in the column. Three thermocouples measured the temperature inside the oven at the inlet, midpoint, and outlet of the glass column. The reported temperature is the average of these three values

Figure (2.2) Flow-through experimental setup at $30^{\circ} \mathbf{C}$. A sulfide solution is first made in a 21 flask (A) then pumped with an HPLC pump (B) through a glass column containing crushed stibnite in an oven (C) before being collected in a syringe for periodic sampling.

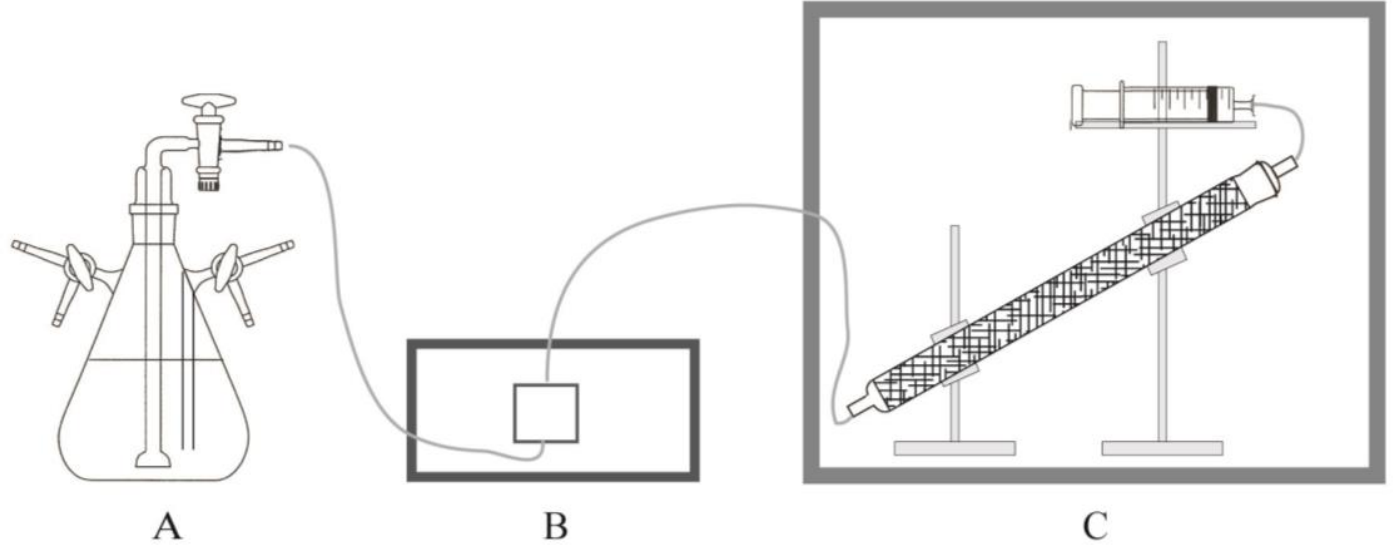


with an estimated uncertainty of $0.4^{\circ} \mathrm{C}$.

For each experiment, a deoxygenated sulfide solution was first prepared in a 21 flask. A sufficient amount of $\mathrm{NaOH}$ was added to 1.5 to 1.751 of $18.3 \mathrm{M} \Omega$ deionised water to adjust the $\mathrm{pH}$. This solution was then deoxygenated by bubbling high purity nitrogen (BOC 99.999\%) through the solution while the flask sat in an ultrasonic bath for a minimum of 30 minutes. After deoxygenation, sulfide was added by bubbling a $\mathrm{H}_{2} \mathrm{~S} / \mathrm{N}_{2}$ gas mixture through the solution until the solution was saturated with respect to the $\mathrm{H}_{2} \mathrm{~S} / \mathrm{N}_{2}$ gas mixture $\left(1 \% \mathrm{H}_{2} \mathrm{~S}, 5 \% \mathrm{H}_{2} \mathrm{~S}, 10 \% \mathrm{H}_{2} \mathrm{~S}, 20 \% \mathrm{H}_{2} \mathrm{~S}, 50 \% \mathrm{H}_{2} \mathrm{~S}\right.$, and $98 \% \mathrm{H}_{2} \mathrm{~S}$ gas mixtures were used). The flask was then connected directly to an HPLC pump, and all lines up to the stibnite column were purged with the deoxygenated solution prior to commencement of each experiment. To maintain a constant sulfide concentration, the appropriate $\mathrm{H}_{2} \mathrm{~S} / \mathrm{N}_{2}$ gas mixture was bubbled through the headspace of the flask during an experiment.

\subsubsection{Analytical methods}

Solution $\mathrm{pH}$ was measured with a Metrohm $\mathrm{pH}$ meter (with temperature probe) which was calibrated against standard buffer solutions daily. The concentrations of reduced sulfur were determined by idiometric back titration. The antimony concentration was measured by inductivelycoupled plasma-optical emission spectroscopy (ICP-OES) for concentrations greater than 50 to 100 $\operatorname{ppb}\left(\sim 4 \times 10^{-7}\right.$ to $8 \times 10^{-7}$ to mol $\left.\mathrm{kg}^{-1}\right)$ and by hydride-generation atomic absorption spectroscopy (HGAAS) for lower concentrations. In preparation for ICP-OES samples, a $1 \mathrm{~mol} \mathrm{~kg}^{-1} \mathrm{NaOH}$ solution was added to the sample for a final concentration of $0.08 \mathrm{~mol} \mathrm{~kg}^{-1} \mathrm{NaOH}$ in the samples to prevent the precipitation of antimony in the presence of sulfide. The ICP-OES detection limit was $10 \mathrm{ppb}(\sim$ $1 \times 10^{-7} \mathrm{~mol} \mathrm{~kg}^{-1}$ ) with an estimated uncertainty of $\sim 20 \%$ at the detection limit. For HG-AAS, the detection limit and estimated uncertainty were $0.3 \mathrm{ppb}\left(\sim 3 \times 10^{-9} \mathrm{~mol} \mathrm{~kg}^{-1}\right)$ and $\sim 20 \%$, respectively (Table A.1). Generation of volatile antimony hydrides from $\mathrm{Sb}$ (III) for HG-AAS requires a sample matrix of $10 \%(\mathrm{v} / \mathrm{v}) \mathrm{HCl}$. Thus, samples to be analyzed by HG-AAS were diluted with an $\mathrm{HCl}$ solution to achieve the desired final $\mathrm{HCl}$ concentration and then bubbled with nitrogen to remove dissolved sulfide and prevent antimony loss. Potassium iodide was added to HG-AAS samples prior to analysis to assure that all antimony was reduced to $\mathrm{Sb}(\mathrm{III})$. The matrices of the antimony standards were matched to the samples for both analysis techniques.

\subsubsection{Selection of aqueous complexes and non-linear least squares fitting}

The stoichiometry of the dominant complexes in solution determines the dependence of stibnite solubility on changes in solution $\mathrm{pH}$ and sulfide concentration. These relationships were used to select the possible species present, as explained in the following, and equilibrium constants for the selected species were determined using a non-linear least squares fitting procedure to fit the measurements of stibnite solubility. 


\section{Development of solubility curves and selection of complexes}

Stibnite solubility as $\mathrm{Sb}^{3+}$ in the absence of complexation can be represented by the following equation when reduced sulfur occurs as HS

$$
0.5 S b_{2} S_{3(S)}+1.5 H^{+}=S b^{3+}+1.5 H S^{-}
$$

The solubility product for this reaction is

$$
K_{s p}=a_{S b^{3+}} \cdot a_{H S^{-}} 1.5 \cdot a_{H^{+}}{ }^{-1.5}
$$

where $a_{i}$ is the activity of an aqueous species. If complexing by aqueous sulfide and/or $\mathrm{OH}^{-}$occurs, then the complexes that form can be represented by the general stoichiometry

$$
\mathrm{Sb}_{\mathrm{x}} \mathrm{S}_{\mathrm{y}} \mathrm{O}_{\mathrm{z}} \mathrm{H}_{\mathrm{w}}{ }^{3 \mathrm{x}-2 \mathrm{y}-2 \mathrm{z}+\mathrm{w}}
$$

in which $x, y, z$, and $w$ are variables that represent the coefficients of the constituent atoms in the complex. The general equation for the formation of the complexes takes the form of

$$
x S b^{3+}+y H S^{-}+(w-y-2 z) H^{+}+z H_{2} O=S b_{x} S_{y} O_{z} H_{w}^{3 x-2 y-2 z+w}
$$

Equation (2.3) can be solved for $\mathrm{Sb}^{3+}$ to give

$$
S b^{3+}=\frac{1}{x} S b_{x} S_{y} O_{z} H_{w}^{3 x-2 y-2 z+w}-\frac{y}{x} H S^{-}+\frac{y+2 z-w}{x} H^{+}+\frac{z}{x} H_{2} O
$$

which can be substituted into (2.1) to give a general equation for the solubility of stibnite as sulfidehydroxide complexes

$$
x \cdot 0.5 S b_{2} S_{3(S)}=S b_{x} S_{y} O_{z} H_{w}^{3 x-2 y-2 z+w}+z H_{2} O+(y+2 z-w-1.5 x) H^{+}+(1.5 x-y) H S^{-}
$$

Defining the activity of water and the pure mineral stibnite as unity, the equilibrium constant for Equation (2.5) then becomes,

$$
K_{x y z w}=a_{S b_{x} S_{y} O_{z} H_{w}^{3 x-2 y-2 z+w}} \cdot a_{H S^{-}}{ }^{1.5 x-y} \cdot a_{H^{+}}{ }^{y+2 z-w-1.5 x}
$$

Taking the logarithm of this expression and solving for the activity of the antimony complex,

$$
\log a_{S b_{x} S_{y} O_{z} H_{w}}=\log K_{x y z w}+(y-1.5 x) \cdot \log a_{H S^{-}}+(y+2 z-w-1.5 x) \cdot p H
$$

From Equation (2.7), the relationship between the activity of a complex and changes in the activity of $\operatorname{HS}^{-}\left(a_{H S-}\right)$ and $\mathrm{pH}$ can derived

$$
\begin{aligned}
& \left(\frac{\partial \log a_{S b_{x} S_{y} O_{z} H_{w}^{3 x-2 y-2 z+w}} \partial \log a_{H S-}}{H S}\right)_{P, T, p H}=y-1.5 x \\
& \left(\frac{\partial \log a_{S b_{x} S_{y} O_{z} H_{w}^{3 x-2 y-2 z+w}}}{\partial p H}\right)_{P, T, a_{H S-}}=y+2 z-w-1.5 x
\end{aligned}
$$

The same approach can be used to derive a general reaction and equilibrium constant written in terms of $\mathrm{H}_{2} \mathrm{~S}^{\circ}$. For the relationship of solubility and $\mathrm{pH}$, this produces

$$
\left(\frac{\partial \log a_{S b_{x} S_{y} O_{z} H_{w}^{3 x-2 y-2 z+w}}}{\partial p H}\right)_{P, T, a_{H_{2} S}}=2 y+2 z-w-3 x
$$

The relationship of solubility and $\log a_{H 2 S}$ is the same as that for $\log a_{H S-}$ expressed in Equation (2.8).

The slopes of experimental solubility curves with respect to $\mathrm{pH}$ or sulfide concentration are compared to ideal slopes calculated from Equations (2.8), (2.9), and (2.10) to select the complex or 
Figure (2.3) Schematic of possible stibnite solubility versus pH curves at constant sulfide (A) or versus sulfide (B) for selected monomers and dimers. Curves are arranged in order of S:Sb ratio. Curves in (A) were calculated using Equations (2.9) and (2.10) in, respectively, the predominance regions of $\mathrm{HS}^{-}$and $\mathrm{H}_{2} \mathrm{~S}$. Curves in (B) used Equation (2.8). The curves for complexes with two or more HS- ligands were calculated such that the first deprotonation occurs at $\mathrm{pH}=5$ and the second at $\mathrm{pH}=9$. The first deprotonation of an $\mathrm{OH}^{-}$ligand is estimated to occur at $\mathrm{pH}=11.8$. In $(\mathrm{A})$, the field where dissolved sulfide is predominantly $\mathrm{HS}^{-}$ is shaded.

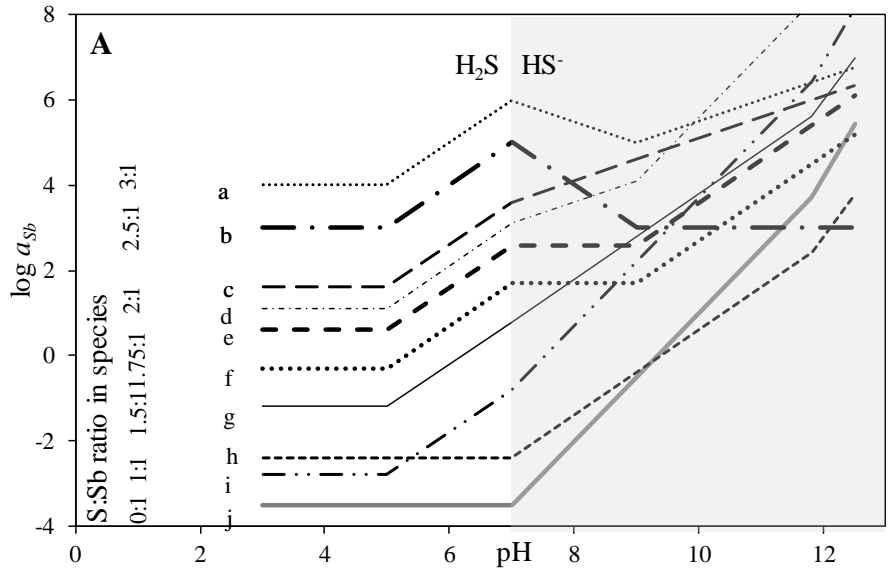

(a) $\mathrm{SbS}_{3} \mathrm{H}_{w}{ }^{\mathrm{w}-3}$

(b) $\mathrm{Sb}_{2} \mathrm{~S}_{5} \mathrm{H}_{\mathrm{w}} \mathrm{w}-4$

(c) $\mathrm{SbS}_{2} \mathrm{H}_{\mathrm{w}}{ }^{\mathrm{w}-1}$ (d) $\mathrm{SbS}_{2} \mathrm{OH}_{\mathrm{w}}{ }^{\mathrm{w}-3}$

(e) $\mathrm{Sb}_{2} \mathrm{~S}_{4} \mathrm{H}_{\mathrm{w}} \mathrm{w}-2$ (f) $\mathrm{Sb}_{4} \mathrm{~S}_{7} \mathrm{H}_{\mathrm{w}}{ }^{\mathrm{w}-2}$

(g) $\mathrm{Sb}_{2} \mathrm{~S}_{3} \mathrm{OH}_{\mathrm{w}}{ }^{\mathrm{w}-2}$
(h) $\mathrm{Sb}_{2} \mathrm{~S}_{2} \mathrm{O}_{2} \mathrm{H}_{\mathrm{w}}{ }^{\mathrm{w}-2}$

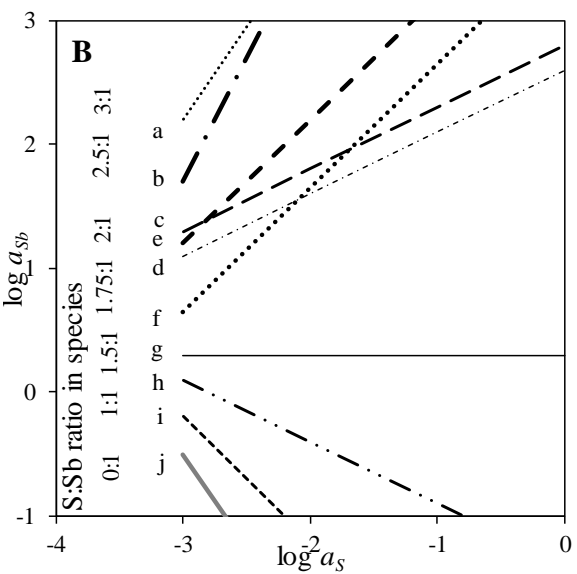

(i) $\mathrm{SbSO}_{2} \mathrm{H}_{\mathrm{w}} \mathrm{w}-3$

(j) $\mathrm{SbO}_{3} \mathrm{H}_{\mathrm{w}} \mathrm{w}-3$

complexes that may be present. In Figure (2.3), ideal solubility versus pH (2.3A) and $\log a_{H S-}(2.3 \mathrm{~B})$ curves are plotted showing the changes in slope associated with progressive deprotonation of $\mathrm{HS}^{-}$and $\mathrm{OH}^{-}$ligands.

The plots were constructed assuming that the first and second deprotonations of HS- ligands bound to $\mathrm{Sb}$ (III) occur at $\mathrm{pH} \approx 5$ and $\approx 9$, respectively, as suggested by previous solubility studies (Krupp, 1988), and assuming that the $\mathrm{OH}^{-}$ligands in mixed-ligand antimony species did not deprotonate until $\mathrm{pH} \approx 12$, as is the case for $\mathrm{OH}^{-}$ligands in $\mathrm{Sb}(\mathrm{OH})_{3}$ (Zakaznova-Herzog and Seward, 2006). At $\mathrm{pH} \leq 7$, the slope of the solubility curve is equal to the negative of the complex charge (i.e., Equation 2.10). Above $\mathrm{pH} \geq 7$, different ionic charges and complex stoichiometries produce various slopes. The relationship of stibnite solubility to the activity of total reduced sulfur (i.e., $\mathrm{HS}^{-}+\mathrm{H}_{2} \mathrm{~S}^{\circ}$ ) is independent of $\mathrm{pH}$ and the protonation state and is thus constant across the $\mathrm{pH}$ region for a given complex (Figure 2.3B). In this study, subscripts are used to indicate the relevant antimony complex, aqueous species or reaction when activities $(a)$, concentrations as molality $(m)$, activity coefficients $(\gamma)$ or equilibrium constants $(K)$ are included in text or equations. Equilibrium constants expressing stibnite solubility in terms of different antimony species (i.e Equation 2.6) are written in terms of $a_{H S-}$ and $a_{H+}$ and balanced in terms of moles of the antimony complex. The stibnite solubility reactions for each the aqueous antimony species considered in speciation models used in non-linear fitting are listed in Table (2.2). 
Table (2.2) Heterogeneous solubility reactions used in the nonlinear least squares fitting.

\begin{tabular}{|c|c|c|}
\hline$K_{x y z w}$ & Aqueous antimony species & Reaction \\
\hline \multicolumn{3}{|c|}{ antimony-hydroxide complexes } \\
\hline$K_{1033}$ & $\mathrm{Sb}(\mathrm{OH})_{3}$ & $0.5 \mathrm{Sb}_{2} \mathrm{~S}_{3}+3 \mathrm{H}_{2} \mathrm{O}=\mathrm{Sb}(\mathrm{OH})_{3}+1.5 \mathrm{HS}^{-}+1.5 \mathrm{H}^{+}$ \\
\hline$K_{1032}$ & $\mathrm{H}_{2} \mathrm{SbO}_{3}^{-}$ & $0.5 \mathrm{Sb}_{2} \mathrm{~S}_{3}+3 \mathrm{H}_{2} \mathrm{O}=\mathrm{H}_{2} \mathrm{SbO}_{3}^{-}+1.5 \mathrm{HS}^{-}+2.5 \mathrm{H}^{+}$ \\
\hline \multicolumn{3}{|c|}{ antimony-sulfide complexes } \\
\hline$K_{1300}$ & $\mathrm{SbS}_{3}{ }^{3-}$ & $0.5 \mathrm{Sb}_{2} \mathrm{~S}_{3}+1.5 \mathrm{HS}^{-}=\mathrm{SbS}_{3}{ }^{3-}+1.5 \mathrm{H}^{+}$ \\
\hline$K_{1301}$ & $\mathrm{HSbS}_{3}{ }^{2-}$ & $0.5 \mathrm{Sb}_{2} \mathrm{~S}_{3}+1.5 \mathrm{HS}^{-}=\mathrm{HSbS}_{3}{ }^{2-}+0.5 \mathrm{H}^{+}$ \\
\hline$K_{1302}$ & $\mathrm{H}_{2} \mathrm{SbS}_{3}^{-}$ & $0.5 \mathrm{Sb}_{2} \mathrm{~S}_{3}+1.5 \mathrm{HS}^{-}+0.5 \mathrm{H}^{+}=\mathrm{H}_{2} \mathrm{SbS}_{3}^{-}$ \\
\hline$K_{1303}$ & $\mathrm{H}_{3} \mathrm{SbS}_{3}$ & $0.5 \mathrm{Sb}_{2} \mathrm{~S}_{3}+1.5 \mathrm{HS}^{-}+1.5 \mathrm{H}+=\mathrm{H}_{3} \mathrm{SbS}_{3}+1.5 \mathrm{HS}^{-}$ \\
\hline$K_{2400}$ & $\mathrm{Sb}_{2} \mathrm{~S}_{4}{ }^{2-}$ & $\mathrm{Sb}_{2} \mathrm{~S}_{3}+\mathrm{HS}^{-}=\mathrm{Sb}_{2} \mathrm{~S}_{4}{ }^{2-}+\mathrm{H}^{+}$ \\
\hline$K_{2401}$ & $\mathrm{HSb}_{2} \mathrm{~S}_{4}^{-}$ & $\mathrm{Sb}_{2} \mathrm{~S}_{3}+\mathrm{HS}^{-}=\mathrm{HSb}_{2} \mathrm{~S}_{4}{ }^{2-}$ \\
\hline$K_{2402}$ & $\mathrm{H}_{2} \mathrm{Sb}_{2} \mathrm{~S}_{4}$ & $\mathrm{Sb}_{2} \mathrm{~S}_{3}+\mathrm{HS}^{-}+\mathrm{H}^{+}=\mathrm{H}_{2} \mathrm{Sb}_{2} \mathrm{~S}_{4}$ \\
\hline$K_{2502}$ & $\mathrm{H}_{2} \mathrm{Sb}_{2} \mathrm{~S}_{5}^{2-}$ & $\mathrm{Sb}_{2} \mathrm{~S}_{3}+2 \mathrm{HS}^{-}=\mathrm{H}_{2} \mathrm{Sb}_{2} \mathrm{~S}_{5}^{2-}$ \\
\hline \multicolumn{3}{|c|}{ antimony-hydroxide-sulfide (mixed-ligand) complexes } \\
\hline$K_{1211}$ & $\mathrm{HSbS}_{2} \mathrm{O}^{2-}$ & $0.5 \mathrm{Sb}_{2} \mathrm{~S}_{3}+0.5 \mathrm{HS}^{-}+\mathrm{H}_{2} \mathrm{O}=\mathrm{HSbS}_{2} \mathrm{O}^{2-}+1.5 \mathrm{H}^{+}$ \\
\hline$K_{1212}$ & $\mathrm{H}_{2} \mathrm{SbS}_{2} \mathrm{O}^{-}$ & $0.5 \mathrm{Sb}_{2} \mathrm{~S}_{3}+0.5 \mathrm{HS}^{-}+\mathrm{H}_{2} \mathrm{O}=\mathrm{H}_{2} \mathrm{SbS}_{2} \mathrm{O}^{-}+0.5 \mathrm{H}^{+}$ \\
\hline$K_{1213}$ & $\mathrm{H}_{3} \mathrm{SbS}_{2} \mathrm{O}$ & $0.5 \mathrm{Sb}_{2} \mathrm{~S}_{3}+0.5 \mathrm{HS}^{-}+\mathrm{H}_{2} \mathrm{O}+0.5 \mathrm{H}^{+}=\mathrm{H}_{3} \mathrm{SbS}_{2} \mathrm{O}$ \\
\hline$K_{1122}$ & $\mathrm{H}_{2} \mathrm{SbSO}_{2}^{-}$ & $0.5 \mathrm{Sb}_{2} \mathrm{~S}_{3}+2 \mathrm{H}_{2} \mathrm{O}=\mathrm{H}_{2} \mathrm{SbSO}_{2}^{-}+0.5 \mathrm{HS}^{-}+1.5 \mathrm{H}^{+}$ \\
\hline$K_{1123}$ & $\mathrm{H}_{3} \mathrm{SbSO}_{2}$ & $0.5 \mathrm{Sb}_{2} \mathrm{~S}_{3}+2 \mathrm{H}_{2} \mathrm{O}=\mathrm{H}_{3} \mathrm{SbSO}_{2}+0.5 \mathrm{HS}^{-}+0.5 \mathrm{H}^{+}$ \\
\hline
\end{tabular}

\section{Speciation of solutions and the non-linear fitting procedure}

Non-linear least squares fitting of experimental solubilities with selected complexes was performed using the DataFitX software (Oakdale Engineering, 2000) after initial derivation of $a_{H^{-}}$ from the measured sulfide concentrations. The fitting procedure fits the following equation:

$m_{S b_{\text {total }}}=\sum^{x y z w} x \cdot m_{S b_{x} S_{y} O_{z} H_{w}^{3 x-2 y-2 z+w}}=\sum^{x y z w} x \cdot a_{S b_{x} S_{y} O_{z} H_{w}^{3 x-2 y-2 z+w}} \cdot \gamma_{S b_{x} S_{y} O_{z} H_{w}^{3 x-2 y-2 z+w}}{ }^{-1}$

which is equivalent to

$$
m_{S b_{\text {total }}}=\sum^{x y z w} x \cdot K_{w x y z} \cdot a_{H S^{-}}^{y-1.5 x} \cdot a_{H^{+}}^{1.5 x+w-y-2 z} \cdot \gamma_{S b_{x} S_{y} O_{z} H_{w}^{3 x-2 y-2 z+w^{-1}}}
$$

Note that the $K_{w x y z}$ used in Equation (2.12) and defined by Equation (2.6) is for a reaction in terms of moles of a given antimony complex. This is in contrast to equations (2.1) and (2.4), which are written in terms of moles of antimony. The inputs to the fitting procedure for each individual experiment were the antimony concentration ( $m o l \mathrm{~kg}^{-1} \mathrm{Sb}_{\text {total }}$ ), the measured $\mathrm{pH}$ as $a_{H+}$, and the calculated $a_{H S-}$ and ionic strength, as detailed in the following section.

The activities of the aqueous species $\mathrm{OH}^{-}, \mathrm{H}^{+}, \mathrm{HS}^{-}, \mathrm{H}_{2} \mathrm{~S}^{\circ}, \mathrm{NaHS}^{\circ}, \mathrm{NaOH}^{\circ}$, and $\mathrm{Na}^{+}$were calculated using reaction and mass balance constraints. The following independent reactions define the equilibrium relationships between these species:

$$
\mathrm{H}_{2} \mathrm{O}=\mathrm{H}^{+}+\mathrm{OH}^{-}
$$


Table (2.3) Supporting thermodynamic data at $30^{\circ} \mathrm{C}$. Logarithms of the equilibrium constants used in fluid speciation calculations and values for the parameters in Equation (2.23).

\begin{tabular}{|c|c|c|c|c|}
\hline Eqn No. & Reaction & $25^{\circ} \mathrm{C}$ & $3^{\circ} \mathrm{C}$ & Reference \\
\hline 2.17 & $\mathrm{H}_{2} \mathrm{O} \Leftrightarrow \mathrm{H}^{+}+\mathrm{OH}^{-}$ & -14.00 & -13.84 & $\mathrm{a}$ \\
\hline 2.18 & $\mathrm{H}_{2} \mathrm{~S}^{\mathrm{o}} \Leftrightarrow \mathrm{H}^{+}+\mathrm{HS}^{-}$ & -6.98 & -6.91 & $\mathrm{~b}$ \\
\hline 2.19 & 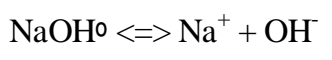 & 0.72 & 0.67 & $\mathrm{c}$ \\
\hline 2.20 & 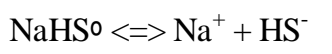 & 1.18 & 1.14 & $\mathrm{~d}$ \\
\hline
\end{tabular}

\begin{tabular}{rlrrr}
\multicolumn{7}{l}{ Debye-Hückel Parameters } & & & \\
2.23 & A & 0.5164 & 0.5148 & $\mathrm{e}$ \\
2.23 & B & $3.25 \mathrm{E}+07$ & $3.26 \mathrm{E}+07$ & $\mathrm{e}$ \\
2.23 & B-dot & 0.041 & 0.041 & $\mathrm{f}$ \\
\hline
\end{tabular}
a. Marshall and Franck (1981)
b. Suleimenov and Seward (1997)
c. Ho and Palmer (1996)
d. Ho et al. (1994), by analogy with $\mathrm{NaCl}^{\circ}$
e. Helges on and Kirkham (1974)
f. Helges on (1969)

$$
\begin{gathered}
\mathrm{H}_{2} \mathrm{~S}^{\circ}=\mathrm{H}^{+}+\mathrm{HS}^{-} \\
\mathrm{NaOH}^{\circ}=\mathrm{Na}^{+}+\mathrm{OH}^{-} \\
\mathrm{NaHS}^{\circ}=\mathrm{Na}^{+}+\mathrm{HS}^{-}
\end{gathered}
$$

For these reactions, following equilibrium constants can be written

$$
\begin{gathered}
K_{w}=a_{\mathrm{H}^{+}} \cdot a_{\mathrm{OH}^{-}} \cdot a_{\mathrm{H}_{2} \mathrm{O}^{-1}} \\
K_{\mathrm{H}_{2} \mathrm{~S}}=a_{\mathrm{H}^{+}} \cdot m_{\mathrm{SH}^{-}} \cdot \gamma_{\mathrm{SH}^{-}} \cdot m_{\mathrm{H}_{2} \mathrm{~S}^{-}}{ }^{-1} \cdot \gamma_{\mathrm{H}_{\mathrm{S}} \mathrm{S}^{-}}{ }^{-1} \\
K_{\mathrm{NaOH}}=m_{\mathrm{Na}^{+}} \cdot \gamma_{\mathrm{Na}^{+}} \cdot m_{\mathrm{OH}^{-}} \cdot \gamma_{\mathrm{OH}^{-}} \cdot m_{\mathrm{NaOH}^{\circ}}{ }^{-1} \cdot \gamma_{\mathrm{NaOH}^{\circ}}{ }^{-1} \\
K_{\mathrm{NaSH}}=m_{\mathrm{Na}^{+}} \cdot \gamma_{\mathrm{Na}^{+}} \cdot m_{\mathrm{SH}^{-}} \cdot \gamma_{\mathrm{SH}^{-}} \cdot m_{\mathrm{NaHS}^{\circ}}{ }^{-1} \cdot \gamma_{\mathrm{NaHS}^{\circ}}{ }^{-1}
\end{gathered}
$$

Additionally, the $\mathrm{Na}$ and $\mathrm{S}$ species are constrained by the following two mass balance equations

$$
\begin{aligned}
m_{\mathrm{Na}_{\text {total }}} & =m_{\mathrm{NaSH}^{\circ}}+m_{\mathrm{Na}^{+}}+m_{\mathrm{NaOH}^{\circ}} \\
m_{S_{\text {total }}} & =m_{\mathrm{H}_{2} \mathrm{~S}^{\circ}}+m_{\mathrm{SH}^{-}}+m_{\mathrm{NaHS}^{\circ}}+\sum^{x y z w} y \cdot m_{S_{x} S_{y} \mathrm{O}_{z} H_{w}} \\
& =m_{\mathrm{H}_{2} S^{\circ}}+m_{\mathrm{SH}^{-}}+m_{\mathrm{NaHS}^{\circ}}+m_{S_{\text {complexed }}}
\end{aligned}
$$

The concentration of sulfur complexed with antimony was unknown prior to determination of the antimony species present. For all experiments with $\mathrm{pH}<10.4$, the concentration of sulfide was much greater than that of antimony and thus $m_{\text {Scomplexed }}$ was negligible. When the concentration of antimony was $\geq 1 \% \mathrm{~S}_{\text {total }}, m_{\text {scomplexed }}$ was likely to be greater than the relative standard deviation of titration measurements $(\sim 3 \%)$. For such experiments, the total sulfide concentration was corrected for the simultaneous titration of $m_{\text {Scomplexed }}$ using the appropriate complex for the $\mathrm{Sb}$ (III) speciation model being tested. The resulting total free sulfide concentration, or $m_{S f r e e}$, was used to derive $a_{H S \text {. }}$

The ionic strengths for experimental solutions varied between $\sim 1 \times 10^{-4}$ and $0.2 \mathrm{~mol} \mathrm{~kg}^{-1}$ but were $<0.02 \mathrm{~mol} \mathrm{~kg}^{-1}$ for the majority of experiments. The activity of water and the activity coefficients for $\mathrm{NaOH}^{\circ}, \mathrm{NaHS}^{\circ}$, and neutral $\mathrm{Sb}$ complexes were set to unity. Activity coefficients for $\mathrm{Na}^{+}, \mathrm{HS}^{-}, \mathrm{H}^{+}$, 
$\mathrm{OH}^{-}$, and aqueous antimony ions were calculated using an extended Debye-Hückel equation (Helgeson, 1969)

$$
-\log \gamma_{i}=\frac{A z_{i}^{2} \sqrt{I}}{1+B a_{i} \sqrt{I}}+\dot{B} \cdot I
$$

where $A, B$, and $\dot{B}$ (or B-dot) are temperature dependent constants calculated from polynomial fits of data in Helgeson (1969) and Helgeson and Kirkham (1974), $z$ is the ion charge, $I$ is the ionic strength, and $a$ is the ion size parameter (in cm), which was set to $4 \times 10^{-8}, 3.5 \times 10^{-8}, 9 \times 10^{-8}$, and $4.5 \times 10^{-8}$ for $\mathrm{Na}^{+}$, $\mathrm{OH}^{-} / \mathrm{HS}^{-}, \mathrm{H}^{+}$, and antimony complexes, respectively (Kielland, 1937). For the $30^{\circ} \mathrm{C}$ experiments, values of $0.5148,3.26 \times 10^{-7}$, and 0.041 were used for parameters $A, B$, and $\dot{B}$, respectively. The ionic strength, $I$, is defined as

$$
I=\frac{1}{2} \sum m_{i} \cdot z_{i}^{2}
$$

For the solutions in these experiments, this was implemented as

$$
I=\frac{1}{2}\left(m_{H^{+}}+m_{O H^{-}}+m_{N a^{+}}+m_{H S^{-}}+\sum^{x y z w} m_{S b_{x} S_{y} O_{z} H_{w}} \cdot(3 x-2 y-2 z+w)^{2}\right)
$$

The thermodynamic data used for speciation calculations and for the non-linear least squares regression fitting are given in Table (2.3). The ion product for water (Equation 2.17) was taken from Marshall and Franck (1981). The first ionization constant for $\mathrm{H}_{2} \mathrm{~S}^{\circ}$ (Equation 2.18) was selected from Suleimenov and Seward (1997). The dissociation constant for $\mathrm{NaOH}^{\circ}$ (Equation 2.19) was from Ho and Palmer (1996). The dissociation constant for NaHS ${ }^{\circ}$ (Equation 2.20) was assumed to be the same as that for $\mathrm{NaCl}^{\circ}$, for which the measurements of Ho et al. (1994) were used.

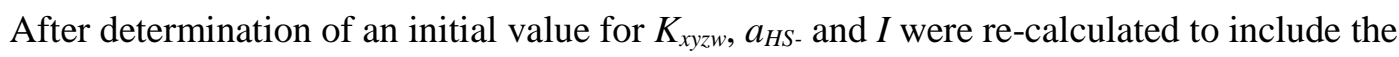
effect of sulfide complexed with antimony on $m_{S f r e e}$ and the effect of charged antimony species on

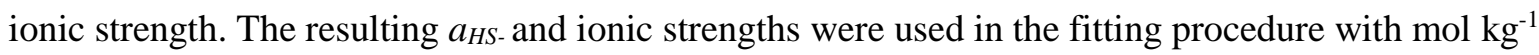
$\mathrm{Sb}_{\text {total }}$ and the measured $\mathrm{pH}$ to produce new estimates for $K_{x y z w .}$ This process was repeated until the $K_{x y z w}$ values for successive iterations converged. Fits converged within $\leq 10$ iterations. The equilibrium constants for these reactions are distinguished by subscripts indicating the antimony species, i.e., $K_{x y z w}$, as defined for Equation (2.6) and listed in Table (2.2).

\subsection{Results}

\subsubsection{Attainment of equilibrium}

The attainment of equilibrium with stibnite in the flow-through apparatus was tested by measuring stibnite solubility at different flow rates in solutions with constant $\mathrm{pH}$ and sulfide concentration. Constant antimony concentrations at variable flow rates are considered to represent equilibrium conditions. As shown in Figure (2.4), antimony concentrations were constant within error for flow rates between $3.5 \mathrm{ml} \mathrm{min}{ }^{-1}$ and $5.5 \mathrm{ml} \mathrm{min}^{-1}$ in tests conducted with the HPLC pump. For a single preliminary experiment conducted with a diaphragm pump but with the same column at $50^{\circ} \mathrm{C}$, stibnite solubility was constant between 1 and $8 \mathrm{ml} \mathrm{min}^{-1}$ and decreased above $\sim 10 \mathrm{ml} \mathrm{min}{ }^{-1}$ flow rate 
Figure (2.4) Solubility of stibnite at different flow rates in solutions with constant pH and sulfide concentration. Sulfide concentrations for different solutions were between 0.02 and $0.1 \mathrm{~mol} \mathrm{~kg}^{-1} \mathrm{~S}^{2-}$ total. The increase of stibnite solubility flow rates $<2 \mathrm{ml} \mathrm{min}^{-1}$ may be attributed to slight oxidation of the solution while passing through the tubing between flask and column, especially for those with higher sulfide contents. Antimony concentrations are constant within error for flow rates between $3.5 \mathrm{ml} \mathrm{min}^{-1}$ and $5.5 \mathrm{ml} \mathrm{min}^{-1}$.

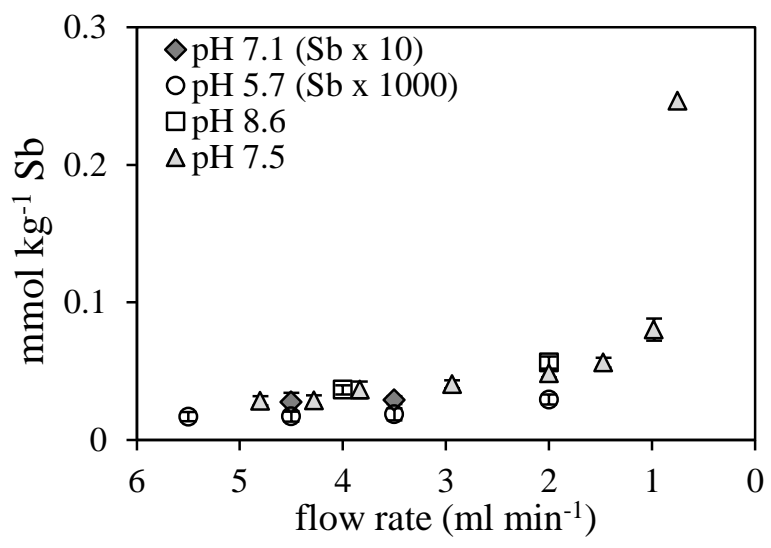

(results not shown). For most solutions tested, especially for those with higher sulfide contents, the solubility of stibnite increased at flow rates $<2 \mathrm{ml} \mathrm{min}^{-1}$. This behaviour may be attributed to slight oxidation of the solution while passing through the Teflon tubing between flask and column, as evidenced by yellowing of some solutions in the Teflon tubing during extremely slow flow rates $(0.01$ $\mathrm{ml} \mathrm{min}{ }^{-1}$ ) when the residence time in the Teflon tubing was $>\sim 6$ hours. The yellowing was due to the formation of polysulfide species. A $4.5 \mathrm{ml} \mathrm{min}{ }^{-1}$ flow rate was used for all subsequent experiments included in the development of the speciation model.

\subsubsection{Measured stibnite solubility curves}

Stibnite solubility measurements are presented in Figure (2.5), and complete results are tabulated in Table (A.2) in Appendix (A). The measured stibnite solubility at different sulfide contents is plotted versus $\mathrm{pH}$ in Figure (2.5A). Stibnite solubility decreased from hundreds of ppm $\left(\sim 10^{-3.5} \mathrm{~mol}\right.$ $\left.\mathrm{kg}^{-1}\right)$ to less than $1 \mathrm{ppb}\left(\sim 10^{-8.5} \mathrm{~mol} \mathrm{~kg}^{-1}\right)$ as $\mathrm{pH}$ decreased from 12 to 4 . The measured stibnite solubility has been projected to a constant pH in Figures (2.5B, C, D, and E). These plots show that stibnite solubility increased with increasing sulfide content for the entire $\mathrm{pH}$ range studied. The increase is greatest between $\mathrm{pH}=5$ and 8 (Figures 2.5C and 2.5D). At $\mathrm{pH}=4.5$, the slope of stibnite solubility slope versus sulfide content was slightly $>+0.5$ (Figure $2.5 \mathrm{E}$ ). For the data shown in these four plots, the sulfide concentration was high enough that the amount of sulfide complexed with antimony did not change the solubility-sulfide concentration relationship within the error of the sulfide measurements.

The slope of the stibnite solubility curve with respect to $\mathrm{pH}$ (i.e., the $\mathrm{Sb} / \mathrm{pH}$ slope), as shown in Figure (2.5A), changes at $\mathrm{pH}=9.5$, at $\mathrm{pH}=7$, possibly at $\mathrm{pH}=6.5$, and at $\mathrm{pH}=5$. These slope changes indicate a change in the dominant reaction controlling stibnite solubility. The dominant dissolved sulfide species changes from $\mathrm{H}_{2} \mathrm{~S}^{\circ}$ to $\mathrm{HS}^{-}$at $\mathrm{pH}>7$ at $30^{\circ} \mathrm{C}$, and this speciation change will result in a change in the stibnite solubility curve regardless of a change in antimony speciation. Thus, 
Figure (2.5) Stibnite solubility versus pH (A) and versus sulfide concentration (B through E). For the sulfide plots, the measured solubility has been projected to a constant $\mathrm{pH}$ ( $\mathrm{pH}$ shown in plots) using a slope of $\mathrm{Sb} / \mathrm{pH}=+1$ for (B) and (D), a slope of $\mathrm{Sb} / \mathrm{pH}=+0.5$ for $(\mathrm{C})$, and zero slope for (E). A linear least squares fits and their slopes are shown for $(B)$ through $(\mathrm{E})$.
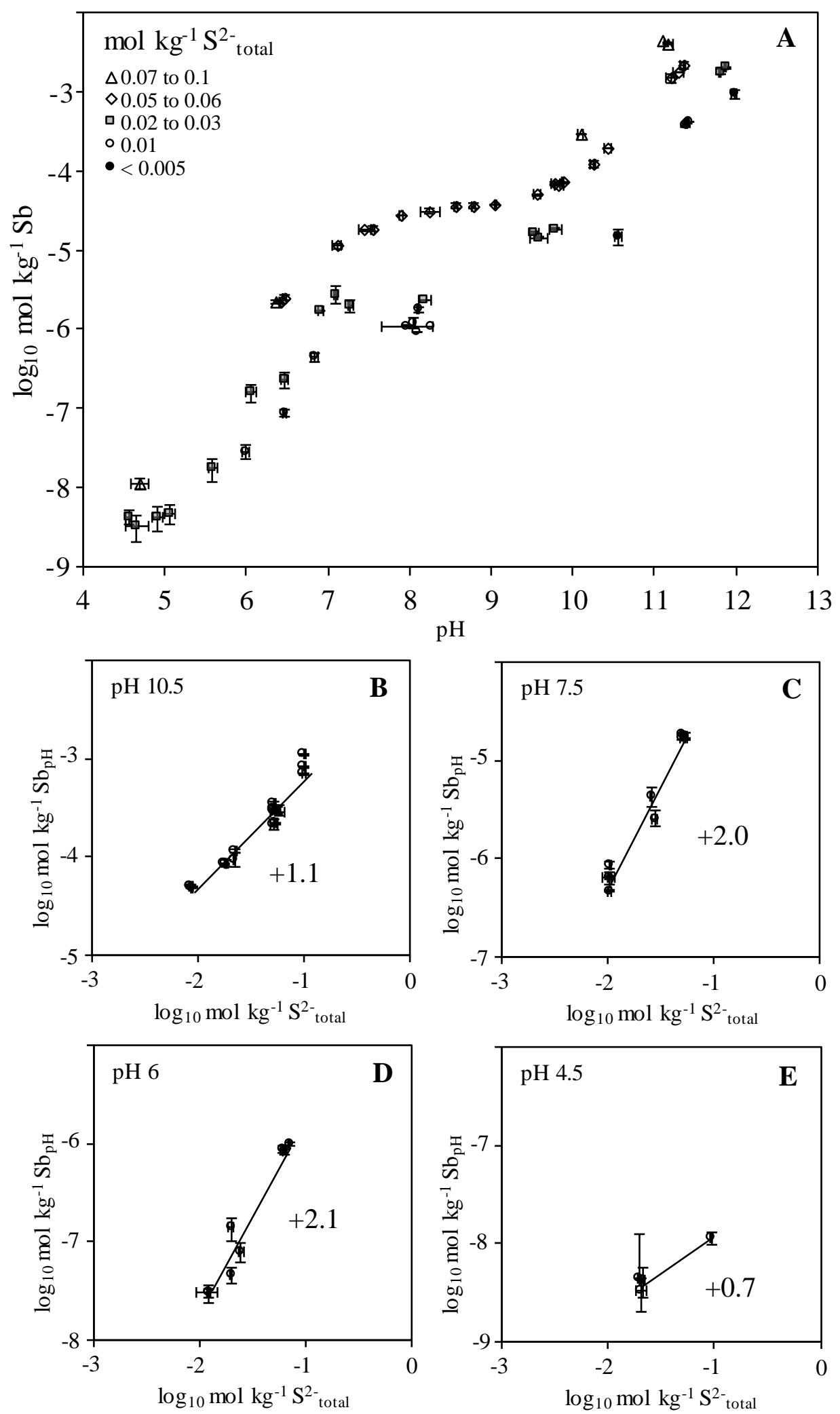
the solubility curve suggests the existence of three to four distinct antimony complexes: one species at $\mathrm{pH}>9$, one to two species at $5<\mathrm{pH}<9$, and another complex at $\mathrm{pH}<5$. The species at low $\mathrm{pH}$ must be a neutral species because the solubility curve slope in Figure (2.5A) approaches a zero slope at $\mathrm{pH}$ $<5$. This is because all neutral $\mathrm{Sb}$ (III)-S-O complexes produce stibnite solubility curves that are independent of $\mathrm{pH}$ when $\mathrm{H}_{2} \mathrm{~S}$ is the dominant form of dissolved sulfide, as can be shown with Equation (2.10). The dependence of stibnite solubility on sulfide activity (approximated by sulfide concentration in Figure 2.5) changed with decreasing $\mathrm{pH}$ from $\sim+1$ at strongly alkaline $\mathrm{pH}$ (Figure $2.5 \mathrm{~A}$ ), to $\sim+2$ at mildly alkaline to mildly acidic $\mathrm{pH}$ (Figures $2.5 \mathrm{C}$ and $2.5 \mathrm{D}$ ), and finally was $\sim+0.7$ at $\mathrm{pH}<5$ (Figure $2.5 \mathrm{E}$ ).

In addition to these experiments in which sulfide was added to the initial experimental solution, two experiments were conducted in which stibnite solubility was measured in deoxygenated, deionised water at $\mathrm{pH}=10.5$ and 12.0 (Sb90 and Sb91 in Table A.2). These experiments are plotted in Figure (2.5A) but are not included in Figure (2.5B). Figure (2.5A) shows that stibnite solubility still increased rapidly with increasing $\mathrm{pH}$ at low sulfide concentrations $\left(<0.005 \mathrm{~mol} \mathrm{~kg}{ }^{-1} \mathrm{~S}^{2-}\right.$ total $)$. The stibnite solubilities measured in these experiments $\left(1.5 \times 10^{-5}\right.$ and $\left.9.3 \times 10^{-4} \mathrm{~mol} \mathrm{~kg}^{-1} \mathrm{Sb}_{\text {total }}\right)$ were greater than that which could be accounted for by the antimony-sulfide complexes present at higher sulfide concentrations. These results were used to estimate the heterogeneous equilibrium constants for the stibnite solubility reactions due to neutral and singly deprotonated antimonous acid (i.e., $\mathrm{Sb}(\mathrm{OH})_{3}$ and $\mathrm{H}_{2} \mathrm{SbO}_{3}{ }^{-}$) and to investigate the possibility of partially deprotonated mixed-ligand monomers at alkaline $\mathrm{pH}$.

\subsubsection{Determining equilibrium constants for antimony-sulfide complexes}

Complexes to be included in speciation models must satisfy both the $\mathrm{pH}$ and sulfide solubility relationships observed. The aqueous antimony species considered and the form of the reaction used for obtaining equilibrium constants for each of these species are compiled in Table (2.2). The preferred speciation model (Fit 30-A) is presented in Table (2.4) and its accompanying plots. These three plots display the fit of the measured solubilities, the relative residuals versus $\mathrm{pH}$, and the distribution of species at $0.01 \mathrm{~mol} \mathrm{~kg}^{-1} \mathrm{~S}^{2-}$ total. Fit (30-A) includes a fully deprotonated $\mathrm{Sb}_{2} \mathrm{~S}_{4}{ }^{2-}$ dimer at high $\mathrm{pH}$, two partially protonated dimers in the near neutral region $\left(\mathrm{H}_{2} \mathrm{Sb}_{2} \mathrm{~S}_{5}{ }^{2-}\right.$ and $\left.\mathrm{HSb}_{2} \mathrm{~S}_{4}^{-}\right)$, and a fully protonated, mixed ligand monomer $\left(\mathrm{H}_{3} \mathrm{SbS}_{2} \mathrm{O}\right)$ at low $\mathrm{pH}$. Fit (30-A) is the preferred fit because of its good fit statistics, its consistency with first shell EXAFS results (Chapter 3), and its agreement with the high temperature data that is best fit with $\mathrm{Sb}_{2} \mathrm{~S}_{4}{ }^{2-}$ and $\mathrm{HSb}_{2} \mathrm{~S}_{4}$ (Chapter 4). Fit (30-A) also has chemically reasonable deprotonation states for the sulfide ligand as suggested by ab initio calculations (Tossell, 2003b)

Included with Fit (30-A) in Table (2.4) are several other fits having similar statistics that were considered but that did not produce the best fit to the data. The first of these fits, Fit (30-B), is identical to Fit (30-A) except for the neutral species. The choice of the neutral species was determined by the +0.7 slope of stibnite solubility curve with respect to sulfide concentration at $\mathrm{pH}=4.5$ (Figure 
Table (2.4) Non-linear least squares fits of stibnite solubility at $30^{\circ} \mathrm{C}$. The plots accompanying each fit show the fit of the measured solubilities at variable sulfide concentrations (left), the relative residuals of the fit (middle), and the distribution of species at $0.01 \mathrm{~mol} \mathrm{~kg}^{-1} \mathrm{~S}^{2-}$ total with the data projected to that sulfide concentration (right). $\mathrm{K}$ is the derived equilibrium constant for the stated reaction (see Table 2.2), $\sigma$ is one standard deviation, $p$ is $\operatorname{Prob}(\mathrm{t})$ for the null hypothesis that $K=0, R^{2}$ is the proportion of the variation in the data that is explained by the fit, and $\mathrm{N}$ is the number of data points.
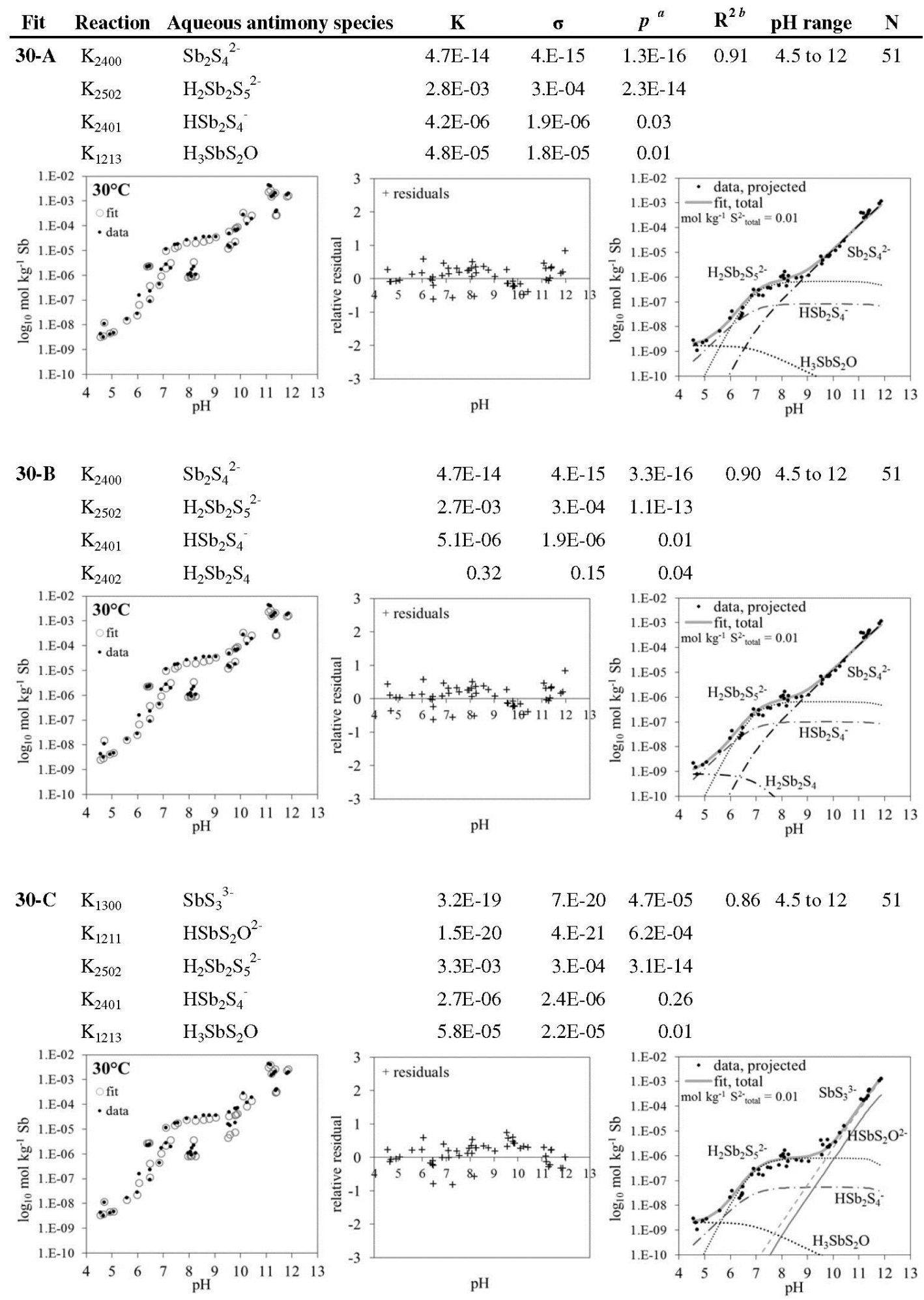

${ }^{a} p$ is Prob(t) for the null hypothesis that $\mathrm{K}=0$, i.e. values of $p$ approaching 1 indicate that a species can be removed without changing the fit.

${ }^{b} R^{2}$ is the ratio of variation in the data explained by the fit to the total variation in the data, i.e. $R^{2}=\frac{\sum_{i=1}^{N}\left(\dot{y}_{i}-\bar{y}\right)^{2}}{\sum_{i=1}^{N}\left(y_{i}-\bar{y}\right)^{2}}$ where $y_{i}$ is the $\mathrm{i}^{\text {th }}$ data point, $\overline{\mathrm{y}}$ is the mean of $\mathrm{N}$ data points, and $\dot{y}_{i}$ is the fit of the $\mathrm{i}^{\text {th }}$ data point. 
2.5E). Given this slope, the moderately acidic region was best fit by the presence of a species with a +1 slope (i.e., $\mathrm{HSb}_{2} \mathrm{~S}_{4}^{-}$) and a species with a +0.5 slope (i.e.,, $\mathrm{H}_{3} \mathrm{SbS}_{2} \mathrm{O}$ ). However, a speciation model using $\mathrm{H}_{2} \mathrm{Sb}_{2} \mathrm{~S}_{4}$ and $\mathrm{HSb}_{2} \mathrm{~S}_{4}^{-}$(Fit 30-B) could fit the data nearly as well given the limited amount of data at this $\mathrm{pH}$. Fit (30-A), which included $\mathrm{H}_{3} \mathrm{SbS}_{2} \mathrm{O}$ and $\mathrm{HSb}_{2} \mathrm{~S}_{4}^{-}$, was the preferred fit because $\mathrm{HSb}_{2} \mathrm{~S}_{4}^{-}$is integral to fits of the higher temperature solubility data and because monomeric rather than dimeric species are expected to be stable at the low antimony concentrations (i.e., $<10^{-8} \mathrm{~mol} \mathrm{~kg}^{-1} \mathrm{Sb}$ ) that define stibnite solubility at $\mathrm{pH}<5$. Neutral antimony complexes that produce slopes of stibnite solubility versus sulfide activity that are $>+1$ (e.g., $\mathrm{H}_{3} \mathrm{SbS}_{3}$ or $\mathrm{H}_{4} \mathrm{Sb}_{2} \mathrm{~S}_{5}$ ) or $<0$ (e.g., $\mathrm{H}_{3} \mathrm{SbSO}_{2}$ and $\left.\mathrm{Sb}(\mathrm{OH})_{3}\right)$ were inconsistent with the observed sulfide dependence at $\mathrm{pH}=4.5$.

An increase in sulfide concentration produced an increase of equal magnitude in the stibnite solubility at moderate to strongly alkaline $\mathrm{pH}$ and 0.01 to $0.1 \mathrm{~mol} \mathrm{~kg}^{-1} \mathrm{~S}^{2-}{ }_{\text {total. }}$. This sulfide dependence could be fit with a speciation modeling containing either $\mathrm{Sb}_{2} \mathrm{~S}_{4}{ }^{2-}$ or a combination of monomers. As described in the introduction, X-ray absorption spectroscopic measurements fail to detect $\mathrm{Sb}-\mathrm{Sb}$ distances in sodium sulfide solutions and may thus be interpreted to suggest the presence of antimonysulfide monomers. Therefore, the possibility of antimony-sulfide monomers at alkaline $\mathrm{pH}$ was considered. The last fit in Table (2.4), Fit (30-C), is one in which the alkaline region was fit with two monomers, $\mathrm{SbS}_{3}{ }^{3-}$ and $\mathrm{HSbS}_{2} \mathrm{O}^{2-}$, instead of $\mathrm{Sb}_{2} \mathrm{~S}_{4}{ }^{2-}$. These two monomers have $\mathrm{Sb}-\mathrm{S}$ solubility curves with, respectively, +1.5 and +0.5 slopes that when combined could approximate the +1 slope of the experimental data shown in Figure (2.5B).

Fit (30-C) had good fit statistics, but this fit was rejected because it contradicted the first shell coordination numbers for antimony that were measured by EXAFS for solutions between $\mathrm{pH} 10.9$ and 11.7 with $\geq 0.02 \mathrm{~mol} \mathrm{~kg}^{-1} \mathrm{~S}^{2-}$ total. The speciation model from Fit (30-C) for alkaline $\mathrm{pH}$ (i.e., $\mathrm{SbS}_{3}{ }^{3-}$ and $\mathrm{HSbS}_{2} \mathrm{O}^{2-}$ ) predicted oxygen atoms in the first coordination shell of antimony at moderate sulfide concentrations but none were detected from the EXAFS at these conditions. In contrast, the speciation model from Fit (30-A) for alkaline $\mathrm{pH}$ (i.e., $\mathrm{Sb}_{2} \mathrm{~S}_{4}{ }^{2-}, \mathrm{Sb}(\mathrm{OH})_{3}$, and $\mathrm{H}_{2} \mathrm{SbO}_{3}{ }^{-}$) predicted average first shell coordination numbers that were consistent with EXAFS results. The details of EXAFS measurements are discussed in Chapter (3).

The choice of $\mathrm{Sb}_{2} \mathrm{~S}_{4}{ }^{2-}$ was further tested by preforming non-linear least squares fits using only the data from $\mathrm{pH} 10$ to $\mathrm{pH} 12$ (fit not shown). The value for the equilibrium constant for $\mathrm{Sb}_{2} \mathrm{~S}_{4}{ }^{2-}\left(K_{2400}\right)$ from this fit $\left(4.3 \times 10^{-14}\right)$ was within error of the fits conducted using the complete data set. The larger oligomer $\mathrm{Sb}_{4} \mathrm{~S}_{7}{ }^{2-}$ produces a solubility curve that is identical to that of $\mathrm{Sb}_{2} \mathrm{~S}_{4}{ }^{2-}$, as can be calculated using Equations (2.8) and (2.9). The smaller dimer was selected because ab initio calculations suggest that the transition from antimony dimers to larger oligomers is energetically unfavorable (Tossell, 1994). Including the fully deprotonated monomer, $\mathrm{SbS}_{3}{ }^{3-}$, produced a fit of the same quality as Fit (30C). In this fit, the high $p$ value for $\mathrm{SbS}_{3}{ }^{3-}$ and large standard deviation of its equilibrium constant suggest that this species does not make a significant contribution to the dissolved antimony at the experimental sulfide concentrations. Therefore, the fully deprotonated dimer $\mathrm{Sb}_{2} \mathrm{~S}_{4}{ }^{2-}$ was judged to be 
Table (2.5) Speciation models that failed to fit stibnite solubility at near neutral $\mathrm{pH}$ at $30^{\circ} \mathrm{C}$. The plots accompanying each fit show the fit of the measured solubilities at variable sulfide concentrations (left), the relative residuals of the fit (middle), and the distribution of species at $0.01 \mathrm{~mol} \mathrm{~kg}^{-1} \mathrm{~S}^{2-}{ }_{\text {total }}$ with the data projected to that sulfide concentration (right). $\mathrm{K}$ is the derived equilibrium constant for the stated reaction (see Table 2.2), $\sigma$ is the standard deviation, $p$ is $\operatorname{Prob}(\mathrm{t})$ for the null hypothesis that $K=0, R^{2}$ is the proportion of the variation in the data that is explained by the fit, and $\mathrm{N}$ is the number of data points.
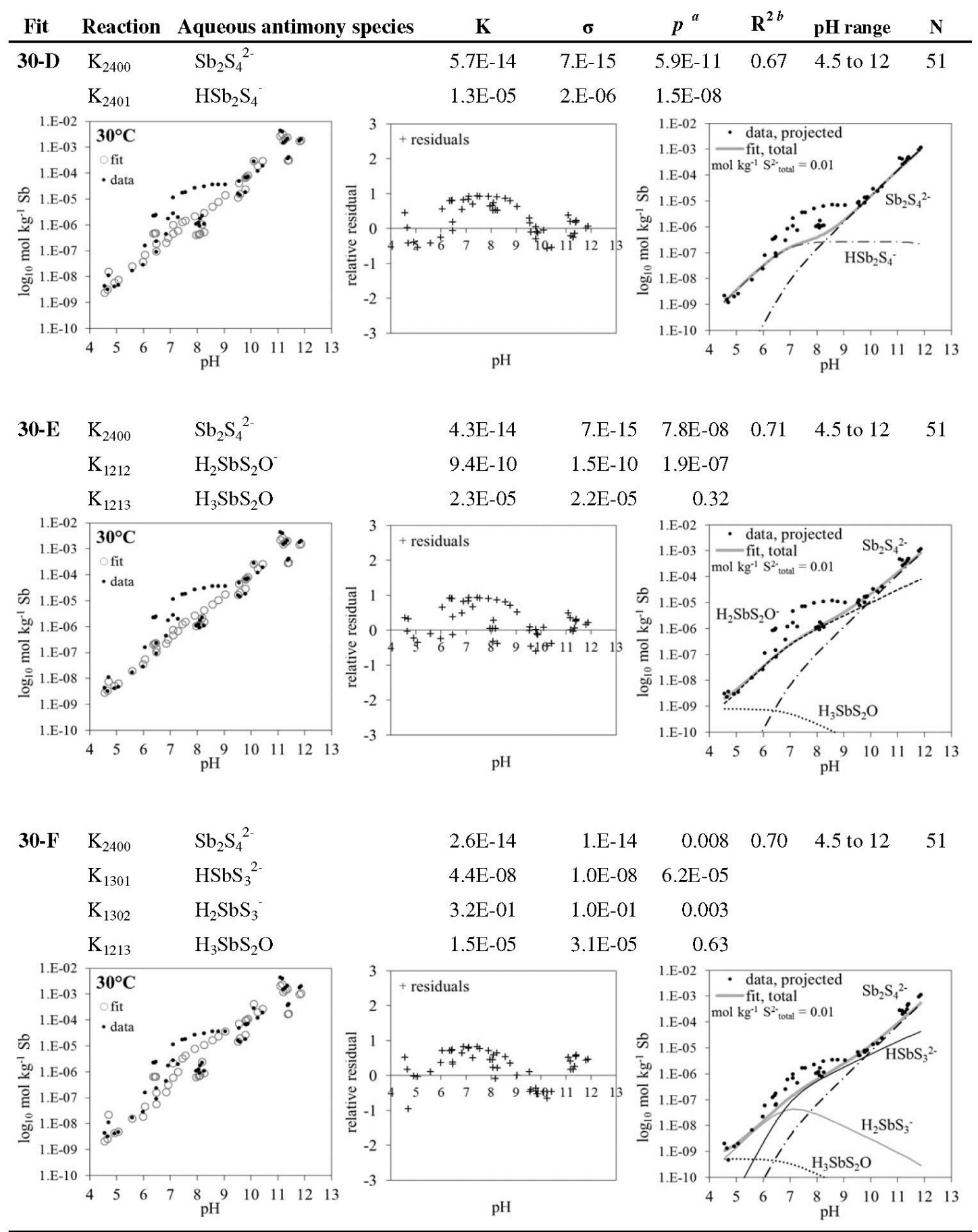

\footnotetext{
${ }^{a} p$ is Prob(t) for the null hypothesis that $\mathrm{K}=0$, i.e. values of $p$ approaching 1 indicate that a species can be removed without changing the fit.

${ }^{b} R^{2}$ is the ratio of variation in the data explained by the fit to the total variation in the data, i.e. $R^{2}=\frac{\sum_{i=1}^{N}\left(\dot{y}_{i}-\bar{y}\right)^{2}}{\sum_{i=1}^{N}\left(y_{i}-\bar{y}\right)^{2}}$

where $y_{i}$ is the $\mathrm{i}^{\text {th }}$ data point, $\overline{\mathrm{y}}$ is the mean of $\mathrm{N}$ data points, and $\dot{y}_{i}$ is the fit of the $\mathrm{i}^{\text {th }}$ data point.
} 
the only significant antimony-sulfide species at $\mathrm{pH}>9$ at stibnite saturation and sulfide concentrations $>0.01 \mathrm{~mol} \mathrm{~kg}^{-1} \mathrm{~S}^{2-}$ total.

Fit (30-A) included the species $\mathrm{H}_{2} \mathrm{Sb}_{2} \mathrm{~S}_{5}^{2-}$, which has not been proposed previously for the $\mathrm{Sb}$ (III)-S(II)- $\mathrm{H}_{2} \mathrm{O}$ system. The fully deprotonated form of this species, $\mathrm{Sb}_{2} \mathrm{~S}_{5}{ }^{4-}$, was put forward by two early studies of antimony speciation in strongly alkaline solutions (Fiala and Konopik, 1950; Shestitko and Demina, 1971), but protonated forms of this Sb-S stoichiometry have not been documented. Fits that did not include $\mathrm{H}_{2} \mathrm{Sb}_{2} \mathrm{~S}_{5}{ }^{2-}$ were not able to fit the solubility data. Examples of such fits are shown in Table (2.5). Attempts to fit the near neutral solubility data using only $\mathrm{HSb}_{2} \mathrm{~S}_{4}{ }^{-}$species (Fit 30-D) produced poor fits with values for $R^{2}=0.70$ because $\mathrm{HSb}_{2} \mathrm{~S}_{4}{ }^{-}$was unable to reproduce stibnite solubility in the near neutral $\mathrm{pH}$ region. The $\mathrm{H}_{2} \mathrm{Sb}_{2} \mathrm{~S}_{5}{ }^{2-}$ moiety is the only species (monomer or dimer) that produces a Sb-pH solubility curve that changes from a +2 slope below to a zero slope at $\mathrm{pH}>\mathrm{pKa}$ of $\mathrm{H}_{2} \mathrm{~S}$. This curve shape was required to fit the experimental data between $\mathrm{pH}=6$ and 9.

Various combinations of monomers, including $\mathrm{H}_{\mathrm{x}} \mathrm{SbS}_{2} \mathrm{O}^{\mathrm{x}-3}$ species (Fit 30-E) and $\mathrm{H}_{\mathrm{x}} \mathrm{SbS}_{3}{ }^{\mathrm{x}-3}$ species (Fit 30-F), were also unable to fit the experimental data. The presence of $\mathrm{H}_{2} \mathrm{Sb}_{2} \mathrm{~S}_{5}{ }^{2-}$ between $\mathrm{pH}=6$ and 9 was also consistent with the greater dependence of stibnite solubility on sulfide activity observed at near neutral pH. As is shown in Figures (2.5C) and (2.5D), the slope describing the dependence of stibnite solubility on sulfide concentration curve is $\sim+2$ immediately above and below the $\mathrm{pK}_{\mathrm{a}}$ of $\mathrm{H}_{2} \mathrm{~S}$ (i.e., at $\mathrm{pH}=6.5$ and 7.5). Antimony-sulfide complexes in the series $\mathrm{H}_{\mathrm{x}} \mathrm{Sb}_{2} \mathrm{~S}_{5}{ }^{\mathrm{x}-4}$ are the only monomeric or dimeric complexes that produce a stibnite solubility versus sulfide activity curve with a slope of +2 (see Figure 2.3B). Antimony-sulfide monomers $\left(\mathrm{H}_{\mathrm{x}} \mathrm{SbS}_{3}{ }^{\mathrm{x}-3}\right)$ also produce a $\mathrm{Sb} / \mathrm{S}$ curve with a slope $>+1$, but they are unable to reproduce stibnite solubility versus $\mathrm{pH}(\mathrm{Sb} / \mathrm{pH})$ curve, as is shown in Fit (30-F).

\subsubsection{Estimating an equilibrium constant for antimonous acid}

The stibnite solubilities in two deionised water experiments conducted at strongly alkaline $\mathrm{pH}$ were greater than what could be accounted for by the antimony-sulfide complexes which were determined from the experiments conducted at higher sulfide concentration. This suggests that additional aqueous antimony species must be present at low sulfide concentrations $\left(<0.005 \mathrm{~mol} \mathrm{~kg}^{-1}\right.$ $\left.\mathrm{S}^{2-}{ }_{\text {total }}\right)$. EXAFS measurements of the solution from one of these two deionised water experiments found that the first coordination shell of dissolved antimony at $\mathrm{pH}=12$ and a sulfide concentration of $\sim 0.001 \mathrm{~mol} \mathrm{~kg}^{-1} \mathrm{~S}^{2-}$ total contained more oxygen than sulfur atoms. Therefore, stibnite solubility and EXAFS measurements require that, in addition to $\mathrm{Sb}_{2} \mathrm{~S}_{4}{ }^{2-}$, antimony-hydroxide and possibly mixedligand species are present at high $\mathrm{pH}$ and low sulfide concentrations.

A fit was conducted in which the solubility data from the two deionized water experiments were combined with the solubility data at higher sulfide concentrations so that provisional values for the equilibrium constants for $\mathrm{Sb}(\mathrm{OH})_{3}$ (i.e., $K_{1033}$ ) and $\mathrm{H}_{2} \mathrm{SbO}_{3}{ }^{-}$(i.e., $K_{1032}$ ) could be determined. In the fitting procedure, $K_{1032}$ was defined as a parameter dependent on $K_{1033}$ using the $\mathrm{pKa}$ of $\mathrm{Sb}(\mathrm{OH})_{3}$ at $30^{\circ} \mathrm{C}$. Thus, the addition of the two species $\mathrm{Sb}(\mathrm{OH})_{3}$ and $\mathrm{H}_{2} \mathrm{SbO}_{3}{ }^{-}$to the speciation model only added 
Table (2.6) Non-linear fits of stibnite solubility at $30^{\circ} \mathrm{C}$ including deionized water experiments. The plots accompanying each fit show the fit of the measured solubilities at variable sulfide concentrations (left), the relative residuals of the fit (middle), and the distribution of species at $0.01 \mathrm{~mol} \mathrm{~kg}^{-1} \mathrm{~S}^{2-}$ total with the data projected to that sulfide concentration (right). $\mathrm{K}$ is the derived equilibrium constant for the stated reaction (see Table 2.2), $\sigma$ is the standard deviation, $p$ is Prob(t) for the null hypothesis that $K=0, R^{2}$ is the proportion of the variation in the data that is explained by the fit, and $\mathrm{N}$ is the number of data points.

Equations for $R^{2}$ and $p$ with Tables (2.4) and (2.5).

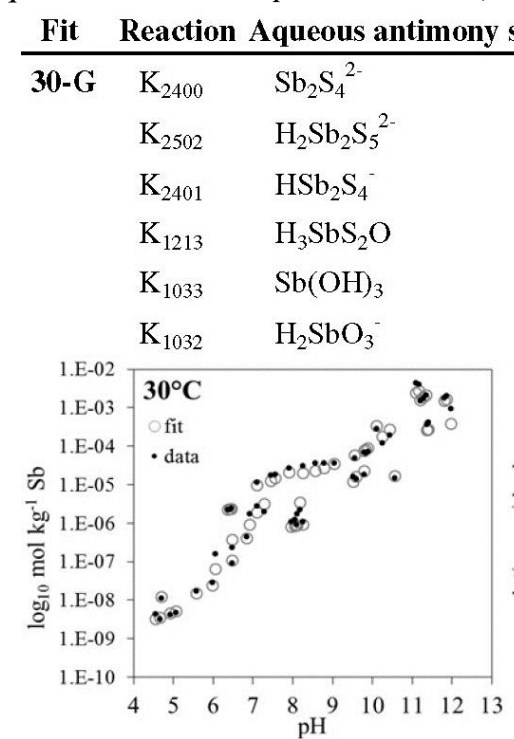

\begin{tabular}{cccccc}
$\mathbf{K}$ & $\boldsymbol{\sigma}$ & $p^{a}$ & $\mathbf{R}^{2 b}$ & $\mathbf{p H}$ range & $\mathbf{N}$ \\
\hline $4.7 \mathrm{E}-14$ & $4 . \mathrm{E}-15$ & $2.2 \mathrm{E}-16$ & 0.90 & 4.5 to 12 & 53 \\
$2.8 \mathrm{E}-03$ & $2.6 \mathrm{E}-04$ & $5.3 \mathrm{E}-14$ & & & \\
$4.2 \mathrm{E}-06$ & $2.0 \mathrm{E}-06$ & $3.9 \mathrm{E}-02$ & & & \\
$4.8 \mathrm{E}-05$ & $1.9 \mathrm{E}-05$ & $1.2 \mathrm{E}-02$ & & & \\
$3.1 \mathrm{E}-27$ & $8 . \mathrm{E}-28$ & $5.6 \mathrm{E}-04$ & & &
\end{tabular}
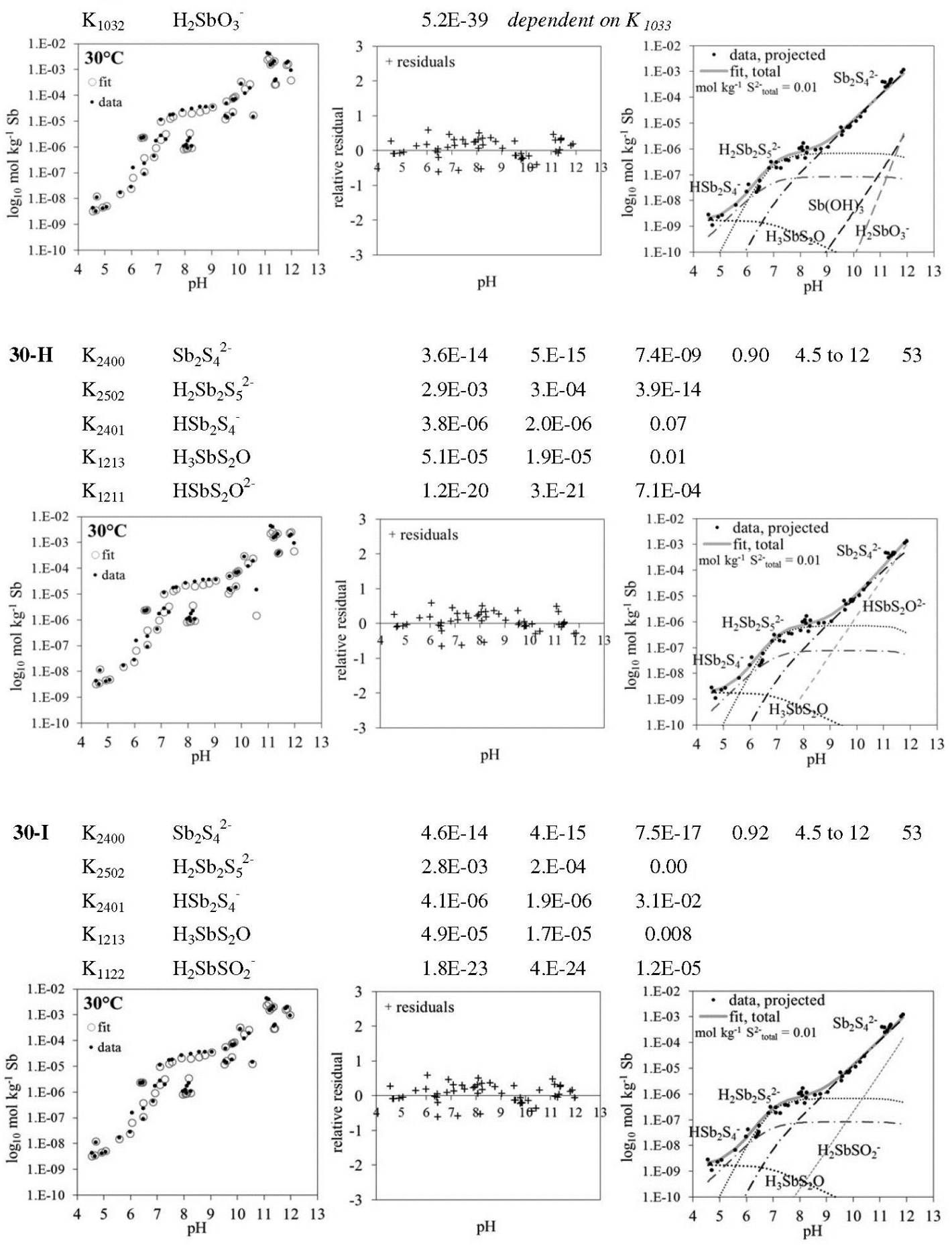
Table (2.7) Previously published values for $\mathbf{K}_{1033}$. The thermodynamic data for $\mathrm{H}_{2} \mathrm{~S}$ and $\mathrm{H}_{2} \mathrm{O}$ presented in this has been used to modify the published reaction when it was in a format other than that used in the current study.

\begin{tabular}{|c|c|c|}
\hline \multicolumn{2}{|c|}{$\mathrm{K}_{1033}$ at (a) 25 or (b) $30^{\circ} \mathrm{C}$} & Reference \\
\hline $2.8 \times 10^{-27}$ & (a) & Spycher and Reed (1981), derived from Popova et al. (1975) \\
\hline $3.4 \times 10^{-28}$ & (a) & $\begin{array}{l}\text { Akinifiyev et al. (1994), based upon Popova et al. (1975) with additional } \\
\text { experimental data at } 350^{\circ} \mathrm{C}\end{array}$ \\
\hline $6.6 \times 10^{-29}$ & (b) & Shikina and Zotov (1999), extrapolated from $200-350^{\circ} \mathrm{C}$ data \\
\hline $3.1 \times 10^{-27}$ & (a) & Filella and May (2003), recalculation of literature data \\
\hline $3.1 \times 10^{-27}$ & (b) & current study, Fit (30-G) \\
\hline
\end{tabular}

one variable, $K_{1033}$, to the fit equation. The estimated values for $K_{1033}$ and $K_{1032}$ enabled prediction of the distribution of antimony species over the range of sulfide concentrations found in natural fluids. In addition, fits were conducted using the two mixed-ligand monomers $\left(\mathrm{HSbS}_{2} \mathrm{O}^{2-}\right.$ and $\left.\mathrm{H}_{2} \mathrm{SbSO}_{2}^{-}\right)$likely to be present at strongly alkaline $\mathrm{pH}$ based upon the slope of the solubility versus $\mathrm{pH}$ curve and on the deprotonation state of $\mathrm{OH}^{-}$and $\mathrm{HS}^{-}$ligands (bound to $\mathrm{Sb}^{3+}$ ) in $\mathrm{Sb}(\mathrm{OH})_{3}$ (Zakaznova-Herzog and Seward, 2006) and antimony-sulfide complexes (determined in this study). The results of these fits are presented in Table (2.6). EXAFS measurements assisted in comparing the speciation models of these three fits.

Fit (30-G) is the fit in which stibnite solubility at alkaline $\mathrm{pH}$ and low sulfide concentrations was due to antimonous acid $\left(\mathrm{Sb}(\mathrm{OH})_{3}\right.$ and $\left.\mathrm{H}_{2} \mathrm{SbO}_{3}{ }^{-}\right)$. The equilibrium constant for $\mathrm{Sb}(\mathrm{OH})_{3}$ from this fit was $3.1 \times 10^{-27}$, which is comparable to previously published values that are listed in Table (2.7). Stibnite dissolves to form neutral antimonous acid according to the following reaction

$$
0.5 \mathrm{Sb}_{2} \mathrm{~S}_{3(\mathrm{~S})}+3 \mathrm{H}_{2} \mathrm{O}=\mathrm{Sb}(\mathrm{OH})_{3}+1.5 \mathrm{HS}^{-}+1.5 \mathrm{H}^{+}
$$

Most of the previously published values for reaction (2.25) at ambient temperatures (i.e., Spycher and Reed, 1989; Filella and May, 2003) have been derived by evaluation and recalculation of literature data that can be traced back to a single experimental study (Popova et al., 1975). More recent experimental work has been carried out at 200 to $350^{\circ} \mathrm{C}$, but the values for $K_{1033}$ at $25^{\circ} \mathrm{C}$ derived by extrapolation of these higher temperature data are 1 to 2 orders of magnitude lower than that estimated in the current study and other reported estimates, which are similar to the current study (Table 2.7).

Additionally, Fit (30-G) predicted average numbers of first shell sulfur and oxygen atoms that were consistent with the results of all of the solutions measured by EXAFS. In contrast, fits using $\mathrm{HSbS}_{2} \mathrm{O}^{2-}$ instead of $\mathrm{Sb}(\mathrm{OH})_{3}$ predicted average coordination shells that were inconsistent with EXAFS measurements. Specifically, a speciation model with $\mathrm{HSbS}_{2} \mathrm{O}^{2-}$ resulted in oxygen ligands in the coordination shell where none where observed by EXAFS (Fit 30-H). A speciation model including $\mathrm{H}_{2} \mathrm{SbSO}_{2}^{-}$(Fit 30-I) resulted in fit statistics equivalent to Fit (30-G) and a similar predicted first coordination shell. However, this mixed-ligand monomer was not present in the best fits of the high temperature data, whereas $\mathrm{Sb}(\mathrm{OH})_{3}$ was an integral part of the speciation models from $\geq 150^{\circ} \mathrm{C}$ (Chapter 4). Therefore, Fit (30-G), which is an extension of Fit (30-A) with $\mathrm{Sb}(\mathrm{OH})_{3}$, and $\mathrm{H}_{2} \mathrm{SbO}_{3}{ }^{-}$at high $\mathrm{pH}$ and low sulfide concentrations, is considered the best fit to the current experimental data and 
provides a reliable estimate of $K_{1033} 3.1 \times 10^{-27}$ at $30^{\circ} \mathrm{C}$ at 1 bar. In the following discussion, the equilibrium constants from Fit (30-G) have been used to construct speciation diagrams for total sulfide concentrations of $0.01,0.001$, and $0.0001 \mathrm{~mol} \mathrm{~kg}^{-1}$.

\subsection{Discussion}

\subsubsection{Comparison of $S b(I I I)-S(I I)$ speciation model with previous studies}

The speciation model for antimony(III) complexes presented here is different from those in previous solubility studies in terms of the solubilities measured and the species proposed at $\mathrm{pH} \leq 9$. Figure (2.6A) compares the speciation model presented in the current study with those from the experimental study of Krupp (1988) and from the literature data re-evaluation of Spycher and Reed (1989). Spycher and Reed (1989) relied heavily on data from Akeret (1953) for their calculations of $25^{\circ} \mathrm{C}$ equilibrium constants. Figure (2.6B) shows the solubility data for stibnite, or amorphous $\mathrm{Sb}_{2} \mathrm{~S}_{3}$

Figure (2.6) Comparison of the preferred speciation model (Fit 30-G, A) and the $30^{\circ} \mathrm{C}$ solubility data (B) from the current study with models and solubility data from previous studies at ambient temperature. The models in (A) are plotted at $\mathrm{S}^{2-}$ total $=0.01 \mathrm{~mol} \mathrm{~kg}^{-1}$. Previous studies include the batchsolubility studies of Akeret (1953) and Krupp (1988), and literature review study of Spycher and Reed (1989).
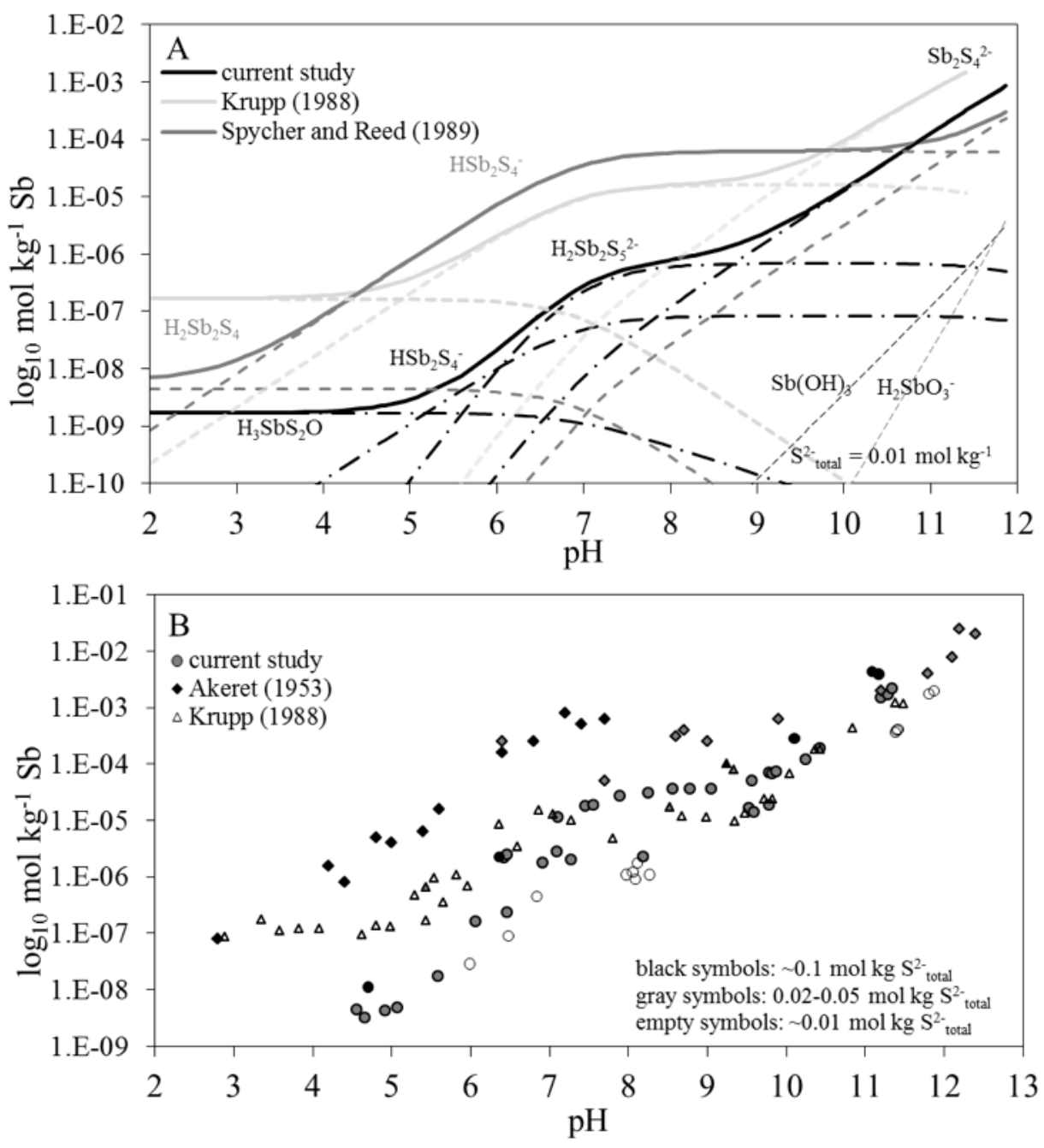
in the case of Akeret (1953), from which these models were derived. The symbol shade (i.e., black, gray, or white/empty) indicates the sulfide concentration ranges $\left(\mathrm{S}^{2-}{ }_{\text {total }}\right)$ used in the experimental studies: $0.1 \mathrm{~mol} \mathrm{~kg}^{-1}, 0.02$ to $0.05 \mathrm{~mol} \mathrm{~kg}^{-1}$, and $\sim 0.01 \mathrm{~mol} \mathrm{~kg}^{-1}$. As can be seen from both subplots, all three datasets have a similar shaped solubility curves, however speciation models of Krupp (1988) and of Spycher and Reed (1989) are 1.5 to 2 orders of magnitude higher than the current study between $\mathrm{pH} \sim 4.5$ and 8.5 .

The current study, as well of those of Kolpakova (1971, 1982), Krupp (1988), Spycher and Reed (1989), have all concluded that the dimer $\mathrm{Sb}_{2} \mathrm{~S}_{4}{ }^{2-}$ is sufficient to account for $\mathrm{Sb}_{2} \mathrm{~S}_{3}$ solubility in alkaline solutions with moderate sulfide concentrations. The solubility curves presented in Figure (2.6) are similar at $\mathrm{pH} \geq 10$ and support the conclusion that $\mathrm{Sb}_{2} \mathrm{~S}_{4}{ }^{2-}$ is the dominant antimony-sulfide species in alkaline solutions across a wide range of sulfide concentrations. The antimony-sulfide monomers, $\mathrm{SbS}_{2}{ }^{-}$and $\mathrm{SbS}_{3}{ }^{3-}$, that have been invoked by some studies (Fiala and Konopik, 1950; Babko and Lisetskaya, 1956; Shestitko and Demina, 1971; Wood, 1989) could not account for the stibnite solubilities measured in this study.

In acidic solutions, fully protonated species are expected for antimony-sulfide and antimonyhydroxide complexes at $\mathrm{pH} \leq 5$ to 6 according to ab initio calculations and comparison with the arsenic-sulfide aqueous complexes. The first deprotonation of $\mathrm{H}_{2} \mathrm{Sb}_{2} \mathrm{~S}_{4}$ was predicted to occur at $\mathrm{pH} \sim$ 5 using correlations between calculated aqueous deprotonation free energies for antimony-sulfide complexes and for sulfur and arsenic hydroxide complexes with experimentally known pK's (Tossell, 2003a). In should be noted as well that antimony(V)-sulfide complexes are expected to deprotonate at a significantly lower $\mathrm{pH}$. The same ab initio approach as was used for $\mathrm{H}_{2} \mathrm{Sb}_{2} \mathrm{~S}_{4}$ predicts that $\mathrm{Sb}(\mathrm{V})$ sulfide dimers will become singly deprotonated at $\mathrm{pH} \sim 2$ and $\mathrm{Sb}(\mathrm{V})$ monomers will become fully deprotonated by $\mathrm{pH}=6$ (Tossell, 2003a, b).

One can also estimate the $\mathrm{pH}$ at which $\mathrm{SH}^{-}$ligands in antimony(III)-sulfide monomers and dimers will deprotonate by considering the thioarsenite $\left(\mathrm{As}(\mathrm{HS})_{3}\right)$ system. This is accomplished by assuming that the $\mathrm{pH}$ difference between the first deprotonation of an $\mathrm{OH}^{-}$ligand in $\mathrm{Sb}(\mathrm{OH})_{3}$ and a HS- ligand in a neutral monomeric antimony(III)-sulfide complex is similar to that measured for $\mathrm{OH}^{-}$ and $\mathrm{HS}^{-}$ligands in $\mathrm{As}(\mathrm{OH})_{3}$ and $\mathrm{As}(\mathrm{HS})_{3}$. With increasing $\mathrm{pH}$ at $25^{\circ} \mathrm{C}, \mathrm{As}(\mathrm{HS})_{3}$ progressively deprotonates at $\mathrm{pH}=3.8,6.5$, and 9.3 to eventually form $\mathrm{AsS}_{3}{ }^{3-}$ at elevated $\mathrm{pH}$ (Zakaznova-Herzog and Seward, 2012). The first deprotonation of $\mathrm{As}(\mathrm{OH})_{3}$ occurs at $\mathrm{pH}=9.25$ at $25^{\circ} \mathrm{C}$ (ZakaznovaHerzog et al., 2006). Therefore, there is a difference of $\sim 5.5 \mathrm{pH}$ units between the first deprotonation of a $\mathrm{HS}^{-}$ligand in $\mathrm{As}(\mathrm{HS})_{3}\left(\right.$ at $\mathrm{pH}=3.8$ ) and of an $\mathrm{OH}^{-}$ligand in $\mathrm{As}(\mathrm{OH})_{3}($ at $\mathrm{pH}=9.3$ ). Applying this difference to the antimony system results in an estimated first deprotonation of antimony(III)-sulfide and antimony(III)-sulfide-hydroxide (i.e., $\mathrm{Sb}\left((\mathrm{HS})_{3-\mathrm{x}}(\mathrm{OH})_{\mathrm{x}}\right.$ ) complexes at $\mathrm{pH} \sim 6$ (i.e., 11.8 - $5.5=$ 6.3). The $\mathrm{OH}^{-}$ligands in mixed-ligand antimony complexes will remain fully protonated over approximately the same $\mathrm{pH}$ range as the $\mathrm{OH}^{-}$ligands in $\mathrm{Sb}(\mathrm{OH})_{3}$, i.e., from $\mathrm{pH}=1.4$ to 11.8 at $25^{\circ} \mathrm{C}$ (Zakaznova-Herzog and Seward, 2006). Thus, a change in the slope of the solubility curve between 
pH 5 and 6 is consistent the deprotonation of an HS- ligand in antimony(III)-sulfide complex or an antimony(III)-sulfide-hydroxide complex.

Identification of the correct Sb-S-O stoichiometry for the equilibrium complex at $\mathrm{pH} \leq 5$ requires experiments at different sulfide concentrations. Such experiments are limited in the current and previous experiments. The experiments of Akeret (1953) were conducted at one sulfide content at $\mathrm{pH}<7$, and thus offer no assistance. Krupp (1988) had four experiments over a range of 0.004 to 0.02 mol kg ${ }^{-1} \mathrm{~S}_{\text {total }}^{2-}$ near $\mathrm{pH} 5.5$. These experiments were consistent with the +1 sulfide dependence expected for $\mathrm{HSb}_{2} \mathrm{~S}_{4}{ }^{-}$and $\mathrm{H}_{2} \mathrm{Sb}_{2} \mathrm{~S}_{4}$, but the data were scattered (the $\mathrm{R}^{2}$ of the best fit line used in selecting $\mathrm{H}_{2} \mathrm{Sb}_{2} \mathrm{~S}_{4}$ was $\sim 0.4$ ) and, at $\mathrm{pH} \sim 5.5$, are in the $\mathrm{pH}$ region dominated by $\mathrm{HSb}_{2} \mathrm{~S}_{4}{ }^{-}$and not by a neutral species. Although the species $\mathrm{H}_{2} \mathrm{Sb}_{2} \mathrm{~S}_{4}$ is consistent with dimers found at higher $\mathrm{pH}$, dimers are expected to become increasingly less stable at the antimony concentrations $\left(<1 \times 10^{-8}\right)$ set by stibnite solubility at acidic $\mathrm{pH}$. In the current study, $\mathrm{H}_{3} \mathrm{SbS}_{2} \mathrm{O}$ was selected because it best reproduced the stibnite solubilities measured at $\mathrm{pH} \sim 4$.5. The choice of $\mathrm{H}_{3} \mathrm{SbS}_{2} \mathrm{O}$ or $\mathrm{H}_{2} \mathrm{Sb}_{2} \mathrm{~S}_{4}$ does not change the speciation model at higher $\mathrm{pH}$.

The shape of the stibnite solubility curve between $\mathrm{pH}=5$ to 9 cannot be fit by the addition of variable protonation states of antimony-sulfide or -hydroxide monomers (i.e., Fits (30-D) through (30F) in Table (2.5)), but may be fit with partially deprotonated dimers. This portion of the solubility curve was assigned to $\mathrm{HSb}_{2} \mathrm{~S}_{4}{ }^{-}$by Krupp $(1988)$ and Kolpakova $(1971,1982)$ based upon their own experimental data and to the same species by Spycher and Reed (1989) using data from Akeret (1953) and others. In the current model, an additional species, $\mathrm{H}_{2} \mathrm{Sb}_{2} \mathrm{~S}_{5}{ }^{2-}$, is included to improve the fit in the circumneutral $\mathrm{pH}$ region. This species could be formed by the addition of an $\mathrm{HS}^{-}$ligand to $\mathrm{HSb}_{2} \mathrm{~S}_{4}^{-}$, as represented by the following reaction.

$$
\mathrm{HSb}_{2} \mathrm{~S}_{4}^{-}+\mathrm{HS}^{-}=\mathrm{H}_{2} \mathrm{Sb}_{2} \mathrm{~S}_{5}^{2-}
$$

The reaction could involve the replacement of one of the bridging sulfur atoms in $\mathrm{HSb}_{2} \mathrm{~S}_{4}{ }^{-}$with an $\mathrm{HS}^{-}$ ligand to form two corner-sharing $\mathrm{SbS}_{3}$ tetrahedra connected by a single bridging sulfur atom. If this is the case, $\mathrm{H}_{2} \mathrm{Sb}_{2} \mathrm{~S}_{5}{ }^{2-}$ could be considered an intermediate between dimers with two bridging sulfur atoms (i.e., $\mathrm{HSb}_{2} \mathrm{~S}_{4}{ }^{-}$and $\mathrm{Sb}_{2} \mathrm{~S}_{4}{ }^{2-}$ ) and a partially protonated $\mathrm{Sb}$-sulfide monomer such as $\mathrm{HSbS}_{3}{ }^{2-}$ or $\mathrm{H}_{2} \mathrm{SbS}_{3}{ }^{-}$, both of which would be favored by higher sulfide contents. The geometry of the $\mathrm{H}_{2} \mathrm{Sb}_{2} \mathrm{~S}_{5}{ }^{2-}$ complex is unknown and was not included by Tossell $(1994,2003 a)$ in his ab initio calculations. Tossell (1994) considered the similar fully protonated moiety $\left(\mathrm{H}_{4} \mathrm{Sb}_{2} \mathrm{~S}_{5}\right)$ and described it as a cornersharing dimer but did not present geometric parameters for the species. By analogy with the $\mathrm{SbS}_{3}$ sites in stibnite and the structure of $\mathrm{Sb}_{2} \mathrm{~S}_{4}$, two distorted tetrahedral $\mathrm{SbS}_{3}$ units could be connected by a corner-sharing sulfur atom in $\mathrm{H}_{2} \mathrm{Sb}_{2} \mathrm{~S}_{5}{ }^{2-}$.

The largest proportional differences between the current and previous studies occur in this intermediate $\mathrm{pH}$ range, and there are several possible explanations for this discrepancy. The solubility experiments of Akeret (1989), which were used to produce the Spycher and Reed (1989) solubility model, were collected using an amorphous antimony-sulfide solid, which would be expected to have higher solubility than crystalline stibnite used in the current study. In general, the experimental data of 
Krupp (1988) lie between those of the current stibnite solubility study and the data of Akeret (1953), who used amorphous $\mathrm{Sb}_{2} \mathrm{~S}_{3}$. Stibnite solubility also increases in the presence of more oxidized forms of sulfur. The stibnite solubility measured by Helz et al. (2002) in a batch solubility study in which $S^{0}$ was present at slightly or below saturation with elemental sulfur was similar to the solubility measured by Akeret (1953). Either oxidation or changes in the equilibrium solid phase could also have been issues during the $\sim 2$ months duration of the $25^{\circ} \mathrm{C}$ batch solubility experiments conducted by Krupp (1988).

The exponential-like increase of antimony concentration at extremely low flow rates that was noted in Figure (2.4) suggests that stibnite solubility is strongly sensitive to slight changes in oxidation state, which would be difficult to control in long-term batch experiments. The short duration of flowthrough solubility experiments (i.e., this current study), enabled by the high mineral-to-fluid reaction ratios achieved in this type of solubility experiment, minimizes the effect of trace amounts of oxygen. In this study, extreme care was taken during the preparation of the experimental solutions to assure a reducing, sulfide solution, and no evidence of oxidation in the reservoir flask (Figure 2.2) was noted during any of the experiments. Additionally, the XAS results presented in the following Chapter (3) are consistent with 3-coordinated $\mathrm{Sb}(\mathrm{III})$ rather than 4-coordinated $\mathrm{Sb}(\mathrm{V})$ being present in the experimental solutions.

\subsubsection{Influence of sulfide concentration on aqueous antimony speciation}

Most of the experiments conducted in this study had sulfide concentrations from $\mathrm{S}^{2-}{ }_{\text {total }}=0.02$ to $0.05 \mathrm{~mol} \mathrm{~kg}^{-1}$, which is above the typical sulfide concentrations found in reducing groundwaters or other fluids present in the Earth's crust. The aqueous antimony speciation in fluids with sulfide concentrations more typical of natural fluids at near ambient temperature can be predicted using the equilibrium constants calculated in this study. Figure (2.7) shows the distribution of aqueous antimony species at stibnite saturation as calculated using the speciation model from Fit (30-G) for three sulfide contents: $\mathrm{S}^{2-}{ }_{\text {total }}=0.01,0.001$, and $0.0001 \mathrm{~mol} \mathrm{~kg}^{-1}$. At the highest of these sulfide concentrations (Figure 2.7A), the distribution of antimony species is similar to the Fit (30-A), with antimony-sulfide dimers predominating at $\mathrm{pH}>5$. At the moderate sulfide concentration $\left(0.001 \mathrm{~mol} \mathrm{~kg}^{-1}\right.$, Figure $\left.2.7 \mathrm{~B}\right)$, $\mathrm{H}_{2} \mathrm{Sb}_{2} \mathrm{~S}_{5}{ }^{2-}$ is no longer a dominant aqueous species at any $\mathrm{pH}$. Instead with decreasing $\mathrm{pH}, \mathrm{Sb}_{2} \mathrm{~S}_{4}{ }^{2-}$ transitions directly to $\mathrm{HSb}_{2} \mathrm{~S}_{4}{ }^{-}$as $\mathrm{pH}$ decreases to $\mathrm{pH} \sim 8$.

The neutral antimonous acid, $\mathrm{Sb}(\mathrm{OH})_{3}$, becomes increasingly important in acidic and alkaline fluids as the sulfide concentration decreases. Antimonous acid is $<1 \%$ of the total dissolved antimony at $\mathrm{pH}=12$ when high concentrations of sulfide are present $\left(\mathrm{S}^{2-}\right.$ total $=0.01 \mathrm{~mol} \mathrm{~kg}^{-1}$, Figure (2.7A)). With an order of magnitude lower sulfide concentration $\left(\mathrm{S}^{2-}{ }_{\text {total }}=0.001 \mathrm{~mol} \mathrm{~kg}^{-1}\right), \mathrm{Sb}(\mathrm{OH})_{3}$ and $\mathrm{H}_{2} \mathrm{SbO}_{3}{ }^{-}$contribute at least $30 \%$ of the dissolved antimony at $\mathrm{pH}>11$ and the percentage of $\mathrm{Sb}(\mathrm{OH})_{3}$ approaches $1 \%$ at $\mathrm{pH}<6$ (Figure 2.7B). With a further decrease of sulfide concentration to $\mathrm{S}^{2-}$ total $=$ $0.0001 \mathrm{~kg}^{-1}, \mathrm{Sb}(\mathrm{OH})_{3}$ is the predominant species from $\mathrm{pH} 7.5$ to 11.8 (Figure 2.7C). At this low sulfide concentration, antimony-sulfide dimers contribute $<10 \%$ of the total dissolved antimony when $\mathrm{pH}<$ 
Figure (2.7) The distribution of $\mathrm{Sb}$ (III) species at $30^{\circ} \mathrm{C}$ from $\mathrm{pH}=3$ to 12 . The relative abundances of antimony species at stibnite saturation are plotted for total sulfide concentrations of $0.01 \mathrm{~mol} \mathrm{~kg}^{-1}$ (A), $0.001 \mathrm{~mol} \mathrm{~kg}^{-1}(\mathrm{~B})$, and $0.0001 \mathrm{~mol} \mathrm{~kg}^{-1}$ (C) using the speciation model and equilibrium constants from Fit (30-G). The plots demonstrate the diminishing importance of antimony-sulfide species with decreasing sulfide concentration. Solution chemistry is identical to that used for Figure (2.8).
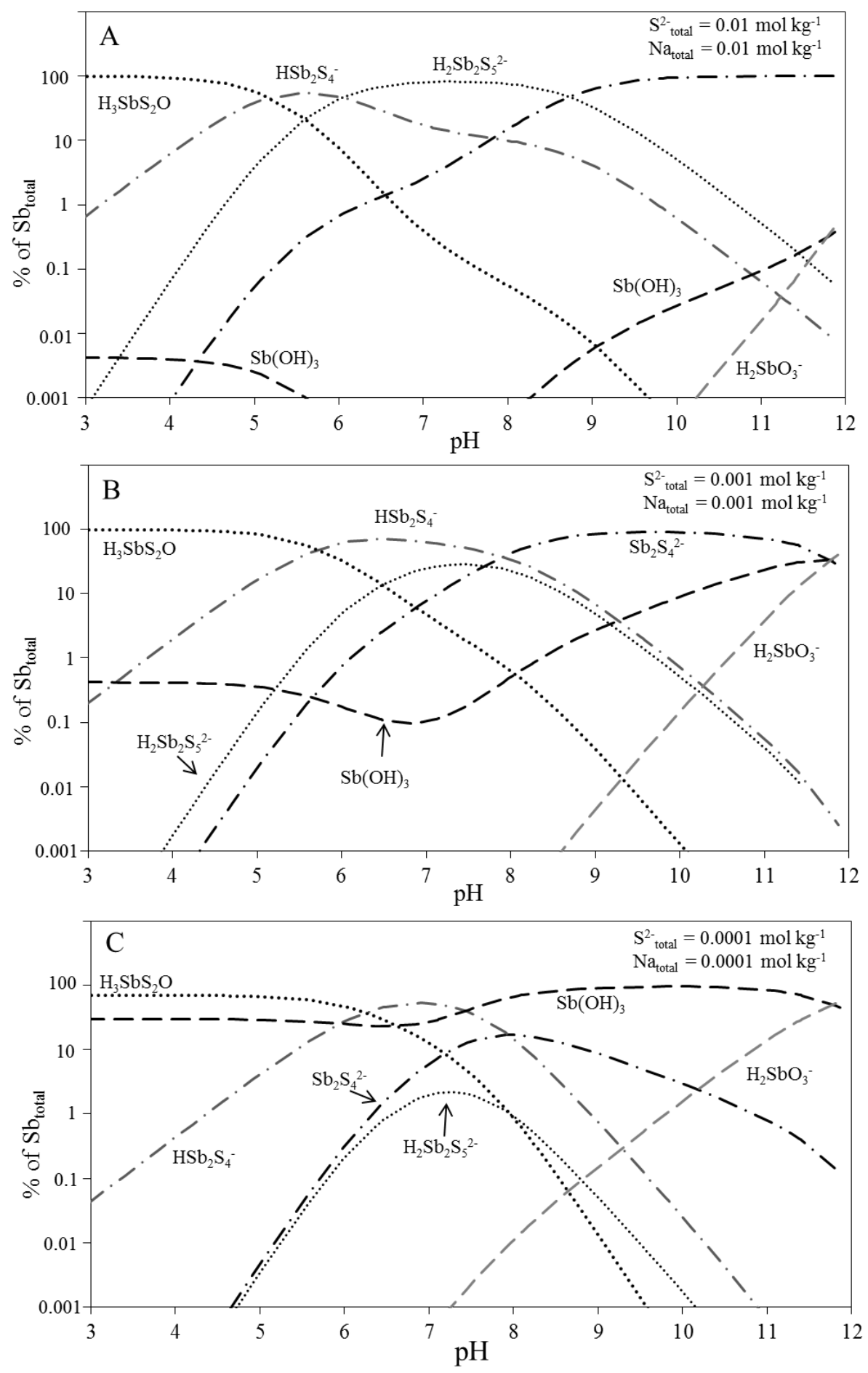
Figure (2.8) Calculated stibnite solubility at $30^{\circ} \mathrm{C}$ from $\mathrm{pH}=3$ to 12 at different total sulfide

concentrations. Plots were constructed using the speciation model and equilibrium constants from Fit (30$\mathrm{G})$, and they demonstrate the change in the shape of the solubility curve as $\mathrm{Sb}(\mathrm{OH})_{3}$ becomes predominant. Solution chemistry is identical to that used for Figure (2.7).
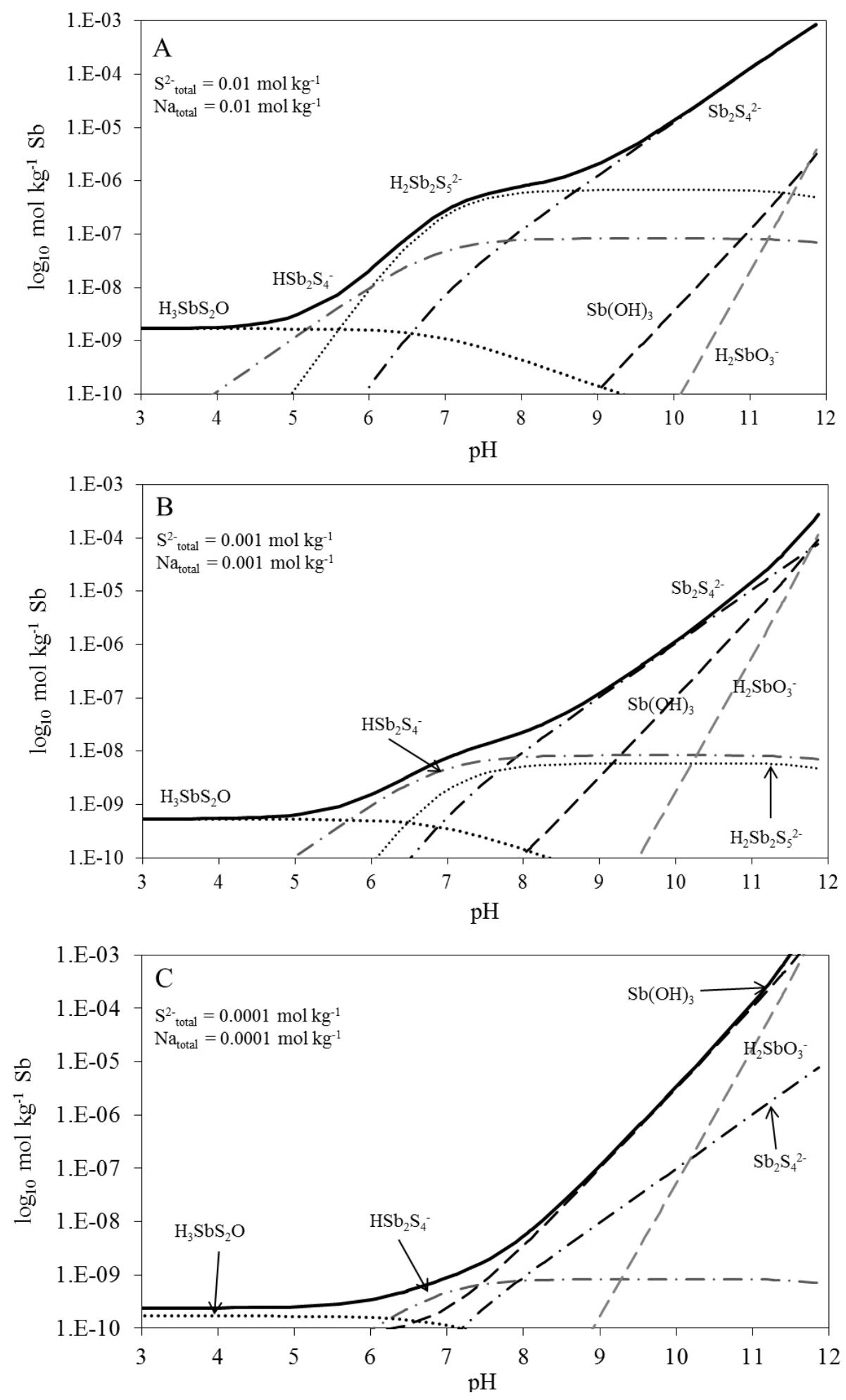
5.5 or $\mathrm{pH}>9$. The partially protonated dimer $\mathrm{HSb}_{2} \mathrm{~S}_{4}^{-}$is the only antimony-sulfide species that still controls stibnite solubility, but it only does so over a small $\mathrm{pH}$ range from approximately $\mathrm{pH}=6.4$ to 7.5 .

The shape of the stibnite solubility curve with respect to $\mathrm{pH}$ also changes as the dominant complexing ligand changes from sulfide ( $\left.\mathrm{HS}^{-}\right)$to hydroxide $\left(\mathrm{OH}^{-}\right)$. This is demonstrated in Figure (2.8), which shows stibnite solubility from $\mathrm{pH}=3$ to 11 for the same three sulfide concentrations as those used in Figure (2.7). At and above $\mathrm{S}^{2-}$ total $=0.001 \mathrm{~mol} \mathrm{~kg}^{-1}$, antimony- sulfide dimers control stibnite solubility in reducing fluids with $\mathrm{pH}$ from circumneutral to alkaline (Figures 2.7A and 2.7B). The partially protonated dimers result in a plateau in the stibnite solubility curve just above neutral $\mathrm{pH}$. The prominence of this feature diminishes as the sulfide concentration decreases and $\mathrm{Sb}(\mathrm{OH})_{3}$ becomes more predominant. At the lowest sulfide concentration $\left(\mathrm{S}^{2-}{ }_{\text {total }}=0.0001 \mathrm{~mol} \mathrm{~kg}^{-1}\right)$, the contribution of $\mathrm{HSb}_{2} \mathrm{~S}_{4}{ }^{2-}$ is barely noticeable in the overall solubility curve (Figure 2.8C). When $\mathrm{Sb}(\mathrm{OH})_{3}$ controls stibnite solubility, it is constant at $\mathrm{pH}<7$ but then increases rapidly with increasing $\mathrm{pH}$ at $\mathrm{pH}>7$ such that at $\mathrm{pH} \geq 10.2$ stibnite solubility is greater in a solution containing $0.0001 \mathrm{~mol}$ $\mathrm{kg}^{-1} \mathrm{~S}^{2-}$ total than in one containing $0.01 \mathrm{~mol} \mathrm{~kg}^{-1} \mathrm{~S}^{2-}{ }_{\text {total. }}$.

\subsection{Conclusions}

The conclusions from this study are:

1) Antimony speciation in alkaline solutions with sulfide concentrations of 0.01 to $0.1 \mathrm{~mol} \mathrm{~kg}^{-1} \mathrm{~S}^{2-}$ total is dominated entirely by $\mathrm{Sb}_{2} \mathrm{~S}_{4}{ }^{2-}$. This conclusion is supported both by stibnite solubility experiments and EXAFS measurements of antimony's first coordination shell.

2) Antimony speciation at stibnite saturation at $30^{\circ} \mathrm{C}$ in solutions with moderate sulfide concentrations is best represented by a speciation model including $\mathrm{Sb}_{2} \mathrm{~S}_{4}{ }^{2-}, \mathrm{H}_{2} \mathrm{Sb}_{2} \mathrm{~S}_{5}{ }^{2-}, \mathrm{HSb}_{2} \mathrm{~S}_{4}{ }_{4}$, and $\mathrm{H}_{3} \mathrm{SbS}_{2} \mathrm{O}$ (Fit 30-A).

3) At low sulfide concentrations $\left(\mathrm{S}^{2-}\right.$ total $\left.\leq 0.001 \mathrm{~mol} \mathrm{~kg}^{-1}\right)$, the presence of $\mathrm{Sb}$ (III)-hydroxide complexes was confirmed both by solubility and EXAFS experiments at strongly alkaline $\mathrm{pH}$. The equilibrium constant representing the contribution of $\mathrm{Sb}(\mathrm{OH})_{3}$ to stibnite solubility that was estimated in the current study is consistent with literature (Fit 30-G).

As the stable antimony sulfide over a wide range fluid conditions and temperatures, stibnite

Table (2.8) Summary of proposed heterogeneous stibnite solubility reactions and the logarithms of their equilibrium constants at $30^{\circ} \mathrm{C}$.

\begin{tabular}{clccc} 
Reaction & & $\log _{10} \mathbf{K}$ & \pm & $\boldsymbol{\sigma}$ \\
\hline $\mathrm{K}_{2400}$ & $\mathrm{Sb}_{2} \mathrm{~S}_{3(\mathrm{~s})}+\mathrm{HS}^{-}=\mathrm{Sb}_{2} \mathrm{~S}_{4}{ }^{2-}$ & -13.33 & \pm & 0.03 \\
$\mathrm{~K}_{2502}$ & $\mathrm{Sb}_{2} \mathrm{~S}_{3(\mathrm{~s})}+2 \mathrm{HS}^{-}=\mathrm{H}_{2} \mathrm{Sb}_{2} \mathrm{~S}_{5}^{2-}$ & -2.56 & \pm & 0.04 \\
$\mathrm{~K}_{2401}$ & $\mathrm{Sb}_{2} \mathrm{~S}_{3(\mathrm{~s})}+\mathrm{HS}^{-}=\mathrm{HSb}_{2} \mathrm{~S}_{4}^{-}$ & -5.4 & \pm & 0.2 \\
$\mathrm{~K}_{1213}$ & $0.5 \mathrm{Sb}_{2} \mathrm{~S}_{3(\mathrm{~s})}+0.5 \mathrm{HS}^{-}+\mathrm{H}_{2} \mathrm{O}=\mathrm{H}_{3} \mathrm{SbS}_{2} \mathrm{O}$ & -4.32 & \pm & 0.02 \\
$\mathrm{~K}_{1033}$ & $0.5 \mathrm{Sb}_{2} \mathrm{~S}_{3(\mathrm{~s})}+3 \mathrm{H}_{2} \mathrm{O}=\mathrm{Sb}(\mathrm{OH})_{3}+1.5 \mathrm{HS}^{-}+1.5 \mathrm{H}^{+}$ & -26.5 & \pm & 0.1 \\
\hline
\end{tabular}


solubility is a basis for understanding antimony behavior in natural fluids. This study found that a scheme of four species (i.e., Fit 30-A) was required to fit the stibnite solubility measured for reducing solutions from $\mathrm{pH} 4$ to 12 containing $\geq 0.01 \mathrm{~mol} \mathrm{~kg}^{-1} \mathrm{~S}^{2-}$ total at $30^{\circ} \mathrm{C}: \mathrm{Sb}_{2} \mathrm{~S}_{4}{ }^{2-}$ at $\mathrm{pH}>9, \mathrm{HSb}_{2} \mathrm{~S}_{4}{ }^{-}$and $\mathrm{H}_{2} \mathrm{Sb}_{2} \mathrm{~S}_{5}{ }^{2-}$ at $\mathrm{pH}=9$ to 5 , and $\mathrm{H}_{3} \mathrm{SbS}_{2} \mathrm{O}$ at $\mathrm{pH}<5$. In alkaline fluids when the sulfide concentration was low $\left(\leq 0.001 \mathrm{~mol} \mathrm{~kg}-1 \mathrm{~S}^{2-}{ }_{\text {total }}\right)$, antimonous acid species were necessary to fit the measured stibnite solubility (Fit 30-G). The change in the dominant complexing ligand from sulfide to hydroxide makes the shape of the stibnite solubility curve change drastically (Figure 2.8). Table (2.8) summarizes the relevant heterogeneous equilibria describing stibnite dissolution in aqueous sulfide solutions at $30^{\circ} \mathrm{C}$ together with the derived equilibrium constants.

Further solubility experiments at low sulfide contents $\left(\leq 0.001 \mathrm{~mol} \mathrm{~kg}^{-1} \mathrm{~S}^{2-}\right.$ total $)$ or ultraviolet spectroscopic measurements will be needed to define the species present during the transition of antimony complexation with sulfide ligands to complexation with hydroxide ligands. Rigorous determination of the equilibrium constant for stibnite solubility in terms of $\mathrm{Sb}(\mathrm{OH})_{3}$, including the possibility of $\mathrm{H}_{2} \mathrm{SbS}_{2} \mathrm{O}^{-}$or $\mathrm{H}_{2} \mathrm{SbSO}_{2}{ }^{-}$or other possible intermediates, could be accomplished with solubility experiments at a strongly alkaline $\mathrm{pH}$ and sulfide concentrations from approximately $10^{-5}$ to $10^{-2} \mathrm{~mol} \mathrm{~kg}^{-1} \mathrm{~S}_{\text {total. }}^{2-}$ These types of experiments were not performed in this study because the current endeavor was focused on the stability and stoichiometry of antimony-sulfide complexes

\subsection{References}

Akeret, R., 1953. Ueber die Löslichkeit von Antimon(3)sulfid. Dissertation (PhD thesis) ETH, Zurich, p. 77.

Akinifiyev, N.N., Zotov, A.V., Shikina, N.D., 1994. Experimental studies and self-consistent thermodynamic data in the Sb(III)-S(II)-O-H system. Geochem. Internat. 31, 27-40.

Arnston, R.H., Dickson, F.W., Tunnel, G., 1966. Stibnite $\left(\mathrm{Sb}_{2} \mathrm{~S}_{3}\right)$ solubility in sodium sulfide solutions. Science 153, 1673-1674.

Babko, A.K., Lisetskaya, G.S., 1956. Equilibrium in reactions of formation of thiosalts of tin, antimony, and arsenic in solution. Russian Journal of Inorganic Chemistry 1, 969-980.

Belevantsev, V.I., Gushchina, L.I., Obolenskii, A.A., 1998a. Antimony in hydrothemal solutions: analysis and generalization of data on antimony(III) chloride complexes. Geochem. Internat. 36.

Belevantsev, V.I., Gushchina, L.I., Obolenskii, A.A., 1998b. Solubility of stibnite, $\mathrm{Sb}_{2} \mathrm{~S}_{3}(\mathrm{cr})$ :A revision of proposed interpretations and refinements. Geochem. Internat. 36, 58-64.

Oakdale Engineering, 2000. DataFitX for Windows Version 2.0: Programer's Manual, Oakdale, Pennylvania, USA

EPA, 2009. National Primary Drinking Water Regulations. EPA 816-F-09-004

Fiala, R., Konopik, N., 1950. Über das Dreistoffsystem $\mathrm{Na}_{2} \mathrm{~S}-\mathrm{Sb}_{2} \mathrm{~S}_{3}-\mathrm{H}_{2} \mathrm{O}$. II. Die auftretenden Bodenkörper und ihre Löslichkeit. Monatshefte für Chemie 81, 505-519.

Filella, M., Belzile, N., Chen, Y.-W., 2002. Antimony in the environment: a review focused on natural waters I. Occurence. Earth-Science Reviews 57, 125-176.

Filella, M., May, P.M., 2003. Computer simulation of the low-molecular-weight inorganic species distribution of antimony(III) and antimony(V) in natural waters. Geochim. Cosmochim. Acta 67, 4013-4031.

Filella, M., May, P.M., 2005. Critical appraisal of available thermodynamic data for the complexation of antimony(III) and antimony(V) by low molecular mass organic ligands. J Environ Monit 7, 1226-1237. 
Gushchina, L.V., Borovikov, A.A., Shebanin, A.P., 2000. Formation of antimony(III) complexes in alkali sulfide solutions at high temperatures: An experimental Raman spectroscopic study. Geochem. Internat. 38, 510-513.

Hannington, M.D., Harðardóttir, V., Garbe-Schönberg, D., Brown, K.L., 2016. Gold enrichment in active geothermal systems by acculating colloidal suspensions. Nature Geoscience.

Helgeson, H.C., 1969. Thermodynamics of hydrothermal systems at elevated temperatues and pressures. American Journal of Science 267, 729-804.

Helgeson, H.C., Kirkham, D.H., 1974. Theoretical prediction of the thermodynamic behavoir of aqueous electolytes at high pressures and temperatures: II. Debye-Huckel parameters for activity coefficients and relative partial molal properties. American Journal of Science 274, 1199-1261.

Helz, G.R., Valerio, Melissa S., Capps, Nathan E., 2002. Antimony speciation in alkaline sulfide solutions: Role of zerovalent sulfur. Environ. Sci. Technol. 36, 943-948.

Ho, P.C., Palmer, D.A., 1996. Ion association of dilute aqueous sodium hydroxide solutions to $600^{\circ} \mathrm{C}$ and $300 \mathrm{MPa}$ by conductance measurements. Journal of Solution Chemistry 25, 711-729.

Ho, P.C., Palmer, D.A., Mesmer, R.E., 1994. Electrical conductivity measurements of aqueous sodium chloride solutions to $600^{\circ} \mathrm{C}$ and $300 \mathrm{MPa}$. Journal of Solution Chemistry 23, 997-1018.

Keller, N.S., Stefansson, A., Sigfusson, B., 2014. Determination of arsenic speciation in sulfidic waters by Ion Chromatography Hydride-Generation Atomic Fluorescence Spectrometry (ICHG-AFS). Talanta 128, 466-472.

Kielland, J., 1937. Individual activity coefficients of ions in aqueous solutions. J. Am. Chem Soc. 59, $1675-1678$.

Kolpakova, N.N., 1971. On the speciation of antimony (III) in sulfide solutions (in Russian), Geochemistry of Hydrothermal Ore Deposition, Nauka, Moscow, pp. 197-209.

Kolpakova, N.N., 1982. Laboratory and field studies of ioinic equilibria in the $\mathrm{Sb}_{2} \mathrm{~S}_{3}-\mathrm{H}_{2} \mathrm{O}-\mathrm{H}_{2} \mathrm{~S}$ system. Geochem. Internat. 19, 46-54.

Krupp, R.E., 1988. Solubility of stibnite in hydrogen sulfide solutions, speciation, and equilibrium constants, from 25 to $350^{\circ}$ C. Geochim. Cosmochim. Acta 52, 3005-3015.

Krupp, R.E., Seward, T. M., 1987. The Rotokawa geothermal system, New Zealand: An active epithermal gold-depositing environment. Econ. Geol. 82, 1109-1129.

Landrum, J.T., Bennett, P.C., Engel, A.S., Alsina, M.A., Pastén, P.A., Milliken, K., 2009. Partitioning geochemistry of arsenic and antimony, El Tatio Geyser Field, Chile. Appl. Geochem. 24, 664676.

Learned, R.E., 1966. The solubilities of quartz, quartz-cinnabar and cinnabar-stibnite in sodium sulfide solutions and their implications for ore genesis, Department of Geology. University of California, Riverside, Riverside, California.

Marshall, W.L., Franck, E.U., 1981. Ion product of water substance, $0-1000^{\circ} \mathrm{C}, 1-10,000$ bars. New international formulation and its background. Journal of Physcial Reference Data 10, 295304.

Mosselmans, J.F.W., Helz, G.R., Pattrick, R.A.D., Charnock, J.M., Vaughan, D.J., 2000. A study of speciation of $\mathrm{Sb}$ in bisulfide solutions by X-ray absorption spectroscopy. Appl. Geochem. 15, 879-889.

Obolensky, A., Gushchina, L., Borisenko, A., Borovikov, A., Pavlova, G., 2007. Antimony in hydrothermal processes: solubility, conditions of transfer, and metal-bearing capacity of solutions. Russian Geology and Geophysics 48, 992-1001.

Okumura, A., Matsumiya, Y., Yamamoto, K., Ueno, R., Suzuki, M., Yamabe, S., 1995. Kinetics of oxygen exchange between arsenic acid and solvent water. Bulletin of the Chemical Society of Japan 68, 1839-1849.

Planer-Friedrich, B., Scheinost, A.C., 2011. Formation and structural characterization of thioantimony species and their natural occurrence in geothermal waters. Environ. Sci. Technol. 45, 68556863.

Planer-Friedrich, B., Suess, E., Scheinost, A.C., Wallschlager, D., 2010. Arsenic speciation in sulfidic waters: Reconciling contradictory spectroscopic and chromatographic evidence. Anal. Chem. 82, 10228-10235.

Planer-Friedrich, B., Wilson, N., 2012. The stability of tetrathioantimonate in the presence of oxygen, light, high temperature and arsenic. Chem. Geol. 322-323, 1-10. 
Pokrovski, G., Borisova, A., Roux, J., Hazemann, J., Petdang, A., Tella, M., Testemale, D., 2006. Antimony speciation in saline hydrothermal fluids: A combined X-ray absorption fine structure spectroscopy and solubility study. Geochim. Cosmochim. Acta 70, 4196-4214.

Popova, M.Y., Khodakovskiy, I.L., Ozerova, N.A., 1975. Measurement of the thermodynamic parameters of antimony hydroxo complexes and hydroflouride complexes up to $200^{\circ} \mathrm{C}$ (in Russian). Geokhimiya 6, 835-843.

Sherman, D.M., Ragnarsdottir, K.V., Oelkers, E.H., 2000. Antimony transport in hydrothermal solutions: an EXAFS study of antimony(V) complexation in alkaline sulfide and sulfidechloride brines at temperatures from $25^{\circ} \mathrm{C}$ to $300^{\circ} \mathrm{C}$ at $\mathrm{P}_{\text {sat. }}$ Chem. Geol. 167, 161-167.

Shestitko, V.S., Demina, O.P., 1971. Potentiometric determination of the composition of the sulfide anions of antimony. Russian Journal of Inorganic Chemistry 16, 1679-1680.

Shikina, N.D., Zotov, A.V., 1999. Solubility of stibnite $\left(\mathrm{Sb}_{2} \mathrm{~S}_{3}\right)$ in water and hydrogen sulfide solutions at temperature of $200-300^{\circ} \mathrm{C}$ under-vapor saturated conditions and a pressure of 500 bars. Geochem. Internat. 37, 82-86.

Smith, C.L., Ficklin, W. H., Thompson, J. M., 1987. Concentrations of arsenic, antimony, and boron in steam and steam condensate at the Geysers, California. J. Volcanol. Geotherm. Res. 32, 329-341.

Spycher, N.F., Reed, M.H., 1989. As(III) and Sb(III) sulfide complexes: An evaluation of stoichiometry and stability from existing experimental data. Geochim. Cosmochim. Acta 53, 2185-2194.

Suleimenov, O.M., Seward, T.M., 1997. A spectrophotometric study of hydrogen sulphide ionisation in aqueous solutions to $350^{\circ} \mathrm{C}$. Geochim. Cosmochim. Acta 61, 5187-5198.

Tella, M., Pokrovski, G.S., 2009. Antimony(III) complexing with O-bearing organic ligands in aqueous solution: An X-ray absorption fine structure spectroscopy and solubility study. Geochim. Cosmochim. Acta 73, 268-290.

Tossell, J.A., 1994. The speciation of antimony in sulfidic solutions: A theorectical study. Geochim. Cosmochim. Acta 58, 5093-5104.

Tossell, J.A., 2003a. Calculation of the energetics for the oxidation of $\mathrm{Sb}$ (III) sulfides by elemental $\mathrm{S}$ and polysulfides in aqueous solution. Geochim. Cosmochim. Acta 67, 3347-3354.

Tossell, J.A., 2003b. Calculation of the visible-UV absorption spectra of hydrogen sulfide, bisulfide, polysulfides, and As and Sb sulfides, in aqueous solution. Geochem. Trans. 4, 28-33.

Ullrich, M.K., Pope, J.G., Seward, T.M., Wilson, N., Planer-Friedrich, B., 2013. Sulfur redox chemistry governs diurnal antimony and arsenic cycles at Champagne Pool, Waiotapu, New Zealand. J. Volcanol. Geotherm. Res. 262, 164-177.

Wilson, N., Webster-Brown, J., 2009. The fate of antimony in a major lowland river system, the Waikato River, New Zealand. Appl. Geochem. 24, 2283-2292.

Wilson, N., Webster-Brown, J., Brown, K., 2007. Controls on stibnite precipitation at two New Zealand geothermal power stations. Geothermics 36, 330-347.

Wilson, N., Webster-Brown, J., Brown, K., 2012. The behaviour of antimony released from surface geothermal features in New Zealand. J. Volcanol. Geotherm. Res. 247-248, 158-167.

Wood, S.A., 1989. Raman spectroscopic determination of the speciation of ore metals in hydrothermal solutions: I. Speciation of antimony in alkaline sulfide solutions at $25^{\circ} \mathrm{C}$. Geochim. Cosmochim. Acta 53, 237-244.

Zakaznova-Herzog, V.P., Seward, T., 2006. Antimonous acid protonation/deprotonation equilibria in hydrothermal solutions to $300^{\circ} \mathrm{C}$. Geochim. Cosmochim. Acta 70, 2298-2310.

Zakaznova-Herzog, V.P., Seward, T.M., 2012. A spectrophotometric study of the formation and deprotonation of thioarsenite species in aqueous solution at $22^{\circ} \mathrm{C}$. Geochim. Cosmochim. Acta 83, 48-60.

Zakaznova-Herzog, V.P., Seward, T.M., Suleimenov, O.M., 2006. Arsenous acid ionisation in aqueous solutions from 25 to $300^{\circ} \mathrm{C}$. Geochim. Cosmochim. Acta 70, 1928-1938.

Zotov, A.V., Shikina, N.D., Akinfiev, N.N., 2003. Thermodynamic properties of the Sb(III) hydroxide complex $\mathrm{Sb}(\mathrm{OH})_{3(\mathrm{aq})}$ at hydrothermal conditions. Geochim. Cosmochim. Acta 67, 1821-1836. 


\section{Chapter (3):}

\section{X-ray absorption spectroscopy measurements of antimony-sulfide and -hydroxide complexes at stibnite saturation}

\subsection{Introduction}

X-ray absorption spectroscopy (XAS) and stibnite $\left(\mathrm{Sb}_{2} \mathrm{~S}_{3}\right)$ solubility measurements are two independent methods of investigating antimony-sulfide complexes in aqueous solutions that have produced apparently conflicting interpretations of antimony-sulfide speciation at alkaline $\mathrm{pH}$. Specifically, XAS experiments have been interpreted in terms of antimony-sulfide monomers (Mosselmans et al., 2000; Planer-Friedrich and Scheinost, 2011), whereas solubility experiments indicate that dimers such as $\mathrm{Sb}_{2} \mathrm{~S}_{4}{ }^{2-}$ and $\mathrm{HSb}_{2} \mathrm{~S}_{4}{ }^{-}$control stibnite solubility (Arnston et al., 1966; Kolpakova, 1971, 1982; Krupp, 1988). In Chapter (2), stibnite solubilities at alkaline $\mathrm{pH}$ at $30^{\circ} \mathrm{C}$ were interpreted in terms of antimony-sulfide dimers at $\mathrm{S}^{2-}{ }_{\text {total }} \geq 0.001 \mathrm{~mol} \mathrm{~kg}^{-1}$ with antimony-hydroxide monomers (i.e., $\mathrm{Sb}(\mathrm{OH})_{3}$ and $\mathrm{H}_{2} \mathrm{SbO}_{3}{ }^{-}$) predominating at $\mathrm{S}^{2-}$ total $\leq 0.0001 \mathrm{~mol} \mathrm{~kg}^{-1}$. The current chapter presents XAS measurements of antimony(III) in solutions of $\mathrm{pH}=10.9$ to 12 that are comparable to the solutions used in the solubility experiments, and it addresses the apparent discrepancy between the two techniques.

$\mathrm{X}$-ray absorption spectroscopy is an in situ method for solids and liquid samples that directly probes the local coordination environment of a targeted element (i.e., antimony in this study) by exciting core level electrons with tunable $\mathrm{X}$-ray radiation to produce an absorption edge that is sensitive to the bonding environment of the targeted element. The extended X-ray fine structure (EXAFS) portion of XAS spectra spans from $\sim 80$ to $\sim 800 \mathrm{eV}$ above this absorption edge and provides information about the identity of, distance to, and number of atoms within several ångstroms (A) of the excited atom. Thus, EXAFS can identify the atoms in the first, and possibly also second, coordination shells of aqueous complexes. The other portion of the XAS spectra, X-ray near edge structure (XANES), extends from $\sim 20 \mathrm{eV}$ below to $\sim 60 \mathrm{eV}$ above the absorption edge and is sensitive to the electronic structure of the excited atom, particularly its valence and bonding geometry. In contrast to XAS experiments, solubility studies indirectly determine the stoichiometry of the dominant aqueous complex (or complexes) by measuring changes in solubility as a result of changes in relevant physiochemical fluid variables, such as $\mathrm{pH}$ and ligand concentrations. Although XAS and 
solubility experiments are, in theory, both acceptable methods for identifying the antimony complexes present in solution, they have thus far produced apparently inconsistent models for antimony speciation in similar alkaline sulfide solutions.

The current and previous antimony sulfide solubility studies find that antimony-sulfide dimers dominate $\mathrm{Sb}$ (III) speciation at alkaline $\mathrm{pH}$, whereas previous XAS studies of very similar solutions have been interpreted in terms of antimony sulfide monomers. As presented Chapter (2), $\mathrm{Sb}$ (III) occurs as the fully deprotonated dimer $\mathrm{Sb}_{2} \mathrm{~S}_{4}{ }^{2-}$ at $\mathrm{pH}>9$ in ambient temperature solutions with sufficient sulfide concentrations. In solutions with low sulfide concentrations, antimonous acid species (i.e., $\mathrm{Sb}(\mathrm{OH})_{3}$ and $\mathrm{H}_{2} \mathrm{SbO}_{3}{ }^{-}$) can account for the observed solubilities. In alkaline $\mathrm{Na}_{2} \mathrm{~S}$ solutions, XAS studies have failed to detect the antimony-antimony interactions in antimony complexes that would be expected if antimony dimers were present, and thus previous XAS results can be used to support the presence of antimony sulfide monomers (Mosselmans et al., 2000; Sherman et al., 2000; PlanerFriedrich and Scheinost, 2011). Planer-Friedrich and Scheinost (2011) detected 1 to 2 oxygen atoms in antimony's first coordination shell in solutions in which the molar concentration of sulfide approached the antimony concentration. This observation is consistent with either a mixed ligand antimony oxysulfide complex or a mixture of sulfide-antimony complexes and antimonous acid. A further complication is that some of the published $\mathrm{Sb} \mathrm{K}$-edge XAS data refer to $\mathrm{Sb}(\mathrm{V})$ and/or partially oxidised $\mathrm{Sb}(\mathrm{III}) /(\mathrm{V})$-containing solutions.

To gain insight into the $\mathrm{Sb}(\mathrm{III})$ speciation in aqueous sulfide solutions, XAS measurements were conducted on solutions obtained by equilibrating stibnite with strongly alkaline ( $\mathrm{pH}=10.9$ to 12.0) sodium sulfide solutions containing varying concentrations of total reduced sulfide $\left(\mathrm{H}_{2} \mathrm{~S}^{\circ}+\mathrm{HS}^{-}\right)$ at $30^{\circ} \mathrm{C}$. The solutions studied by XAS included both solutions in which the sulfide concentration was much greater than the antimony concentrations and solutions in which Sb-O interactions were expected due to the low sulfide concentration. The solutions studied were produced concomitantly with the solubility experiments described in the previous chapter, and so are directly comparable to the thermodynamic model developed in Chapter (2). In this chapter, attempts are made to resolve the differences between $\mathrm{Sb}$ (III) speciation models predicted by XAS measurements (antimony-sulfide monomers) and derived from solubility experiments (antimony-sulfide dimers) and to define the limitations of XAS studies in detecting antimony species present in solutions.

\subsubsection{Previous XAS studies of antimony in aqueous solutions}

Three previous X-ray absorption spectroscopy studies of aqueous antimony-sulfide speciation in sodium sulfide solutions have been published (Mosselmans et al., 2000; Sherman et al., 2000; Planer-Friedrich and Scheinost, 2011). Ambient temperature measurements included solutions having $\mathrm{pH}=8$ to 13 that contained 0.001 to $1 \mathrm{~mol} \mathrm{~kg}^{-1} \mathrm{~S}^{2-}$ total. Sherman et al. (2000) and Mosselmans et al. (2000) also report a few data up to $300^{\circ} \mathrm{C}$. The changes in the antimony coordination environment detected at these higher temperature measurements are not discussed further in this chapter but are 
Table (3.1) Summary of previous EXAFS studies of antimony speciation in solution.

\begin{tabular}{|c|c|c|c|c|c|c|c|c|}
\hline & $\mathrm{Sb}$ & & & First sh & ell distance & $s(\AA)$ & Ligands in & \\
\hline $\mathrm{T}\left({ }^{\circ} \mathrm{C}\right)$ & $\left(\mathrm{mol} \mathrm{kg}^{-1}\right)$ & Solution components & $\mathrm{S}: \mathrm{Sb}$ ratio & $\mathrm{Sb}-\mathrm{O}$ & $\mathrm{Sb}-\mathrm{Cl}$ & $\mathrm{Sb}-\mathrm{Sb}$ & first shell & Reference \\
\hline Hydroxide & and chlorid & le complexes & & & & & & \\
\hline $25-250$ & $0.04-0.1$ & $2-3 \mathrm{~mol} \mathrm{~kg}^{-1} \mathrm{HCl}$ & na & - & $2.38-2.42$ & - & $3 \mathrm{Cl}$ & $a$ \\
\hline $30-400$ & $0.01-0.3$ & DI water & na & $1.96-1.97$ & - & - & 30 & $b$ \\
\hline & & $2.3 \mathrm{~mol} \mathrm{~kg}^{-1} \mathrm{NaCl}, 0.1 \mathrm{~mol}$ & $\mathrm{~kg}^{-1} \mathrm{HCl}$ & 1.97 & $2.37-2.47$ & - & $2.5 \mathrm{Cl}+0.5 \mathrm{O}$ & \\
\hline & & $3.5 \mathrm{~mol} \mathrm{~kg}^{-1} \mathrm{HCl}$ & & - & $2.39-2.43$ & - & $3 \mathrm{Cl}$ & \\
\hline $20-60$ & $0.003-0.02$ & $\mathrm{Sb}_{2} \mathrm{O}_{3}$ in DI water & na & $1.96-1.98$ & - & - & $3-4 \mathrm{O}$ & $c$ \\
\hline Sulfide con & nplexes & & & $\mathrm{Sb}-\mathrm{O}$ & $\mathrm{Sb}-\mathrm{S}$ & $\mathrm{Sb}-\mathrm{Sb}$ & & \\
\hline $25-300$ & $0.05-0.1$ & $\begin{array}{l}0.2-0.1 \mathrm{~mol} \mathrm{~kg}^{-1} \mathrm{NaHS}, \pm \\
1 \mathrm{~mol} \mathrm{~kg}^{-1} \mathrm{NaCl}\end{array}$ & $4: 1,12: 1$ & - & 2.34 & - & $4 \mathrm{~S}$ & $d$ \\
\hline$-193-200$ & $0.001-0.1$ & $\begin{array}{l}0.1-2.5 \mathrm{~mol} \mathrm{~kg}^{-1} \mathrm{NaHS}, \pm \\
0.02 \mathrm{~mol} \mathrm{~kg}^{-1} \mathrm{CO}^{2-}, \pm \\
\text { elemental sulfur }\end{array}$ & $3: 1$ to $150: 1$ & - & $2.0-2.43$ & $\sim 4.15^{h}$ & $3-4 S$ & $e$ \\
\hline-258 & 0.01 & $\begin{array}{l}0.02 \text { to } 0.2 \mathrm{~mol} \mathrm{~kg}^{-1} \mathrm{NaHS} \\
\text { reduced sample preparati }\end{array}$ & $\begin{array}{l}2: 1,10: 1,20: 1 \\
\text { on }\end{array}$ & 2.05 & $2.40-2.41$ & - & $2 \mathrm{~S}+1 \mathrm{O}, 3-4 \mathrm{~S}$ & S \\
\hline & & oxidising sample preparat & & 1.96 & $2.33-2.40$ & $5.64^{i}$ & $3 \mathrm{~S}+2 \mathrm{O}, 4 \mathrm{~S}$ & \\
\hline
\end{tabular}

$a$ Oelkers et al. (1998)

$b$ Pokrovski et al. (2006)

$c$ Tella and Pokrovski (2009)

$d$ Sherman et al. (2000), only fits from 25 and $35^{\circ} \mathrm{C}$ reported. Up to 0.6 oxygen atoms in first coordination shell beginning at $200^{\circ} \mathrm{C}$

$e$ Mosselmans et al. (2000), only fits from -193 and $25^{\circ} \mathrm{C}$ tabulated. Evidence for 1 oxygen at $200^{\circ} \mathrm{C}$

$f$ Planer-Friedrich and Scheinost (2011)

$g$ Chloride not found in first shell in solution containing $\mathrm{NaCl}$

$h$ Evidence of $\mathrm{Sb}-\mathrm{Sb}$ interaction but insufficient data to fit

$i \mathrm{Sb}$-Sb observed in solution with $2 \mathrm{~S}: 1 \mathrm{Sb}$ molar concentration ratio

considered with this study's high temperature solubility experiments in Chapter (4). The ambient temperature EXAFS results from these and several other XAS studies of antimony in solution are summarised briefly in Table (3.1). To achieve the high antimony concentrations $\left(>\sim 0.001 \mathrm{~mol} \mathrm{~kg}^{-1}\right.$ $\mathrm{Sb})$ required for EXAFS, XAS measurements of $\mathrm{Sb}$ in aqueous solution are generally limited to alkaline pH's. The first shell Sb-O distances were typically between 1.95 and $2.0 \AA$, while the distances for less electronegative ligands, including $\mathrm{Cl}^{-}$and $\mathrm{HS}^{-}$, varied between 2.33 and $2.42 \AA$.

In the sodium sulfide solutions, the antimony species detected by XAS are influenced by how the redox-sensitive solutions were prepared. Sherman et al. (2000) measured XAS Sb K-edge spectra on solutions containing 0.2 to $1 \mathrm{~mol} \mathrm{~kg}^{-1} \mathrm{~S}_{\text {total }}$ that were buffered using $\mathrm{NaCl}$ or $\mathrm{NaOH}$ to strongly alkaline ( $\mathrm{pH} 12$ to 13$)$ or extremely acidic $(\mathrm{pH}<2)$ conditions. Although the solutions were prepared from $\mathrm{Sb}(\mathrm{III})$ and $\mathrm{S}(\mathrm{II})$ reagents, laboratory procedures to control oxygen (i.e., de-oxygenation of solutions or preparation in a glove box) were not used. The solutions became light yellow to green in colour, indicating the probable formation of polysulfides due to oxidation. For this reason, and due to the fitted coordination numbers $(\sim 4)$ and generally shorter Sb-S distances $(2.33-2.34 \AA$ ), the authors interpreted the spectra in terms of a four-coordinated $\mathrm{Sb}(\mathrm{V})$ species (thioantimonates, e.g., $\mathrm{SbS}_{4}{ }^{3-}$ ). 
Thus, the results from Sherman (2000) are not directly comparable to the $\mathrm{Sb}(\mathrm{III})-\mathrm{S}(\mathrm{II})$ system considered in the current study.

Mosselmans et al. (2000) and Planer-Friedrich and Scheinost (2011) applied more stringent methods than Sherman et al. (2000) to avoid oxidation (by atmospheric oxygen) when preparing their antimony sulfide solutions and found first coordination shells consistent with tetrahedral $\mathrm{Sb}(\mathrm{III}) \mathrm{S}_{3}$ in many of their solutions. Mosselmans et al. (2000) prepared alkaline ( $\mathrm{pH} 8$ to 14) sodium sulfide (NaHS) solutions by reacting $\mathrm{N}_{2}$-purged $\mathrm{NaOH}-\mathrm{NaHS}$ solutions with stibnite and, in some cases, with $\mathrm{Na}_{2}\left(\mathrm{CO}_{3}\right)^{2-}$ and/or elemental sulfur. The EXAFS results from solutions containing $\mathrm{Na}_{2}\left(\mathrm{CO}_{3}\right)^{2-}$ or elemental sulfur suggested a 4-coordinated $\mathrm{Sb}(\mathrm{V})$-sulfide species, similar to results from Sherman et al. (2000). Other solutions contained 3-coordinated Sb(III) sulfide species or possibly a mixture of $\mathrm{Sb}(\mathrm{V})$ - and $\mathrm{Sb}(\mathrm{III})$-sulfide complexes. In addition, the formation of polysulfide species by the reaction of elemental sulfur with HS- cannot be excluded, and these polysulfide species would also form stable moieties with $\mathrm{Sb}(\mathrm{III})$ and/or $\mathrm{Sb}(\mathrm{V})$.

Planer-Friedrich and Scheinost (2011) studied the effects on antimony sulfide speciation of oxygenated vs. deoxygenated sample preparation and of the aqueous sulfide concentration relative to that of antimony using both XAS and separation of antimony species by liquid chromatography (IC) prior to elemental analysis by inductively coupled plasma-mass spectrometry (ICP-MS). Their samples consisted of complementary suites of $0.01 \mathrm{~mol} \mathrm{~kg}^{-1} \mathrm{Sb}$ (III) solutions that were prepared under reducing (i.e., prepared and sealed in a glovebox) and oxidising conditions (i.e., sealed with exposure to atmospheric oxygen) and in which the molar sulfide concentration was two to twenty times greater than that of antimony.

In the solutions from the reduced sample suite analysed by Planer-Friedrich and Scheinost (2011), antimony was surrounded by $\sim 3.5$ neighbouring atoms within $3 \AA$. The identity of the atoms changed with sulfide concentration. When the sulfide concentration was greater than ten times that of

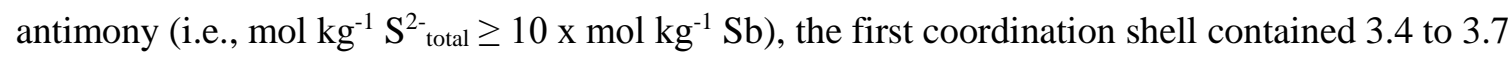
sulfur atoms at $\sim 2.4 \AA$. In contrast, when the sulfide concentration was only two times that of the antimony concentration (i.e., $\mathrm{mol} \mathrm{kg}^{-1} \mathrm{~S}^{2-}$ total $=2 \times \mathrm{mol} \mathrm{kg}^{-1} \mathrm{Sb}$ ), the first coordination shell contained 2 sulfur atoms at $\sim 2.4 \AA$ and an oxygen atom at $2.05 \AA$. For the samples prepared under more oxidising conditions, the occurrence of sulfur and oxygen within the first shell was similar; however the total number of first shell scattering atoms was higher $(\sim 4)$ and the Sb-S distance was smaller ( $2.34 \AA$ ). The authors interpreted these changes as evidence of oxidation of $\mathrm{Sb}(\mathrm{III})$ to $\mathrm{Sb}(\mathrm{V})$ during sample preparation under oxidising conditions. For both Mosselmans et al. (2000) and PlanerFriedrich and Scheinost (2011), the majority of the sodium sulfide solutions that were prepared with the exclusion of atmospheric oxygen (i.e., complete preparation in an glove box) and without elemental sulfur additions had first coordination shells containing < 4 sulfur atoms at 2.34 to $2.41 \AA$. In addition to these XAS studies of antimony in hydrosulfide solutions, there have been a limited number of XAS studies of Sb speciation in aqueous solutions containing chloride (Oelkers et 
al., 1998; Pokrovski et al., 2006) and various organic ligands (Tella and Pokrovski, 2009). These studies provide examples of the range of Sb-O distances possible under different conditions and the shape of the Sb XANES associated with different ligands and geometries. The EXAFS study of Oelkers et al. (1998) demonstrated that antimony forms 3-coordinated chloride complexes from 25 to $260^{\circ} \mathrm{C}$ in strongly saline acidic fluids $\left(\mathrm{HCl} \geq 2.3 \mathrm{~mol} \mathrm{~kg}^{-1}\right)$. Pokrovski et al. (2006) considered antimony complexation up to $400^{\circ} \mathrm{C}$ in pure water, moderately acidic $\mathrm{NaCl}-\mathrm{HCl}$ solutions, and strongly acidic $\mathrm{HCl}$ solutions. A 3-coordinated $\mathrm{Sb}-\mathrm{O}$ species, consistent with antimonous acid, $\mathrm{Sb}(\mathrm{OH})_{3}$, was dominant in pure water and was a major species in $\mathrm{NaCl}-\mathrm{HCl}$ solutions. The $\mathrm{Sb}-\mathrm{O}$ distance was $1.97 \pm 0.01 \AA$, regardless of temperature or chloride concentration.

Complexing of antimony with chloride ligands occurred in both the $\mathrm{HCl}$ and $\mathrm{NaCl}-\mathrm{HCl}$ solutions, and the results were interpreted in terms of $\mathrm{SbCl}_{2}{ }^{+}, \mathrm{SbCl}_{3}, \mathrm{SbCl}(\mathrm{OH})_{2}$, and $\mathrm{SbCl}(\mathrm{OH})_{3}{ }^{-}$ based on average coordination numbers from EXAFS, linear combination fitting (LCF) of the XANES, and solubility measurements. In addition to analysis of the EXAFS, Tella and Pokrovski (2009) used solid reference materials to interpret the Sb XANES of solutions containing $\mathrm{Sb}$ (III) and various organic ligands. They found that antimony occurred as antimonous acid species or as bidentate Sb-organic ligand complexes, depending on the type and location of functional groups in the organic ligands present.

\subsubsection{X-ray near edge fine structure (XANES) at the Sb K-edge}

In the XAS Sb K-edge solutions discussed above, interpretation of the Sb speciation has largely been limited to the EXAFS portion of the XAS spectrum. The XANES portion of Sb K-edge $\mathrm{X}$-ray absorption spectra is rarely considered in XAS studies of antimony in solution and has never been used to quantitatively study the complexation of antimony in aqueous hydrosulfide solutions. Sherman et al. (2000) did not report the Sb K-edge positions of the Sb sulfide complexes in their solutions. Mosselmans et al. (2000) and Planer-Friedrich and Scheinost (2011) did report edge energy positions for their samples but found that the edge positions of solutions interpreted in terms of $\mathrm{Sb}$ (III) and $\mathrm{Sb}(\mathrm{V})$ sulfide complexes overlapped and were in general between those of $\mathrm{Sb}(\mathrm{III})$ in stibnite and $\mathrm{Sb}(\mathrm{V})$ in oxides. Fortunately, there are a number of recent quantitative XANES investigations of $\mathrm{Sb}$ valence and bonding environment ( $\mathrm{Sb}-\mathrm{O}$ versus $\mathrm{Sb}-\mathrm{S}$ bonds) in minerals, synthetic phases, and of $\mathrm{Sb}$ adsorbed onto various iron oxide phases (Scheinost et al., 2006; Kirsch et al., 2008; Fawcett et al., 2009; Varrica et al., 2013). As described in the following, these data can provide useful insights into how the features of the Sb K-edge XANES change with changes in antimony valence state and coordination environments.

An increase in atomic valence results in a slight increase in the energy position of the absorption edge. For the $\mathrm{Sb} \mathrm{K}$-edge, the edge position is 3 to $5 \mathrm{eV}$ higher in $\mathrm{Sb}(\mathrm{V})$-oxides than in $\mathrm{Sb}$ (III)-S and Sb(III)-O solids (e.g. Scheinost et al., 2006; Kirsch et al., 2008; Fawcett et al., 2009; Guo et al., 2014; Hockmann et al., 2014). The absorption edge position is usually defined for XANES 
spectra as the maximum of the first derivative of the energy spectra, and is located at $30491 \mathrm{eV}$ for $\mathrm{Sb}(0), \sim 30,492$ to $30,493 \mathrm{eV}$ for $\mathrm{Sb}(\mathrm{III})$, and 30,495 to 30,498 eV for $\mathrm{Sb}(\mathrm{V})$. The edge position and several other features of the XANES spectra are shown for stibnite and two solutions in Figure (3.1). Increases in the edge position have been used to infer valence in adsorbed complexes in Sbcontaminated soils (Takaoka et al., 2005; Mitsunobu et al., 2006; Mitsunobu et al., 2011; Hockmann et al., 2014). Features in the XANES spectra after the edge, including the height of the white line and the presence of a post-edge shoulder, are sensitive to the coordination geometry (e.g. Ebitani et al., 1992; Tella and Pokrovski, 2009; Beauchemin et al., 2012). Together with EXAFS analysis, these features have been used to confirm antimony's coordination environment and/or valence by comparison to reference spectra (Ebitani et al., 1992; Ackermann et al., 2009; Beauchemin et al., 2012; Varrica et al., 2013; Mills et al., 2014) or to calculated theoretical spectra (Yiwata et al., 2001; Lu et al., 2002).

Interpretation of the $\mathrm{Sb} \mathrm{K}$-edge XANES is more challenging than lower energy edges because of significant spectral broadening that is caused by the short corehole lifetime of the $\mathrm{Sb} 1 \mathrm{~s}$ electrons and poor monochromator resolution at the energy of the Sb K-edge (Krause and Oliver, 1979). The broad $\mathrm{Sb}$ K-edge spectra may cause the absorption edges of $\mathrm{Sb}(\mathrm{III})$ and $\mathrm{Sb}(\mathrm{V})$ to be indistinguishable, especially for samples with low antimony concentrations. The absorption edge in antimony minerals with two antimony valence states is often a single wide spectral feature rather than two distinct edges, as is the case for the As K-edge in mixed-valence arsenic samples (Fawcett et al., 2009). Several

Figure (3.1) Antimony K-edge XANES and first derivative spectra for representative mineral and solution samples from the current study. Major spectral features described in text are indicated by shaded regions. Spectra have been shifted along the vertical axis for clarity. Note the high noise in the solution XANES relative to that for stibnite.
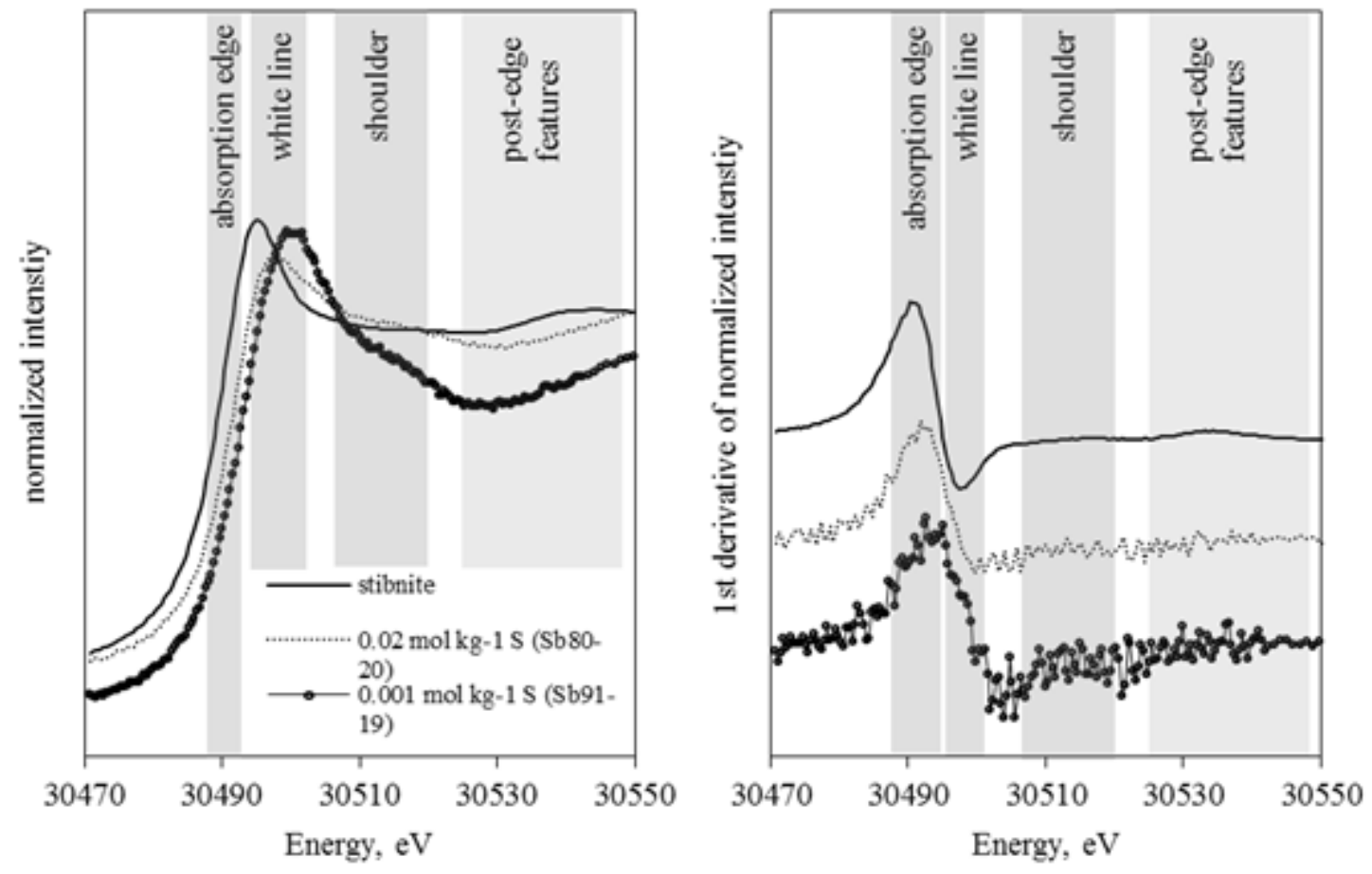
recent studies employing Sb XAS to investigate the chemistry of antimony in environmental sediment samples containing $\sim 0.01$ to $3 \mathrm{~mol} \mathrm{~kg}^{-1} \mathrm{Sb}$ found that the XANES was inconclusive and instead used the coordination number of the first shell, typically three for $\mathrm{Sb}(\mathrm{III})$ and six for $\mathrm{Sb}(\mathrm{V})$ in solids, to determine antimony valence (Ilgen et al., 2012; Ritchie et al., 2013; Ilgen et al., 2014). Antimony XAS studies from the material science literature frequently use Sb XANES measured at the lower energy $\mathrm{Sb}$ LIII or LI edges, where spectral broadening is dramatically lower (e.g. Flavell et al., 1997; Matsuzawa et al., 2003; Geraldo et al., 2007). In the current study, EXAFS, XANES, and the results of the solubility experiments were considered together.

\subsection{Methods}

Samples for XAS measures were collected in conjunction with the $30^{\circ} \mathrm{C}$ stibnite solubility experiments (Chapter 2). The solution properties are summarised in Table (3.2). Samples were collected in air-tight syringes directly from a flow-through apparatus containing stibnite, and the $\mathrm{pH}$, total sulfide concentration and total antimony concentration were measured, as described in the previous chapter. For XAS analysis, samples were sealed in quartz glass ampoules that had been purged with high purity nitrogen $\left(99.999 \% \mathrm{~N}_{2}\right)$ from which any residual oxygen had been removed by reaction with copper at $450^{\circ} \mathrm{C}$. The ampoules had wall thickness of $1 \mathrm{~mm}$ and an internal path length of $7 \mathrm{~mm}$. The top closure on the ampoules had be narrowed and elongated but still allowed injection of the solution into the nitrogen purged space via a catheter directly from the gas tight syringe. The constricted portion of the ampoule permitted rapid and effective sealing of the glass ampoule with an oxy-acetylene torch.

Antimony K-edge XAS spectra were measured at ambient temperature at the XAS Beamline at the Australian Synchrotron. The beam energy was selected using a Si(311) monochromator that was calibrated relative to the $\mathrm{Sb} \mathrm{K}$-edge of $\mathrm{Sb}$ foil $(30,491 \mathrm{eV})$. Reference solid samples were measured in transmission mode. Solution samples were measured in fluorescence mode in a $90^{\circ}$ geometry using a 36 element germanium detector. The distance between the detector and the sample was varied for each solution so that the fluorescence signal received by the detector was within its linear range. Thus, no deadtime correction was necessary. The sample holder and beam flight path were purged with helium. The energy resolution of the beam at the Sb K-edge is approximately $1 \mathrm{eV}$.

Table (3.2) Chemistry of XAS solutions in order of highest to lowest pH

\begin{tabular}{|c|c|c|c|c|}
\hline Sample & pH & mol kg ${ }^{-1} S^{2-}$ total & $\mathrm{mol} \mathrm{kg}{ }^{-1} \mathrm{Sb}$ & molar S:Sb \\
\hline Sb91-19 & 12.0 & 0.001 & 0.0009 & $1.5: 1$ \\
\hline Sb80-20 & 11.7 & 0.019 & 0.0013 & $15: 1$ \\
\hline $\mathrm{Sb} 75-20$ & 11.4 & 0.009 & 0.0003 & $26: 1$ \\
\hline Sb51-24 & 10.9 & 0.097 & 0.0054 & $18: 1$ \\
\hline
\end{tabular}


Multiple scans were taken for all samples to improve signal-to-noise ratio and then merged for each sample after aligning individual scans to the reference foil. The number of scans required to produce a reasonable signal varied from a minimum of two to a maximum of eighteen for solutions containing $10^{-3}$ and $10^{-4} \mathrm{~mol} \mathrm{~kg}^{-1} \mathrm{Sb}$, respectively. Re-alignment of the beam was repeated at a maximum of every five scans. Initial raw data conversion was performed using the programs Average and Sakura for transmission and fluorescence scans, respectively (Kappen and Ruben, 2013; Australian Synchrotron, 2016). Data processing and analysis were conducted with Athena and Artemis within the Demeter 0.9.17 suite of programs (Ravel and Newville, 2005). Background subtraction using the AUTOBAK procedure and normalization of measured spectra to the absorption edge-step were conducted in Athena. Fitting of normalized spectra was completed in Artemis.

Fitting of EXAFS spectra involves determining the number and Sb-scatterer distances of possible coordinating atoms around the excited atom (here $\mathrm{Sb}$ ) that best reproduce the measured EXAFS spectra. Interpretation of spectra from unknown samples is enabled by theoretical calculation of the backscattering amplitude and phase-shift functions of different scattering atoms (e.g., sulfur versus oxygen) using known crystal structures. The fit parameters are the coordination number $(C N)$, the distance from the central antimony atom to backscattering atoms $(R)$, the energy shift between the measured absorption edge and that used in calculations of theoretical backscattering amplitude and phase-shift functions $\left(\Delta E_{0}\right)$, and lastly a Debye-Waller-like factor $\left(\sigma^{2}\right)$ that accounts for thermal and structural disorder in the Sb-backscatter distance. An additional factor, the amplitude reduction factor $\left(S_{0}^{2}\right)$, corrects for excited electrons that do not produce EXAFS. The theoretical backscattering amplitude and phase-shift functions for Sb-S paths were calculated with FEFF6 from the tetrahedrite crystal structure (endmember $\mathrm{Cu}_{12} \mathrm{Sb}_{4} \mathrm{~S}_{13}$ ), one of the few antimony sulfide minerals containing isolated $\mathrm{SbS}_{3}$ tetrahedra (Peterson and Miller, 1968). The backscattering amplitude and phase-shift functions for $\mathrm{Sb}-\mathrm{O}$ paths were calculated from the senarmonite $\left(\mathrm{Sb}_{2} \mathrm{O}_{3}\right.$, cubic) structure (Whitten et al., 2004). The structure of stibnite used in fitting solid reference samples and second shell $\mathrm{Sb}-\mathrm{Sb}$ interactions in solutions were from Lundegaard et al. (2003). Fits were performed in $R$-space on the background subtracted, normalized and Fourier transformed spectra and are shown in Figure (3.2). Fits were performed at wavenumber $(k)$ weightings of 1, 2, and 3 simultaneously. Further constraints used in fitting procedures are noted in Table (3.3).

The value for the scattering amplitude factor $\left(S_{0}{ }^{2}\right)$ to be used in the fitting of the EXAFS of the unknown solutions was determined by fitting the EXAFS spectrum from the stibnite reference sample. The scattering amplitude factor is an estimate of the proportion of electrons participating in scattering and is usually set to a value between 0.7 and 1. The stibnite EXAFS spectrum is difficult to fit because the stibnite crystallographic structure contains four unique Sb-S bond distances between 2.4 and $2.9 \AA$ that cannot be individually distinguished in the EXAFS spectra but appear as one Sb-S distance at $2.51 \AA$ (Lundegaard et al., 2003). Attempts were made to fit the stibnite spectra with only the shortest two Sb-S distances (2.48 and $2.52 \AA$ ) with their coordination numbers set by their abundances in the 
stibnite structure but this produced values for the scattering amplitude factor greater than 1 (i.e., $S_{0}^{2}>$ 1). Adding a contribution from the next shortest $\mathrm{Sb}-\mathrm{S}$ path at $2.66 \AA$ resulted in improved fits and generated $\mathrm{S}_{0}^{2}$ values between 0.80 and 0.99 . A value of 0.95 was used in subsequent fitting of solution EXAFS because this value is typical of values used in EXAFS studies at the Sb K-edge (Oelkers et al., 1998; Sherman et al., 2000; Millet et al., 2003; Tella and Pokrovski, 2009; Planer-Friedrich and Scheinost, 2011; Ilgen et al., 2012; Sinsermsuksakul et al., 2012; Ritchie et al., 2013; Ilgen et al., 2014).

\subsection{Results}

The compositions of the solutions studied are given in Table (3.2). The absorption edge energies, details of the EXAFS spectra used in fitting procedures, and the results from the fitting of the EXAFS portion of the XAS spectra are given in Table (3.3). The best fits were selected based upon the minimization of both the $R$ factor, which indicates the misfit of the fitted model relative to the data, and the reduced $\chi^{2}$, which is the estimated uncertainty including the number of fit variables

Table (3.3) EXAFS results. Fits of EXAFS were completed in $R$-space at $k$-weights of 1, 2, and 3 simultaneously. The amplitude reduction factor $\left(S_{0}{ }^{2}\right)$ was set to 0.95 (see text for explanation). Error of individual fits is listed at the $95 \%$ confidence level for the fit variables to show variation in quality of fits. These fit errors do not include the uncertainty involved in the fit settings or constraints. Estimated total uncertainty for $C N$ is $\sim 25 \%$ and for $R$ it is $\sim 0.01 \AA$. Additional fit constraints are noted for individual fits.

\begin{tabular}{|c|c|c|c|c|c|c|c|c|c|c|c|c|c|c|}
\hline \multirow[b]{2}{*}{ Sample } & \multirow[b]{2}{*}{ Edge } & \multicolumn{2}{|l|}{ Fit Settings } & \multicolumn{2}{|c|}{ Fit Results } & \multirow[b]{2}{*}{ \pm} & \multirow[b]{2}{*}{$\mathbf{R}(\AA)$} & \multirow[b]{2}{*}{ \pm} & \multirow[b]{2}{*}{$\Delta \mathrm{E}_{0}$} & \multirow[b]{2}{*}{ \pm} & \multirow[b]{2}{*}{$\sigma^{2}$} & \multirow[b]{2}{*}{ \pm} & \multirow[b]{2}{*}{$\operatorname{Red} \chi^{2 a}$} & \multirow[b]{2}{*}{$\mathbf{R}$ factor ${ }^{b}$} \\
\hline & & $R$-range (§) & $k$-range & Atom & $\mathbf{C N}$ & & & & & & & & & \\
\hline \multirow[t]{3}{*}{ Sb91-19 } & 30493.9 & 1.3 to 4.5 & 2.5 to 13 & $\mathrm{~S}$ & 1.6 & 0.2 & 2.34 & 0.01 & 8.5 & set $^{c}$ & 0.0030 & set $^{c}$ & 6.9 & 0.051 \\
\hline & & & & $\mathrm{O}$ & 3.0 & 0.2 & 1.97 & 0.01 & 3.2 & 1.9 & 0.0010 & & & \\
\hline & & & & $\mathrm{Sb}$ & 1.2 & 0.7 & 3.78 & 0.03 & 5.8 & set $^{c}$ & 0.0034 & 0.0015 & & \\
\hline $\mathrm{Sb} 80-20$ & 30492.0 & 1.4 to 3 & 3 to 13 & S & 3.3 & 0.2 & 2.38 & 0.00 & 8.8 & 0.6 & 0.0037 & 0.0006 & 3.6 & 0.010 \\
\hline Sb75-20 & 30491.4 & 1.35 to 2.75 & 3 to 10 & $S$ & 3.5 & 0.8 & 2.36 & 0.02 & 7.3 & 2.5 & 0.0046 & 0.0030 & 24.7 & 0.027 \\
\hline Sb51-24 & 30490.7 & 1.33 to 3 & 3 to 14.5 & S & 3.4 & 0.2 & 2.35 & 0.00 & 8.2 & 0.7 & 0.0022 & 0.0005 & 43.1 & 0.011 \\
\hline \multirow[t]{2}{*}{ Stibnite } & 30490.7 & 1.4 to 4.5 & 3 to 13 & $\mathrm{~s}^{e}$ & 2.3 & 0.1 & 2.51 & 0.005 & 5.8 & 0.6 & 0.0067 & 0.0008 & 361.3 & 0.013 \\
\hline & & & & $\mathrm{Sb}^{f}$ & 2.1 & 0.8 & 3.86 & 0.02 & "-" & "-" & 0.0142 & 0.0049 & & \\
\hline $\mathrm{Sb}_{2} \mathrm{O}_{5}$ & 30491.7 & 1 to 3 & 3 to 8.5 & $\mathrm{O}$ & 2.7 & 0.2 & 1.98 & 0.01 & 9.4 & 0.9 & 0.0049 & 0.0018 & 38.5 & 0.011 \\
\hline
\end{tabular}

\footnotetext{
${ }^{a}$ Reduced Chi-squared $\chi^{2}=\frac{N_{\text {indp } p t s}}{N_{\text {data } p t s}} \sum_{i}\left(\frac{\text { data }_{i}-f i t_{i}}{\varepsilon_{i}}\right)^{2} /\left(N_{\text {indp pts }}-N_{\text {fit variables }}\right)$

${ }^{b} \mathrm{R}$ factor (mean square misfit) $=\frac{\sum\left(\text { data }_{i}-f i t_{i}\right)^{2}}{\sum_{i} \text { data }^{2}}$

${ }^{c}$ Insufficient independent points to fit all variables freely. $\Delta E_{0}$ and in some cases $\sigma^{2}$ for selected fit set to average of values from best EXAFS fits (i.e. Sb80-20 and Sb51-24) or stibnite where appropriate. See text for details

${ }^{d}$ value for $\sigma^{2}$ constrained to $\geq 0.001$

e average first shell in stibnite from crystallographic data: $2 \mathrm{~S}$ atoms at $2.52 \AA$

${ }^{f}$ average second shell in stibnite from crystallographic data: $2 \mathrm{Sb}$ atoms at $3.82 \AA$
}

relative to the number of independent points. As defined above, $\Delta E_{0}$ is the difference between the measured and theoretical edge energies and $\sigma^{2}$ quantifies the amount of disorder present in the $\mathrm{Sb}$ - 
backscatter distance. The fit parameters related to the structure of the aqueous complexes are the identity of backscattering atoms, the coordination number $(C N)$, and the Sb-backscatterer distance $(R)$. The fits are compared to the measured spectra in $k$-space and in $R$-space in Figure (3.2).

\subsubsection{X-ray absorption spectra of solutions containing sufficient sulfide to complex antimony}

The first coordination shell of antimony contained only sulfur atoms in solutions where the amount of sulfur present was sufficient to fully complex antimony (i.e., when $\mathrm{mol} \mathrm{kg}^{-1} \mathrm{~S}^{2-}{ }_{\text {total }} \geq 3 \mathrm{x}$ mol $\mathrm{kg}^{-1} \mathrm{Sb}$ ). The three solutions between $\mathrm{pH}=10.9$ and 11.7 (Sb51-24, Sb75-20, and Sb80-20) contained enough dissolved sulfide for $\mathrm{Sb}_{2} \mathrm{~S}_{4}{ }^{2-}$ to be the thermodynamically stable aqueous complex. These samples had first coordination shells with 3.3 to 3.5 sulfur atoms at distances of 2.35 to $2.38 \AA$. The spectra of the concentrated hydrosulfide solutions did not show evidence for longer-range $\mathrm{Sb}$-Sb interactions, and therefore only the shorter $\mathrm{Sb}-\mathrm{O}$ and $\mathrm{Sb}-\mathrm{S}$ paths were fitted.

\subsubsection{X-ray absorption spectra of solutions containing insufficient sulfide to complex antimony}

The EXAFS spectra from the deionised water solubility experiment (Sb91-19), in which the concentration of sulfide was insufficient to fully complex antimony, showed that antimony is

Figure (3.2) The background subtracted EXAFS (A) and Fourier transforms (B). The EXAFS (a) are plotted at a $k$-weighting of 2.The R-space Fourier transforms (b) have not been corrected for phase shift. Spectra have been shifted along the vertical axes for clarity. The raw data are plotted with solid lines and the fits with dashed lines.
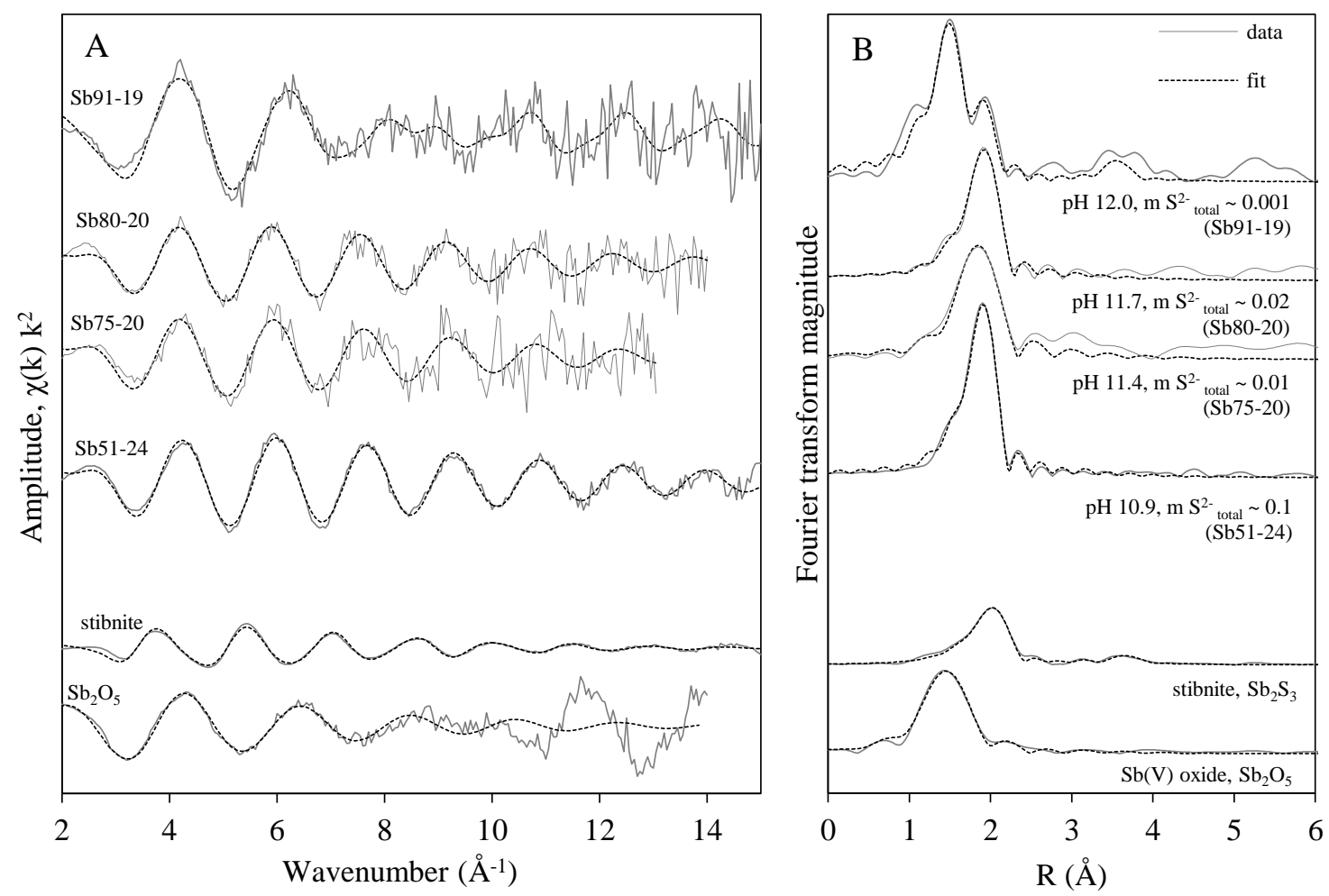
complexed with both hydroxide and sulfide ligands at $\mathrm{pH} \approx 12$ and $\mathrm{S}^{2-}$ total $\approx 0.001 \mathrm{~mol} \mathrm{~kg}^{-1} \mathrm{~S}^{2-}$ total. The Fourier transform (FT) of the EXAFS had two distinct peaks originating from the first coordination shell of antimony: an Sb-O path at $\sim 1.4 \AA$ and an Sb-S path at $~ 1.8 \AA$ (distances not corrected for phase shift, see Figure (3.2)). The number of independent data points in the portion of the EXAFS spectra used to fit the first coordination shell was only slightly greater than the number of individual fit parameters, i.e., $C N, R, \Delta E_{0}$, and $\sigma^{2}$ for both the $\mathrm{Sb}-\mathrm{S}$ and $\mathrm{Sb}-\mathrm{O}$ paths, needed to fit the first coordination shell. Therefore, constraints derived from fits of the concentrated sulfide solutions were placed on the $\Delta E_{0}$ and $\sigma^{2}$ parameters.

In fitting sample $\mathrm{Sb} 91-19$, the $\Delta E_{0}$ and $\sigma^{2}$ fit parameters for the $\mathrm{Sb}-\mathrm{S}$ path were set to the average of their fitted values in fits of the two best quality spectra (Sb80-20 and Sb51-24). Values of some of the fitted parameters, particularly the $C N$ of sulfur, were sensitive to the details of the constraints used for $\sigma^{2}$, but the Sb-ligand distances were not sensitive to the approach used to constrain $\sigma^{2}$. The $\sigma^{2}$ parameter for the $\mathrm{Sb}-\mathrm{O}$ path was scaled relative to the $\mathrm{Sb}-\mathrm{S}$ distance, and the best fits were achieved with the value of the $\mathrm{Sb}-\mathrm{O} \sigma^{2}$ parameter at $1 / 3^{\text {rd }}$ to $1 / 5^{\text {th }}$ of the value of the $\mathrm{Sb}-\mathrm{S} \sigma^{2}$. This approach produced first shell fits containing 2.9 to 3.1 oxygen atoms at $\sim 1.97 \AA$ and 1.3 to 1.6 sulfur atoms at $\sim 2.34 \AA$. Some previous Sb XAS studies have found a similar magnitude difference between the value of $\sigma^{2}$ for $\mathrm{Sb}-\mathrm{O}$ paths and the value for less electronegative ligands $\left(\mathrm{S}^{2-}\right.$ and $\left.\mathrm{Cl}^{-}\right)$in solutions where both types of ligands were complexing Sb(III). In Pokrovksi et al. (2006; 2008) and PlanerFriedrich and Scheinost (2011), the $\sigma^{2}$ values for Sb-O paths were $\sim 3$ times less than the values for the longer $\mathrm{Sb}-\mathrm{Cl}$ and $\mathrm{Sb}-\mathrm{S}$ paths in solutions where both types of ligands were complexed with antimony.

The EXAFS of sample Sb91-19 also had evidence of longer-range features between 3 and 4 $\AA$. This is a similar distance to that at which first shell Sb-Sb interactions were fit in the stibnite EXAFS and where $\mathrm{Sb}$-Sb interactions in $\mathrm{Sb}_{2} \mathrm{~S}_{4}$ dimers might be expected. These features could be fit with a single $\mathrm{Sb}$-Sb path at $\sim 3.8 \AA$ or with two Sb-Sb paths at different distances, one at $\sim 3.8 \AA$ and a second at $\sim 4.0 \AA$. The fit of the first shell distances remained the same whether one or two Sb were considered. The number of antimony atoms in the first coordination shell could in principle be varied from $\sim 1$ to $\sim 3$, depending on how the $\sigma^{2}$ parameter for the shell was constrained. However, constraining the $\sigma^{2}$ of the $\mathrm{Sb}$-Sb path to be greater than the $\sigma^{2}$ of the shorter $\mathrm{Sb}$-S path produced a coordination number that is consistent with an $\mathrm{Sb}_{2} \mathrm{~S}_{4}$ dimer. This is considered a reasonable constraint because a longer path would be expected to be more "disordered" than a shorter path. This fit is presented in Table (3.3) and was used to plot the fit in Figure (3.2).

\subsubsection{X-ray near edge fine structure of aqueous antimony complexes}

The energy positions of the absorption edges for antimony solutions and the reference solid phases (stibnite and synthetic $\mathrm{Sb}_{2} \mathrm{O}_{5}$ ) are listed in Table (3.3) and are graphically compared to 
absorption edges reported by previous authors for antimony hydrosulfide solutions and a range antimony minerals and solid phases Figure (3.3). The absorption edge energies for antimony dissolved in the sulfide solutions varied between 30,490.7 and 30,493.9 eV. These edge positions are generally higher than that of the antimony(III) bound to sulfide in stibnite but not as high as those usually measured for $\mathrm{Sb}(\mathrm{V})$ reference solids $(30,495-30,497 \mathrm{eV})$. The measured Sb K-edge position for stibnite was within $0.5 \mathrm{eV}$ of that reported for stibnite in the Sb K-edge XANES summary paper by Fawcett et al. (2009), slightly above that for the reference Sb metal foil $(30,491 \mathrm{eV})$, and similar to $\mathrm{Sb}$ (III) oxides ( $30492 \mathrm{eV})$. However, the absorption edge position for $\mathrm{Sb}$ in the $\mathrm{Sb}(\mathrm{V})$ oxide, $\mathrm{Sb}_{2} \mathrm{O}_{5}$, measured in this study was $\sim 3 \mathrm{eV}$ lower than what is expected for $\mathrm{Sb}(\mathrm{V})$. Two previous XAS studies have found that commercial $\mathrm{Sb}_{2} \mathrm{O}_{5}$ can contain a significant proportion (up to $\sim 50 \%$ ) of a $\mathrm{Sb}$ (III) impurity (Scheinost et al., 2006; Beauchemin et al., 2012). Because of these previous observations and the fact that the stibnite $\mathrm{Sb}$ edge position was correct, the nominally $\mathrm{Sb}_{2} \mathrm{O}_{5}$ sample was probably contaminated with an $\mathrm{Sb}$ (III) component and the edge position that was measured in this study is not believed to be representative of an $\mathrm{Sb}(\mathrm{V})$ edge. The $\mathrm{Sb}(\mathrm{V})$ edge positions found in previous studies were therefore used instead in the evaluation of antimony valence in the experimental solutions.

The Sb K-edge XANES edge energies of most of the solutions measured in this study are between energies that can be definitively attributed to $\mathrm{Sb}$ (III) (i.e., $\leq 30,492 \mathrm{eV}$ ) and energies that can be definitively attributed to $\mathrm{Sb}(\mathrm{V})$ (i.e., $\geq 30,495 \mathrm{eV}$ ). Therefore, antimony(III) complexes cannot be

Figure (3.3) Antimony K-edge energies for solid reference samples and experimental solutions. For reference, the current study is compared to values from previous studies of antimony in aqueous sulfide solutions (Mosselmans et al., 2000; Planer-Friedrich and Scheinost, 2011) and in minerals and environmental matrices (Scheinost et al., 2006; Kirsch et al., 2008; Ackermann et al., 2009; Fawcett et al., 2009; Guo et al., 2014; Hockmann et al., 2014)

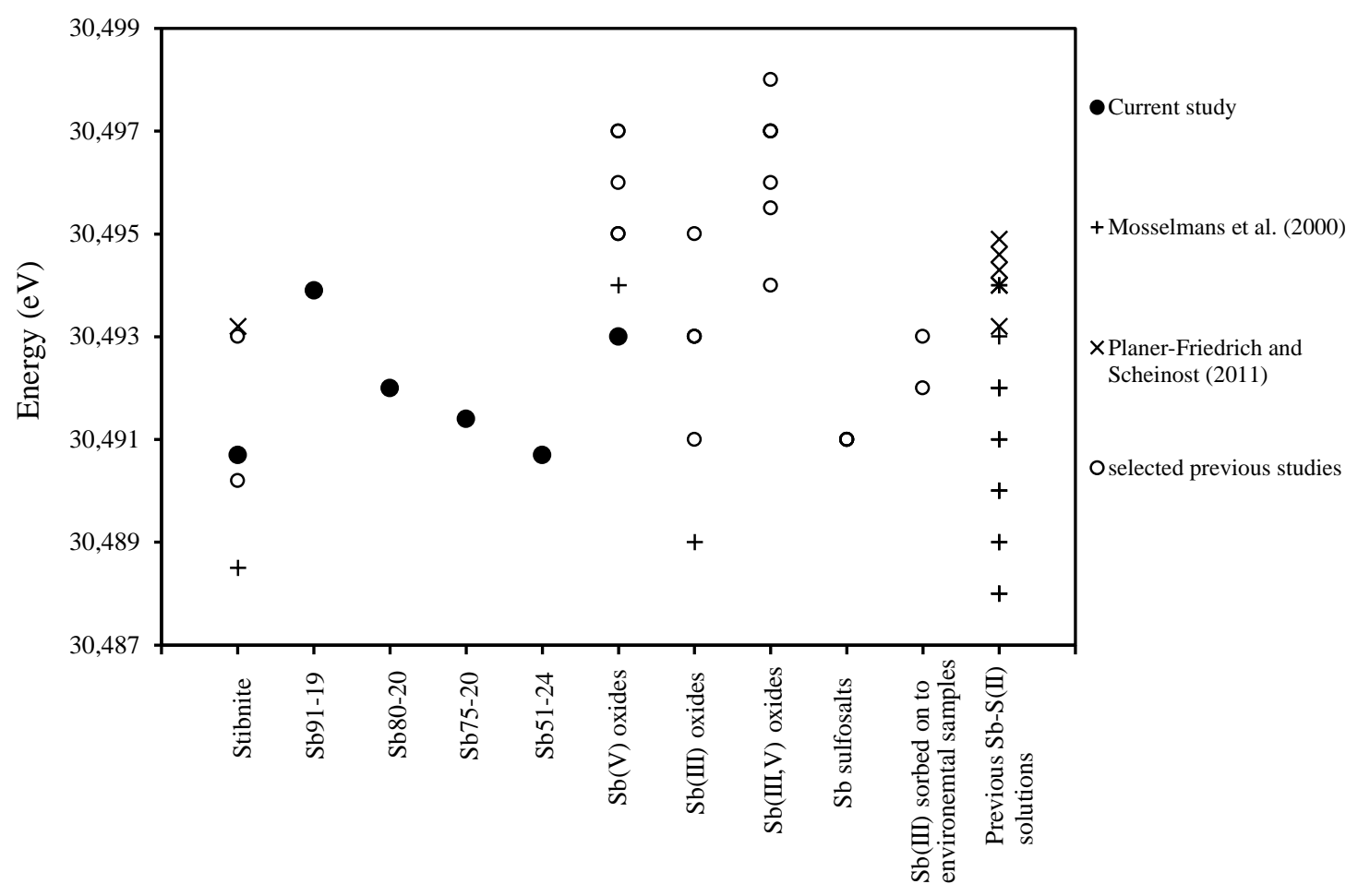


identified nor antimony(V) complexes excluded using the XANES spectra alone. The observed Sb-S distances and coordination numbers for the solutions with high sulfide concentrations are more similar to those expected for $\mathrm{Sb}(\mathrm{III})-\mathrm{S}$ complexes (i.e., 3 sulfur atoms at 2.37 - $2.41 \AA$ ) in comparison to those for $\mathrm{Sb}(\mathrm{V})$-sulfide complexes (4 to 4.2 sulfur atoms at $\leq 2.34 \AA$ ). In addition, the fit associated with the highest numbers of coordinated sulfurs (i.e., 3.5) had the poorest fit statistics. The XAS study by Sherman et al. (2000) which measured the EXAFS spectra of $\mathrm{Sb}(\mathrm{V})$-sulfide complexes did not report Sb K-edge positions, and so direct comparison to the XANES of $\mathrm{Sb}(\mathrm{V})$ in a hydrosulfide solution is not possible. Although the presence of $\mathrm{Sb}(\mathrm{V})$ or mixed-valence $\mathrm{Sb}(\mathrm{III}, \mathrm{V})$ species cannot be definitively excluded for all of the solutions in the current study, the XANES and EXAFS measurements of the solutions presented in Table (3.3) and Figure (3.2) are consistent with $\mathrm{Sb}$ (III) interactions with sulfide and hydroxide ligands.

\subsection{Discussion}

\subsubsection{Motivation for combining solubility and spectroscopic approaches}

This current research combined the techniques of flow-through solubility experiments with XAS measurements to study antimony interactions with sulfide ligands in reducing aqueous solutions. This approach was taken in an attempt to overcome the inherent limitations of each technique. The solubility approach can only provide information about aqueous speciation at saturation (i.e. stibnite in this study), and the approach is further limited by the possibility that numerous possible combinations of different aqueous complexes may be able to produce speciation models that are statistically indistinguishable (but not necessary equally chemically reasonable). An example of this inherent difficulty in interpreting solubility experiments is the multiple fits in Chapter (2) with $\mathrm{R}^{2}$ values close to 0.9. In contrast, spectroscopic techniques, including XAS, directly provide information about the complexes present in a solution and can be used to study solutions with analyte concentrations below that needed to reach saturation for the conditions of the experiment (i.e. ligand activity, $\mathrm{pH}$, temperature, and pressure). However, the information derived from a spectroscopic experiment is often limited to one or several very specific characteristics of the aqueous complex or complexes. Identifying unique complexes from this information may not be possible without additional assumptions or constraints. For XAS at the $\mathrm{Sb}$ K-edge, measured spectra can provide average first shell coordination numbers (i.e. the number of scatterers) and antimony valence, but data interpretation can be made difficult by the presence of mixed-ligand complexes, mixtures of singleligand complexes, or complexes with multiple Sb-ligand distances within the first coordination shell. Additionally, some spectroscopic techniques, including XAS and Raman spectroscopy for antimony, are limited to elemental concentrations several orders of magnitude higher than concentrations that would be of interest in applied environmental or geological problems. 


\subsubsection{Antimony first shell coordination measured by EXAFS and predicted by stibnite solubility studies}

The number of sulfur and oxygen atoms in antimony's first coordination shell predicted by the several solubility models is compared to the average coordination shell measured by EXAFS in Table (3.4). The EXAFS results for antimony coordination in strongly alkaline solutions were taken from Table (3.3). The average coordination shells at stibnite saturation that were predicted by four different $30^{\circ} \mathrm{C}$ speciation models, i.e., Fits (30-C), (30-G), (30-H), and (30-I), are also presented. The predicted coordination shells were calculated from the species distribution for the $\mathrm{pH}$ and sulfide concentrations of XAS samples using the equilibrium constants presented in Table (2.4) for Fit (30-C) and Table (2.6) for the three remaining fits. Fit (30-C) is the speciation model that included only monomers (i.e. $\mathrm{SbS}_{3}{ }^{3-}$ and $\left.\mathrm{HSbS}_{2} \mathrm{O}^{-}\right)$at strongly alkaline $\mathrm{pH}$, while Fits (30-G), (30-H), and (30-I) had $\mathrm{Sb}_{2} \mathrm{~S}_{4}{ }^{2-}$ and either $\mathrm{Sb}(\mathrm{OH})_{3}+\mathrm{H}_{2} \mathrm{SbO}_{3}$ or a mixed-ligand monomer. Thus, the data presented in Table (3.4) can be used to evaluate which speciation models derived from stibnite solubility measurements are consistent with the XAS measurements.

Both $\mathrm{SbS}_{3}{ }^{3-}$ and $\mathrm{Sb}_{2} \mathrm{~S}_{4}{ }^{2-}$ have three sulfur atoms in antimony's first coordination shell. The structures of $\mathrm{Sb}_{2} \mathrm{~S}_{4}{ }^{2-}$ and $\mathrm{H}_{\mathrm{x}} \mathrm{SbS}_{3}{ }^{\mathrm{x}-3}$, as represented by $\mathrm{H}_{3} \mathrm{SbS}_{3}$, are shown in Figure (3.4). The structure of stibnite $\left(\mathrm{Sb}_{2} \mathrm{~S}_{3}\right)$, also shown in Figure (3.4), contains a tetrahedral $\mathrm{SbS}_{3}$ site (the outer antimony atoms in the diagram) and a square pyramid $\mathrm{SbS}_{5}$ site. In contrast, both aqueous species consists of "tetrahedral" $\mathrm{Sb}$ (III) $\mathrm{S}_{3}$ units with a lone pair of electrons at one apex. In $\mathrm{H}_{\mathrm{x}} \mathrm{Sb}_{2} \mathrm{~S}_{4}{ }^{\mathrm{X}-2}$, two of the sulfur atoms are shared with another antimony atom producing two connected $\mathrm{SbS}_{3}$ units that face in opposite directions. Each antimony atom in $\mathrm{Sb}_{2} \mathrm{~S}_{4}{ }^{2-}$ will have a single first shell antimony atom located at 3 to $4 \AA$. Both $\mathrm{SbS}_{3}{ }^{3-}$ and $\mathrm{Sb}_{2} \mathrm{~S}_{4}{ }^{2-}$ contain three sulfur atoms at $\sim 2.4 \AA$ in the first coordination shell

Table (3.4) Comparison of average first shell coordination numbers in strongly alkaline solutions measured by EXAFS and those predicted by speciation models derived from stibnite solubility measurements (Chapter 2).

EXAFS Solubility

\begin{tabular}{|c|c|c|c|c|c|c|c|c|c|c|c|c|}
\hline \multirow[b]{3}{*}{ Sample } & \multirow[b]{3}{*}{ pH } & \multirow[b]{3}{*}{$\mathrm{mol} \mathrm{kg}^{-1} \mathrm{~S}^{2-}$} & \multicolumn{2}{|c|}{ EXAFS } & \multicolumn{4}{|c|}{ Solubility } & \multirow{2}{*}{\multicolumn{2}{|c|}{ Fit $(30-H)^{b}$}} & \multirow{2}{*}{\multicolumn{2}{|c|}{ Fit $(30-I){ }^{b}$}} \\
\hline & & & & & \multicolumn{2}{|c|}{ Fit $(30-C)^{a}$} & \multicolumn{2}{|c|}{ Fit $(30-G)^{b}$} & & & & \\
\hline & & & $\mathbf{S}$ & $\mathbf{O}$ & $\mathbf{S}$ & $\mathbf{O}$ & $\mathbf{S}$ & O & $\mathbf{S}$ & $\mathbf{O}$ & $\mathbf{S}$ & $\mathbf{O}$ \\
\hline $\mathrm{Sb} 51-24$ & 10.9 & 0.097 & 3.4 & n.d. & 2.9 & 0.2 & 3.0 & 0.0 & 2.9 & 0.1 & 3.0 & 0.0 \\
\hline $\mathrm{Sb} 75-20$ & 11.4 & 0.009 & 3.7 & n.d. & 2.2 & 0.8 & 3.0 & 0.0 & 2.5 & 0.5 & 2.9 & 0.1 \\
\hline $\mathrm{Sb} 80-20$ & 11.7 & 0.019 & 3.3 & n.d. & 2.4 & 0.6 & 3.0 & 0.0 & 2.5 & 0.5 & 3.0 & 0.0 \\
\hline Sb91-19 & 12.0 & 0.001 & 1.6 & 3.1 & 2.0 & 1.0 & 0.6 & 2.4 & 2.1 & 0.9 & 1.1 & 1.9 \\
\hline
\end{tabular}

Complexes included in fits and tables in Chapter (2) with fit statistics:

Fit (30-C): $\mathrm{SbS}_{3}{ }^{3-}+\mathrm{HSbS}_{2} \mathrm{O}^{2-}+\mathrm{H}_{2} \mathrm{Sb}_{2} \mathrm{~S}_{5}{ }^{2-}+\mathrm{HSb}_{2} \mathrm{~S}_{4}{ }^{-}+\mathrm{H}_{3} \mathrm{SbS}_{2} \mathrm{O}$ (Table 2.4)

Fit (30-G): $\mathrm{Sb}_{2} \mathrm{~S}_{4}{ }^{2-}+\mathrm{H}_{2} \mathrm{Sb}_{2} \mathrm{~S}_{5}{ }^{2-}+\mathrm{HSb}_{2} \mathrm{~S}_{4}{ }^{-}+\mathrm{H}_{3} \mathrm{SbS}_{2} \mathrm{O}+\mathrm{Sb}(\mathrm{OH})_{3}+\mathrm{H}_{2} \mathrm{SbO}_{3}{ }^{-}$(Table 2.6)

Fit (30-H): $\mathrm{Sb}_{2} \mathrm{~S}_{4}{ }^{2-}+\mathrm{H}_{2} \mathrm{Sb}_{2} \mathrm{~S}_{5}{ }^{2-}+\mathrm{HSb}_{2} \mathrm{~S}_{4}{ }^{-}+\mathrm{H}_{3} \mathrm{SbS}_{2} \mathrm{O}+\mathrm{HSbS}_{2} \mathrm{O}^{2-}$ (Table 2.6)

Fit (30-I): $\mathrm{Sb}_{2} \mathrm{~S}_{4}{ }^{2-}+\mathrm{H}_{2} \mathrm{Sb}_{2} \mathrm{~S}_{5}{ }^{2-}+\mathrm{HSb}_{2} \mathrm{~S}_{4}{ }^{-}+\mathrm{H}_{3} \mathrm{SbS}_{2} \mathrm{O}+\mathrm{H}_{2} \mathrm{SbSO}_{2}{ }^{-}$(Table 2.6)

${ }^{a}$ fits conducted with added sulfide experiments $(\mathrm{N}=51)$

${ }^{b}$ fits conducted including deionised water experiments $(\mathrm{N}=53)$ 
Figure (3.4) Local coordination of antimony within stibnite, an antimony(III)-sulfide monomer (represented with $\mathrm{H}_{3} \mathrm{SbS}_{3}$ ), and an antimony(III)-sulfide dimer (represented with $\mathrm{Sb}_{2} \mathrm{~S}_{4}{ }^{2-}$ ). Stibnite contains both a 5-coordinated and a 3-coordinated site. In the figure, five of the 5-coordinated sites and three of the 3-coordinated sites are represented.

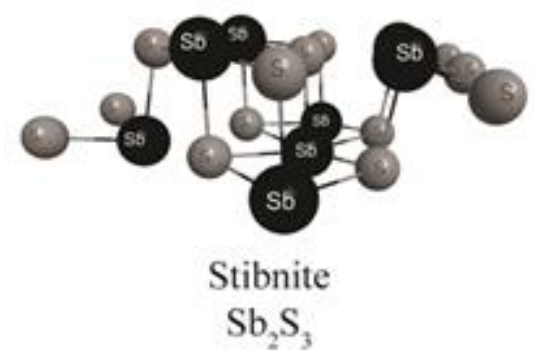

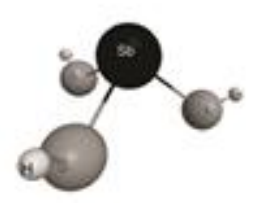

$\mathrm{Sb}$ (III) monomer $\mathrm{H}_{3} \mathrm{SbS}_{3}$

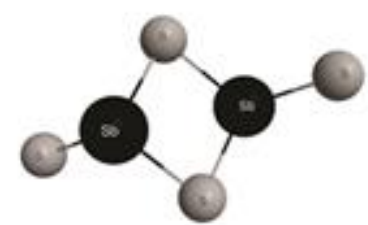

$\mathrm{Sb}$ (III) fully deprotonated dimer $\mathrm{Sb}_{2} \mathrm{~S}_{4}{ }^{2+}$

(Tossell, 1994), and thus speciation models containing these two species cannot be distinguished based solely upon the number of sulfur atoms measured by EXAFS. However, $\mathrm{SbS}_{3}{ }^{3-}$ and $\mathrm{Sb}_{2} \mathrm{~S}_{4}{ }^{2-}$ contain different ratios of sulfur to antimony atoms, and so, for the same experimental stibnite solubility versus sulfide concentration curve, these two speciation models will produce different average coordination shells as antimony complexation changes from sulfide to hydroxide ligands with decreasing sulfide concentration. In other words, stibnite solubility data produce criteria (i.e. predicted average first shell coordination numbers) that, when combined with EXAFS measurements, enable the presence of either $\mathrm{SbS}_{3}{ }^{3-}$ or $\mathrm{Sb}_{2} \mathrm{~S}_{4}{ }^{2-}$ to be determined.

As can be seen from the predicted average coordination numbers in Table (3.4), the speciation model used in Fit (30-C) (i.e. $\mathrm{SbS}_{3}{ }^{3-}+\mathrm{HSbS}_{2} \mathrm{O}^{2-}$ at strongly alkaline $\mathrm{pH}$ ) predicts oxygen atoms in the coordination shell where none were observed spectroscopically and a first coordination shell with more sulfur atoms than oxygen atoms when $\mathrm{S}^{2-}{ }_{\text {total }}=0.001 \mathrm{~mol} \mathrm{~kg}^{-1}$, which is opposite to the EXAFS results. In contrast, solubility-derived speciation models with $\mathrm{Sb}_{2} \mathrm{~S}_{4}{ }^{2-}$ at alkaline $\mathrm{pH}$ more closely reproduce the coordination shells found by EXAFS. In particular, the preferred speciation model (i.e. Fit 30-G) from Chapter (2) produces similar oxygen coordination numbers to the EXAFS. Therefore, the EXAFS results are consistent with $\mathrm{Sb}_{2} \mathrm{~S}_{4}{ }^{2-}$ but not with $\mathrm{SbS}_{3}{ }^{3-}$ even though $\mathrm{Sb}$-Sb interactions at 3 to $4 \AA$, which would be indicative of dimeric species, were not detected.

The failure of XAS to detect $\mathrm{Sb}$-Sb interactions in antimony-sulfide complexes (i.e. in $\mathrm{H}_{\mathrm{x}} \mathrm{Sb}_{2} \mathrm{~S}_{4}{ }^{\mathrm{x}-2}$ ) is not unique to this study. Both Mosselmans et al. (2000) and Planer-Friedrich and Scheinost (2011) did not find second shell interactions antimony sulfide solutions in which $\mathrm{Sb}_{2} \mathrm{~S}_{4}{ }^{2-}$ should be stable (i.e. strongly alkaline and with sulfide concentration >> antimony concentration). Evidence in Mosselmans et al. (2000) for longer range interactions was limited to a feature at $\sim 4.1 \AA$ in a $\mathrm{pH} 8.3$ solution containing carbonate and $0.1 \mathrm{~mol} \mathrm{~kg}^{-1} \mathrm{~S}^{2-}{ }_{\text {total }}$ that did not improve fit parameters. Planer-Friedrich and Scheinost (2011) fit a longer range feature from the EXAFS of the oxic solution with the lowest sulfide concentration with a $5.64 \AA \mathrm{Sb}-\mathrm{Sb}$ path. However, this distance is greater than that expected for $\mathrm{Sb}-\mathrm{Sb}$ shell in $\mathrm{Sb}_{2} \mathrm{~S}_{4}{ }^{2-}$. In the current study, a feature was also found in the sample with the lowest sulfide solution (Sb91-19) that could be well fit with one or two Sb-Sb distances at 
3.8 $\AA$ (results section 3.3.3. and Table (3.3)). Small features at 3.8 ̊ similar to those in the Sb91-19 spectrum were observed in the EXAFS spectra of $\mathrm{Sb}(\mathrm{III})$ complexed with bidentate organic ligands and were interpreted in terms of several linear multiple scattering paths between $\mathrm{Sb}, \mathrm{O}$, and $\mathrm{C}$ (Tella and Pokrovski, 2009). This could suggest the presence of an Sb-S-O complex at the transition from antimony-sulfide to antimony-hydroxide complexes. However, such a complex is not required by solubility data and would be difficult to identify from XAS without further constraints on its structure or stoichiometry. In both Planer-Friedrich and Scheinost (2011) and the current study, Sb-Sb interactions only appear in solutions containing comparable numbers of both sulfide and hydroxide ligands, and this relationship suggests that these features could be artifacts of the Fourier transformation of noisy XAS spectra containing two significant components ( $\mathrm{Sb}-\mathrm{O}$ and $\mathrm{Sb}-\mathrm{S}$ ) rather than evidence of a dimeric species.

The amount and precision of structural and electronic information that can be gained from the XAS spectra is limited by structural disorder in the sample, which is generally greater in solutions than in mineral phases, and by spectra broadening, which is greater for high atomic number elements. Millimolar antimony concentrations $\left(0.001 \mathrm{~mol} \mathrm{~kg}^{-1}\right)$ were close to the minimum concentrations that could produce useful XAS spectra using the facilities available in to this study. XAS analysis could identify both $\mathrm{Sb}-\mathrm{O}$ and $\mathrm{Sb}-\mathrm{S}$ paths at $<3 \AA$ but was unable to resolve $\mathrm{Sb}-\mathrm{Sb}$ interactions in solutions with antimony concentrations between 0.0003 and $0.005 \mathrm{~mol} \mathrm{~kg}^{-1}$. However, as discussed above, XAS produced information that assisted in the interpretation of data from solubility experiments and enabled elimination of a speciation model containing $\mathrm{SbS}_{3}{ }^{3-}$ in alkaline solutions (i.e., at $\mathrm{pH}>9.5$ ) in equilibrium with stibnite.

\subsubsection{Re-evaluation of previous $S b(I I I)-S(I I) X A S$ studies and future research directions}

The XAS results of the current study are similar to those found in previous studies of $\mathrm{Sb}$ (III) in sodium sulfide solutions. This is demonstrated by the average first coordination shells shown graphically in Figure (3.5) in which the number of first shell sulfur atoms is plotted versus the $\mathrm{S}: \mathrm{Sb}$ molar concentration ratio using the EXAFS results from the current study and the results selected from Mosselmans et al. (2000) and Planer-Friedrich and Scheinost (2011) that were the most comparable to the current study (i.e. XAS of antimony in alkaline sulfide solutions prepared without exposure to atmospheric oxygen). For Mosselmans et al. (2000), only data from sodium sulfide solutions with published antimony concentrations are plotted, and solutions with $\mathrm{Na}_{2}(\mathrm{CO})_{3}{ }^{2-}$ and/or elemental sulfur are not included. For Planer-Friedrich and Scheinost (2011), the solutions prepared without exposure to atmospheric oxygen are plotted. Also included in Figure (3.5) are the first shell oxygen atoms for the same solutions, so that Figure (3.5) shows how the average coordination environment of antimony, as measured by EXAFS, changes from hydroxide ligands to sulfide ligands with increasing sulfide concentration. 
Figure (3. 5) First coordination shells of antimony(III) complexes at different sulfide concentrations. Average coordination numbers for oxygen and sulfide ligands in around antimony alkaline sodium sulfide solutions from $\mathrm{Sb}$ K-edge measurements conducted in the current and two previous studies. The samples from Mosselmans et al. (2000) lacking published antimony concentrations and those containing $\mathrm{Na}_{2}(\mathrm{CO})_{3}{ }^{2-}$ and/or elemental sulfur are not plotted. The sulfide concentration used for the molar concentration ratio is the total sulfide in the solution, i.e., not corrected for the sulfide complexed with antimony.

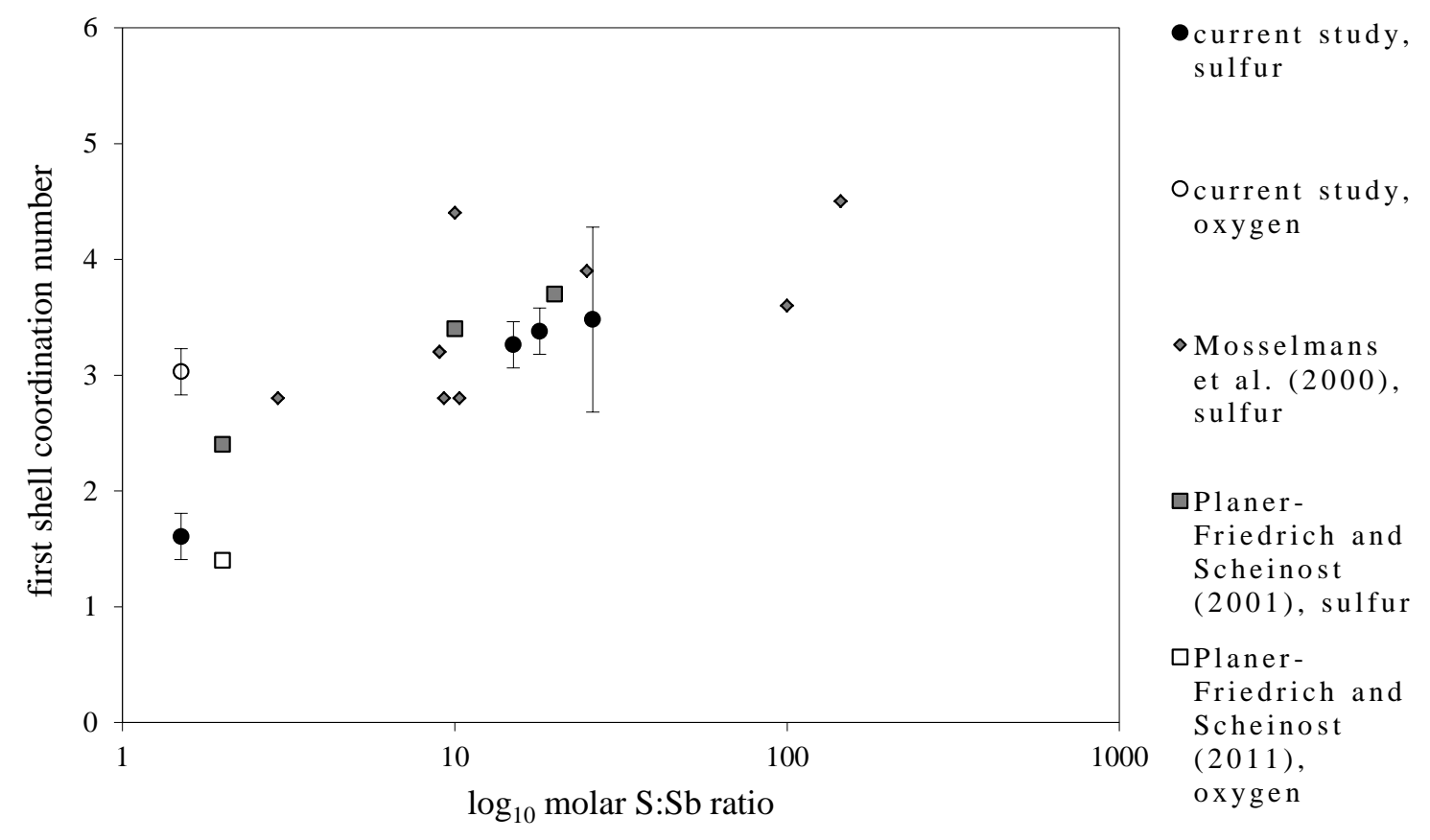

In all three studies, the number of coordinating sulfur atoms was usually between 2.9 and 3.7 when there was sufficient sulfide to fully complex the dissolved antimony, whereas oxygen atoms (or a decrease in the number of sulfur atoms in the data from Mosselmans et al. (2000)) occurred in the first coordination shell when the sulfide concentration approached or was less than the antimony concentration. There is considerable scatter in some of the data from Mosselmans et al. (2000) for similar S:Sb ratios, which could have resulted from incipient oxidation during sample preparation and/or storage prior to measurement. In should be noted that in the current study, the sample with largest number of coordinating sulfur atoms (3.5 sulfurs) also had the largest uncertainties in the fit, due to the lower quality spectra derived from the lowest antimony concentration (i.e. $0.0003 \mathrm{~mol} \mathrm{~kg}^{-1}$ ). For the "best" EXAFS data from the current study (i.e. Sb80-20 and Sb51-54), the number of coordinating sulfur atoms did not increase with increasing $S: S b$ ratio within the error of the coordination numbers and was between 3.3 and 3.4. Although the previous studies also did not detect $\mathrm{Sb}-\mathrm{Sb}$ interactions in an antimony-sulfide complex, the number of sulfur and oxygen atoms in the average coordination shell and how these numbers change with the relative amount of sulfide in these studies are consistent with the current study and therefore with the presence of $\mathrm{Sb}_{2} \mathrm{~S}_{4}{ }^{2-}$.

Using the sulfur and oxygen ligand coordination numbers shown in Figure (3.5) as a guide, future XAS studies of antimony sulfide solutions with $S: S b$ ratios between 1:2 and 10:1 could be used to evaluate how well Sb K-edge EXAFS quantifies low numbers of coordinating sulfur and oxygen 
atoms. Mixed-ligand species were not needed to fit the solubility in Chapter (2). However, this study had limited data at low sulfide concentrations and alkaline $\mathrm{pH}$ and such a species could be found by a solubility study focused on these conditions. Multiple XAS measurements at constant $\mathrm{pH}$ and different sulfide concentrations should spectroscopically record the entire transition from antimony-hydroxide to antimony-sulfide complexes and would be a valuable addition to studies interested in how $\mathrm{Sb}(\mathrm{OH})_{3}$ and $\mathrm{Sb}_{2} \mathrm{~S}_{4}{ }^{2-}$ are related at alkaline $\mathrm{pH}$. Additionally, evaluating both EXAFS and XANES spectra from $\mathrm{Sb}(\mathrm{V})-\mathrm{S}$ (II) solutions has not been done (Sherman et al.(2000) only reported EXAFS results from $\mathrm{Sb}(\mathrm{V})$ solutions). Including well-characterised $\mathrm{Sb}(\mathrm{V})$ solutions in future XAS experiments would greatly assist in quantifying an $\mathrm{Sb}(\mathrm{V})$ component in XAS spectra from antimony sulfide solutions with mixed or ambiguous oxidation states.

\subsection{Conclusions}

The main conclusions originating from the XAS analysis presented in this chapter are

1. The first coordination shell of antimony in alkaline sodium sulfide solutions at stibnite saturation contained 3.3 to 3.5 sulfur atoms at 2.35 to $2.38 \AA$ when the sulfide concentration was more than ten times the antimony concentration. In solutions when the sulfide concentration was set by the dissociation of stibnite, there were 3 oxygen atoms at $1.97 \AA$ and 1 to 2 sulfur atoms at $2.34 \AA$.

2. By the measurement of the average coordination environment of antimony at different sulfide concentrations, XAS measurements were able to confirm the presence of $\mathrm{Sb}_{2} \mathrm{~S}_{4}{ }^{2-}$ indicated by solubility studies, although XAS as unable to detect the $\mathrm{Sb}$ shell present in the dimer.

This study sought to use ambient temperature XAS measurements to support the antimony-sulfide speciation model derived from $30^{\circ} \mathrm{C}$ stibnite solubility data in Chapter (2). The speciation model derived from solubility measurements in strongly alkaline solutions included $\mathrm{Sb}_{2} \mathrm{~S}_{4}{ }^{2-}$ in solutions at higher sulfide concentrations and included $\mathrm{Sb}(\mathrm{OH})_{3}$, and $\mathrm{H}_{2} \mathrm{SbO}_{3}{ }^{-}$in dilute sulfide solutions as the sulfide concentration decreased from 0.1 to $0.0001 \mathrm{~mol} \mathrm{~kg}^{-1} \mathrm{~S}^{2-}$ total. The first shell coordination environments measured by XAS in four solutions were consistent with this speciation model. However, $\mathrm{Sb}$-Sb interactions such those expected for $\mathrm{Sb}_{2} \mathrm{~S}_{4}{ }^{2-}$ were not detected, even though the solutions in this study were chosen to give the best chance of detecting such features. Without constraints provided by the solubility data that related the coordination environment to the sulfide concentration, the XAS results could be erroneously interpreted as being due to $\mathrm{SbS}_{3}{ }^{3-}$.

\subsection{References}

Ackermann, S., Giere, R., Newville, M., Majzlan, J., 2009. Antimony sinks in the weathering crust of bullets from Swiss shooting ranges. Sci Total Environ 407, 1669-1682. 
Arnston, R.H., Dickson, F.W., Tunnel, G., 1966. Stibnite $\left(\mathrm{Sb}_{2} \mathrm{~S}_{3}\right)$ solubility in sodium sulfide solutions. Science 153, 1673-1674.

Australian Synchrotron, 2016. Data / analysis (XAS). http://www.synchrotron.org.au/aussyncbeamlines/x-ray-absorption-spectroscopy/dataanalysis.

Beauchemin, S., Kwong, Y.T.J., Desbarats, A.J., MacKinnon, T., Percival, J.B., Parsons, M.B., Pandya, K., 2012. Downstream changes in antimony and arsenic speciation in sediments at a mesothermal gold deposit in British Columbia, Canada. Appl. Geochem. 27, 1953-1965.

Ebitani, K., Hattori, H., Tanaka, T., 1992. Structural consideration of antimony pentafluoride deposited on metal oxides (silica, alumina, and silica-alumina) by x-ray absorption (EXAFS/XANES) spectroscopy. The Journal of Physical Chemistry 96, 5430-5434.

Fawcett, S.E., Gordon, R.A., Jamieson, H.E., 2009. Optimizing experimental design, overcoming challenges, and gaining valuable information from the Sb K-edge XANES region. Am. Miner. 94, 1377-1387.

Flavell, W.R., Mian, M., Roberts, A.J., Howlett, J.F., Sarker, M.M., Wincott, P.L., Bilsborrow, R.L., Dorssen, G.v., 1997. EXAFS studies of $\mathrm{SrSn}_{1-\mathrm{x}} \mathrm{Sb}_{\mathrm{x}} \mathrm{O}_{3}$ and $\mathrm{BaPb}_{1-\mathrm{x}} \mathrm{Bi}_{\mathrm{x}} \mathrm{O}_{3}$. Journal Material Chemistry 7.

Geraldo, V., Briois, V., Scalvi, L.V.A., Santilli, C.V., 2007. EXAFS investigation on Sb incorporation effects to electrical transport in $\mathrm{SnO}_{2}$ thin films deposited by sol-gel. Journal of the European Ceramic Society 27, 4265-4268.

Guo, X., Wu, Z., He, M., Meng, X., Jin, X., Qiu, N., Zhang, J., 2014. Adsorption of antimony onto iron oxyhydroxides: adsorption behavior and surface structure. J Hazard Mater 276, 339-345.

Hockmann, K., Lenz, M., Tandy, S., Nachtegaal, M., Janousch, M., Schulin, R., 2014. Release of antimony from contaminated soil induced by redox changes. J Hazard Mater 275, 215-221.

Ilgen, A.G., Foster, A.L., Trainor, T.P., 2012. Role of structural Fe in nontronite NAu-1 and dissolved $\mathrm{Fe}(\mathrm{II})$ in redox transformations of arsenic and antimony. Geochim. Cosmochim. Acta 94, 128145.

Ilgen, A.G., Majs, F., Barker, A.J., Douglas, T.A., Trainor, T.P., 2014. Oxidation and mobilization of metallic antimony in aqueous systems with simulated groundwater. Geochim. Cosmochim. Acta 132, 16-30.

Kappen, P., Ruben, G., 2013. Sakura,Synchrotron Light Source Australia Pty Ltd., http://www.synchrotron.org.au/aussyncbeamlines/x-ray-absorption-spectroscopy/sakura.

Kirsch, R., Scheinost, A.C., Rossberg, A., Banerjee, D., Charlet, L., 2008. Reduction of antimony by nano-particulate magnetite and mackinawite. Mineral. Mag. 72, 185-189.

Kolpakova, N.N., 1971. On the speciation of antimony (III) in sulfide solutions (in Russian), Geochemistry of Hydrothermal Ore Deposition, Nauka, Moscow, pp. 197-209.

Kolpakova, N.N., 1982. Laboratory and field studies of ioinic equilibria in the $\mathrm{Sb}_{2} \mathrm{~S}_{3}-\mathrm{H}_{2} \mathrm{O}-\mathrm{H}_{2} \mathrm{~S}$ system. Geochem. Internat. 19, 46-54.

Krause, M.O., Oliver, J.H., 1979. Natural widths of atomic K and L levels, Ka X-Ray lines and several KLL Auger lines. Journal of Physical and Chemical Reference Data 8, 329-338.

Krupp, R.E., 1988. Solubility of stibnite in hydrogen sulfide solutions, speciation, and equilibrium constants, from 25 to $350^{\circ} \mathrm{C}$. Geochim. Cosmochim. Acta 52, 3005-3015.

Lu, K., Wang, Q., Li, C., Wang, Y., Chen, X., 2002. The structure, electronic states and properties in liquid Ga-Sb and In-Sb systems. Journal of Non-Crystalline Solids 312-314, 34-40.

Lundegaard, L.F., Miletich, R., Balic-Zunic, T., Makovicky, E., 2003. Equation of state and crystal structure of $\mathrm{Sb}_{2} \mathrm{~S}_{3}$ between 0 and $10 \mathrm{GPa}$. Physics and Chemistry of Minerals 30, 463-468.

Matsuzawa, K., Shido, T., Iwasawa, Y., 2003. Reversible structure transformation of antimony oxides on $\mathrm{SiO}_{2}$ relevant to selective catalytic oxidation of ethanol. Langmuir 19, 2756-2762.

Millet, J.M.M., Baca, M., Pigamo, A., Vitry, D., Ueda, W., Dubois, J.L., 2003. Study of the valence state and coordination of antimony in MoVSbO catalysts determined by XANES and EXAFS. Applied Catalysis A: General 244, 359-370.

Mills, S.J., Etschmann, B., Kampf, A.R., Poirier, G., Newville, M., 2014. Sb ${ }^{5+}$ and $\mathrm{Sb}^{3+}$ substitution in segnitite: A new sink for As and $\mathrm{Sb}$ in the environment and implications for acid mine drainage. Am. Miner. 99, 1355-1359.

Mitsunobu, S., Harada, T., Takahashi, Y., 2006. Comparison of antiomny behavior with that of arsenic under various soil redox conditions. Environ. Sci. Technol. 40, 7270-7276. 
Mitsunobu, S., Takahashi, Y., Utsunomiya, S., Marcus, M.A., Terada, Y., Iwamura, T., Sakata, M., 2011. Identification and characterization of nanosized tripuhyite in soil near Sb mine tailings. Am. Miner. 96, 1171-1181.

Mosselmans, J.F.W., Helz, G.R., Pattrick, R.A.D., Charnock, J.M., Vaughan, D.J., 2000. A study of speciation of $\mathrm{Sb}$ in bisulfide solutions by X-ray absorption spectroscopy. Appl. Geochem. 15, 879-889.

Oelkers, E.H., Sherman, D.M., Ragnarsdottir, K.V., Collins, C., 1998. An EXAFS spectroscopic study of aqueous antimony(III)-chloride complexation at temperatures from 25 to $250^{\circ} \mathrm{C}$. Chem. Geol. 151, 21-27.

Peterson, R.C., Miller, I., 1968. Crystal structure and cation distribution in freibergite and tetrahedrite. Mineral. Mag. 50, 717-721.

Planer-Friedrich, B., Scheinost, A.C., 2011. Formation and structural characterization of thioantimony species and their natural occurrence in geothermal waters. Environ. Sci. Technol. 45, 68556863.

Pokrovski, G., Borisova, A., Roux, J., Hazemann, J., Petdang, A., Tella, M., Testemale, D., 2006. Antimony speciation in saline hydrothermal fluids: A combined X-ray absorption fine structure spectroscopy and solubility study. Geochim. Cosmochim. Acta 70, 4196-4214.

Pokrovski, G.S., Roux, J., Hazemann, J.L., Borisova, A.Y., Gonchar, A.A., Lemeshko, M.P., 2008. In situ X-ray absorption spectroscopy measurement of vapour-brine fractionation of antimony at hydrothermal conditions. Mineral. Mag. 72, 667-681.

Ravel, B., Newville, M., 2005. ATHENA, ARTEMIS, HEPHAESTUS: data analysis for X-ray absorption spectroscopy using IFEFFIT. J. Synchrotron Radiat. 12, 537-541.

Ritchie, V.J., Ilgen, A.G., Mueller, S.H., Trainor, T.P., Goldfarb, R.J., 2013. Mobility and chemical fate of antimony and arsenic in historic mining environments of the Kantishna Hills district, Denali National Park and Preserve, Alaska. Chem. Geol. 335, 172-188.

Scheinost, A.C., Rossberg, A., Vantelon, D., Xifra, I., Kretzschmar, R., Leuz, A.-K., Funke, H., Johnson, C.A., 2006. Quantitative antimony speciation in shooting-range soils by EXAFS spectroscopy. Geochim. Cosmochim. Acta 70, 3299-3312.

Sherman, D.M., Ragnarsdottir, K.V., Oelkers, E.H., 2000. Antimony transport in hydrothermal solutions: an EXAFS study of antimony(V) complexation in alkaline sulfide and sulfidechloride brines at temperatures from $25^{\circ} \mathrm{C}$ to $300^{\circ} \mathrm{C}$ at $\mathrm{P}_{\text {sat. }}$ Chem. Geol. 167, 161-167.

Sinsermsuksakul, P., Chakraborty, R., Kim, S.B., Heald, S.M., Buonassisi, T., Gordon, R.G., 2012. Antimony-doped tin(II) sulfide thin films. Chemistry of Materials 24, 4556-4562.

Takaoka, M., Fukutani, S., Yamamoto, T., Horiuchi, M., Satta, N., Takeda, N., Oshita, K., Yoneda, M., Morisawa, S., Tanaka, T., 2005. Determination of chemical form of antimony in contaminated soil around a smelter using X-ray absorption fine structure. Analytical Sciences 21, 769-773.

Tella, M., Pokrovski, G.S., 2009. Antimony(III) complexing with O-bearing organic ligands in aqueous solution: An X-ray absorption fine structure spectroscopy and solubility study. Geochim. Cosmochim. Acta 73, 268-290.

Tossell, J.A., 1994. The speciation of antimony in sulfidic solutions: A theorectical study. Geochim. Cosmochim. Acta 58, 5093-5104.

Varrica, D., Bardelli, F., Dongarrà, G., Tamburo, E., 2013. Speciation of Sb in airborne particulate matter, vehicle brake linings, and brake pad wear residues. Atmospheric Environment 64, 1824.

Whitten, A.E., Dittrich, B., Spackman, M.A., Turner, P., Brown, T.C., 2004. Charge density analysis of two polymorphs of antimony(III) oxide. Dalton Transactions 1, 23-29.

Yiwata, N., Harigaya, M., Tani, K., Hayakawa, K., Fujikawa, T., 2001. Sb K-edge absorption fine structure of $\mathrm{Sb}_{2} \mathrm{Te}_{3}$. J. Synchrotron Radiat. 8, 752-754. 


\section{Chapter (4):}

\section{Stibnite solubility and antimony speciation in hydrosulfide solutions from 70 to $400^{\circ} \mathrm{C}$}

\subsection{Introduction}

The antimony dissolved in reducing high temperature aqueous fluids occurs as complexes with sulfide ( $\left.\mathrm{HS}^{-}\right)$or hydroxide $\left(\mathrm{OH}^{-}\right)$ligands depending on the $\mathrm{pH}$ and sulfide concentration. The response of antimony sulfide solubility to changes in $\mathrm{pH}$, dissolved sulfide content, and temperature will be determined by the relative stability of different antimony complexes. The stability constants for antimony(III)-sulfide and antimony(III)-hydroxide complexes presented in this Chapter can be used to evaluate antimony transport and deposition chemistry in hydrothermal systems, including as part of hydrothermal ore deposition and in fluids utilized for geothermal power generation.

Hydrothermal fluids from active geothermal systems often contain tens to hundreds of $\mathrm{ppb} \mathrm{Sb}$ $\left(\sim 10^{-7}\right.$ to $\left.10^{-6} \mathrm{~mol} \mathrm{~kg}^{-1} \mathrm{Sb}\right)$ and concentrations as high as $1-3 \mathrm{ppm} \mathrm{Sb}\left(\sim 10^{-5} \mathrm{~mol} \mathrm{~kg}^{-1} \mathrm{Sb}\right)$ occur in some systems (Weissberg et al., 1979; Stauffer and Thompson, 1984; Simmons and Brown, 2007; Hardardottir et al., 2009; Landrum et al., 2009; Planer-Friedrich and Scheinost, 2011; Ullrich et al., 2013; Hannington et al., 2016; Simmons et al., 2016). Deposition of antimony sulfides from such fluids has produced antimony-rich deposits within and around some hot springs, including quite spectacularly at Champagne Pool, Waiotapu, New Zealand (Weissberg, 1969). Such systems are modern analogs for epithermal ore deposits, and they can serve as model systems to investigate ore deposition processes and to contrast the chemistry of antimony with that of other elements that complex with sulfide ligands to a greater or lesser degree. In particular, an improved understanding of antimony chemistry would elucidate the concurrent enrichment of antimony, arsenic and gold that is observed in some hydrothermal fluids, hydrothermal ore deposits, and hydrothermal altered rocks (e.g., Williams-Jones and Normand, 1997; Migdisov and Bychkov, 1998; Simmons and Browne, 2000). Precipitation of antimony sulfide scale, primarily as microscopic needles of stibnite, in geothermal power stations is not common but in some systems is extensive and problematic (Raymond et al., 2005; Wilson et al., 2007; Morteani et al., 2010). Thermodynamic data for antimony at the physicochemical conditions present in the power stations can be used to develop procedures to eliminate, or at least minimize, stibnite precipitation within such facilities.

The complexation of antimony(III) in hydrosulfide solutions at $30^{\circ} \mathrm{C}$ was investigated in Chapter (2). At ambient temperatures, antimony(III) readily complexes with HS- ligands across the 
whole $\mathrm{pH}$ range whenever there is sufficient free dissolved sulfide. Stibnite solubility increases with increasing $\mathrm{pH}$ from $\sim 10^{-9} \mathrm{~mol} \mathrm{~kg}^{-1} \mathrm{Sb}$ at $\mathrm{pH}=4$ to $\sim 10^{-3} \mathrm{~mol} \mathrm{~kg}^{-1} \mathrm{Sb}$ at $\mathrm{pH}=12$, with an intermediate region where stibnite solubility is independent of $\mathrm{pH}$ between $\mathrm{pH}=7$ and 9. In this Chapter, equilibrium constants for antimony(III)-sulfide and antimony-hydroxide complexes are derived from stibnite solubility experiments conducted in a flow-through reactor from 70 to $400^{\circ} \mathrm{C}$ at pressures slightly above saturated water vapor pressure (swvp) up to 300 bars. Experimental conditions were targeted to investigate the behaviour of antimony-sulfide complexes in hydrothermal ore solutions. Thus, fluids with $\mathrm{pH}$ between 3 and 9 and sulfide contents between 0.005 and $0.05 \mathrm{~mol} \mathrm{~kg}^{-1} \mathrm{~S}^{2-}$ total were studied. This is the first study to present measurements of stibnite solubility above the critical point of water.

\subsubsection{Previous studies of antimony speciation in hydrosulfide solutions at elevated temperatures}

\section{Solubility studies}

The solubility of stibnite was first measured at elevated temperatures in conjunction with that of cinnabar $(\mathrm{HgS})$ in concentrated $\mathrm{Na}_{2} \mathrm{~S}$ solutions ( 0.1 to $0.6 \mathrm{~mol} \mathrm{~kg}^{-1} \mathrm{~S}^{2-}$ total $)$ from $150^{\circ} \mathrm{C}$ to $250^{\circ} \mathrm{C}$ at 100 bars by Learned (1966). In these alkaline, sulfide-rich solutions, stibnite solubility was very high $\left(\sim 10^{-1} \mathrm{~mol} \mathrm{~kg}^{-1} \mathrm{Sb}\right)$ and increased proportionally with the sulfide concentration. Kolpakova (1982) measured stibnite solubility in acidic to slightly alkaline $0.01 \mathrm{~mol} \mathrm{~kg}^{-1} \mathrm{KCl}$ solutions at 50 and $95^{\circ} \mathrm{C}$. In the moderate sulfide concentrations $\left(\sim 10^{-3} \mathrm{~mol} \mathrm{~kg}^{-1} \mathrm{~S}^{2-}{ }_{\text {total }}\right)$ studied by Kolpakova, the proportional relationship between stibnite solubility and sulfide concentration was maintained, even in the higher $\mathrm{pH}$ solutions when the dissolved antimony concentration was greater than the total un-complexed sulfide concentration. Kolpakova interpreted the results in terms of the reaction

$$
\mathrm{Sb}_{2} \mathrm{~S}_{3(\mathrm{~S})}+\mathrm{HS}^{-}<=>\mathrm{HSb}_{2} \mathrm{~S}_{4}^{-}
$$

based upon previous studies at $25^{\circ} \mathrm{C}$, which identified $\mathrm{HSb}_{2} \mathrm{~S}_{4}{ }^{-}$as the dominant species in weakly alkaline pH fluids (Kolpakova, 1971). Wood et al. (1987) used antimony complexation models developed by previous researchers to interpret stibnite solubility in $\mathrm{H}_{2} \mathrm{O}-\mathrm{NaCl}-\mathrm{CO}_{2}$ solutions from 200 to $350^{\circ} \mathrm{C}$ as part of an assemblage including pyrite, pyrrhotite, magnetite, sphalerite, galena, bismuthinite, argenitite, gold, and molybdenite. Wood and co-authors attributed most of the dissolved antimony to $\mathrm{Sb}(\mathrm{OH})_{3}$ due to the low sulfide content available in the pyrite-pyrrhotite-magnetite buffered system, and used their new stibnite solubility data to estimate equilibrium constants for the reaction

$$
0.5 \mathrm{Sb}_{2} \mathrm{~S}_{3}+3 \mathrm{H}_{2} \mathrm{O}<=>\mathrm{Sb}(\mathrm{OH})_{3}+1.5 \mathrm{HS}^{-}+1.5 \mathrm{H}^{+}
$$

The stibnite solubility experiments conducted by Krupp (1988) covered a wider range of temperature $\left(25\right.$ to $\left.350^{\circ} \mathrm{C}\right), \mathrm{pH}$ (2.5 to 11.5$)$, and sulfide concentration $\left(10^{-2.5}\right.$ to $10^{-1} \mathrm{~mol} \mathrm{~kg}^{-1} \mathrm{~S}^{2-}$ total $)$ than any previous experimental work. For the moderate sulfide content of these experiments, Krupp presented a speciation model in which the antimony-sulfide dimer, $\mathrm{H}_{\mathrm{x}} \mathrm{Sb}_{2} \mathrm{~S}_{4}{ }^{\mathrm{x}-2}$, was predominant across 
Figure (4.1) Previously published values of equilibrium constants for stibnite solubility in terms of (A) $\mathrm{Sb}(\mathrm{OH})_{3}$ (Equation 4.2), (B) $\mathrm{Sb}_{2} \mathrm{~S}_{4}{ }^{2-}$, and (C) $\mathrm{HSb}_{2} \mathrm{~S}_{4}^{-}$(Equation 4.1). If necessary, values have been adjusted to the form of the reaction as displayed in the figure with the $\mathrm{K}_{\mathrm{w}}$ and/or $\mathrm{K}_{\mathrm{H} 2 \mathrm{~S}}$ used in the reference, if available, or that consistent with this study.
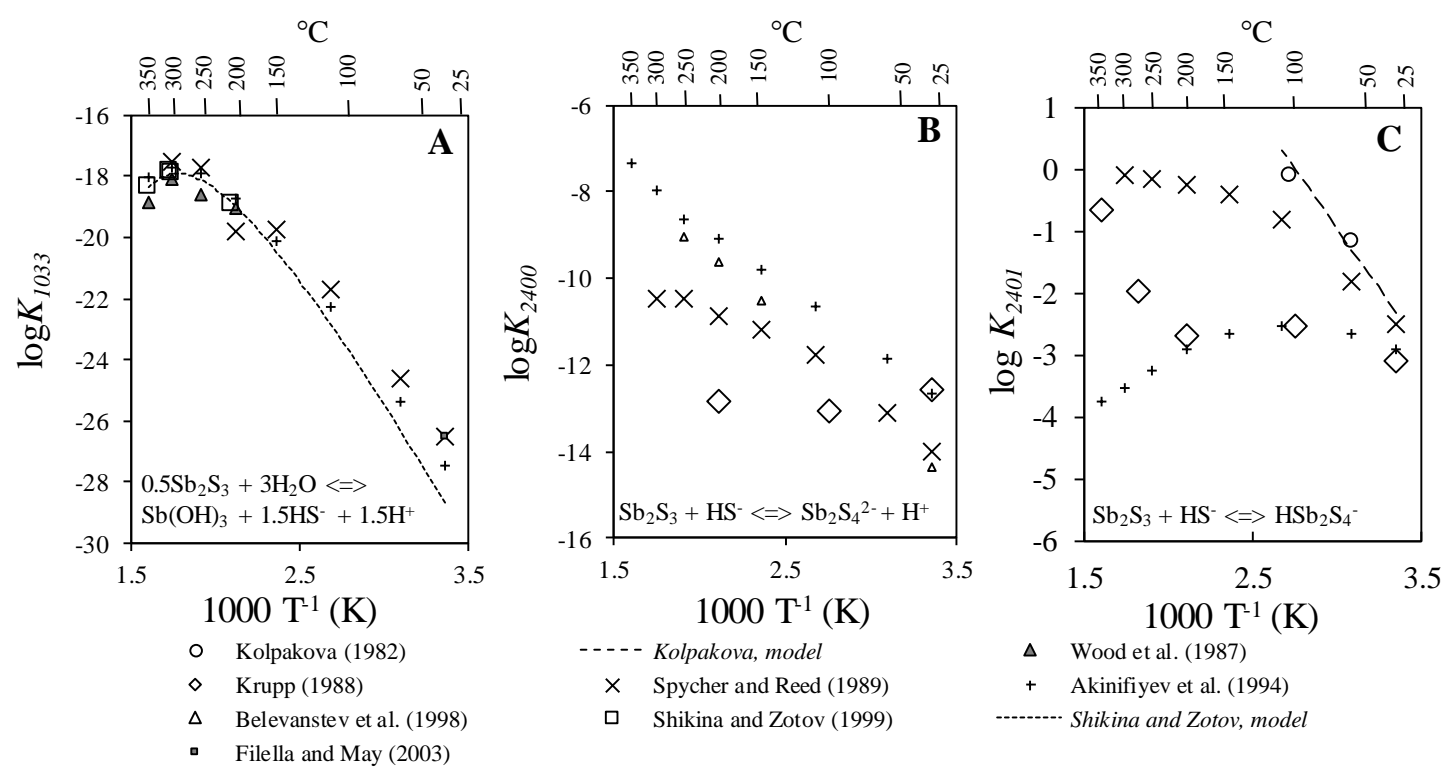

the entire $\mathrm{pH}$ range up to 100 to $150^{\circ} \mathrm{C}$. With increasing temperature, the neutral, mixed-ligand dimer $\mathrm{Sb}_{2} \mathrm{~S}_{2}(\mathrm{OH})_{2}$ became the predominant species in all but the most alkaline $(\mathrm{pH}>\sim 9)$.

Akinifiyev et al. (1994) combined new experimental data at $350^{\circ} \mathrm{C}$ with data from multiple previous studies from 25 to $350^{\circ} \mathrm{C}$ to derive a self-consistent set of thermodynamic parameters for the system $\mathrm{Sb}$ (III)-Sb(II)- $\mathrm{H}_{2} \mathrm{O}$ using the Helgeson-Kirkham-Flowers (HFK) formulation (Tanger and Helgeson, 1988). This study used the same sulfide speciation model as Krupp (1988) but rejected the mixed-ligand dimer $\mathrm{Sb}_{2} \mathrm{~S}_{2}(\mathrm{OH})_{2}$ in favour of several antimony hydroxide species, primarily $\mathrm{Sb}(\mathrm{OH})_{3}$, based upon determinations of that species' thermodynamic parameters in the simpler $\mathrm{Sb}(\mathrm{III})-\mathrm{H}_{2} \mathrm{O}$ system. As a result, the values of the equilibrium constants for antimony-sulfide complexes from Akinfiyev et al. (1994) and Krupp (1988) are in poor agreement above $200^{\circ} \mathrm{C}$. This is shown in Figure (4.1), in which published equilibrium constants values for the reactions represented by Equations (4.1) and (4.2) and stibnite solubility in terms of $\mathrm{Sb}_{2} \mathrm{~S}_{4}{ }^{2-}$ are compared.

Shikina and Zotov (1999) presented further stibnite solubility experiments at 200 and $300^{\circ} \mathrm{C}$ that supported the predominance of $\mathrm{Sb}(\mathrm{OH})_{3}$ in low-sulfide solutions at acidic to neutral $\mathrm{pH}$. Zotov et al. (2003) re-evaluated the standard thermodynamic properties and HFK parameters for $\mathrm{Sb}(\mathrm{OH})_{3}$ in light of the data from Shikina and Zotov (1999) and new $\mathrm{Sb}$ (III) oxide (senarmonite $\left(\mathrm{Sb}_{2} \mathrm{O}_{3}\right.$, crubic) and valentinite $\left.\left(\mathrm{Sb}_{2} \mathrm{O}_{3, \text { rhombic }}\right)\right)$ solubility experiments. For the high extremes of $\mathrm{pH}$ and sulfide concentration, Belevantsev et al. (1998) fitted a speciation model including $\mathrm{Sb}_{2} \mathrm{~S}_{4}{ }^{2-}$ and $\mathrm{SbS}_{2}{ }^{-}$to previously collected stibnite solubility data for strongly alkaline and very concentrated hydrosulfide $(\geq$ $0.05 \mathrm{~S}^{2-}$ total) solutions. Their revised equilibrium constant for reaction (4.1) is similar to that derived from lower $\mathrm{pH}$ experiments when $\mathrm{Sb}(\mathrm{OH})_{3}$ is included in the complexation model (Figure 4.1). 
$X$-ray absorption and Raman spectroscopy studies

A limited number of X-ray absorption spectroscopy (XAS) and Raman spectroscopy measurements have been conducted on antimony(III) hydrosulfide solutions above $100^{\circ} \mathrm{C}$. These measurements can provide independent qualitative information about the species present in solution to compare with models derived from solubility experiments. Mosselmans et al. (2000) and Sherman et al. (2000) carried out Sb K-edge XAS in sodium sulfide solutions above $100^{\circ} \mathrm{C}$. In both of these studies, evidence for the presence of complexes containing $\mathrm{OH}^{-}$ligands, in the form of detectable first shell oxygen atoms and/or a decrease in the total number of first shell sulfur atoms, was found at 150 and $200^{\circ} \mathrm{C}$. For some solutions, first shell sulfur atoms and first shell oxygen atoms were equally abundant by $250^{\circ} \mathrm{C}$. The measurements presented in Sherman et al. (2000) were almost certainly conducted on the $\mathrm{Sb}(\mathrm{V})-\mathrm{S}(\mathrm{II})-\mathrm{H}_{2} \mathrm{O}$ system due to the solution preparation procedures used, but the behaviour of $\mathrm{Sb}$ (III)-S(II) and $\mathrm{Sb}$ (III)-O(II) bonds may be qualitatively similar to that of $\mathrm{Sb}$ (V)-S(II) and $\mathrm{Sb}(\mathrm{V})-\mathrm{O}(\mathrm{II})$ bonds. A figure summarizing the changes detected by XAS in antimony's first coordination shell with increasing temperature from 25 to $250^{\circ} \mathrm{C}$ is included in the Discussion.

In a Raman spectroscopy study from the same era, Gushchina et al. (2000) investigated antimony in two $\mathrm{Na}_{2} \mathrm{~S}$ solutions with different sulfide concentrations from 25 to $250^{\circ} \mathrm{C}$. The spectral features found in this study were summarised in Chapter (2) and shown in Figure (2.1). With increasing temperature, two spectral features became more pronounced: a peak at $280 \mathrm{~cm}^{-1}$ and a shoulder at $380 \mathrm{~cm}^{-1}$. In the $25^{\circ} \mathrm{C}$ measurements, the spectral feature at $280 \mathrm{~cm}^{-1}$ was associated with low sulfide concentrations relative to antimony concentrations (molar $\mathrm{S}: \mathrm{Sb}<2: 1$ ) and the feature at $380 \mathrm{~cm}^{-1}$ was associated with high sulfide concentrations (molar S:Sb > 15:1). All other peaks that were prominent at $25^{\circ} \mathrm{C}$ diminished with increasing temperature, especially at and above $175^{\circ} \mathrm{C}$. Both Raman and XAS spectroscopic studies are consistent with a significant change in antimony speciation between 100 and $200^{\circ} \mathrm{C}$.

\subsubsection{Interpretations of the change in stibnite solubility's dependence on sulfide concentration with temperature}

Multiple studies have found that stibnite solubility increases with increasing sulfide concentration in acidic to alkaline fluids up to 100 to $150^{\circ} \mathrm{C}$. Since the early $1980 \mathrm{~s}$, this trend has been interpreted in terms of stibnite solubility being controlled by $\mathrm{H}_{2} \mathrm{Sb}_{2} \mathrm{~S}_{4}, \mathrm{HSb}_{2} \mathrm{~S}_{4}{ }^{-}$, and $\mathrm{Sb}_{2} \mathrm{~S}_{4}{ }^{2-}$, but the reported values for the appropriate stibnite solubility constants vary by up to four orders of magnitude (Figure (4.1); Kolpakova, 1982; Spycher and Reed, 1989; Akinifiyev et al., 1994; Belevantsev et al., 1998; Shikina and Zotov, 1999). At temperatures $>\sim 120^{\circ} \mathrm{C}$, stibnite becomes more soluble with decreasing sulfide concentration in acidic solutions when the sulfide concentrations are $<\sim 0.01 \mathrm{~mol}$ $\mathrm{kg}^{-1} \mathrm{~S}^{2-}$ total. This is consistent with the detection of oxygen atoms in the first coordination shell in some high temperature EXAFS experiments (Mosselmans et al., 2000; Sherman et al., 2000). 
Krupp (1988) interpreted the change in stibnite solubility as due to hydroxy ligands replacing non-bridging sulfurs forming a mixed ligand dimer (i.e., $\left.\mathrm{Sb}_{2} \mathrm{~S}_{2}(\mathrm{OH})_{2}\right)$. Other studies, which relied on stibnite solubility experiments conducted at lower sulfide concentrations and on thermodynamic data for $\mathrm{Sb}(\mathrm{OH})_{3}$ derived from the $\mathrm{Sb}(\mathrm{III})-\mathrm{O}-\mathrm{H}$ system, have rejected the mixed-ligand species $\mathrm{Sb}_{2} \mathrm{~S}_{2}(\mathrm{OH})_{2}$ in favor of increasing stability of $\mathrm{Sb}(\mathrm{OH})_{3}$ (Akinifiyev et al., 1994; Shikina and Zotov, 1999; Zotov et al., 2003). The stability of $\mathrm{Sb}(\mathrm{OH})_{3}$ and its contribution to stibnite solubility are quite well constrained with experimental studies from up to $350^{\circ} \mathrm{C}$. However, the stoichiometry and stability of antimonysulfide complexes at higher temperatures are less well studied. A transition from antimony-sulfide ligand interactions to antimony-hydroxide ligand interactions is expected with increasing temperature due to the increasingly "hard" character of metal-ligand interactions as the dielectric constant of water decreases. The combination of temperature, $\mathrm{pH}$, and sulfide activity at which antimony complexation changes from sulfide to hydroxide ligands will be different from other elements, of particular interest are arsenic and gold, and different affinities for the sulfide and hydroxide ligands will affect the relative distribution of these three commonly associated elements (i.e., $\mathrm{Sb}$, As, and $\mathrm{Au}$ ) in hydrothermal ore deposits.

\subsection{Methods}

\subsubsection{High pressure-temperature flow-through reaction system and solution preparation}

Experiments from 70 to $400^{\circ} \mathrm{C}$ were conducted in a hydrothermal flow-through autoclave reactor. The flow-through approach has previously been used to conduct high-temperature metal sulfide solubility studies (e.g., Stefánsson and Seward, 2004; Tagirov et al., 2007), and a similar apparatus to the one in the current study has been used to investigate water-rock reaction (e.g., Sonney and Mountain, 2013). A diagram of the apparatus is shown in Figure (4.2). The system consisted of two piston pumps that moved fluid from a 11 fluid reservoir through two $19.3 \mathrm{ml}$ reaction vessels, the second containing stibnite, and through a backpressure regulator at the exit of the system. The reaction vessels were located in separate ovens and, in this study, the first of these vessels was used to pre-heat the solution and the second reaction vessel contained $\sim 56 \mathrm{~g}$ of crushed and cleaned natural stibnite sieved to between 0.125 and $0.5 \mathrm{~mm}$ grain size. Both vessels and all connecting tubing were constructed from titanium. A titanium frit was placed at the entrance and exit of the stibnite reaction vessel to prevent movement of fine stibnite particles into the exit tubing.

The tubing sections between the ovens and between the second oven and the backpressure regulator were wrapped with heating tape to maintain a constant temperature after passage from the first vessel. The temperature of the heating tape between the stibnite reaction vessel and the backpressure regulator was maintained at 10 to $20^{\circ} \mathrm{C}$ above that in the oven to prevent re-precipitation of stibnite in the exit tubing for experiments up to $\sim 330^{\circ} \mathrm{C}$. At $350^{\circ} \mathrm{C}$ and in supercritical experiments, 
the temperatures in the tubing and the stibnite reaction vessel were set at the same temperature to avoid stibnite precipitation due to decreasing fluid density with slight increases in temperature. In this experimental system, the pressure was constant throughout. Once the fluid reservoir was filled, the entire system was closed to oxygen and the input fluid conditions remained constant. Each experiment started at $70^{\circ} \mathrm{C}$ and then stibnite solubility was measured with increasing temperature up to at least $350^{\circ} \mathrm{C}$. A minimum of two hours was needed to heat up the ovens and reaction vessels between temperature points. The system was allowed to fully cool to $70^{\circ} \mathrm{C}$ before the start of the next experiment.

The deoxygenated hydrosulfide solutions were prepared as described previously (Chapter 2). Hydrosulfide solutions with selected $\mathrm{pH}$ and sulfide concentrations were made by bubbling $\mathrm{H}_{2} \mathrm{~S} / \mathrm{N}_{2}$ gas mixtures through deoxygenated dilute $\mathrm{NaOH}$ or $\mathrm{HCl}$ solutions in a 21 flask. The experimental solution was then transferred to the fluid reservoir before each experiment using the flow-through system's pumps. Prior to transferring the solutions, all tubing and lines between the preparation flask and the fluid reservoir were evacuated to exclude oxygen from the solution during transfer. The appropriate $\mathrm{H}_{2} \mathrm{~S} / \mathrm{N}_{2}$ gas mixture was slowly passed through the headspace in the flask during the transfer to maintain constant pressure and prevent degassing of $\mathrm{H}_{2} \mathrm{~S}$ from the solution. The ambient temperature $\mathrm{pH}$ and total sulfide content $\left(\mathrm{mol} \mathrm{kg}^{-1} \mathrm{~S}^{2-}\right.$ total) of solutions collected directly from the fluid reservoir were measured at the beginning and end of experiments. These values are the $\mathrm{pH}$ and $\mathrm{mol} \mathrm{kg}-$ ${ }^{1} \mathrm{~S}_{\text {total }}$ values listed in Table (4.1).

After completion of all the experiments, the flow-through reaction vessel was disassembled and the reacted stibnite was inspected. No secondary mineral phases were observed and the surfaces of

Figure (4.1) Diagram of flow-through autoclave reactor. Experimental solutions are placed in the fluid reservoir under oxygen exclusion and then pumped through the vessels in Oven 1 and then Oven 2 before being collected in a syringe at the exit of the backpressure regulator. The fluid pressure is monitored at the pumps and the backpressure regulator inlet. The temperature is monitored at the entrance and exit of the reaction vessel and in the tubing leading to the backpressure regulator.

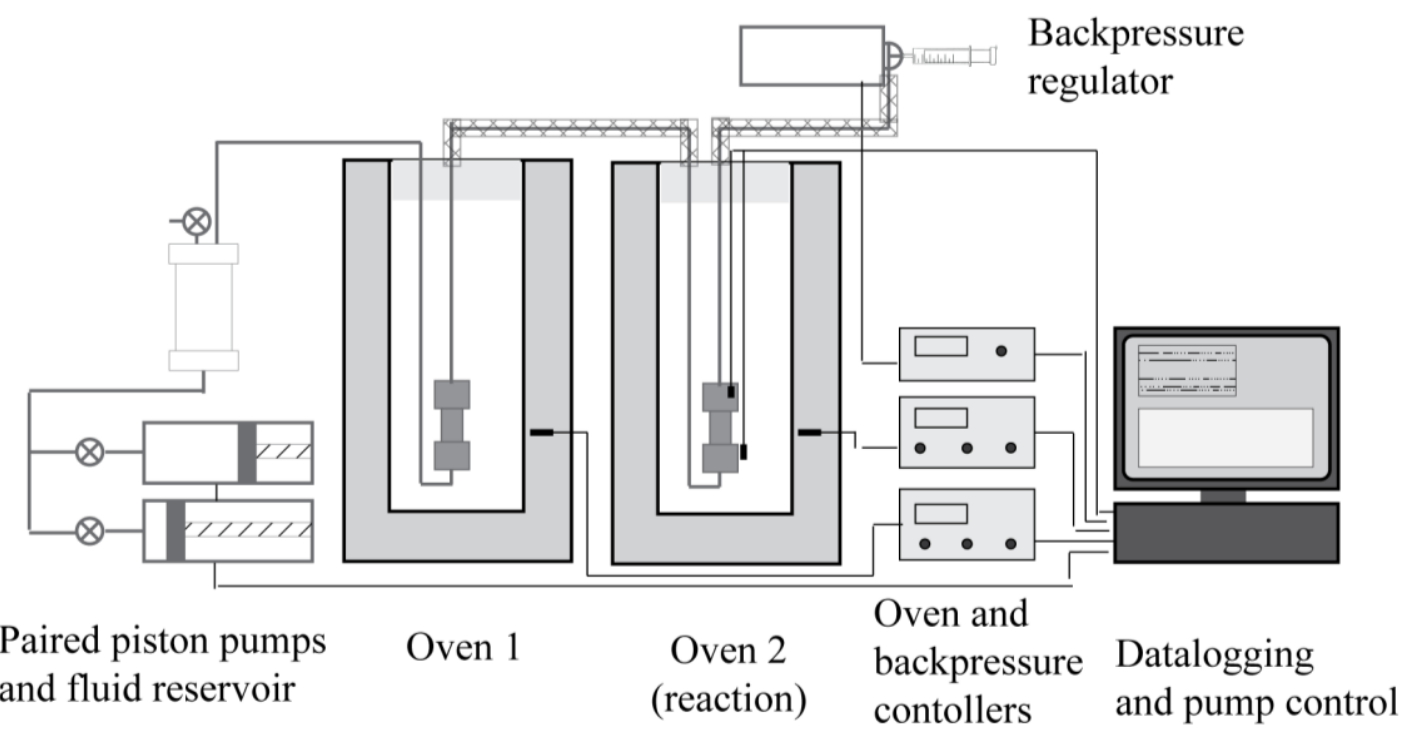


Table (4.1) Input fluid conditions for high temperature experiments.

\begin{tabular}{|c|c|c|c|c|}
\hline Exp. & $\mathrm{pH}_{\text {input }}$ & $\begin{array}{c}\mathrm{S}_{\text {total }}^{2-} \\
\left(\mathrm{mol} \mathrm{kg}^{-1}\right) \\
\end{array}$ & $\begin{array}{c}\mathrm{NaOH}^{\mathrm{a}} \text { or } \mathrm{HCl}^{\mathrm{b}} \\
\left(\mathrm{mol} \mathrm{kg}^{-1}\right)\end{array}$ & $\begin{array}{l}\text { temperature } \\
\text { range }\end{array}$ \\
\hline$\overline{\mathrm{Sb} 94}$ & 7.40 & 0.023 & $2.02 \mathrm{E}-02^{\mathrm{a}}$ & 200 \\
\hline Sb97 & 7.52 & 0.022 & $2.02 \mathrm{E}-02^{\mathrm{a}}$ & 150 \\
\hline Sb98 & 7.11 & 0.029 & $2.07 \mathrm{E}-02^{\mathrm{a}}$ & $150-300$ \\
\hline Sb99 & 7.24 & 0.028 & $2.07 \mathrm{E}-02^{\mathrm{a}}$ & $100-350$ \\
\hline Sb100 & 6.45 & 0.012 & $3.08 \mathrm{E}-03^{\mathrm{a}}$ & $70-400$ \\
\hline Sb101 & 4.61 & 0.009 & 0.0 & $70-230$ \\
\hline $\mathrm{Sb} 102$ & 3.53 & 0.009 & $2.99 \mathrm{E}-04^{b}$ & $70-400$ \\
\hline Sb103 & 3.57 & 0.028 & $2.84 \mathrm{E}-04^{b}$ & $70-150$ \\
\hline Sb104 & 5.04 & 0.011 & $5.10 \mathrm{E}-05^{\mathrm{a}}$ & $70-400$ \\
\hline Sb105 & 7.15 & 0.003 & $2.00 \mathrm{E}-03^{\mathrm{a}}$ & $70-400$ \\
\hline Sb106 & 5.88 & 0.011 & $9.26 \mathrm{E}-04^{\mathrm{a}}$ & $70-350$ \\
\hline Sb107 & 8.55 & 0.010 & $1.04 \mathrm{E}-02^{\mathrm{a}}$ & $70-400$ \\
\hline Sb108 & 8.43 & 0.050 & $5.03 \mathrm{E}-02^{\mathrm{a}}$ & $70-300$ \\
\hline Sb109 & 6.41 & 0.024 & $6.74 \mathrm{E}-03^{\mathrm{a}}$ & $70-350$ \\
\hline
\end{tabular}

${ }^{\text {a }}$ Experiments with $\mathrm{NaOH}$ added to the initial solution

${ }^{\mathrm{b}}$ Experiments with $\mathrm{HCl}$ added to the initial solution

None of the high temperature experiments contained both $\mathrm{HCl}$ and $\mathrm{NaOH}$

the reacted stibnite had metallic lustre and did not shown evidence of oxidation under magnification. Scanning electron microprobe (SEM) images of stibnite grains after completion of experiments showed that the grains in the reaction vessel had embayed grain boundaries indicative of dissolution (Figure A.2). X-ray fluorescence (XRF) analyses (i.e., Sb and S concentrations) of these grains were consistent with stoichiometric stibnite. Amorphous Sb-S phases or antimony-oxide minerals, such as senarmonite, were not observed by visual inspection of the reacted grains or by SEM or XRF.

\subsubsection{Sample collection}

The experimental solutions were collected directly into a 50ml syringe at the exit of the backpressure regulator. For experiments up to $150^{\circ} \mathrm{C}$, the solution was collected into an empty syringe. The output $\mathrm{pH}$ of this solution was determined at ambient temperature using a Metrohm $\mathrm{pH}$ meter (calibrated daily), and the total sulfide content was measured by idiometric back titration. For higher temperatures, the solution was collected into a syringe containing a measured amount of chilled $\mathrm{NaOH}$ solution. This was done to prevent precipitation of stibnite upon cooling and to prevent the flashing of the solution upon exiting the back pressure regulator. The amount and concentration of the $\mathrm{NaOH}$ solution was such that the final $\mathrm{NaOH}$ concentration in the sample was appropriate for direct measurement by ICP-OES (i.e., $0.08 \mathrm{~mol} \mathrm{~kg}^{-1} \mathrm{NaOH}$ ). The total sulfide concentration, but not the output $\mathrm{pH}$, was measured in the 200 to $400^{\circ} \mathrm{C}$ samples. The analysis of total antimony by ICP-OES was the same as that described in Chapter (2). The $\mathrm{pH}$ was measured at room temperature and is listed 
as $\mathrm{pH}_{\text {exit }}$ in Table (A.2). In preliminary tests, the total antimony and sulfide concentrations in solutions collected in empty syringes or in collected in syringes containing a $\mathrm{NaOH}$ solution were the same for the 70 to $150^{\circ} \mathrm{C}$ experiments, indicating that collection into an alkaline solution was not needed for these more moderate temperatures.

\subsubsection{Speciation of solutions and calculation of $\mathrm{pH}$}

The $\mathrm{pH}$ of the solution at the experimental temperature and pressure was calculated from the charge balance of the solution considering the following components: $\mathrm{OH}^{-}, \mathrm{H}^{+}, \mathrm{HS}^{-}, \mathrm{H}_{2} \mathrm{~S}^{\circ}, \mathrm{NaHS}^{\circ}$, $\mathrm{NaOH}^{\circ}, \mathrm{Na}^{+}, \mathrm{Cl}^{-}, \mathrm{HCl}^{\circ}$, and the appropriate antimony species for each speciation model. These are the same components as considered in Chapter (2), with the addition of $\mathrm{HCl}^{\circ}$ and $\mathrm{Cl}^{-}$. The mass action and mass balance relationships for the first seven components were defined in Chapter (2) in Equations (2.13) through (2.22). The dissociation of the ion pair $\mathrm{HCl}^{\circ}$ is given by

$$
\mathrm{HCl}^{\circ}=\mathrm{H}^{+}+\mathrm{Cl}^{-}
$$

for which the equilibrium constant is defined as

$$
K_{\mathrm{HCl}^{\circ}}=\mathrm{m}_{\mathrm{H}^{+}} \cdot \gamma_{\mathrm{H}^{+}} \cdot m_{\mathrm{Cl}^{-}} \cdot \gamma_{\mathrm{Cl}^{-}} \cdot m_{\mathrm{HCl}^{\circ}}{ }^{-1} \cdot \gamma_{\mathrm{HCl}^{\circ}}{ }^{-1}
$$

Experimental solutions contained additions of $\mathrm{HCl}$ or $\mathrm{NaOH}$ but never both. Thus, the $\mathrm{NaCl}^{\circ}$ ion pair was not included in calculations. The mole fractions of the total sulfide, sodium, and chloride present as $\mathrm{HS}^{-}, \mathrm{Na}^{+}$, and $\mathrm{Cl}^{-}$(i.e., $X_{H S-}, X_{N a+}$, and $X_{C l-}$ ) are given by the following equations, which are developed in Appendix (A):

$$
\begin{aligned}
& X_{H S^{-}}=\frac{m_{H S^{-}}}{m_{S_{\text {free }}}}=\frac{1}{1+\frac{a_{H^{+}} \gamma_{H S^{-}}}{K_{H_{2} S}}+\frac{\gamma_{H S^{-}} \gamma_{a^{+}} m_{N a^{+}}}{K_{N a H S^{\circ}}}} \\
& X_{N a^{+}}=\frac{m_{N a^{+}}}{m_{N a_{\text {total }}}}=\frac{1}{1+\frac{\gamma_{N a^{+} \gamma_{H S^{-}} m_{H S^{-}}}}{K_{N a S H^{\circ}}}+\frac{\gamma_{N a^{+} K_{W}}}{K_{N a O H^{\circ} a^{+}}}} \\
& X_{C l^{-}}=\frac{1}{1+\frac{\gamma_{C l} \gamma_{H^{+}} m_{H^{+}}}{K_{H C l^{\circ}}}}
\end{aligned}
$$

These fractions occur in the following balance equations that were used to calculate $\mathrm{pH}$ for the experiments containing $\mathrm{NaOH}$ (Equation 4.8) or $\mathrm{HCl}$ (Equation 4.9):

$$
\begin{gathered}
0=m_{H^{+}}-m_{O H^{-}}-m_{S_{f r e e}} \cdot X_{H S^{-}}+m_{N a_{\text {total }}} \cdot X_{N a^{+}}+\sum^{x y z w}(3 x-2 y-2 z+w) \cdot m_{S b_{x} S_{y} O_{z} H_{w}} \\
0=a_{H^{+}} \cdot \gamma_{H^{+}}{ }^{-1}-a_{O H^{-}} \cdot \gamma_{O H^{-}}{ }^{-1}-m_{S_{f r e e}} \cdot X_{H S^{-}}-m_{C l_{\text {total }}} \cdot X_{C l^{-}}+ \\
\sum^{x y z w}(3 x-2 y-2 z+w) \cdot m_{S b_{x} S_{y} O_{z} H_{w}}
\end{gathered}
$$

In these equations, $w, x, y$, and $z$ are variables that define the stoichiometry of various antimony complexes as developed previously in the Methods section of Chapter (2).

The amount of sulfide complexed with antimony was taken into account in Equations (4.5) through (4.7) by using $m S$ free to calculate $m_{H S \text {. }}$ As discussed in the text with Equation (2.22), $m_{S f r e e}$ is the amount of the total sulfide not complexed with antimony and is defined as

$$
m_{S_{\text {free }}}=m_{S_{\text {total }}}-m_{S_{\text {complexed }}}=m_{H_{2} S^{\circ}}+m_{S H^{-}}+m_{N a S H^{\circ}}-\sum^{x y z w} y \cdot m_{S b_{x} S_{y} O_{z} H_{w}}
$$


Table (4.2) Summary of supporting thermodynamic data.

\begin{tabular}{|c|c|c|c|c|c|c|}
\hline Reaction & $70^{\circ} \mathrm{C}$ & $150^{\circ} \mathrm{C}$ & $250^{\circ} \mathrm{C}$ & $350^{\circ} \mathrm{C}$ & $400^{\circ} \mathrm{C}$ & Reference \\
\hline$\overline{\mathrm{H}_{2} \mathrm{O} \Leftrightarrow \mathrm{H}^{+}+\mathrm{OH}^{-}}$ & -12.813 & -11.637 & -11.193 & -12.295 & -22.497 & $\mathrm{a}$ \\
\hline $\mathrm{H}_{2} \mathrm{~S}_{(\mathrm{aq})} \Leftrightarrow \mathrm{H}^{+}+\mathrm{HS}^{-}$ & -6.564 & -6.495 & -7.163 & -8.908 & -18.033 & $\mathrm{~b}$ \\
\hline $\mathrm{NaOH} \cong \Leftrightarrow \mathrm{Na}^{+}+\mathrm{OH}^{-}$ & 0.304 & -0.269 & -0.916 & -1.844 & -5.187 & $\mathrm{c}$ \\
\hline $\mathrm{NaSH} \cong \Leftrightarrow \mathrm{Na}^{+}+\mathrm{HS}^{-}$ & 0.870 & 0.378 & -0.286 & -1.457 & -6.574 & $\mathrm{~d}$ \\
\hline $\mathrm{HCl} \circ \Leftrightarrow \mathrm{H}^{+}+\mathrm{Cl}^{-}$ & 0.702 & 0.411 & -0.422 & -2.234 & -9.868 & $\mathrm{e}$ \\
\hline \multicolumn{7}{|c|}{ Debye-Hückel Parameters } \\
\hline A & 0.5455 & 0.6975 & 0.9594 & 1.9108 & 3.1077 & $\mathrm{f}$ \\
\hline $\mathrm{B}$ & $3.370 \mathrm{E}+07$ & $3.570 \mathrm{E}+07$ & $3.83 \mathrm{E}+07$ & $4.08 \mathrm{E}+07$ & $4.21 \mathrm{E}+07$ & $\mathrm{f}$ \\
\hline Bdot & 0.044 & 0.047 & 0.03 & 0 & 0 & $\mathrm{~g}$ \\
\hline
\end{tabular}
a. Marshall and Franck (1981)
b. Suleimenov and Seward (1997) and modified following Stefánsson and Seward (2004), see text
c. Ho and Palmer (1996)
d. Ho et al. (1994), by analogy with $\mathrm{NaCl}^{\circ}$
e. Ruaya and Seward (1987) up to $100^{\circ} \mathrm{C}$ and Ho et al. (2001) at higher temperatures
f. Helgeson and Kirkham (1974)
g. Helgeson (1969)

$* \log \mathrm{K}$ are at $1 \mathrm{bar}$ to $70^{\circ} \mathrm{C}$, at swvp for 150 to $350^{\circ} \mathrm{C}$, and at 200 bar for $400^{\circ} \mathrm{C}$

$K_{w}, K_{H 2 S}, K_{\mathrm{NaOH}^{\circ}}$, and $K_{\mathrm{NaHS}}{ }^{\circ}$ are defined by Equations (2.17) through (2.20).

The speciation and charge balance calculations were preformed in two iterative loops within the non-linear least squares refinement of stibnite solubility constants. First, the fluid was speciated using an estimated $\mathrm{pH}$ and an initial estimate of the solution's ionic strength. The $\mathrm{pH}$ was then varied until the solution was charged balanced within the fitting constraints $\left(10^{-9}\right.$ to $\left.10^{-10}\right)$ using the Solver add-in to Excel (Fylstra et al., 1998). The new ionic strength calculated from this balanced solution was used to adjust (or re-speciate) the solution model, and the refinement procedure was repeated until the ionic strength of consecutive iterations converged. Charged antimony complexes were included in the calculation of ionic strength, as in Chapter (2), with the addition of an additional term to Equation

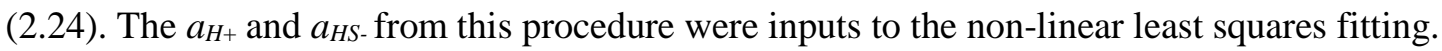

The activity coefficients for charged species were calculated using an extended version of the Debye-Hückel equation (Equation 2.23). The activity coefficients of neutral species were set to unity. The temperature dependence of the ion-independent parameters $A, B$, and $\dot{B}$ (or B-dot) were calculated from polynomial best fits to tabulations of the values in Helgeson (1969) and Helgeson and Kirkham (1974). The pressure dependence of these parameters is small over the pressure range of this study and so was not considered. At and above $300^{\circ} \mathrm{C}$, the $\dot{B}$ parameter was set to zero so that the B-dot extension reduced to the conventional, extended Debye-Hückel equation. The ion size parameter, $\stackrel{a}{\text {, }}$ was assumed to be independent of temperature, and thus the values used were the same as those listed in Chapter (2) for $\mathrm{Na}^{+}, \mathrm{OH}^{-}, \mathrm{HS}^{-}, \mathrm{H}^{+}$and antimony species. A value of $3 \times 10^{-8}$ was used for the ion size parameter of $\mathrm{Cl}^{-}$(Kielland, 1937). 
The sources for the equilibrium constants at the physical conditions of the experiments are summarised in Table (4.2), in which the values are listed for select temperatures. The sources are the same as in Chapter (2) for the ion product of water, the dissociation constant of $\mathrm{NaHS}^{\circ}$ (taken as analogous to $\mathrm{NaCl}^{\circ}$ ), and the dissociation constant of $\mathrm{NaOH}^{\circ}$ (Marshall and Franck, 1981; Ho et al., 1994; Ho and Palmer, 1996). The dissociation constant of $\mathrm{HCl}^{\circ}$ was taken from Ruaya and Seward (1987) for temperatures up to $250^{\circ} \mathrm{C}$. Above $250^{\circ} \mathrm{C}$, a three term density equation from Ho et al. (2001) was used. For the first dissociation constant of $\mathrm{H}_{2} \mathrm{~S}^{\circ}$, the equation at swvp from Suleimenov and Seward (1997) was modified for increased pressure using the molar volume change of the reaction reported by Ellis and McFadden (1972) up to $250^{\circ} \mathrm{C}$. Above $250^{\circ} \mathrm{C}$, a four term density equation was used to extrapolate the disassociation constant to $350^{\circ} \mathrm{C}$ (Mesmer et al., 1988; Stefánsson and Seward, 2004). The density of the fluid was calculated from the measured temperatures and pressures according to the IAPWS-IF97 industrial standard (Wagner et al., 2000; Spang, 2002).

\subsubsection{Fitting of heterogeneous solubility constants}

Determination of the values for heterogeneous solubility constants ( $K_{x y z w}$, Equation 2.6$)$ for different antimony speciation models was completed using a non-linear least squares fitting procedure as described in Chapter (2) in Section (2.2.3), with the exception that $a_{H+}$ was the pH calculated for experimental temperatures rather than the $\mathrm{pH}$ measured at ambient temperature. The inputs to the fitting procedure were $a_{H+}, a_{H S-}$, ionic strength $(I)$, and the measured stibnite solubility (mol kg $\mathrm{Sb}_{\text {total }}$ ). Fits were conducted using data collected at constant temperature, and the values for $K_{x y z w}$ determined from the non-linear least squares fitting were used to recalculate the distribution of aqueous species and the $\mathrm{pH}$. This iterative process was repeated until $K_{x y z w}$ converged and the calculated $\mathrm{pH}$ did not change between successive iterations.

\subsection{Results}

\subsubsection{Attainment of equilibrium}

In preliminary experiments, stibnite solubility was measured at various flow rates at 150 and $200^{\circ} \mathrm{C}$ to evaluate if the system was at equilibrium. A plateau in measured antimony concentration with decreasing flow rate between 3 and $7 \mathrm{ml} \mathrm{min}^{-1}$ flow rate was taken to indicate that the system was at equilibrium and is shown for both temperatures in Figure (4.3). A decrease in antimony

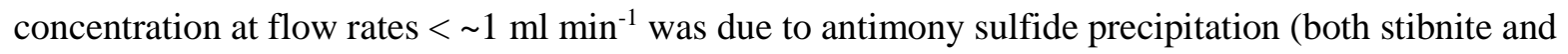
amorphous antimony sulfide) during fluid cooling at the exit to the flow through system. A decrease in concentration at flow rates of $>7 \mathrm{ml} \mathrm{min}^{-1}$ may indicate that the system has not reached equilibrium during the fluid residence time at $150^{\circ} \mathrm{C}$. At temperatures $>150^{\circ} \mathrm{C}$, reaction kinetics were faster and equilibrium was reached at faster flow rates. Flow rates of 4.5 to $5 \mathrm{ml} \mathrm{min}^{-1}$ were used during experiments from 70 to 200 and flow rates of 6 to $7 \mathrm{ml} \mathrm{min}^{-1}$ at higher temperatures, with $7 \mathrm{ml} \mathrm{min}^{-1}$ 
Figure (4.3) Stibnite solubility at different flow rates at $150^{\circ} \mathrm{C}$ (A) and $200^{\circ} \mathrm{C}$ (B). Flow rate test were conducted using slightly alkaline solutions containing moderate sulfide ( $\mathrm{pH} \sim 7.5$ and 0.02 mol $\mathrm{kg}^{-1} \mathrm{~S}^{2-}$ total; Sb94 and Sb97). Error bars are $2 \sigma$ from the median solubility. Data points without error bars are individual measurements.
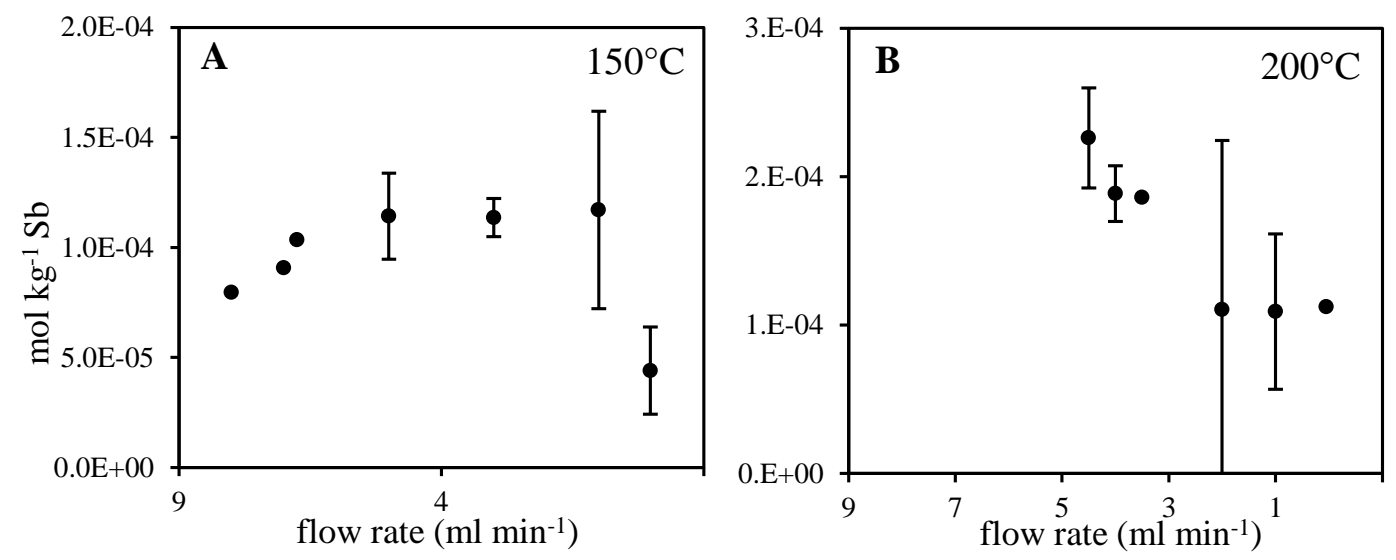

being the fastest flow rate that could be used at 350 to $400^{\circ} \mathrm{C}$ without flashing of the solution during collection into a syringe containing a weighed amount of chilled $\mathrm{NaOH}$ solution.

\subsubsection{Pressure dependence of stibnite solubility from 100 to $350^{\circ} \mathrm{C}$}

Stibnite solubility experiments in this study were generally conducted at slightly above swvp. However, in five experiments, additional measurements of stibnite solubility were taken at higher pressures up to 250 bars to determine the effect of pressure on stibnite solubility in this temperature range. The results of these measurements are shown in Figure (4.4), in which are plotted the stibnite solubilities measured at constant temperature and various pressures for several solutions with different $\mathrm{pH}$ and sulfide concentrations. As can be seen from Figure (4.4), stibnite solubility is independent of pressure within the error of the solubility measurements from 110 to $350^{\circ} \mathrm{C}$.

Figure (4.4) Variation in stibnite solubility with pressure at constant temperature and input fluid conditions for five experiments from 110 to $350^{\circ} \mathrm{C}$. Pressure and antimony concentration error bars are $2 \sigma$.

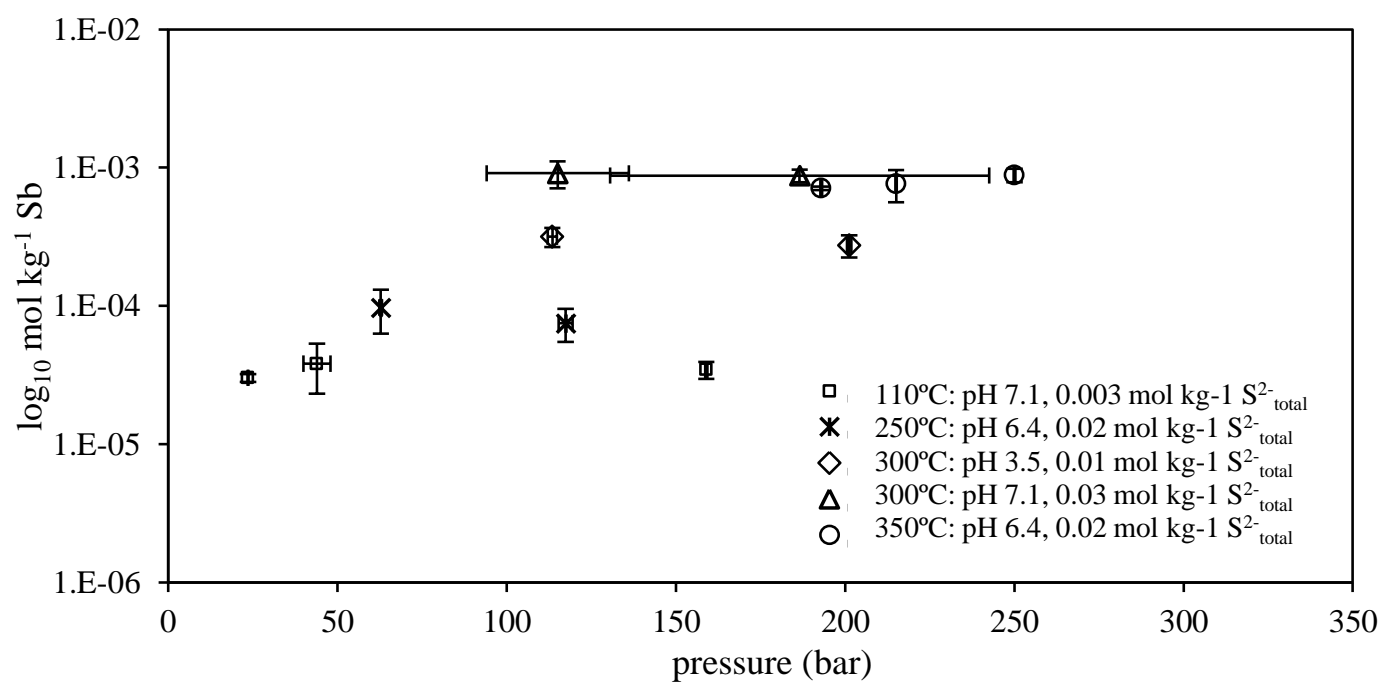


Figure (4.5) Measured stibnite solubility from 70 to $350^{\circ} \mathrm{C}$ plotted with respect to $\mathrm{pH}$ (left) and sulfide concentration (right). Range of sulfide concentrations are indicated by symbols: black circles $\sim 0.003 \mathrm{~mol} \mathrm{~kg}{ }^{-1} \mathrm{~S}^{2-}$ total, open circles $\sim 0.01 \mathrm{~mol} \mathrm{~kg}^{-1} \mathrm{~S}^{2-}$ total, gray squares 0.02 to $0.03 \mathrm{~mol} \mathrm{~kg}^{-1}$ $\mathrm{S}^{2-}$ total, and open diamonds $=0.05$ to $0.06 \mathrm{~mol} \mathrm{~kg}^{-1} \mathrm{~S}^{2-}$ total. Error bars are $2 \sigma$.
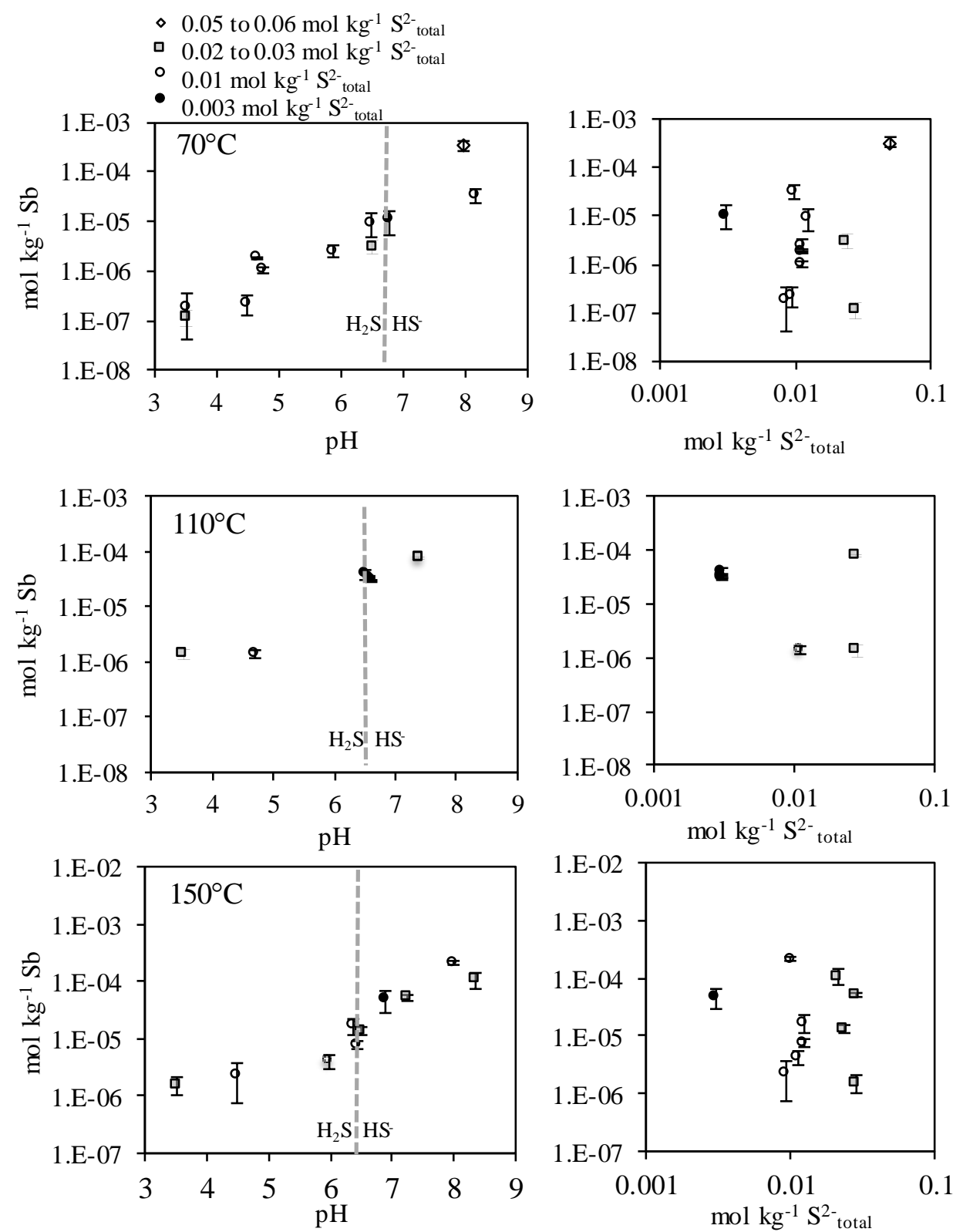

\subsubsection{General changes in stibnite solubility with temperature}

The results from stibnite solubility experiments from 70 to $350^{\circ} \mathrm{C}$ are shown in Figure (4.5), in which measured stibnite solubilities are plotted without projection to constant sulfide or $\mathrm{pH}$. The complete stibnite solubility results are tabulated in Appendix (A). The shape of the stibnite solubility curve with respect to $\mathrm{pH}$ and the dependence of stibnite solubility on sulfide concentration changed as the temperature increased from 70 to $400^{\circ} \mathrm{C}$. From 70 to $150^{\circ} \mathrm{C}$, the general shape of the stibnite solubility curve was similar to that at $30^{\circ} \mathrm{C}$. As at $30^{\circ} \mathrm{C}$, stibnite solubility was independent of $\mathrm{pH}$ at 
Figure (4.5) continued...
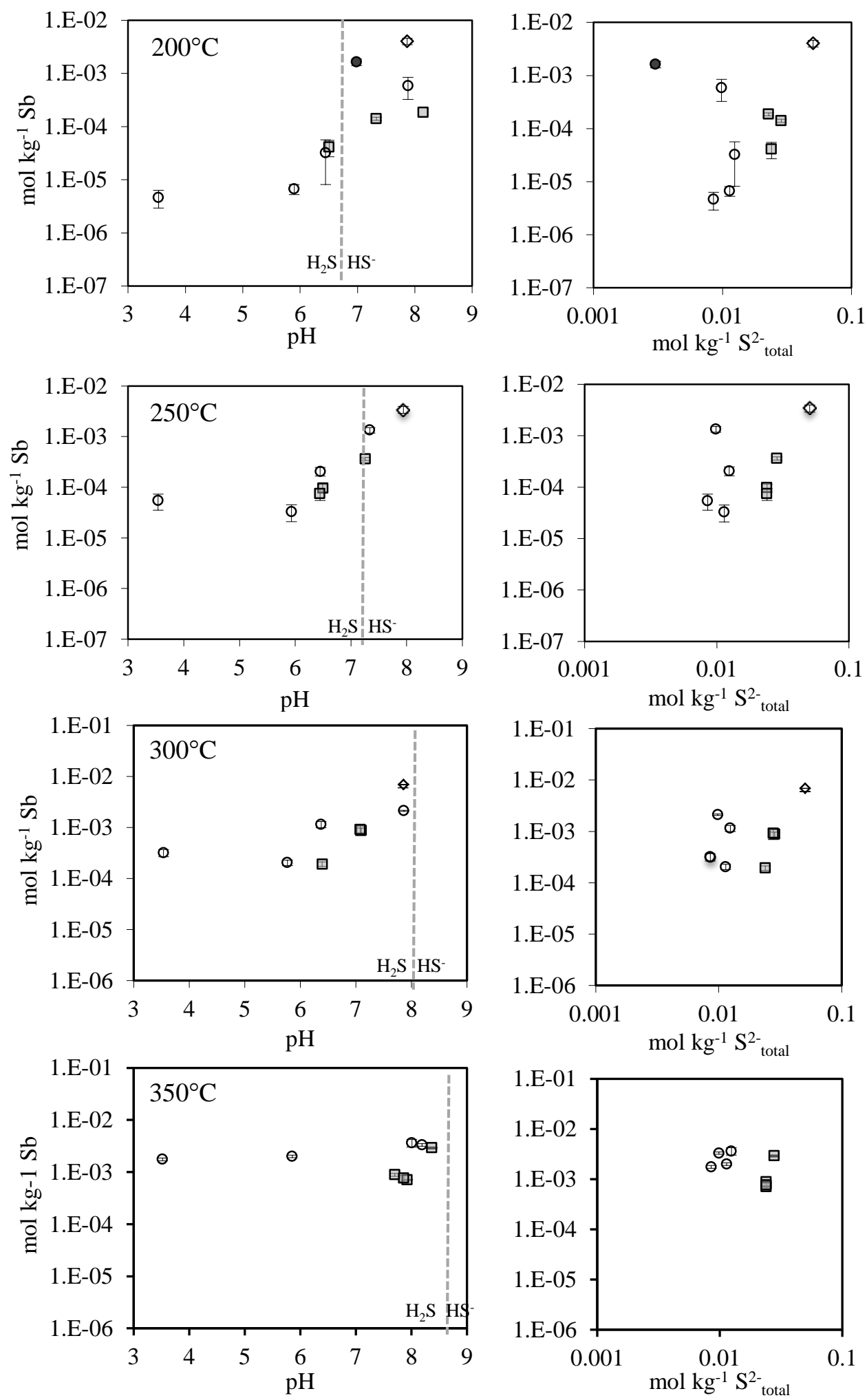
$\mathrm{pH}<5$ at $150^{\circ} \mathrm{C}$, indicating the presence of a neutral complex. At $\mathrm{pH}>5$, stibnite solubility generally increased with increasing $\mathrm{pH}$ but was independent of $\mathrm{pH}$ for a small $\mathrm{pH}$ region around where $\mathrm{pH}=$ pKa of $\mathrm{H}_{2} \mathrm{~S}^{\circ}$. Fitting of this feature required partially protonated antimony-sulfide dimers as at $30^{\circ} \mathrm{C}$. Above $150^{\circ} \mathrm{C}$, the prominence of the plateau in stibnite solubility at $\mathrm{pH}$ near the $\mathrm{pKa}$ of $\mathrm{H}_{2} \mathrm{~S}^{\circ}$ diminished, and at temperatures $\geq 250^{\circ} \mathrm{C}$, it was no longer present. Over the same temperature range, stibnite solubility became negatively rather than positively related to the sulfide concentration across the entire $\mathrm{pH}$ range except for the most alkaline experiments $(\mathrm{pH} \sim 8.5)$. These general patterns suggest that antimony-sulfide dimers (i.e., $\mathrm{HSb}_{2} \mathrm{~S}_{4}{ }^{-}$and $\mathrm{Sb}_{2} \mathrm{~S}_{4}{ }^{2-}$ ) were replaced by $\mathrm{Sb}(\mathrm{OH})_{3}$, and possibly other mixed-ligand complexes, as the temperature increased above $150^{\circ} \mathrm{C}$ at the moderate sulfide concentrations ( 0.01 to $0.02 \mathrm{~mol} \mathrm{~kg}^{-1} \mathrm{~S}^{2-}$ total). At $400^{\circ} \mathrm{C}$, stibnite solubility was 0.015 to 0.016 mol kg-1 Sb (nearly 2000 ppm) at 300 bars. Stibnite solubility in supercritical fluids decreased by approximately two orders of magnitude with a pressure decrease from 300 to 200 bars.

\subsubsection{Fitting of stibnite solubility from 70 to $350^{\circ} \mathrm{C}$}

\section{Stibnite solubility at 70 and $110^{\circ} \mathrm{C}$}

The heterogeneous stibnite solubility reactions relevant to the following discussion are presented in Table (4.3). A complete set of reactions considered in the interpretation of measured solubility curves was presented Table (2.2). Plots of the results for selected fits are shown with the results of fits in Tables (4.4) through (4.8). For the 70 and $110^{\circ} \mathrm{C}$ solubility data, the species $\mathrm{HSb}_{2} \mathrm{~S}_{4}{ }^{-}$ was able to fit most of the experimental data (Table 4.4) except at the high and low pH ends of the data range. Fitting these $\mathrm{pH}$ extremes required a neutral species at $\mathrm{pH}<4$ and a species producing a $\mathrm{Sb} / \mathrm{pH}$ slope $\sim+1$ (i.e., $\mathrm{Sb}_{2} \mathrm{~S}_{4}{ }^{2-}$ ) at $\mathrm{pH}>7.5$ (Fit 70-A). The limited number of solubility experiments at low $\mathrm{pH}$ meant that the Sb-S-O stoichiometry of the neutral complex could not be determined for each

Table (4.3) Summary of heterogeneous stibnite solubility reactions. Reactions included in following tables of fit results (i.e., Tables (4.4) through (4.8)). See Chapter (2) for complete set of aqueous antimony species considered (Table 2.2).

\begin{tabular}{lll}
$\mathbf{K}_{\text {xyzw }}$ & Aqueous antimony species & Reaction \\
\hline \multicolumn{2}{l}{ antimony-hydroxide complexes } \\
$\mathrm{K}_{1033}$ & $\mathrm{Sb}(\mathrm{OH})_{3}$ & \\
$\mathrm{~K}_{1032}$ & $\mathrm{H}_{2} \mathrm{SbO}_{3}{ }^{-}$ & $0.5 \mathrm{Sb}_{2} \mathrm{~S}_{3}+3 \mathrm{H}_{2} \mathrm{O}=\mathrm{Sb}(\mathrm{OH})_{3}+1.5 \mathrm{HS}^{-}+1.5 \mathrm{H}^{+}$ \\
\multicolumn{2}{l}{ antimony-sulfide complexes } & $0.5 \mathrm{Sb}_{2} \mathrm{~S}_{3}+3 \mathrm{H}_{2} \mathrm{O}=\mathrm{H}_{2} \mathrm{SbO}_{3}{ }^{-}+1.5 \mathrm{HS}^{-}+2.5 \mathrm{H}^{+}$ \\
$\mathrm{K}_{2400}$ & $\mathrm{Sb}_{2} \mathrm{~S}_{4}{ }^{2-}$ & \\
$\mathrm{K}_{2401}$ & $\mathrm{HSb}_{2} \mathrm{~S}_{4}{ }^{-}$ & $\mathrm{Sb}_{2} \mathrm{~S}_{3}+\mathrm{HS}^{-}=\mathrm{Sb}_{2} \mathrm{~S}_{4}{ }^{2-}+\mathrm{H}^{+}$ \\
antimony-hydroxide-sulfide (mixed-ligand) complexes \\
$\mathrm{K}_{1211}$ & $\mathrm{HSbS}_{2} \mathrm{O}^{2-}$ & $0.5 \mathrm{Sb}_{2} \mathrm{~S}_{3}+0.5 \mathrm{HS}^{-}+\mathrm{H}_{2} \mathrm{O}=\mathrm{HSbS}_{2} \mathrm{O}^{2-}+1.5 \mathrm{H}^{+}$ \\
$\mathrm{K}_{1212}$ & $\mathrm{H}_{2} \mathrm{SbS}_{2} \mathrm{O}^{-}$ & $0.5 \mathrm{Sb}_{2} \mathrm{~S}_{3}+0.5 \mathrm{HS}^{-}+\mathrm{H}_{2} \mathrm{O}=\mathrm{H}_{2} \mathrm{SbS}_{2} \mathrm{O}^{-}+0.5 \mathrm{H}^{+}$ \\
$\mathrm{K}_{1213}$ & $\mathrm{H}_{3} \mathrm{SbS}_{2} \mathrm{O}$ & $0.5 \mathrm{Sb}_{2} \mathrm{~S}_{3}+0.5 \mathrm{HS}^{-}+\mathrm{H}_{2} \mathrm{O}+0.5 \mathrm{H}^{+}=\mathrm{H}_{3} \mathrm{SbS}_{2} \mathrm{O}$ \\
\hline
\end{tabular}


Table (4.4) Fits of stibnite solubility at 70 and $110^{\circ} \mathrm{C}$. Accompanying each fit are plots of the data and the fit at experimental sulfide concentrations (left), the relative residuals of the fit (middle), and the data and the distribution of species at $0.01 \mathrm{~mol} \mathrm{~kg}^{-1} \mathrm{~S}^{2-}$ total $(r i g h t)$. $\mathrm{K}$ is the equilibrium constant for the appropriate reaction from Table (4.3.), $\sigma$ is one standard deviation, $p$ and $R^{2}$ are fit statistics defined below, and $N$ is the number of data points for each fit.

\begin{tabular}{cclcccccc} 
Fit & Reaction $^{\boldsymbol{a}}$ & Aqueous antimony species & $\mathbf{K}$ & $\boldsymbol{\sigma}$ & $\boldsymbol{p}^{\boldsymbol{b}}$ & $\mathbf{R}^{2 \boldsymbol{c}}$ & $\mathbf{p H}$ range & $\mathbf{N}$ \\
\hline 70-A & $K_{2400}$ & $\mathrm{Sb}_{2} \mathrm{~S}_{4}{ }^{2-}$ & $1.3 \mathrm{E}-11$ & $2.2 \mathrm{E}-11$ & 0.58 & 0.57 & 3.5 to 7.7 & 8 \\
& $K_{2401}$ & $\mathrm{HSb}_{2} \mathrm{~S}_{4}{ }^{-}$ & $6.6 \mathrm{E}-04$ & $2.7 \mathrm{E}-04$ & 0.06 & & & \\
& $K_{1213}$ & $\mathrm{H}_{3} \mathrm{SbS}_{2} \mathrm{O}$ & $1.5 \mathrm{E}-03$ & $1.9 \mathrm{E}-03$ & 0.47 & & &
\end{tabular}
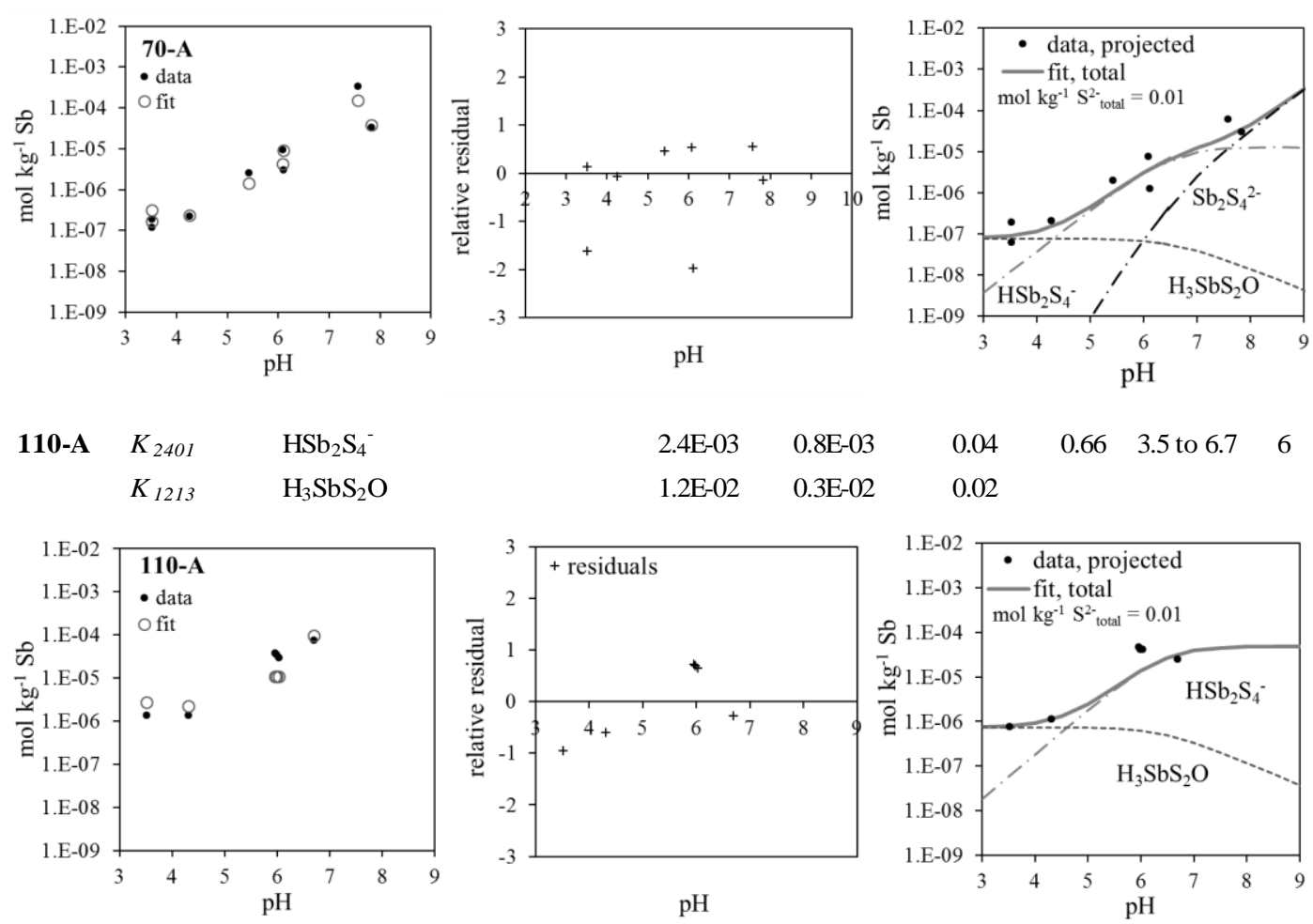

Relative residual is the difference between the fit and measured antimony concentrations normalized to the solubility, i.e. $\left(\mathrm{mol} \mathrm{kg}{ }^{-1} \mathrm{Sb}_{\mathrm{exp}}-\mathrm{mol} \mathrm{kg}^{-1} \mathrm{Sb}_{\mathrm{fit}}\right) / \mathrm{mol} \mathrm{kg}^{-1} \mathrm{Sb}_{\exp }$

${ }^{a} \mathrm{~K}_{\mathrm{xyzw}}$ as defined in Table (4.3)

${ }^{b}$ The $p$ value is $\operatorname{Prob}(\mathrm{t})$ for the null hypothesis that $\mathrm{K}=0$, i.e. values approaching 1 indicate that a species can be removed without changing the fit.

${ }^{c} R^{2}$ is the ratio of variation in the data explained by the fit to the total variation in the data, i.e. $R^{2}=\frac{\sum_{i=1}^{N}\left(\dot{\mathrm{y}}_{i}-\overline{\mathrm{y}}\right)^{2}}{\sum_{i=1}^{N}\left(y_{i}-\overline{\mathrm{y}}\right)^{2}}$, where $y_{i}$
is the antimony concentration of the $i^{\text {th }}$ data point, $\bar{y}$ is the mean of $N$ data points, and $\dot{y}_{i}$ is the fit the the $i^{\text {th }}$ data point.

temperature independently and the species used in the $30^{\circ} \mathrm{C}$ model have been used. Both species $\mathrm{H}_{2} \mathrm{Sb}_{2} \mathrm{~S}_{4}$ and $\mathrm{H}_{3} \mathrm{SbSO}_{2}$ could be used to fit the 70 to $150^{\circ} \mathrm{C}$ data, but the goodness of fit statistics of fits with $\mathrm{H}_{2} \mathrm{Sb}_{2} \mathrm{~S}_{4}$ or $\mathrm{H}_{3} \mathrm{SbSO}_{2}$ were not as good as those with $\mathrm{H}_{3} \mathrm{SbS}_{2} \mathrm{O}$ (fits not shown). The experimental data at $70^{\circ} \mathrm{C}$ barely extended up to the alkaline $\mathrm{pH}$ where $\mathrm{Sb}_{2} \mathrm{~S}_{4}{ }^{2-}$ was present and so the fitted value for the equilibrium constant for $\mathrm{Sb}_{2} \mathrm{~S}_{4}{ }^{2-}\left(K_{2400}\right)$ has a larger uncertainty than at other temperatures.

Attempts to include $\mathrm{H}_{2} \mathrm{Sb}_{2} \mathrm{~S}_{5}{ }^{2-}$ in fits of $70^{\circ} \mathrm{C}$ and higher temperature data failed because the solubility versus $\mathrm{pH}$ slope which the species produces at $\mathrm{pH}<\mathrm{pKa}$ of $\mathrm{H}_{2} \mathrm{~S}^{o}$ (i.e., a $\mathrm{Sb} / \mathrm{pH}$ slope $=+2$ ) was not representative of the data. A solubility curve using $\mathrm{H}_{2} \mathrm{Sb}_{2} \mathrm{~S}_{5}{ }^{2-}$ has a +2 slope at $\mathrm{pH}<\mathrm{pKa}$ of $\mathrm{H}_{2} \mathrm{~S}$, but the experimental curve was best fit by species with a +1 slope from $\mathrm{pH}=5$ to 7 (i.e., by a 
singly charged negative species at $\mathrm{pH}<\mathrm{pKa}$ of $\mathrm{H}_{2} \mathrm{~S}^{\circ}$ ). At $70^{\circ} \mathrm{C}$, fits including singly charged complexes other than $\mathrm{HSb}_{2} \mathrm{~S}_{4}^{-}$(i.e., $\mathrm{H}_{2} \mathrm{SbS}_{2} \mathrm{O}^{-}$and $\mathrm{H}_{2} \mathrm{SbS}_{3}{ }^{-}$) did not improve the quality of the fit (i.e., $\mathrm{H}_{2} \mathrm{SbS}_{3}{ }^{-}+\mathrm{SbS}_{3}{ }^{3-}$ ) or they were unable to fit the data in the alkaline region (i.e., $\mathrm{H}_{2} \mathrm{SbS}_{2} \mathrm{O}^{-}$). Thus, $\mathrm{Sb}_{2} \mathrm{~S}_{4}{ }^{2-}$ and $\mathrm{HSb}_{2} \mathrm{~S}_{4}{ }^{-}$are considered to be the major aqueous antimony species at $70^{\circ} \mathrm{C}$ at moderate sulfide concentrations $\left(0.01\right.$ to $\left.0.02 \mathrm{~mol} \mathrm{~kg}^{-1}\right)$ and at $\mathrm{pH}=4$ to 8 .

For a limited number of experiments $(\mathrm{N}=6)$, stibnite solubility was also measured at $110^{\circ} \mathrm{C}$. The $\mathrm{pH}$ range of these experiments did not extend high enough to include $\mathrm{Sb}_{2} \mathrm{~S}_{4}{ }^{2-}$, and fits of these experiments were used to improve the interpolation of equilibrium constants for $\mathrm{HSb}_{2} \mathrm{~S}_{4}{ }^{-}$and $\mathrm{H}_{3} \mathrm{SbS}_{2} \mathrm{O}$ between 70 and $150^{\circ} \mathrm{C}$ (Fit (110-A) in Table (4.4)).

\section{Stibnite solubility from 150 to $250^{\circ} \mathrm{C}$}

At $150^{\circ} \mathrm{C}$, the inclusion of $\mathrm{HSb}_{2} \mathrm{~S}_{4}{ }^{-}$in the model produced a good fit to the stibnite solubility data between $\mathrm{pH} \approx 5$ to 7 and $\mathrm{Sb}_{2} \mathrm{~S}_{4}{ }^{2-}$ contributed significantly at $\mathrm{pH}>8$, but fitting of the data from experiments with mildly acidic and alkaline fluids required the addition of antimony species with a negative dependence on the sulfide concentration (i.e., $\mathrm{Sb}(\mathrm{OH})_{3}, \mathrm{H}_{3} \mathrm{SbSO}_{2}$, or $\mathrm{H}_{2} \mathrm{SbSO}_{2}{ }^{-}$). The preferred speciation model for stibnite solubility at $150^{\circ} \mathrm{C}$ is shown in Table (4.5). In this fit (Fit 150A), four aqueous antimony species are responsible for stibnite solubility: $\mathrm{Sb}_{2} \mathrm{~S}_{4}{ }^{2-}, \mathrm{HSb}_{2} \mathrm{~S}_{4}^{-}, \mathrm{H}_{3} \mathrm{SbS}_{2} \mathrm{O}$, and $\mathrm{Sb}(\mathrm{OH})_{3}$. This speciation model is similar to the speciation model for 30 and $70^{\circ} \mathrm{C}$ (i.e., $\mathrm{Sb}_{2} \mathrm{~S}_{4}{ }^{2-}$ $\left.+\mathrm{HSb}_{2} \mathrm{~S}_{4}^{-}+\mathrm{H}_{3} \mathrm{SbS}_{2} \mathrm{O}\right)$ with the addition of $\mathrm{Sb}(\mathrm{OH})_{3}$, which contributed significantly to stibnite solubility at $\mathrm{pH}<5$ and at $\mathrm{pH}>7$ when $\mathrm{S}^{2-}$ total $\leq 0.02 \mathrm{~mol} \mathrm{~kg}^{-1}$. Previously published values (Spycher and Reed, 1989; Akinifiyev et al., 1994; Shikina and Zotov, 1999) for stibnite solubility in terms of $\mathrm{Sb}(\mathrm{OH})_{3}$ (Reaction (4.2), $\left.K_{1033}\right)$ ranged from $3.16 \times 10^{-21}$ to $1.7 \times 10^{-20}$ at $150^{\circ} \mathrm{C}$, as shown graphically in Figure (4.1). The value obtained in this study is $K_{1033}=2.2 \times 10^{-19}$ (from Fit 150-A).

At $150^{\circ} \mathrm{C}$, there was one experiment and only one sulfide concentration at strongly alkaline conditions. Thus, the Sb-S stoichiometry of the species present here could not be determined uniquely from the data. The species $\mathrm{Sb}_{2} \mathrm{~S}_{4}{ }^{2-}$ was selected at alkaline $\mathrm{pH}$ because $\mathrm{HSb}_{2} \mathrm{~S}_{4}$ - produced the best fits to the circumneutral region and $\mathrm{Sb}_{2} \mathrm{~S}_{4}{ }^{2-}$ was necessary to reproduce stibnite solubility in the alkaline region at 200 and $250^{\circ} \mathrm{C}$.

To confirm if $\mathrm{HSb}_{2} \mathrm{~S}_{4}{ }^{-}$is still the best species to reproduce the distinctive shape of the stibnite solubility curve at $\mathrm{pH} \approx \mathrm{pKa}$ of $\mathrm{H}_{2} \mathrm{~S}$, fits using other singly charged species (i.e., $\mathrm{H}_{2} \mathrm{SbS}_{2} \mathrm{O}^{-}$and $\mathrm{H}_{2} \mathrm{SbS}_{3}{ }^{-}$) were completed at 150,200 , and $250^{\circ} \mathrm{C}$. An example of such fits at $150^{\circ} \mathrm{C}$ follow Fit (150A) in Table (4.5). A good fit could be obtained with the $\mathrm{H}_{x} \mathrm{SbS}_{2} \mathrm{O}^{3-x}$ series (i.e., $\mathrm{H}_{3} \mathrm{SbS}_{2} \mathrm{O}, \mathrm{H}_{2} \mathrm{SbS}_{2} \mathrm{O}^{-}$, and $\mathrm{HSbS}_{2} \mathrm{O}^{2-} ;$ Fit $150-\mathrm{B}$ ), but fits using these species diverged from the measured solubility data at $\mathrm{pH}>7$ both at 150 and at $200^{\circ} \mathrm{C}$. This is because species $\mathrm{H}_{2} \mathrm{SbS}_{2} \mathrm{O}^{-}$was unable to reproduce the change in the slope of stibnite solubility versus $\mathrm{pH}$ curve at neutral $\mathrm{pH}$ and consistently overestimated the stibnite solubility at $\mathrm{pH}>7$. As a result, the relative residuals from Fit (150-B) were all negatively biased at $\mathrm{pH}>6$ (see the middle plot accompanying Fit (150-B)). In contrast, the fit at $150^{\circ} \mathrm{C}$ using $\mathrm{HSb}_{2} \mathrm{~S}_{4}^{-}$produced a random distribution of residuals across the experimental $\mathrm{pH}$ range. Combinations 
Table (4.5) Preferred fit of stibnite solubility at $150^{\circ} \mathrm{C}(150-\mathrm{A})$ and fits demonstrating misfit of speciation models including $\mathrm{H}_{2} \mathrm{SbS}_{2} \mathrm{O}^{-}(150-\mathrm{B})$ and $\mathrm{H}_{2} \mathrm{SbS}_{3}^{-}$(150-C). Accompanying each fit are plots of the data and the fit at experimental sulfide concentrations (left), the relative residuals of the fit (middle), and the data and the distribution of species at $0.01 \mathrm{~mol} \mathrm{~kg}^{-1} \mathrm{~S}^{2-}$ total $(r i g h t) . \mathrm{K}$ is the equilibrium constant for the appropriate reaction from Table (4.3.), $\sigma$ is one standard deviation, $p$ and $R^{2}$ are fit statistics defined in Table (4.4), and $N$ is the number of data points for each fit.

\begin{tabular}{cclcccccc} 
Fit & Reaction $^{\boldsymbol{a}}$ & Aqueous antimony species & $\mathbf{K}$ & $\boldsymbol{\sigma}$ & $\boldsymbol{p}$ & $\mathbf{R}^{2}$ & $\mathbf{p H}$ range & $\mathbf{N}$ \\
\hline $\mathbf{1 5 0}-\mathrm{A}$ & $K_{2400}$ & $\mathrm{Sb}_{2} \mathrm{~S}_{4}{ }^{2-}$ & $2.3 \mathrm{E}-11$ & $1.0 \mathrm{E}-11$ & 0.07 & 0.99 & 3.5 to 7.8 & 9 \\
& $K_{2401}$ & $\mathrm{HSb}_{2} \mathrm{~S}_{4}{ }^{-}$ & $9.1 \mathrm{E}-04$ & $1.0 \mathrm{E}-04$ & 0.0002 & & & \\
& $K_{1213}$ & $\mathrm{H}_{3} \mathrm{SbS}_{2} \mathrm{O}$ & $1.5 \mathrm{E}-02$ & $0.6 \mathrm{E}-02$ & 0.05 & & & \\
& $K_{1033}$ & $\mathrm{Sb}(\mathrm{OH})_{3}$ & $2.0 \mathrm{E}-19$ & $0.3 \mathrm{E}-19$ & 0.002 & & &
\end{tabular}
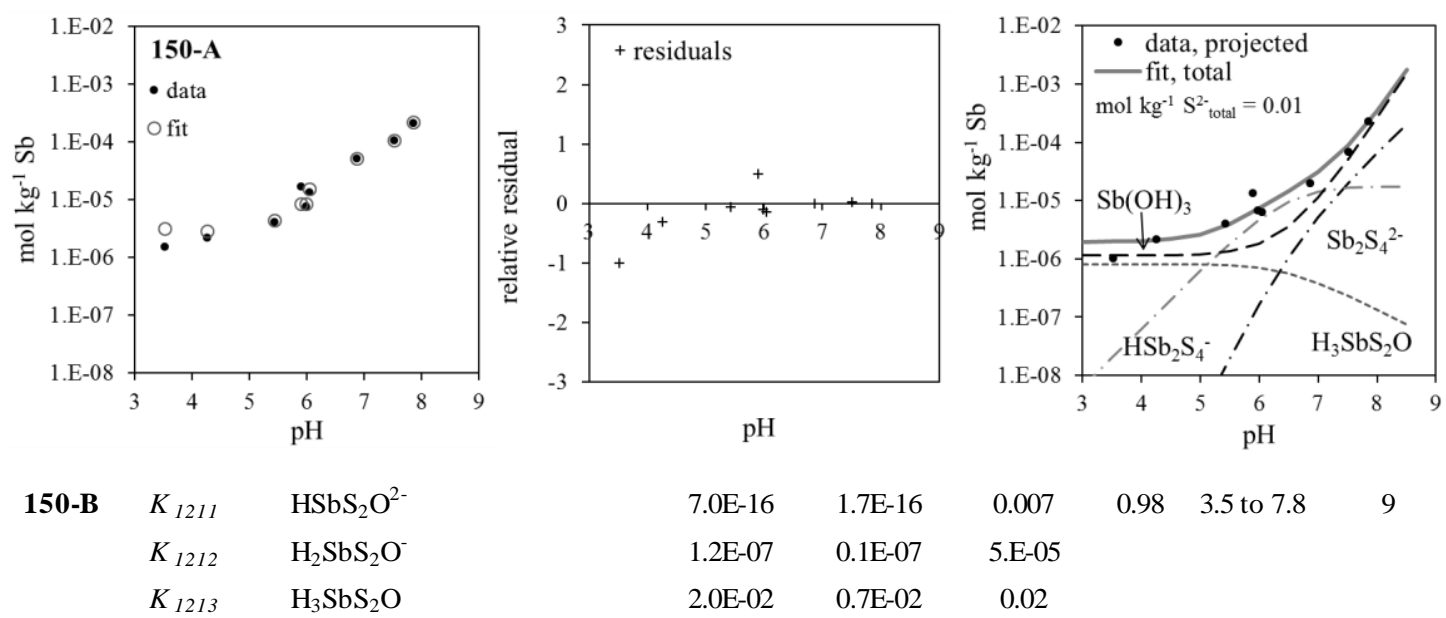

7.0E-16

1.7E-16

0.007

$0.98 \quad 3.5$ to 7.8

$1.2 \mathrm{E}-07$

$0.1 \mathrm{E}-07$

5.E-05

2.0E-02

0.7E-02

0.02
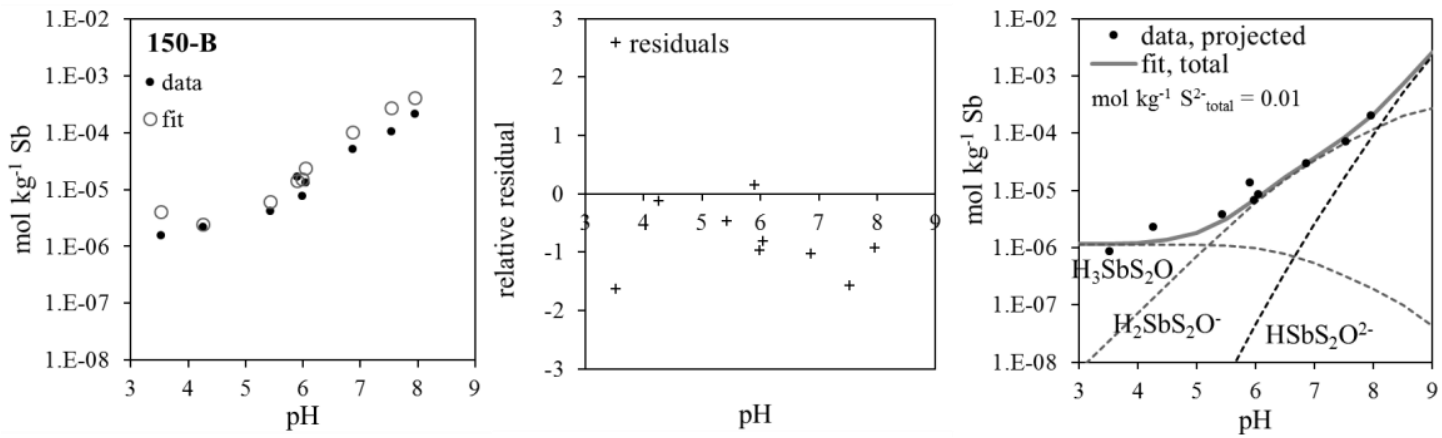

Relative residual is the difference between the fit and measured antimony concentrations normalized to the solubility, i.e. $\left(\mathrm{mol} \mathrm{kg}{ }^{-1} \mathrm{Sb}_{\text {exp }}-\mathrm{mol} \mathrm{kg}{ }^{-1} \mathrm{Sb}_{\mathrm{fit}}\right) / \mathrm{mol} \mathrm{kg}^{-1} \mathrm{Sb}_{\mathrm{exp}}$

${ }^{a} \mathrm{~K}_{\mathrm{xyzw}}$ as defined in Table (4.3)

of partially $\mathrm{Sb}-\mathrm{S}$ monomers $\left(\mathrm{H}_{3} \mathrm{SbS}_{3}{ }^{\mathrm{x}-3}\right)$ produced fits with poor statistics relative to fits which included $\mathrm{HSb}_{2} \mathrm{~S}_{4}$ -

At $200^{\circ} \mathrm{C}$, fits including $\mathrm{Sb}(\mathrm{OH})_{3}$ and $\mathrm{HSb}_{2} \mathrm{~S}_{4}{ }^{-}$were able to fit all of the data from $\mathrm{pH}=3.5$ to 8 except for in the most alkaline solutions containing the highest sulfide concentration (Table 4.6). This individual point at $\mathrm{pH}=7.9$ required the addition of a second antimony-sulfide complex, i.e., $\mathrm{Sb}_{2} \mathrm{~S}_{4}{ }^{2-}$ or $\mathrm{SbS}_{3}{ }^{3-}$ which produced fits of very similar quality. The dimer $\mathrm{Sb}_{2} \mathrm{~S}_{4}{ }^{2-}$ was selected because it produced the best fits to stibnite solubility from 30 to $150^{\circ} \mathrm{C}$ and because the value for $K_{2400}$ at $200^{\circ} \mathrm{C}$ was consistent with how the value for $\mathrm{K}_{2400}$ changed at lower and higher temperatures (Fit 200-A). 
Table (4.6) Fit stibnite solubility at $200^{\circ} \mathrm{C}$. Accompanying each fit are plots of the data and the fit at experimental sulfide concentrations (left), the relative residuals of the fit (middle), and the data and the distribution of species at $0.01 \mathrm{~mol} \mathrm{~kg}^{-1} \mathrm{~S}^{2-}$ total $($ right $) . \mathrm{K}$ is the equilibrium constant for the appropriate reaction from Table (4.3.), $\sigma$ is one standard deviation, $p$ and $R^{2}$ are fit statistics defined in Table (4.4), and $N$ is the number of data points for each fit.

\begin{tabular}{ccccccccc} 
Fit & Reaction $^{\boldsymbol{a}}$ & Aqueous antimony species & $\mathbf{K}$ & $\boldsymbol{\sigma}$ & $\boldsymbol{p}$ & $\mathbf{R}^{\mathbf{2}}$ & $\mathbf{p H}$ range & $\mathbf{N}$ \\
\hline 200-A & $K_{2400}$ & $\mathrm{Sb}_{2} \mathrm{~S}_{4}{ }^{2-}$ & $3.4 \mathrm{E}-11$ & $2.6 \mathrm{E}-11$ & 0.25 & 0.92 & 3.5 to 7.9 & 8 \\
& $K_{2401}$ & $\mathrm{HSb}_{2} \mathrm{~S}_{4}{ }^{-}$ & $2.3 \mathrm{E}-03$ & $1.1 \mathrm{E}-03$ & 0.09 & & & \\
& $K_{1033}$ & $\mathrm{Sb}(\mathrm{OH})_{3}$ & $2.9 \mathrm{E}-19$ & $3.0 \mathrm{E}-19$ & 0.37 & & &
\end{tabular}
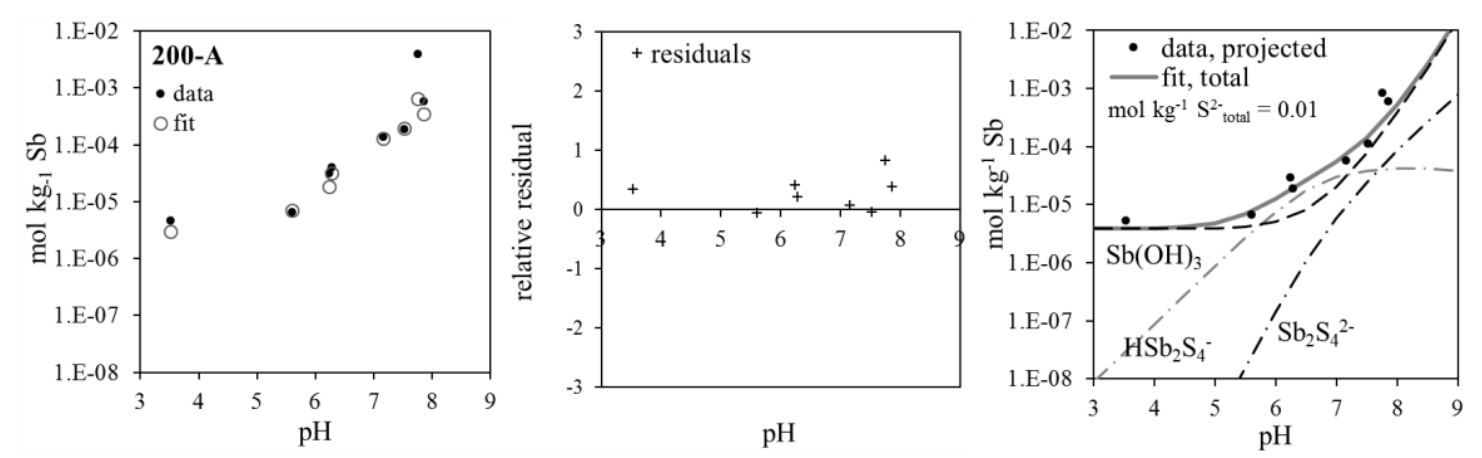

Relative residual is the difference between the fit and measured antimony concentrations normalized to the solubility, i.e. $\left(\mathrm{mol} \mathrm{kg}{ }^{-1} \mathrm{Sb}_{\text {exp }}-\mathrm{mol} \mathrm{kg}^{-1} \mathrm{Sb}_{\text {fit }}\right) / \mathrm{mol} \mathrm{kg}^{-1} \mathrm{Sb}_{\text {exp }}$

${ }^{a} \mathrm{~K}_{\mathrm{xyzw}}$ as defined in Table (4.3)

The value for $K_{1033,200^{\circ} \mathrm{C}}=2.8 \times 10^{-19}$ from this study is very similar to the published value of $K_{1033}=$ $1.9 \times 10^{-19}$ of Akinifiyev et al. (1994).

At $250^{\circ} \mathrm{C}$, a speciation model considering $\mathrm{Sb}(\mathrm{OH})_{3}$ as the only species contributing to stibnite solubility produced a fit with $R^{2}=0.52$ (Fit not shown in Table (4.7)). The antimonous acid species, $\mathrm{Sb}(\mathrm{OH})_{3}$, can account for all of the dissolved antimony at $\mathrm{pH}<7$ and at $\mathrm{pH}=7.8$ in solutions with $0.01 \mathrm{~mol} \mathrm{~kg}^{-1} \mathrm{~S}^{2-}{ }_{\text {total. }}$. However, stibnite solubility at $\mathrm{pH}=7.8$ with a sulfide concentration of $\sim 0.05$ mol kg-1 $\mathrm{S}^{2-}$ total and between $\mathrm{pH}=6.5$ to 7.5 could not be fit with $\mathrm{Sb}(\mathrm{OH})_{3}$ alone, and these experiments required a speciation model containing two partially deprotonated, dimeric antimonysulfide complexes. A speciation model including $\mathrm{Sb}(\mathrm{OH})_{3}, \mathrm{HSb}_{2} \mathrm{~S}_{4}{ }^{-}$, and $\mathrm{Sb}_{2} \mathrm{~S}_{4}{ }^{2-}$ produced the best fit in terms of both $R^{2}$ and $p$ values (Fit 250-A) and is the preferred fit.

Other combinations of antimony-sulfide dimers and monomers, including $\mathrm{H}_{2} \mathrm{SbSO}_{2}{ }^{-}$and $\mathrm{H}_{2} \mathrm{SbS}_{2} \mathrm{O}^{-}$, did not improve fit statistics. The speciation models with mixed-ligand monomers were able to partially fit the data because, although $\mathrm{HSb}_{2} \mathrm{~S}_{4}{ }^{-}$was the predominate species $\mathrm{pH}=5$ to 7.5 , $\mathrm{Sb}(\mathrm{OH})_{3}$ contributed up to $\sim 30 \%$ to the total antimony concentration in this $\mathrm{pH}$ range at 200 and $250^{\circ} \mathrm{C}$. As a result, intermediate species with lesser sulfide dependence than $\mathrm{HSb}_{2} \mathrm{~S}_{4}{ }^{-}$could produce moderately good fits to the data. However, these species did not produce the best fits to the data, as was demonstrated with Fit (150-B), in which $\mathrm{H}_{2} \mathrm{SbS}_{2} \mathrm{O}^{-}$consistently over-estimated stibnite solubility at higher $\mathrm{pH}$ values. The dimer $\mathrm{HSb}_{2} \mathrm{~S}_{4}{ }^{-}$fitted the circumneutral region more accurately. It was concluded that the good fit statistics which could be produced by a mixed-ligand monomer (e.g., 
Table (4.7) Fit of stibnite solubility at $250^{\circ} \mathrm{C}$. Accompanying each fit are plots of the data and the fit at experimental sulfide concentrations (left), the relative residuals of the fit (middle), and the data and the distribution of species at $0.01 \mathrm{~mol} \mathrm{~kg}^{-1} \mathrm{~S}^{2-}$ total $(r i g h t) . \mathrm{K}$ is the equilibrium constant for the appropriate reaction from Table (4.3.), $\sigma$ is one standard deviation, $p$ and $R^{2}$ are fit statistics defined in Table (4.4), and $N$ is the number of data points for each fit.

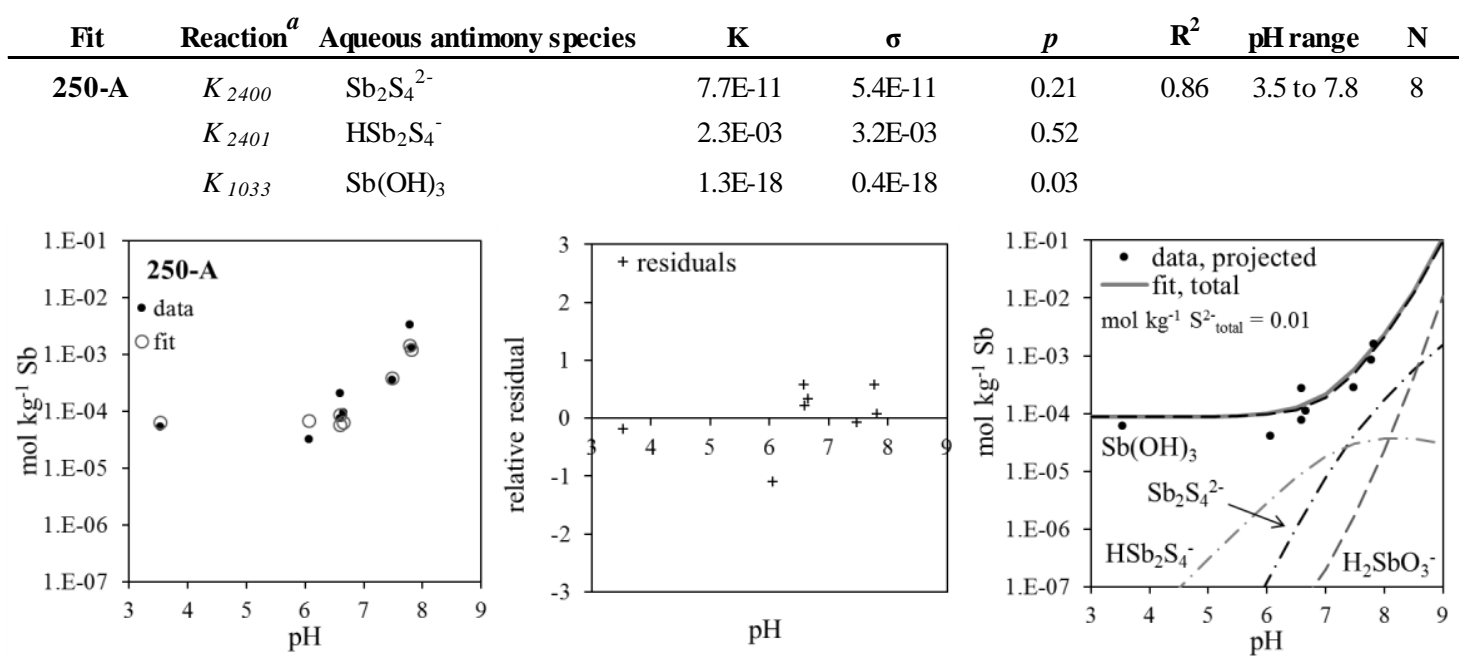

Relative residual is the difference between the fit and measured antimony concentrations normalized to the solubility, i.e. $\left(\mathrm{mol} \mathrm{kg}-1 \mathrm{Sb}_{\text {exp }}-\mathrm{mol} \mathrm{kg}^{-1} \mathrm{Sb}_{\mathrm{fit}}\right) / \mathrm{mol} \mathrm{kg}^{-1} \mathrm{Sb}_{\text {exp }}$

${ }^{a} \mathrm{~K}_{\mathrm{xyzw}}$ as defined in Table (4.3)

$\mathrm{H}_{2} \mathrm{SbS}_{2} \mathrm{O}^{-}$) were the result of both $\mathrm{Sb}(\mathrm{OH})_{3}$ and $\mathrm{HSb}_{2} \mathrm{~S}_{4}{ }^{-}$being present in significant proportions rather than evidence for the predominance of a single intermediate species. The value of $K_{1033}=1.3 \times 10^{-18}$ at $250^{\circ} \mathrm{C}$ from this study is in reasonable agreement with values for this equilibrium constant of $K_{1033}=$ $7.5 \times 10^{-19}$ and $K_{1033}=1.2 \times 10^{-18}$ reported by Akinifiyev et al. (1994) and Shikina and Zotov (1999), respectively.

\section{Stibnite solubility at 300 and $350^{\circ} \mathrm{C}$}

Stibnite solubility at 300 and $350^{\circ} \mathrm{C}$ continued the trend starting at $150^{\circ} \mathrm{C}$ of a diminishing importance of the antimony-sulfide complexes and an increasing predominance of $\mathrm{Sb}(\mathrm{OH})_{3}$. The preferred speciation model and plots of their fits are shown in Table (4.8). The preferred speciation model includes $\mathrm{Sb}_{2} \mathrm{~S}_{4}{ }^{2-}, \mathrm{Sb}(\mathrm{OH})_{3}$, and $\mathrm{H}_{2} \mathrm{SbO}_{2}{ }^{-}$(Fits (300-A) and (350-A)). The $\mathrm{pH}$ at which $\mathrm{Sb}(\mathrm{OH})_{3}$ deprotonates to form $\mathrm{H}_{2} \mathrm{SbO}_{3}{ }^{-}$decreases from 11.82 at $30^{\circ} \mathrm{C}$ to 9.88 at $350^{\circ} \mathrm{C}$ (Zakaznova-Herzog and Seward, 2006), and as a result, $\mathrm{H}_{2} \mathrm{SbO}_{3}{ }^{-}$makes a larger contribution to the dissolved antimony in alkaline fluids at higher temperatures, and it was therefore included in the 300 and $350^{\circ} \mathrm{C}$ fits. As in the $30^{\circ} \mathrm{C}$ dionised water experiments, this was done by adding $K_{1032}$ as a parameter dependent on $K_{1033}$. Thus, the addition of $\mathrm{H}_{2} \mathrm{SbO}_{3}{ }^{-}$did not increase the number of independent variables in the fitting equation. The value for the $\mathrm{pKa}$ of $\mathrm{Sb}(\mathrm{OH})_{3}$ has not been determined at $350^{\circ} \mathrm{C}$, but was estimated to be 9.85 based on Zakaznova-Herzog and Seward's (2006) spectroscopic measurements from 25 to $300^{\circ} \mathrm{C}$. The deprotonated antimonous acid species, $\mathrm{H}_{2} \mathrm{SbO}_{3}{ }^{-}$, contributed $\leq 1 \%$ and $\leq 2 \%$ of the total dissolved antimony in the experiments at 300 and $350^{\circ} \mathrm{C}$, respectively. 
Table (4.8) Fits of stibnite solubility at 300 and $350^{\circ}$ C. Fits (300-A) and (350-A) are the preferred speciation models. Fit (300-B), which used antimonous acid species only, demonstrates that $\mathrm{Sb}(\mathrm{OH})_{3}$ is responsible for stibnite solubility. Accompanying each fit are plots of the data and the fit at experimental sulfide concentrations (left), the relative residuals of the fit (middle), and the data and the distribution of species at $0.01 \mathrm{~mol} \mathrm{~kg}^{-1} \mathrm{~S}^{2-}$ total $($ right). $\mathrm{K}$ is the equilibrium constant for the appropriate reaction from Table (4.3.), $\sigma$ is one standard deviation, $p$ and $R^{2}$ are fit statistics defined in Table (4.4), and $N$ is the number of data points for each fit.

\begin{tabular}{ccccccccc} 
Fit & Reaction $^{\boldsymbol{a}}$ & Aqueous antimony species & $\mathbf{K}$ & $\boldsymbol{\sigma}$ & $\boldsymbol{p}$ & $\mathbf{R}^{2}$ & pH range & $\mathbf{N}$ \\
\hline 300-A & $K_{2400}$ & $\mathrm{Sb}_{2} \mathrm{~S}_{4}{ }^{2-}$ & $1.7 \mathrm{E}-10$ & $0.5 \mathrm{E}-11$ & 0.01 & 0.91 & 3.5 to 8 & 9 \\
& $K_{1033}$ & $\mathrm{Sb}(\mathrm{OH})_{3}$ & $1.3 \mathrm{E}-18$ & $0.2 \mathrm{E}-18$ & $4 . \mathrm{E}-04$ & & & \\
& $K_{1032}$ & $\mathrm{H}_{2} \mathrm{SbO}_{3}{ }^{-}$ & $1.7 \mathrm{E}-28$ & dependent on $K_{1033}$ & & &
\end{tabular}
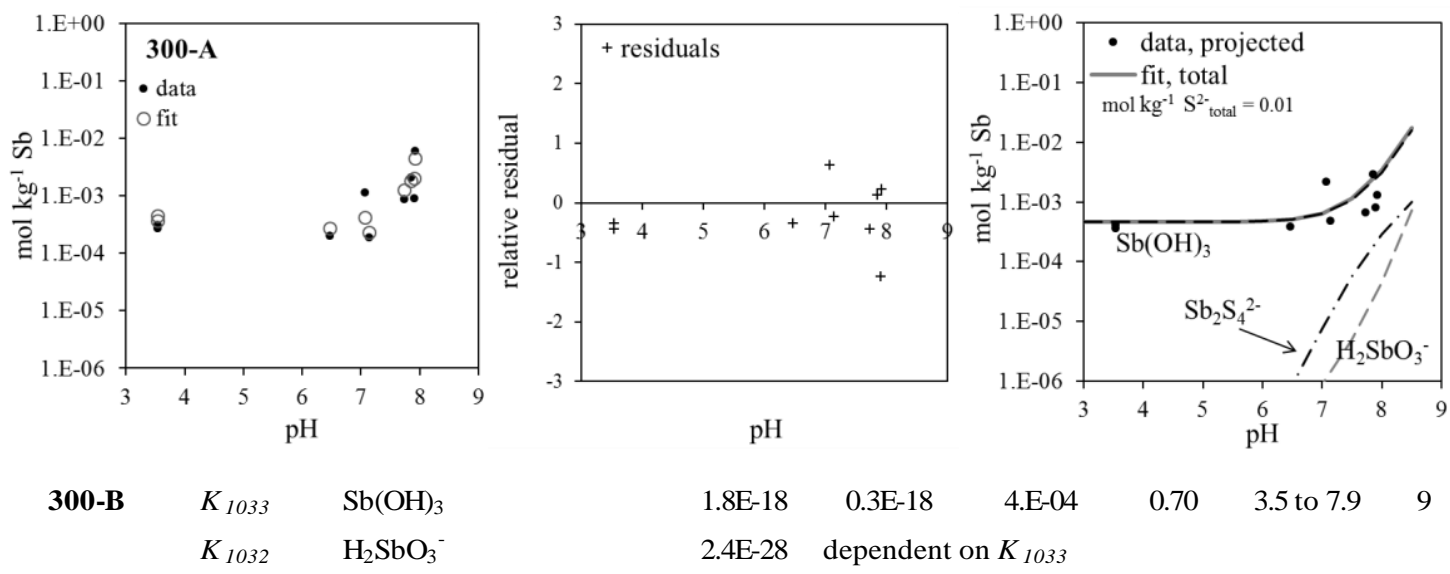

\section{E-04}

$0.70 \quad 3.5$ to $7.9 \quad 9$
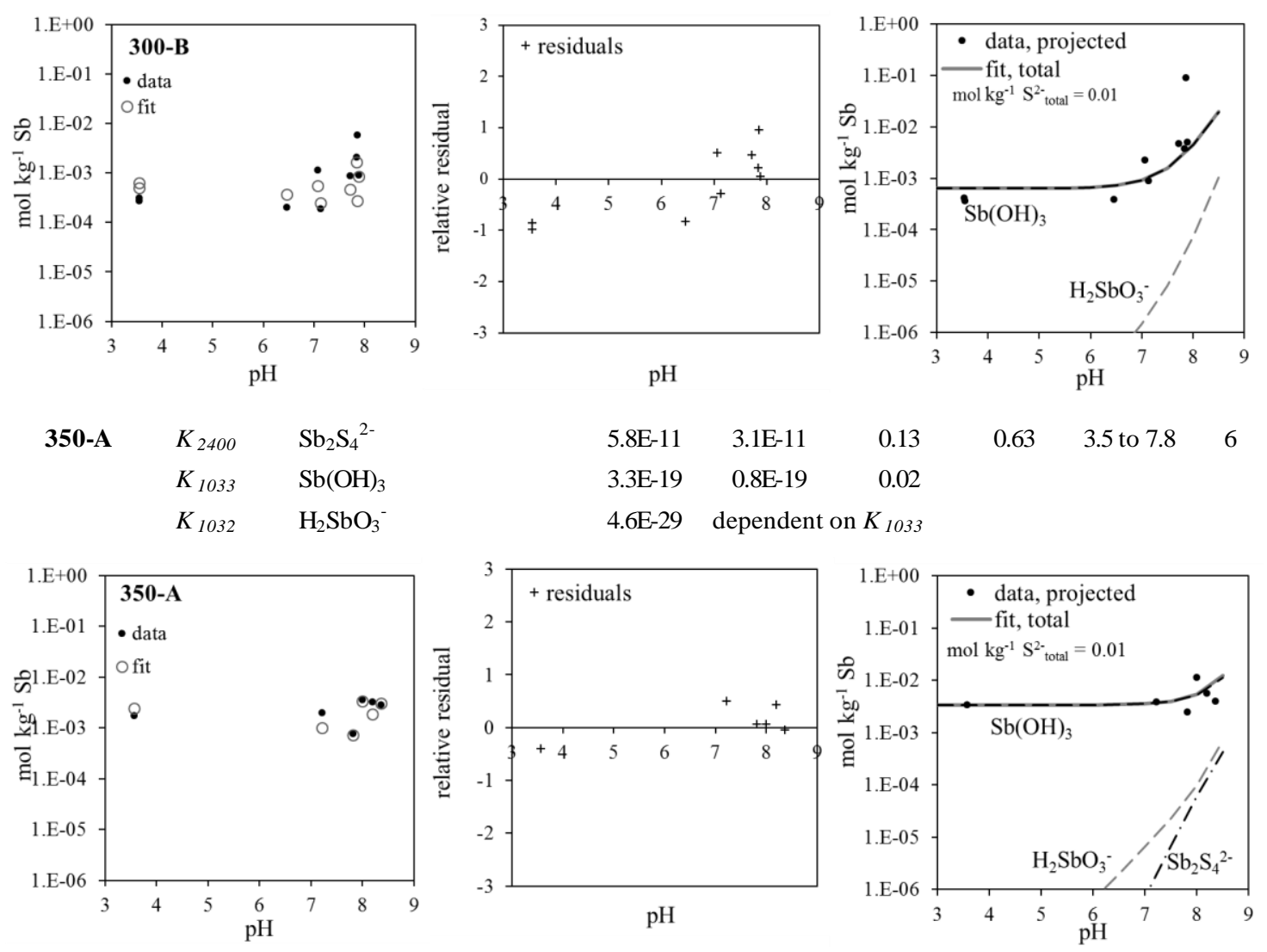

Relative residual is the difference between the fit and measured antimony concentrations normalized to the solubility, i.e. (mol $\mathrm{kg}^{-1}$ $\left.\mathrm{Sb}_{\text {exp }}-\mathrm{mol} \mathrm{kg}^{-1} \mathrm{Sb}_{\mathrm{fit}}\right) / \mathrm{mol} \mathrm{kg}^{-1} \mathrm{Sb}_{\text {exp }}$

${ }^{a} \mathrm{~K}_{\mathrm{xyzw}}$ as defined in Table (4.3) 
At 300 and $350^{\circ} \mathrm{C}, \mathrm{Sb}(\mathrm{OH})_{3}$ was the major antimony species in all solutions containing $\leq 0.03$ mol kg ${ }^{-1} \mathrm{~S}^{2-}$ total. However, at both 300 and $350^{\circ} \mathrm{C}$, an antimony-sulfide complex was needed to fit the $\mathrm{pH} \approx 8$ experiments with sulfide concentrations of 0.03 to $0.06 \mathrm{~mol} \mathrm{~kg}^{-1} \mathrm{~S}^{2-}$ total. An example of a fit using only antimony-hydroxide complexes is Fit (300-B), which used $\mathrm{Sb}(\mathrm{OH})_{3}$ and $\mathrm{H}_{2} \mathrm{SbO}_{3}{ }^{-}$. Fit (300B) had $R^{2}=0.70$, but the antimony concentrations predicted by this fit for the experiments at $\mathrm{pH} \approx 8$ and $\mathrm{S}^{2-}$ total $=0.06 \mathrm{~mol} \mathrm{~kg}{ }^{-1}$ were $<10 \%$ of the measured stibnite antimony concentrations, suggesting that an antimony-sulfide complex is present at these higher sulfide concentrations.

The experimental solubilities were well fitted with a speciation model including $\mathrm{Sb}(\mathrm{OH})_{3}$, $\mathrm{H}_{2} \mathrm{SbO}_{3}{ }^{-}$, and $\mathrm{Sb}_{2} \mathrm{~S}_{4}{ }^{2-}$. In addition, the values of $K_{2400}$ at 300 and $350^{\circ} \mathrm{C}$ from fits using this speciation model were consistent the behavior of $K_{2400}$ at lower temperatures. In contrast, when $\mathrm{HSb}_{2} \mathrm{~S}_{4}{ }^{-}$was included in the speciation model at these temperatures, the value of its equilibrium constant $\left(K_{2401}=\right.$ $6 \times 10^{-2}$ ) was an order of magnitude too high based upon the behavior of $K_{2401}$ at lower temperatures. At temperatures $>\sim 100^{\circ} \mathrm{C}, \mathrm{HSb}_{2} \mathrm{~S}_{4}{ }^{-}$does not become more stable with increasing temperature because $K_{2401}$ is effectively constant between 110 and $250^{\circ} \mathrm{C}$ (i.e., $K_{2401,110^{\circ} \mathrm{C}}=2.5 \times 10^{-3}$ and $K_{2401,250^{\circ} \mathrm{C}}=$ $\left.2.4 \times 10^{-3}\right)$. It was judged that the contribution of $\mathrm{HSb}_{2} \mathrm{~S}_{4}{ }^{-}$at 300 and $350^{\circ} \mathrm{C}$ was too small to accurately estimate its equilibrium constant, and hence, this species was not included in the preferred speciation model. At $300^{\circ} \mathrm{C}, \mathrm{Sb}(\mathrm{OH})_{3}$ was the major aqueous antimony species except when $\mathrm{pH} \geq 7.3$ and $\mathrm{S}^{2-}$ total $\geq 0.03$. At $350^{\circ} \mathrm{C}, \mathrm{Sb}_{2} \mathrm{~S}_{4}{ }^{2-}$ is also the dominant species at $\mathrm{pH} \geq \sim 8$ when $\mathrm{S}^{2-}{ }_{\text {total }} \geq 0.03$, where $\mathrm{Sb}_{2} \mathrm{~S}_{4}{ }^{2-}$ predominates. The values for the $K_{1033}$ using the preferred speciation model overlap with previously published values at 300 and $350{ }^{\circ} \mathrm{C}$ (refer to Figure (4.8) in the Discussion).

\subsubsection{Stibnite solubility at $400^{\circ} \mathrm{C}$ in supercritical fluids and in fluids with vapour-like densities}

Stibnite solubility approached 2,000 ppm $\left(\sim 0.015 \mathrm{~mol} \mathrm{~kg}^{-1} \mathrm{Sb}\right)$ in fluids at 396 and $401{ }^{\circ} \mathrm{C}$ when the pressure was $\sim 300$ bar, which corresponded to fluid densities of 0.3 to $0.4 \mathrm{~g} \mathrm{~cm}^{-3}$. With these extremely high concentrations of dissolved antimony, minor amounts of stibnite precipitation caused clogging of the exit tubing connected to the backpressure regulator and of the backpressure regulator itself after only a few samples had been taken. At lower pressures, particularly at $<200$ bar, stibnite solubility decreased rapidly, and conducting experiments at $\leq 250$ bar in fluids with vapourlike densities $\left(\rho_{H 2 O} \leq 0.3 \mathrm{~g} \mathrm{~cm}^{-3}\right)$ enabled collection of more replicate samples. In Figure (4.6), the measured solubilities are plotted versus the input $\mathrm{pH}$, which is the $\mathrm{pH}$ of initial solution as it enters the flow-through system at ambient temperature (Table 4.1). The pressure of individual data points and the input sulfide concentration are as indicated. The pressure had a strong influence on the stibnite solubility for all the experiments, and small increases in pressure produced large increases in stibnite solubility for the five different input $\mathrm{pH}$ 's. The sulfide concentration in the output solution after reaction with stibnite was higher than the concentration in the input solution because of sulfide added by stibnite dissolution. The measured sulfide concentration in the output solution was used in estimating $K_{1033}$. 
Figure (4.6) Stibnite solubility between 390 and $406^{\circ} \mathrm{C}$ versus input solution pH. The experimental pressure (in bars) is listed with each data point and the shade of the data points indicates the sulfide concentration of the input experimental solution (i.e., filled symbols contained sulfide concentrations of $0.01 \mathrm{~mol} \mathrm{~kg}^{-1}$ and the open symbols $\left.\sim 0.003 \mathrm{~mol} \mathrm{~kg}^{-1}\right)$.

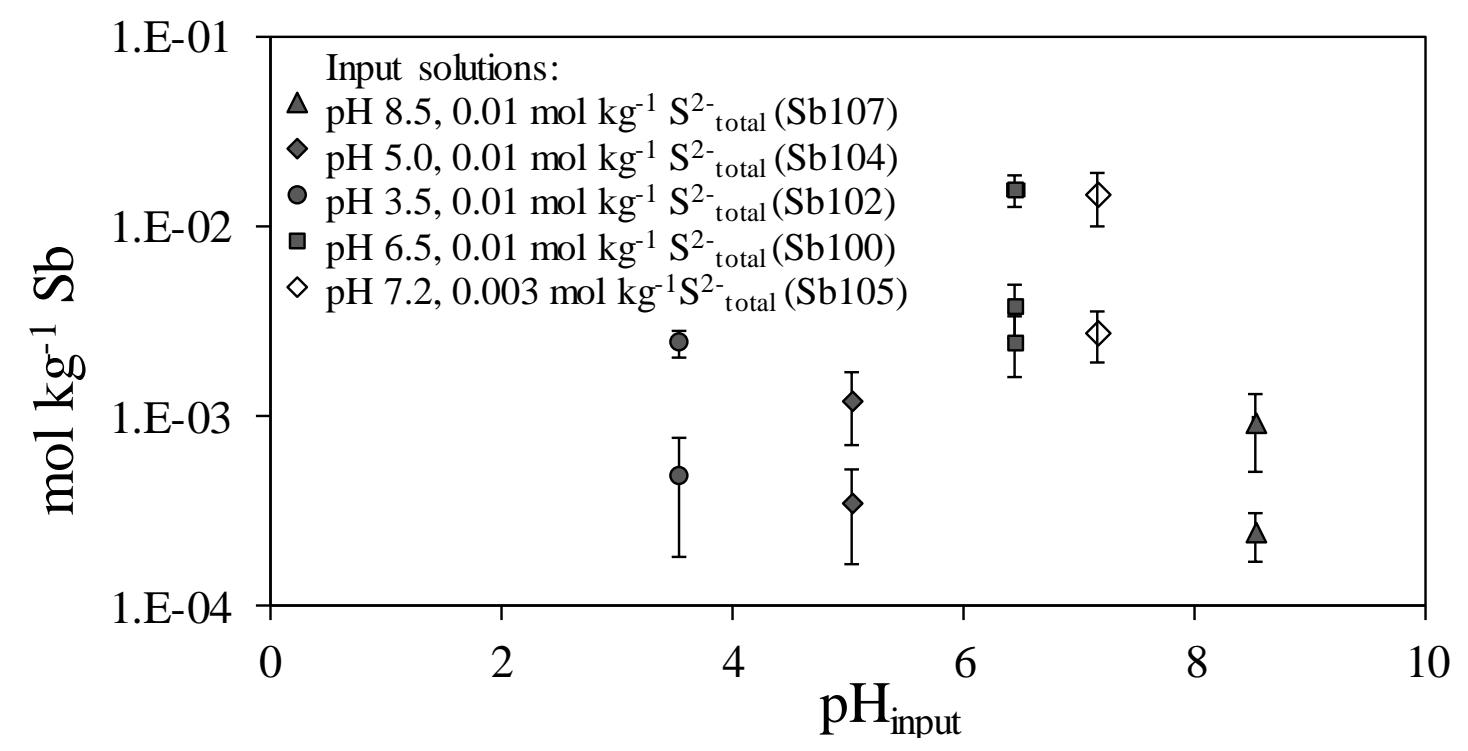

Experiments were completed at temperatures from 390 to $406^{\circ} \mathrm{C}$ and 159 to 304 bar, producing a variation in fluid density from 0.07 to $0.42 \mathrm{~g} \mathrm{~cm}^{-3}$. Fluids with these characteristics can be involved in the formation of hydrothermal ore deposits, particularly in systems that involve a transition between high temperature $\left(>400^{\circ} \mathrm{C}\right)$ porphyry environments to lower temperature, lower pressure epithermal environments (e.g., Heinrich et al., 2004; Williams-Jones and Heinrich, 2005; Hurtig and Williams-Jones, 2015). The relationship of stibnite solubility to experimental pressure and fluid density is shown in Figure (4.7). In contrast to the insignificant pressure dependence of stibnite solubility observed between 110 and $350^{\circ} \mathrm{C}$ (Figure 4.4), stibnite solubility decreased by 2.5 orders of magnitude in the supercritical fluids over the pressure range studied. However, the solubility of stibnite at $401{ }^{\circ} \mathrm{C}$ and 159 bar, which corresponded to a fluid density of $\rho_{H^{2} O} \approx 0.07 \mathrm{~g} \mathrm{~cm}^{-3}$, was still approximately the same as its solubility in the liquid phase at $300^{\circ} \mathrm{C}$ at swvp in a $\mathrm{pH}<6$ fluid (i.e., Fit (300-A) in Table (4.8)).

The temperature and pressure conditions for which the ion association constants given in Table (4.2) are well constrained by experimental data are limited to conditions in which $\rho_{\mathrm{H} 2 \mathrm{O}}>0.25 \mathrm{~g}$ $\mathrm{cm}^{-3}$ for $\mathrm{HCl}^{\circ}$ and $\mathrm{NaOH}^{\circ}$ (Ho and Palmer, 1996; Ho et al., 2001) and $\rho_{H 2 O}>0.6 \mathrm{~g} \mathrm{~cm}^{-3}$ for $\mathrm{NaHS}^{\circ}$ (by analogy with $\mathrm{NaCl}$; Ho et al., 1994). However, the experimental data from the current study had a maximum density of $\rho_{\mathrm{H} 2 \mathrm{O}}=0.42 \mathrm{~g} \mathrm{~cm}^{-3}$ and most were $<0.2 \mathrm{~g} \mathrm{~cm}^{-3}$. Therefore, the solution charge balance and the activities of aqueous species including $\mathrm{Na}^{+}, \mathrm{HS}^{-}$, and $\mathrm{Cl}^{-}$could only be estimated between 390 and $406^{\circ} \mathrm{C}$ and their values became increasing uncertain at lower pressures.

Neutral antimonous acid, $\mathrm{Sb}(\mathrm{OH})_{3}$, is expected to be the main aqueous antimony species based upon the predominance of this species at 300 and $350^{\circ} \mathrm{C}$ and upon the increasing stability of neutral species given the low dielectric constant of water under these conditions. Assuming $\mathrm{Sb}(\mathrm{OH})_{3}$ 
Figure (4.7) Stibnite solubility at $\sim 400^{\circ} \mathrm{C}$ versus pressure (A) and fluid density (B). The chemistry of the input solution is indicated. Below a fluid density of $\sim 0.2 \mathrm{~g} \mathrm{~cm}^{-3}$, stibnite solubility decreases by nearly one and half orders of magnitude.
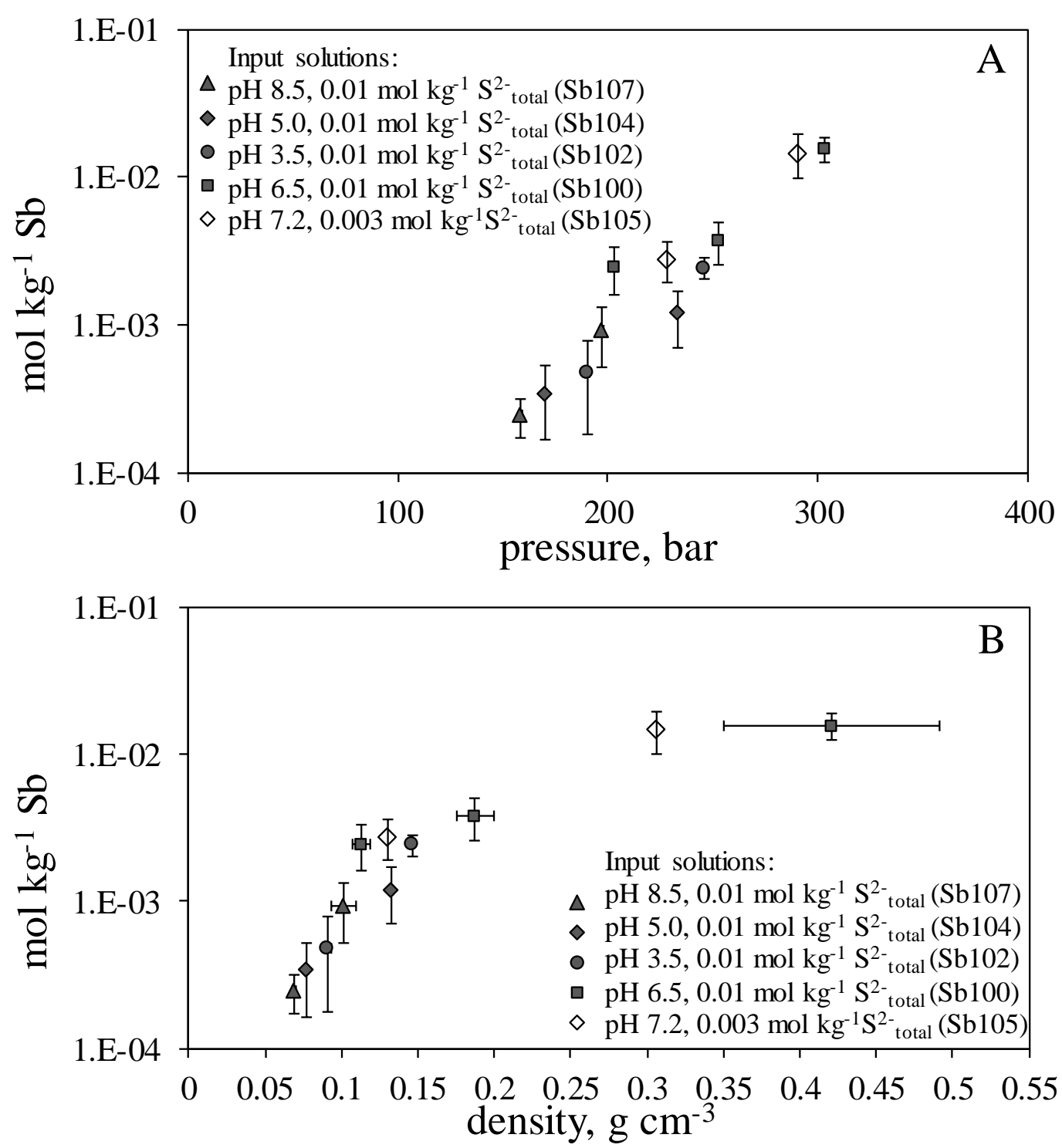

was the only species present, values for $K_{1033}$ were estimated for the three highest density solutions with $\rho_{H 2 O}=0.19,0.31$, and 0.42 , resulting in $K_{1033}=10^{-27.0}, 10^{-22.3}$, and $10^{-19.9}$, respectively. The predicted stibnite solubility is compared to the solubility data in Figure (4.8A) and $K_{1033}$ is plotted versus $\rho_{\mathrm{H} 2 \mathrm{O}}$ in Figure (4.8B). These values are consistent with lower temperature data considering that $K_{1033}$ reached a maximum of $10^{-17.9}$ at 250 and $300^{\circ} \mathrm{C}$ (Table 4.8) and then decreased to $10^{-18.5}$ at $350^{\circ} \mathrm{C}$. Stibnite solubility across the entire experimental pressure range was also evaluated using a density equation of the form

$$
\log \mathrm{Sb}\left(\mathrm{mol} \mathrm{kg} \mathrm{kg}^{-1}\right)=a+b \cdot \log \rho_{\mathrm{H}_{2} \mathrm{O}}
$$

where $\rho_{\mathrm{H} 2 \mathrm{O}}$ is the fluid density in $\mathrm{g} \mathrm{cm}^{-3}$ and $a$ and $b$ are constants (Pokrovski et al., 2013). A fit with $a$ $=-0.7052$ and $b=2.3693$ had $R^{2}=91.3$ and is shown with the experimental data in Figure (4.8A). Inclusion of a temperature-dependent factor did not improve the fit. 
Figure (4.8) Stibnite solubility (A) and estimated $K_{1033}(B)$ between 390 and $406^{\circ} \mathrm{C}$ as a function of fluid density. Fits of data using estimated $\mathrm{K}_{1033}$ and a density model (Equation 4.11) are also shown in (A).
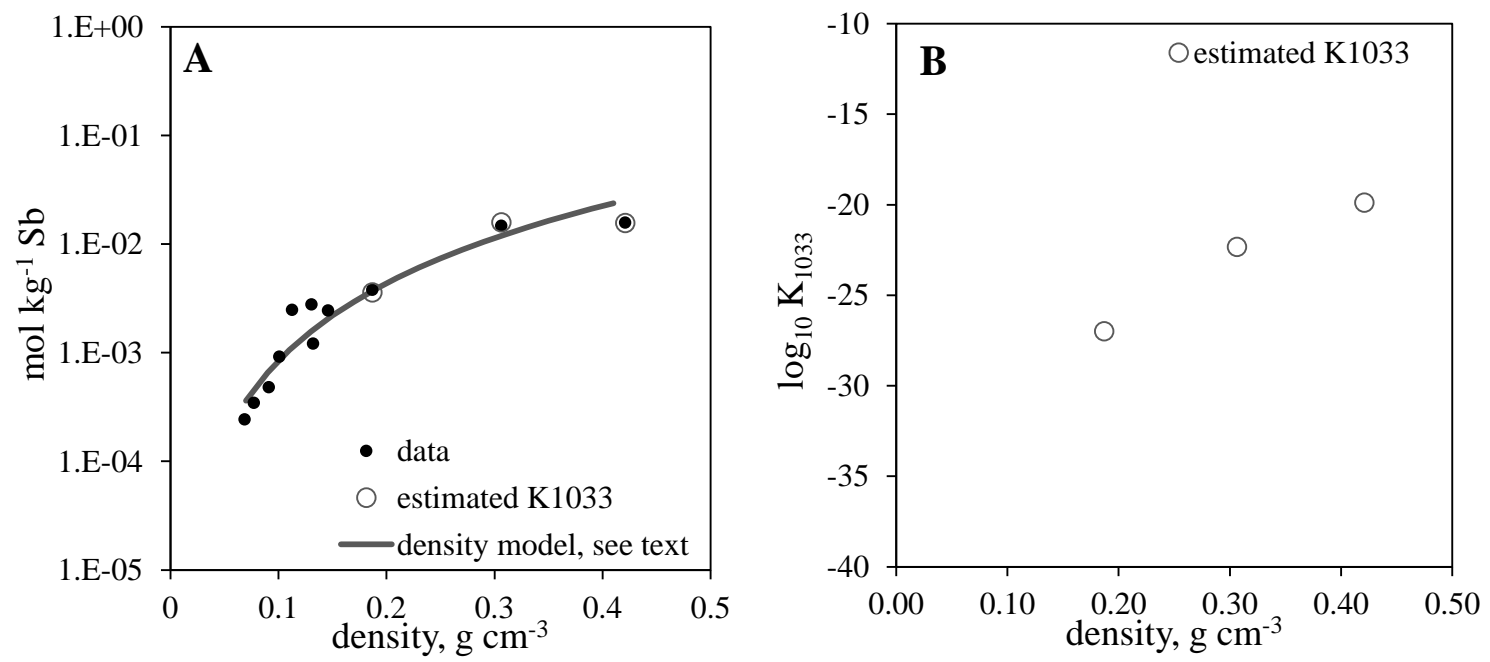

\subsection{Discussion}

\subsubsection{Temperature dependence of equilibrium constants for $\mathrm{Sb}_{2} \mathrm{~S}_{4}^{2-}, \mathrm{HSb}_{2} \mathrm{~S}_{4}$, and $\mathrm{Sb}(\mathrm{OH})_{3}$}

The logarithms of equilibrium constants derived from measurements of stibnite solubility in this study are summarised in Table (4.9). This table includes values for the equilibrium constants for $\mathrm{Sb}_{2} \mathrm{~S}_{4}{ }^{2-}, \mathrm{HSb}_{2} \mathrm{~S}_{4}^{-}, \mathrm{H}_{3} \mathrm{SbS}_{2} \mathrm{O}$, and $\mathrm{Sb}(\mathrm{OH})_{3}$ determined from 70 to $350^{\circ} \mathrm{C}$ in this Chapter and those for the same reactions at $30^{\circ} \mathrm{C}$ from Chapter (2). The experimentally determined values for $\log K_{1033}$, $\log K_{2401}$, and $\log K_{2400}$ are compared to previously published values for these reactions in Figure (4.9). Also included in Figure (4.9) curves of $\log K_{x y z w}$ versus temperature ( $T$, in Kelvin) that were derived from the form of the Van't Hoff isochore which best fitted the data, i.e.

$$
\log K_{x y z w}=a+b T+c T^{2}+d T^{-1}+e \log _{10}(\mathrm{~T})
$$

The constants for these fitted lines are found in Table (4.10). The heterogeneous equilibrium constants for the antimony-sulfide complexes (i.e., $\mathrm{Sb}_{2} \mathrm{~S}_{4}{ }^{2-}, \mathrm{HSb}_{2} \mathrm{~S}_{4}^{-}$, and $\mathrm{H}_{3} \mathrm{SbS}_{2} \mathrm{O}$ ) increased rapidly between 30 and $70^{\circ} \mathrm{C}$ and reached maximums at 150 to $300^{\circ} \mathrm{C}$, depending on the complex. The value of $K_{2400}$ was greatest $\left(K_{2400}=10^{-9.6}\right)$ at $300^{\circ}$ and then decreased slightly at $350^{\circ} \mathrm{C}$. The equilibrium constant for the partially protonated dimer $\left(\mathrm{HSb}_{2} \mathrm{~S}_{4}^{-}, K_{2401}\right)$ increased rapidly between 30 and $70^{\circ} \mathrm{C}$ but then remained effectively constant between 110 and $250^{\circ} \mathrm{C}$. The ambient temperature neutral species, $\mathrm{H}_{3} \mathrm{SbS}_{2} \mathrm{O}$, did not contribute to the dissolved antimony concentration at $>150^{\circ} \mathrm{C}$ and its equilibrium constant could not be determined at higher temperatures.

At $150^{\circ} \mathrm{C}, \mathrm{Sb}(\mathrm{OH})_{3}$ began to be an important species, and $K_{1033}$ reached a maximum value of $10^{-17.9}$ at 250 and $300^{\circ} \mathrm{C}$. The equilibrium constant for stibnite solubility in terms of $\mathrm{H}_{2} \mathrm{SbO}_{3}{ }^{-}$was estimated using published values for the deprotonation reaction of $\mathrm{Sb}(\mathrm{OH})_{3}(\mathrm{Zakaznova-Herzog}$ and 
Table (4.9) Experimentally derived logarithms of equilibrium constants for heterogeneous stibnite solubility reactions from 30 to $350^{\circ} \mathrm{C}$ at saturated water vapour pressure. The given uncertainties are one standard deviation (i.e., 1 $\sigma$ ); details of fits are shown in Table $(2.4)$ for $30^{\circ} \mathrm{C}$ data and Tables (4.4) through (4.8) for higher temperatures.

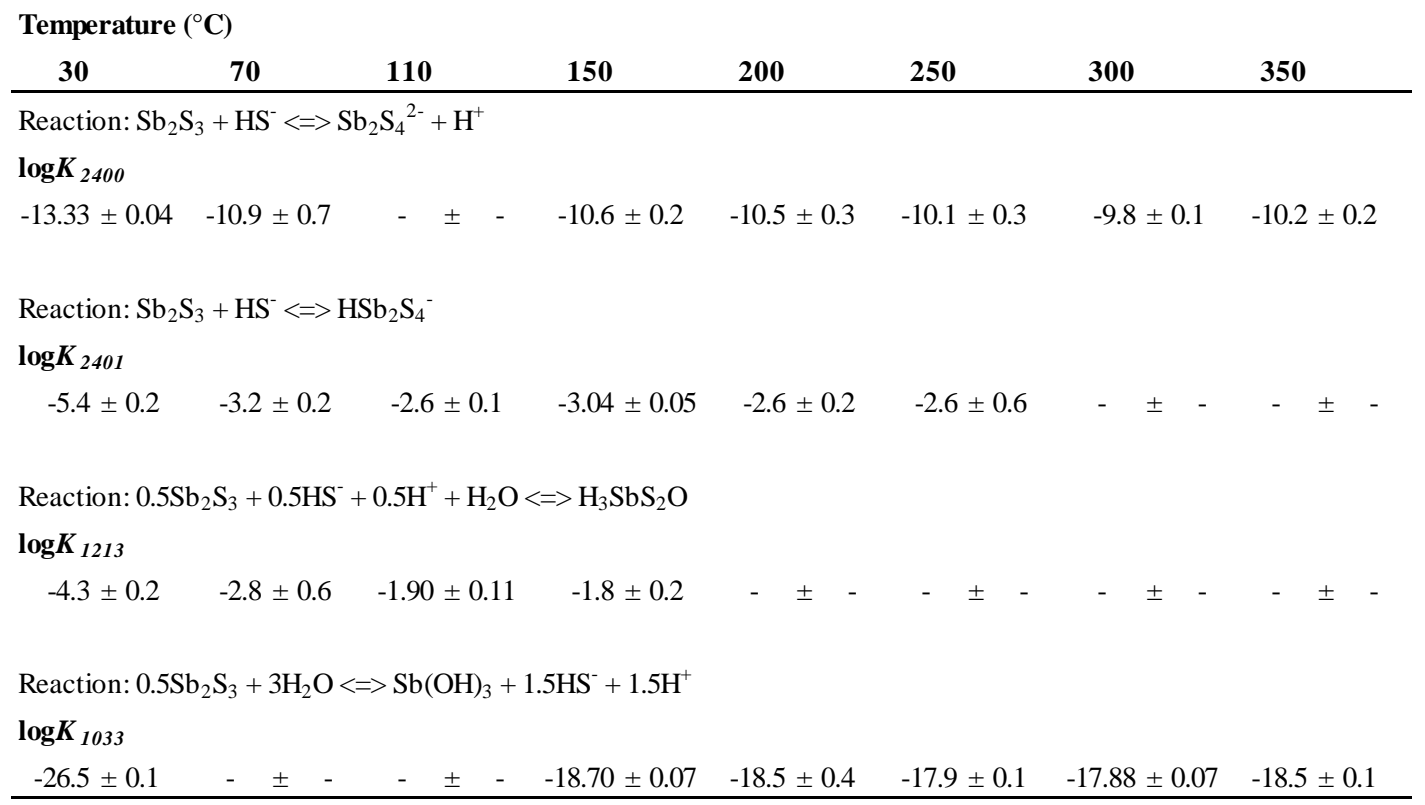

Seward, 2006). However, it did not contribute significantly to the total dissolved antimony concentration at 300 or $350^{\circ} \mathrm{C}$ (i.e., was $\leq 2 \%$ of the total dissolved antimony) and so its equilibrium constant could not be independently determined and is not included in the Table (4.9).

The values for $\log K_{1033}, \log K_{2401}$, and $\log K_{2400}$ are compared to previously published values for these reactions in Figure (4.9). The estimated value for $K_{1033}$ was in excellent agreement with the literature at $30^{\circ} \mathrm{C}$, as were the values from 200 to $300^{\circ} \mathrm{C}$ (Figure 4.9A). The literature data includes values for $K_{1033}$ derived from antimony (III)-oxide batch solubility studies (Spycher and Reed, 1989), stibnite batch solubility-based studies from 200 to $300^{\circ} \mathrm{C}$ (Shikina and Zotov, 1999), and stibnite solubility in a system containing other additional sulfide minerals (Wood et al., 1987). The agreement between the new solubility data derived from flow-through solubility experiments with moderate to

Table (4.10) Coefficients for fits to Equation (4.12).

\begin{tabular}{ccccccc}
\multicolumn{7}{c}{$\log K_{x y z w}=a+b \mathrm{~T}+c \mathrm{~T}^{2}+d \mathrm{~T}^{1}+e \log _{10} \mathrm{~T}$} \\
\hline $\log K_{2400}$ & 102 & 0 & 0 & $-8.13 \mathrm{E}+03$ & -35.4 & 30 to $350^{\circ} \mathrm{C}$ \\
& & & & & & \\
$\log K_{2401}$ & 222 & 0 & 0 & $-1.41 \mathrm{E}+04$ & -72.9 & 30 to $250^{\circ} \mathrm{C}$ \\
$\log K_{1213}$ & 47.1 & $-5.86 \mathrm{E}-02$ & 0 & $-1.02 \mathrm{E}+04$ & 0 & 30 to $150^{\circ} \mathrm{C}$ \\
& & & & & & \\
$\log K_{1033}$ & 37.2 & $-5.23 \mathrm{E}-02$ & 0 & $-1.45 \mathrm{E}+04$ & 0 & 30 to $350^{\circ} \mathrm{C}$ \\
\hline
\end{tabular}


Figure (4.9) Temperature dependence of logarithms of the equilibrium solubility constants for heterogeneous stibnite solubility reactions involving $\mathrm{Sb}(\mathrm{OH})_{3}(\mathrm{~A}), \mathrm{Sb}_{2} \mathrm{~S}_{4}{ }^{2-}(\mathrm{B})$, and $\mathrm{HSb}_{2} \mathrm{~S}_{4}^{-}(\mathrm{C})$.
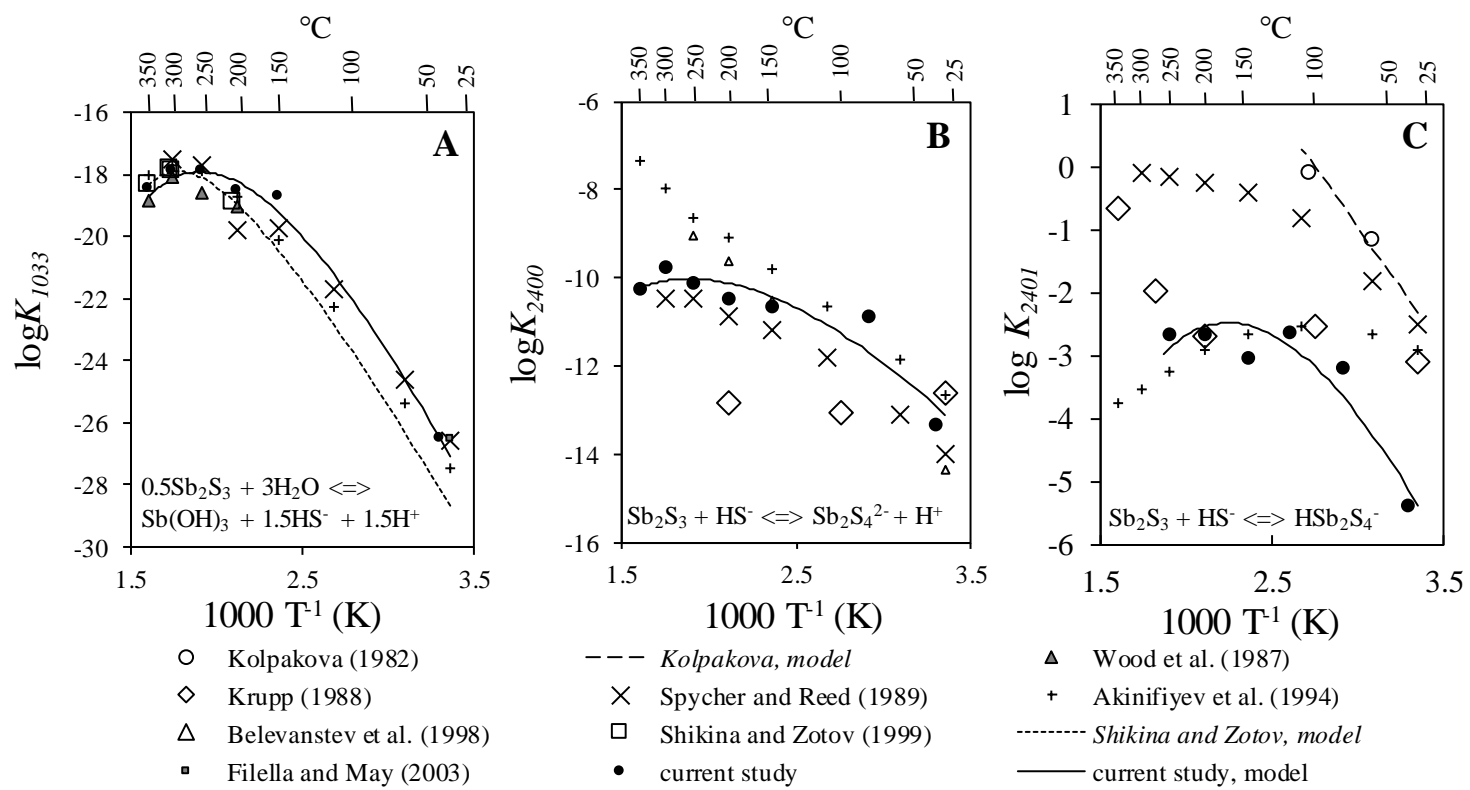

high sulfide concentrations (i.e., this study) and the previously published data derived from an array of experimental conditions suggests that the $K_{1033}$ presented here is robust and confirms that $\mathrm{Sb}(\mathrm{OH})_{3}$ will be the primary aqueous antimony species in many hydrothermal environments, depending on the reduced sulfur activity.

There was more scatter in the previously published thermodynamic data for the antimonysulfide dimers (i.e., $\mathrm{Sb}_{2} \mathrm{~S}_{4}{ }^{2-}$ and $\mathrm{HSb}_{2} \mathrm{~S}_{4}^{-}$, Figures 4.9B and 4.9C) than for $\mathrm{Sb}(\mathrm{OH})_{3}$ (Figure 4.9A). The equilibrium constant for the fully deprotonated antimony-sulfide dimer $\left(K_{2400}, \mathrm{Sb}_{2} \mathrm{~S}_{4}{ }^{2-}\right)$ lay approximately in the middle of previously published values and was most similar to, although generally higher than, the data from Spycher and Reed (1989). The value for $K_{2400}$ derived from that published by Krupp (1988) followed a different trend from the rest of the data at temperatures > $100^{\circ} \mathrm{C}$. The equilibrium constant for the partially protonated dimer $\left(K_{2401}, \mathrm{HSb}_{2} \mathrm{~S}_{4}{ }^{-}\right)$was in reasonable agreement with the data from Krupp (1988) and Akinifiyev et al. (1994) from 100 to $200^{\circ} \mathrm{C}$. However, above $200^{\circ} \mathrm{C}$, the values for $K_{2401}$ from Krupp (1988) increased by nearly three orders of magnitude, while values from the current study and from Akinifiyev et al. (1994) remained constant or decreased slightly. The other literature data for $K_{2401}$ are 1 to 3 orders of magnitude higher than the current study and Akinifiyev et al. (1994) at temperatures $>50^{\circ} \mathrm{C}$. In the current and previous studies, obtaining thermodynamic data for $\mathrm{Sb}_{2} \mathrm{~S}_{4}{ }^{2-}$ and $\mathrm{HSb}_{2} \mathrm{~S}_{4}{ }^{-}$often involved the interpretation of solubility results from experimental conditions where multiple antimony-sulfide species and $\mathrm{Sb}(\mathrm{OH})_{3}$ were present. Failure to accurately constrain the contribution of multiple species is likely behind some of the spurious equilibrium constants reported for $\mathrm{Sb}_{2} \mathrm{~S}_{4}{ }^{2-}$ and $\mathrm{HSb}_{2} \mathrm{~S}_{4}{ }^{-}$. 


\subsubsection{Evidence for changes in antimony speciation at elevated temperatures from previous spectroscopic studies}

Three studies have used Raman or X-ray absorption spectroscopy (XAS) to study aqueous antimony-sulfide interactions up to $300^{\circ} \mathrm{C}$, and both types of spectroscopic techniques found distinct changes in antimony spectra between 150 and $200^{\circ} \mathrm{C}$. A Raman spectroscopy study by Gushchina et al. (2000) detected a major change in antimony speciation beginning at $\sim 150^{\circ} \mathrm{C}$, as was shown schematically in Figure (2.1) in Chapter (2). The authors did not identify the complex or complexes responsible for the change in the Raman spectrum at higher temperatures. However, it should be noted that one of the high temperature spectral features (a peak at $280 \mathrm{~cm}^{-1}$ ) was only present at $25^{\circ} \mathrm{C}$ in solutions where the sulfide concentration was only slightly greater than the antimony concentration, i.e. a solution chemistry where the antimonous acid species might be expected.

The extended x-ray fine structure (EXAFS) portion of XAS spectra can identify and quantify the number of different coordinating atoms in an aqueous complex. EXAFS studies of antimony in sodium sulfide solutions find oxygen atoms and/or decrease in the number of sulfur atoms in antimony's first coordination shell beginning at $150^{\circ} \mathrm{C}$ for both $\mathrm{Sb}(\mathrm{III})$ and $\mathrm{Sb}(\mathrm{V})$ (Mosselmans et al., 2000; Sherman et al., 2000). The number of sulfur and oxygen atoms in the first coordination shell from these studies is plotted versus temperature in Figure (4.10). Unfortunately, only solutions containing $\mathrm{Sb}(\mathrm{V})$, have been studied at temperatures $>150^{\circ} \mathrm{C}$ (Sherman et al., 2000) and thus are not strictly comparable to this study.

Figure (4.10) Previously published EXAFS results for antimony in sodium sulfide solutions at elevated temperatures. Plot shows the number of coordinating sulfur and oxygen atoms reported by Mosselmans et al. (2000) and Sherman et al. (2000) for solutions from 25 to $350^{\circ} \mathrm{C}$. Chemistries of the experimental solutions are listed in the legend.

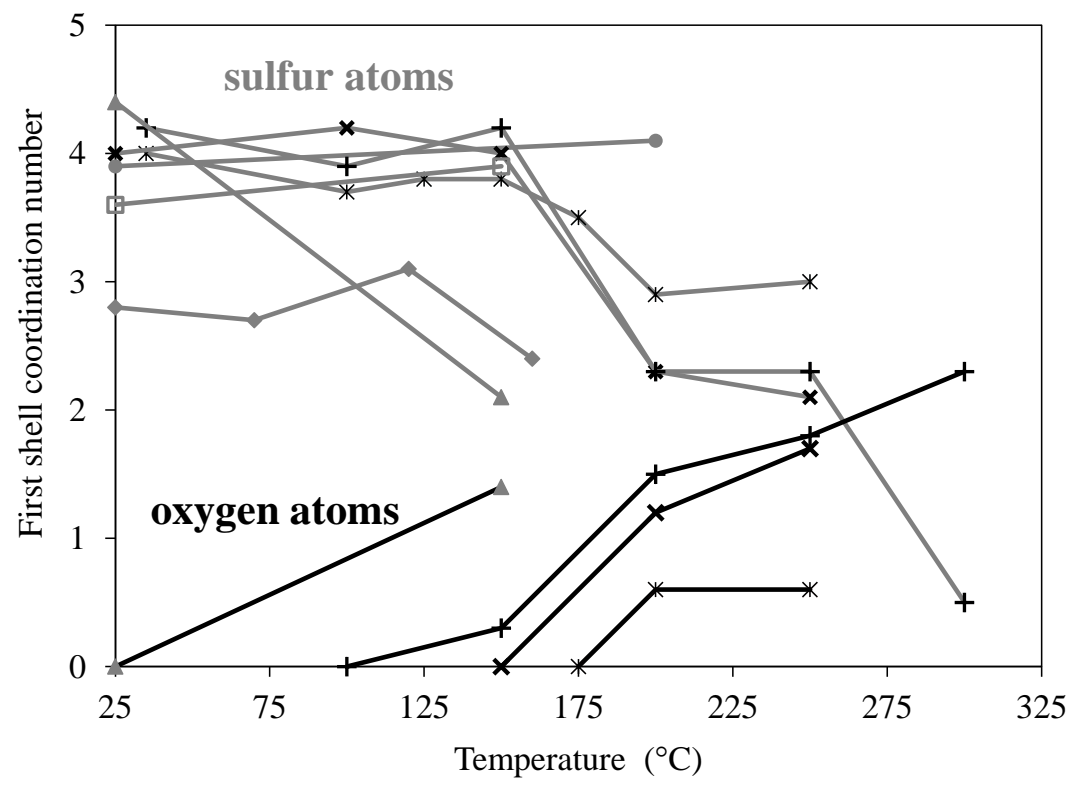

* $0.1 \mathrm{~mol} \mathrm{~kg}-1 \mathrm{Sb}+1 \mathrm{~mol}$ $\mathrm{kg}-1 \mathrm{~S} *$

X $0.05 \mathrm{~mol} \mathrm{~kg}-1 \mathrm{Sb}+0.2 \mathrm{~mol}$ $\mathrm{kg}-1 \mathrm{~S}+\mathrm{NaOH}^{*}$

+ $0.05 \mathrm{~mol} \mathrm{~kg}-1 \mathrm{Sb}+0.2 \mathrm{~mol}$ kg-1 S $+\mathrm{NaOH}+\mathrm{NaCl}^{*}$

$0.03 \mathrm{~mol} \mathrm{~kg}-1 \mathrm{Sb}+0.1 \mathrm{~mol}$ kg-1 S+NaOH**

$\square 0.001 \mathrm{~mol} \mathrm{~kg}-1 \mathrm{Sb}+0.1$ mol kg-1 S+NaOH**

$0.001 \mathrm{~mol} \mathrm{~kg}-1 \mathrm{Sb}+0.01$ mol kg-1 S+NaOH**

$0.1 \mathrm{~mol} \mathrm{~kg}-1 \mathrm{Sb}+2.5 \mathrm{~mol}$ kg-1 S**

* Sherman et al. (2000)

** Mosselmans et al. (2000) 


\subsubsection{Stibnite solubility and antimony speciation applied in natural hydrothermal fluids}

\section{Stibnite solubility in geothermal reservoir fluids}

The motivation for the current study was to provide thermodynamic data to assist in the interpretation of antimony behavior in natural, sulfide-containing hydrothermal fluids. Of particular interest are calculations of stibnite saturation in (a) the reservoir conditions of active hydrothermal systems (i.e., slightly alkaline, $\sim 200$ to $300^{\circ} \mathrm{C}$ ) and (b) in the lower temperature, sometimes more acidic conditions present within geothermal power generation stations, where significant and problematic precipitation of stibnite precipitation from geothermal fluids has been documented in New Zealand (Dorrington and Brown, 2000; Ward et al., 2006; Wilson et al., 2007). Therefore, plots of stibnite solubility from $\mathrm{pH}=3$ to 9 and the distribution of antimony species at stibnite saturation have been constructed for a range of sulfide concentrations $\left(\mathrm{S}^{2-}{ }_{\text {total }}=0.0001\right.$ to $\left.0.1 \mathrm{~mol} \mathrm{~kg}^{-1}\right)$. Such plots have been constructed at a temperature representative of reservoir conditions $\left(250^{\circ} \mathrm{C}\right.$, Figure 4.11$)$ and approximate operational temperatures within the Rotokawa and Ngawha geothermal stations (200 to $100^{\circ} \mathrm{C}$, Figure 4.12 ).

The antimony concentration of deep hydrothermal fluids has been measured or estimated in the deep fluids of six hydrothermal systems in the Taupo Volcanic Zone (TVZ) in New Zealand currently utilized for geothermal power generation (Broadlands-Ohaaki, Kawerau, Rotokawa, Mokai, and Wairakei) and for a seventh TVZ system (Waiotapu) (Weissberg, 1969; Weissberg et al., 1979; Krupp and Seward, 1990; Simmons and Brown, 2007; Simmons et al., 2016). The antimony concentration in these deep fluids ranged from $5.7 \times 10^{-8}$ to $9.8 \times 10^{-6} \mathrm{~mol} \mathrm{~kg}^{-1}$ (7 to $1200 \mathrm{ppb}$ ) and the total sulfide concentration varied between 0.00026 and $0.0071 \mathrm{~mol} \mathrm{~kg}^{-1}$ (median $\sim 0.003 \mathrm{~mol} \mathrm{~kg}^{-1}$ ). The $\mathrm{pHs}$ calculated at the reservoir temperatures are between $\mathrm{pH} \sim 5$ and 7 . The Ngawha hydrothermal system (Barnes and Seward, 1997), located outside of the TVZ, has the highest antimony concentrations of any active hydrothermal system in New Zealand $\left(1.3 \times 10^{-5}\right.$ to $1.7 \times 10^{-5} \mathrm{~mol} \mathrm{~kg}^{-1}$; Brown and Simmons, 2003; Wilson et al., 2007). The shaded area in Figure (4.11) shows the range of antimony concentrations reported in deep geothermal fluids sampled from New Zealand geothermal wells $\left(1 \times 10^{-7}\right.$ to $\left.1 \times 10^{-5} \mathrm{~mol} \mathrm{~kg}^{-1}\right)$.

At reservoir temperatures $\left(200\right.$ to $\left.250^{\circ} \mathrm{C}\right), \mathrm{Sb}(\mathrm{OH})_{3}$ is the dominant aqueous antimony species, although antimony-sulfide complexes contributed between 1 to $13 \%$ of the total antimony between $\mathrm{pH}=5.5$ and 9 if $\mathrm{S}^{2-}{ }_{\text {total }}=0.01 \mathrm{~mol} \mathrm{~kg}^{-1}$. This is demonstrated in Figure (4.11), which shows the stibnite saturation curve and the distribution of antimony species at $250^{\circ} \mathrm{C}$ for four sulfide contents $\left(\mathrm{S}^{2-}{ }_{\text {total }}=0.0001,0.001,0.01\right.$, and $\left.0.1 \mathrm{~mol} \mathrm{~kg}^{-1}\right)$. Antimony concentrations $\left(1.3 \times 10^{-4}\right.$ to $8.1 \times 10^{-3}$ or 16 to $988 \mathrm{ppm}$ ) reported in fluid inclusions from epithermal gold deposits in the Coromandel Peninsula, New Zealand (Simpson et al., 2015) approach stibnite solubility at $250^{\circ} \mathrm{C}$ for a sulfide concentration of $0.01 \mathrm{~mol} \mathrm{~kg}^{-1}$ (Figure 4.11C), as do the antimony concentrations in fluid inclusions from some of the magmatic-hydrothermal ore deposits included in Williams-Jones and Heinrich (2005). 
Figure (4.11) Stibnite solubility at $250^{\circ} \mathrm{C}$ for $\mathrm{S}^{2-}{ }_{\text {total }}=0.0001,0.001,0.01$, and $0.1 \mathrm{~mol} \mathrm{~kg}^{-1}$. This range of sulfide concentrations covers the range of sulfide concentrations recorded for active hydrothermal systems from a variety of geologic settings. The gray region indicates the range of antimony concentrations measured in active New Zealand hydrothermal systems (Simmons and Brown, 2007; Wilson et al., 2007; Simmons et al. 2016).
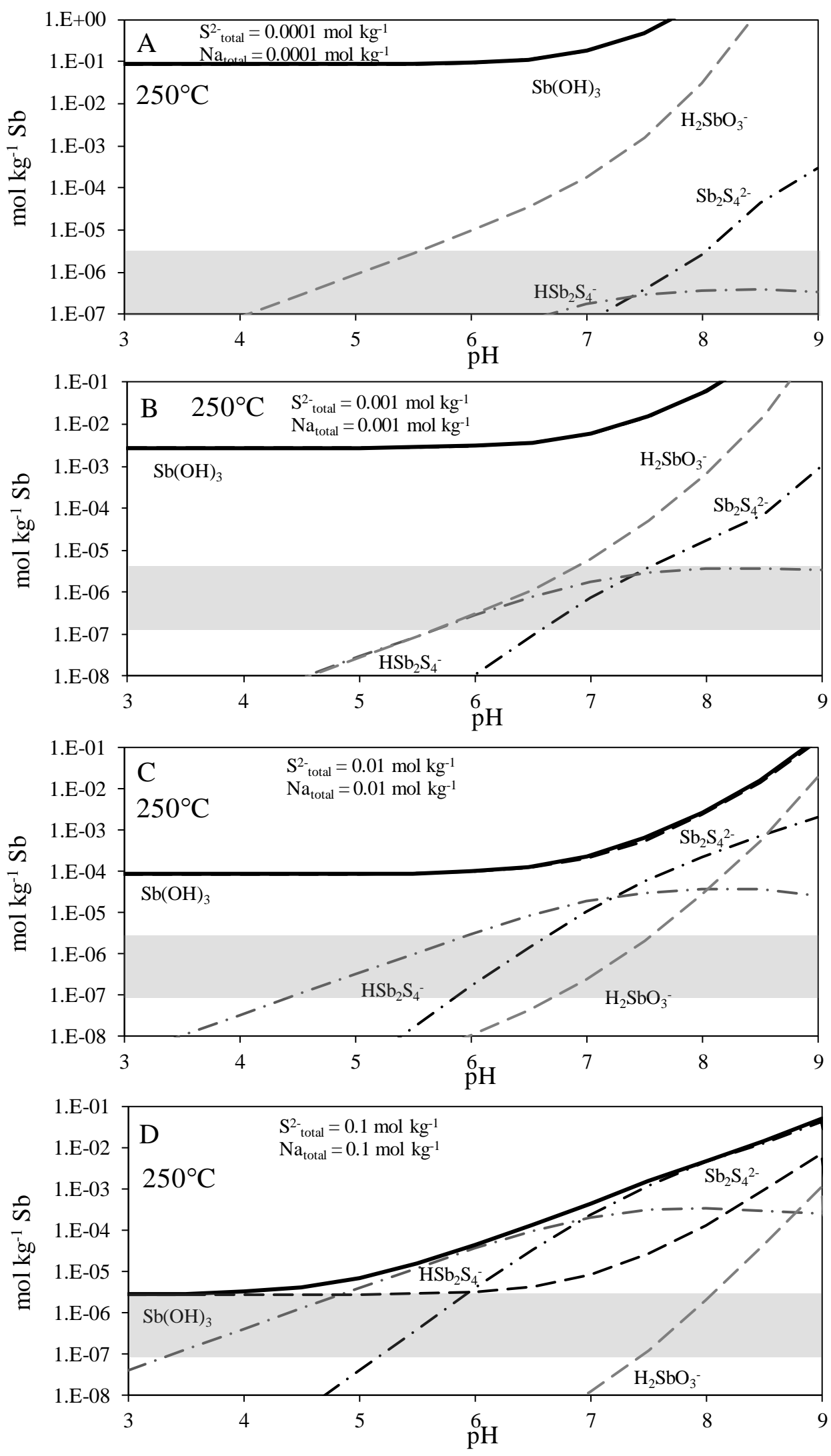
However, fluids sampled directly from geothermal wells with temperatures between 200 and $300^{\circ} \mathrm{C}$, represented by the shaded area in Figure (4.11), are understaturated with respect to stibnite. The undersaturation of stibnite is consistent with observations from active geothermal systems in the TVZ and in Nevada, U.S.A. that the enrichment of antimony in hydrothermally-altered rocks is most intense at shallow depths (i.e., $<500 \mathrm{~m}$ or even $<100 \mathrm{~m}$ depths) where temperatures are $<150^{\circ} \mathrm{C}$ (Weissberg, 1969; Chambefort and Dilles, 2015). As demonstrated in the following discussion of stibnite precipitation within two geothermal power stations, fluids with antimony concentrations $1 \times 10^{-5} \mathrm{~mol} \mathrm{~kg}^{-1}$ can become over-saturated with respect to stibnite at $150^{\circ} \mathrm{C}$ if $\mathrm{pH}<7$.

\section{Stibnite solubility in the Rotokawa and Ngawha geothermal power stations}

The precipitation of stibnite, or stibnite scaling, within two New Zealand geothermal power stations was studied in detail by Wilson et al. (2007). The Rotokawa and Ngawha power stations are binary facilities in which heat energy from geothermal fluid is transferred to a secondary working fluid (which drives the turbine) using a series of heat exchangers. The geothermal fluid is then reinjected to recharge the aquifer. During its transit through the power station, the geothermal fluid undergoes decreases in both temperature and $\mathrm{pH}$. For Rotokawa, the temperature and $\mathrm{pH}$ decrease are from $\sim 220$ to $\sim 150^{\circ} \mathrm{C}$ and from $\mathrm{pH}=7$ to 5.7 , respectively, whereas for Ngawha, they vary from $\sim 200$ to $\sim 90^{\circ} \mathrm{C}$ and from $\mathrm{pH}=7.1$ to 6.6. The largest temperature decrease occurs in the heat exchanger units, while the $\mathrm{pH}$ decrease occurs in response to mixing of acidic condensed vapour with the brine part way through the heat exchange process. Between the high temperature well and reinjection, the antimony concentration in the fluid decreases from $7.8 \times 10^{-6}$ to $1.4 \times 10^{-6}$ (960 to $170 \mathrm{ppb}$ ) at Rotokawa and from $1.3 \times 10^{-5}$ to $3 \times 10^{-6}$ (1600 to $375 \mathrm{ppb}$ ) at Ngawha. Most of the stibnite scaling (i.e., precipitation) is observed within the heat exchanger units. Wilson et al. (2007) concluded that stibnite deposition primarily occurred in response to a $\mathrm{pH}$ change at Rotokawa and due to temperature decrease at Ngawha. However, thermodynamic modeling of the system in this earlier study was limited by the available data, and antimony-sulfide complexes were not included in the stibnite saturation calculations.

Figures (4.12A) and (4.12B) show the solubility of stibnite as a function of $\mathrm{pH}$ for the temperatures and sulfide concentrations reported by Wilson et al. (2007) for the Rotokawa and Ngawha power stations, respectively, as calculated with the new thermodynamic data from the current study. Also plotted are antimony concentrations measured by Wilson et al. (2007) at different locations within the two power stations. The shade of these data points indicates the sample temperature. The sulfide concentration in these fluids varied from 0.0002 to $0.0009 \mathrm{~mol} \mathrm{~kg}^{-1}$ depending on the sampling location and the stibnite solubility curve at these different sulfide concentrations is included for Ngawha. 
Stibnite solubility curves for Rotokawa fluids are shown in Figure (4.12A) at 220, 170, 160, and $150^{\circ} \mathrm{C}$, which reflect the temperatures within the power station of separated brine $\left(\sim 220^{\circ} \mathrm{C}\right)$ prior to the heat exchangers ("HE"), of fluids within two heat exchangers (one using the brine only $\left(170^{\circ} \mathrm{C}\right.$ ) and a second using a mixture of brine and condensed vapour $\left(160\right.$ to $\left.151^{\circ} \mathrm{C}\right)$ ), and of reinjected fluid $\left(148^{\circ} \mathrm{C}\right)$. This lower temperature brine-vapour heat exchanger unit is where stibnite deposition has been observed.

According to Figure (4.12A), the fluid remained undersaturated with respect to stibnite throughout the entire system but most closely approached stibnite saturation in the mixed brine-vapour heat exchanger and in the reinjection line. This was due to the large decrease in stibnite solubility

Figure (4.12) Stibnite solubility curves for fluids in the Rotokawa (A) and Ngawha (B) power stations. Stibnite solubilities (solid lines) have been calculated using equations from Table (4.10) for total sulfide concentrations and temperatures representative of fluid conditions based upon data reported in Wilson et al. (2007). Species distributions are for the lowest temperature. Also included are dissolved antimony concentrations (open and closed circles) measured by Wilson et al. (2007), with the sample temperature indicated by symbol shade. "HE" refers to heat exchanger. The sulfide concentration at Ngawha varied between $\mathrm{S}^{2-}{ }_{\text {total }} \sim 0.0004$ and $0.0007 \mathrm{~mol} \mathrm{~kg}^{-1}$; and the influence of this variation on stibnite solubility is indicated at 195 and $160^{\circ} \mathrm{C}$ by the width of the solubility curves.
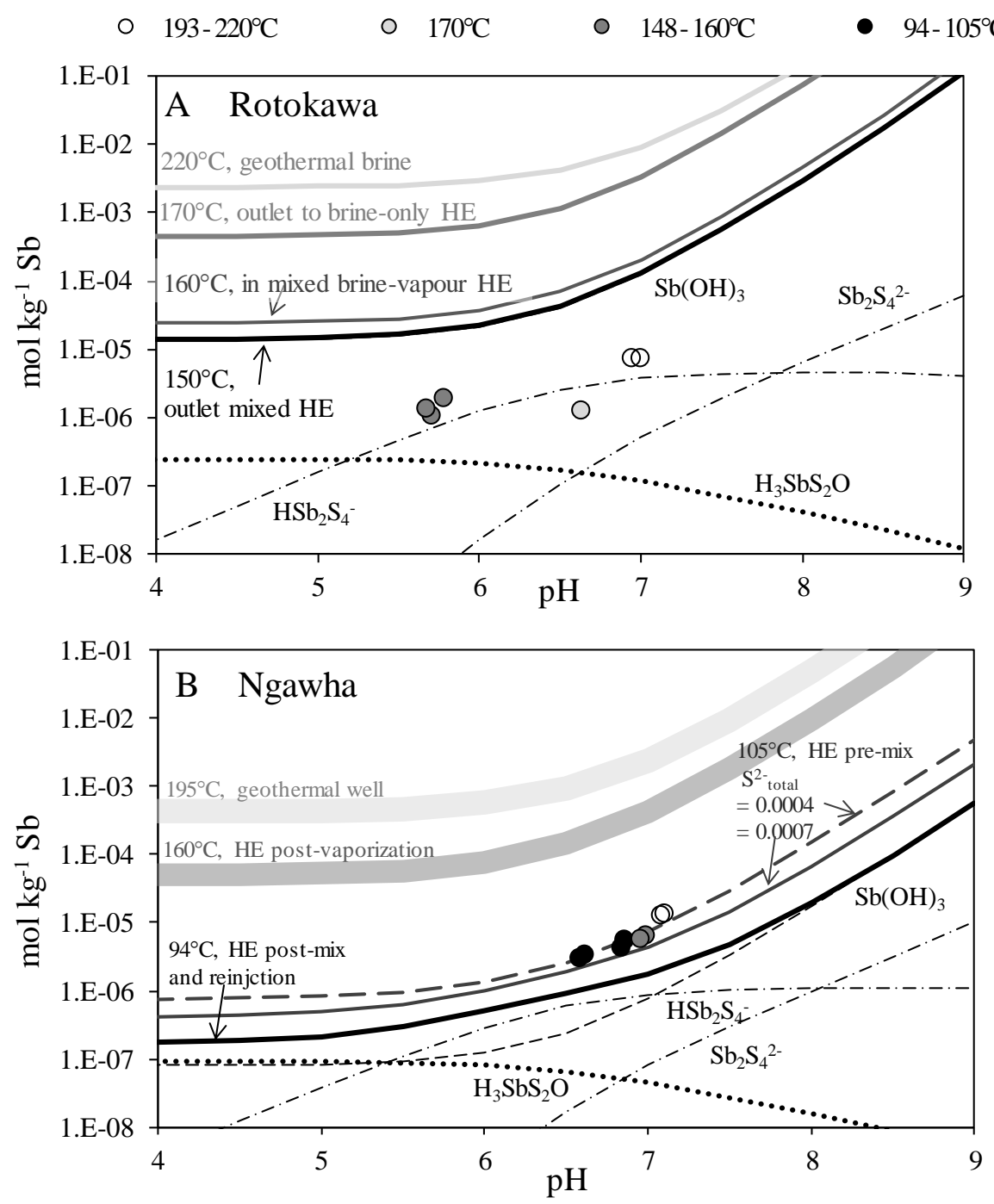
between 170 and $150^{\circ} \mathrm{C}$ as the stability of $\mathrm{Sb}(\mathrm{OH})_{3}$ begins to rapidly decrease with decreasing temperature (i.e., see the curve for $K_{1033}$ in Figure (4.9)). However, antimony concentrations measured in the outlet fluids from both heat exchangers $\left(1.3 \times 10^{-6}\right.$ to $2.0 \times 10^{-6} \mathrm{~mol} \mathrm{~kg}^{-1}$ or 160 to $\left.250 \mathrm{ppb}\right)$ were lower than concentrations in the input brine $\left(7.9 \times 10^{-6} \mathrm{~mol} \mathrm{~kg}^{-1}, \sim 960 \mathrm{ppb}\right)$, which implies that precipitation of an antimony solid phase did occur, possibly within the system prior to the sampling location. It should be noted that the value for $K_{1033}$ calculated between $\sim 100$ and $175^{\circ} \mathrm{C}$ using the equation in Table (4.10) is greater than previously published (Figure 4.9). This region of variability corresponds to the temperature range in which $K_{1033}$ was not experimentally determined in this study because of the moderate to high sulfide concentrations used. If the value of $K_{1033}$ decreases by about one order of magnitude at 160 and $170^{\circ} \mathrm{C}$, which is within the variation observed in previous studies for $K_{1033}$ at these temperatures, the fluids exiting the brine-vapour heat exchanger (at $\sim 160^{\circ} \mathrm{C}$ ) and in the reinjection line (at $\sim 150^{\circ} \mathrm{C}$ ) become saturated with respect to stibnite.

The antimony concentration in the input geothermal fluids at the Ngawha power station is higher than at Rotokawa (Figure 4.12B). The total sulfide concentration for fluids at Ngawha reported by Wilson et al. (2007) varied between $\sim 0.0004$ and $0.0007 \mathrm{~mol} \mathrm{~kg}^{-1}$. This sulfide concentration variation resulted in slight changes to the stibnite solubility, which is indicated with line width at 195 and $160^{\circ} \mathrm{C}$ and with two separate lines at $105^{\circ} \mathrm{C}$. Based upon total dissolved antimony concentrations measured by Wilson et al. (2007), the fluids in the Ngawha power station are undersaturated with respect to stibnite at the geothermal well head $\left(\right.$ at $\sim 200^{\circ} \mathrm{C}$ ) and after vapour-brine separation (at $160^{\circ} \mathrm{C}$ ). However, the temperature decreases within the heat exchanger, and fluids are at stibnite saturation when next sampled at $\sim 105^{\circ} \mathrm{C}$. The temperature of the fluid further decreases to $\sim 93^{\circ} \mathrm{C}$ and the $\mathrm{pH}$ decreases to $\mathrm{pH} \approx 5.7$ with the addition of condensed vapour, making stibnite over saturated and contributing to additional stibnite precipitation as indicated by a decrease in antimony concentration before and after the addition of the condensed vapor (from $\sim 5.6 .1 \times 10^{-6} \mathrm{~mol} \mathrm{~kg}^{-1}$ to $\sim$ $\left.4 \times 10^{-6} \mathrm{~mol} \mathrm{~kg}^{-1}\right)$. At the Ngawha power station, $\mathrm{HSb}_{2} \mathrm{~S}_{4}^{-}$becomes important when the fluid temperature decreases to $105^{\circ} \mathrm{C}$. At $93^{\circ} \mathrm{C}$, this antimony-sulfide dimer is the dominant aqueous antimony species at the near neutral $\mathrm{pH}$ of the fluids, and it causes stibnite solubility to be higher by approximately an order of magnitude from what it would be if modeled with $\mathrm{Sb}(\mathrm{OH})_{3}$ alone.

\section{Antimony speciation in surface hot springs}

The discussion above emphasizes the dramatic changes in stibnite solubility of between $10^{-2}$ to $10^{-6} \mathrm{~mol} \mathrm{~kg}^{-1}$ that occur in natural hydrothermal systems as buoyantly ascending fluids rise through fracture permeability in the Earth's crust and undergo boiling, cooling, and mixing with near surface fluids. In the upper 500 to $100 \mathrm{~m}$ of hydrothermal systems, the mixing of hydrothermal fluids with acidic steam-heated waters and oxygenated meteoric waters, changes in redox environment, ligand (i.e., reduced sulfur) transfer to a volatile-rich steam phase, and changes in $\mathrm{pH}$ accompanying these processes will play important roles in the transport and deposition chemistry of antimony. At temperatures $<100^{\circ} \mathrm{C}$ in surface hot springs, stibnite solubility will decrease further. Such an 
Figure (4.13) Stibnite solubility and antimony speciation from $\mathrm{pH}=4$ to 9 for $\mathrm{a} 70^{\circ} \mathrm{C}$ fluid with $\sim 15$ ppm sulfide. Gray shaded region indicates approximate $\mathrm{pH}$ range observed in Champagne Pool and associated range in stibnite solubility ( 4 to $20 \mathrm{ppb} \mathrm{Sb})$.

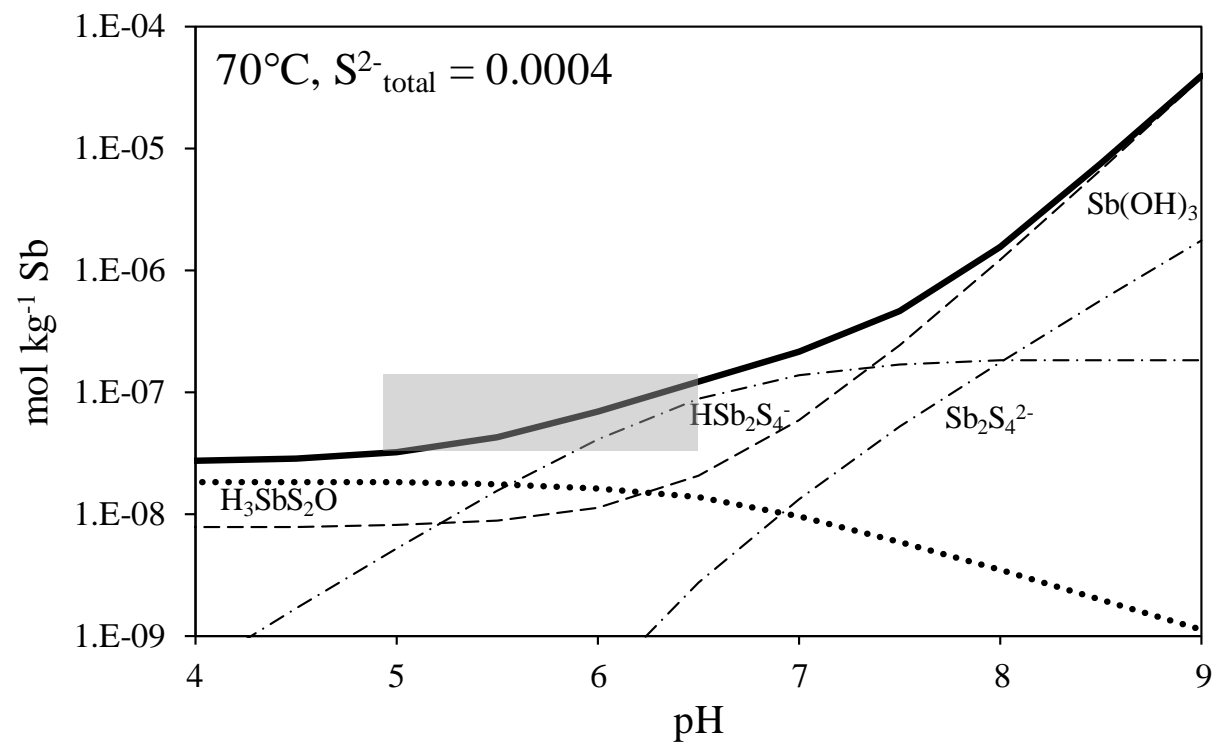

environment is represented in Figure (4.13) with a $70^{\circ} \mathrm{C}$ fluid containing 15 ppm sulfide. For these conditions, the dominant aqueous antimony species at stibnite saturation in slightly acidic fluids (indicated by gray shaded region) is $\mathrm{HSb}_{2} \mathrm{~S}_{4}{ }^{-}$. Stibnite solubility at $\mathrm{pH} \approx 6.5$ is $\sim 20 \mathrm{ppb}$ (i.e., $\sim 1.5$ $\mathrm{x} 10^{-7} \mathrm{~mol} \mathrm{~kg}^{-1}$ ) and then decreases with decreasing $\mathrm{pH}$ to $4 \mathrm{ppb}$ at $\mathrm{pH}=5$, which is a similar antimony concentration range to that observed in studies of trace metals in surface fluids from active hydrothermal systems in New Zealand and elsewhere (Pope et al., 2004; Pope et al., 2005; PlanerFriedrich and Scheinost, 2011; Ullrich et al., 2013).

\subsection{Conclusions}

The main findings from the high temperature solubility experiments presented in here are:

1) Stibnite solubility from 70 to $350^{\circ} \mathrm{C}$ with total sulfide concentration $\left(\mathrm{S}^{2-}{ }_{\text {total }}\right)$ from 0.003 to 0.06 mol kg-1 and between pH 3.5 to 9 requires a scheme of four species to account for the solubility curve. The four species were $\mathrm{Sb}_{2} \mathrm{~S}_{4}{ }^{2-}, \mathrm{HSb}_{2} \mathrm{~S}_{4}^{-}, \mathrm{H}_{3} \mathrm{SbS}_{2} \mathrm{O}$, and $\mathrm{Sb}(\mathrm{OH})_{3}$.

a. Between 70 to $110^{\circ} \mathrm{C}$, stibnite solubility was due to $\mathrm{Sb}_{2} \mathrm{~S}_{4}{ }^{2-}, \mathrm{HSb}_{2} \mathrm{~S}_{4}{ }^{-}$, and $\mathrm{H}_{3} \mathrm{SbS}_{2} \mathrm{O}$.

b. At $150^{\circ} \mathrm{C}$, all four complexes were present, with $\mathrm{Sb}(\mathrm{OH})_{3}$ contributing significantly to stibnite solubility in acidic and alkaline solutions with $\mathrm{S}^{2-}{ }_{\text {total }}<0.02 \mathrm{~mol} \mathrm{~kg}^{-1}$.

c. From 200 to $250^{\circ} \mathrm{C}, \mathrm{Sb}_{2} \mathrm{~S}_{4}{ }^{2-}, \mathrm{HSb}_{2} \mathrm{~S}_{4}^{-}$, and $\mathrm{Sb}(\mathrm{OH})_{3}$ were the major complexes. The stability of $\mathrm{Sb}(\mathrm{OH})_{3}$ continued to increase such that $\mathrm{Sb}_{2} \mathrm{~S}_{4}{ }^{2-}$ and $\mathrm{HSb}_{2} \mathrm{~S}_{4}{ }^{-}$were limited to $\mathrm{S}^{2-}{ }_{\text {total }} \geq 0.03 \mathrm{~mol} \mathrm{~kg}^{-1}$.

d. At 300 and $350^{\circ} \mathrm{C}, \mathrm{Sb}_{2} \mathrm{~S}_{4}{ }^{2-}$ and $\mathrm{Sb}(\mathrm{OH})_{3}$ were the only species present.

e. At $\sim 400^{\circ} \mathrm{C}$, stibnite solubility in supercritical fluids was extremely sensitive to pressure and solubilities are consistent with the presence of $\mathrm{Sb}(\mathrm{OH})_{3}$ at pressures $<350$ bar. 
The experimentally determined equilibrium constants up to $350^{\circ} \mathrm{C}$ are summarised in Table (4.9). The best fits to various forms of the Van't Hoff isochore, $\log K_{x y z w}=a+b \mathrm{~T}+c \mathrm{~T}^{2}+d \mathrm{~T}^{-1}+e \log _{10}(\mathrm{~T})$, are given in Table (4.10).

2) Stibnite solubility is independent of pressure from 70 to $350^{\circ} \mathrm{C}$ up to 250 bar. In supercritical solutions, stibnite solubility is strongly dependent on pressure and this temperature dependence can be described using $\log \mathrm{Sb}=a+b \log \left(\rho_{\mathrm{H} 2 \mathrm{O}}\right)$ with $a=-0.7052$ and $b=2.3693$ and the concentration of antimony in mol kg-1.

3) High temperature fluids in active hydrothermal systems containing $\sim 1 \times 10^{-5} \mathrm{~mol} \mathrm{~kg}^{-1} \mathrm{Sb}$ are undersaturated with respect to stibnite at $\geq 200^{\circ} \mathrm{C}$. At temperatures $<150^{\circ} \mathrm{C}$, these solutions may become oversaturated with respect to stibnite depending on the sulfide content and fluid $\mathrm{pH}$. In the slightly acidic and low sulfide concentrations of a hot spring such as Champagne Pool (Waiotapu), stibnite solubility is $\leq 4 \times 10^{-7} \mathrm{~mol} \mathrm{~kg}^{-1}$ (i.e., $<\sim 50 \mathrm{ppb}$ ).

The stibnite solubility experiments in this study confirmed that antimony speciation in reducing, sulfide-containing fluids changes from antimony-sulfide complexes to $\mathrm{Sb}(\mathrm{OH})_{3}$ with increasing temperature. The temperature at which this change occurs will vary depending on the sulfide concentration in the hydrothermal fluid. As shown in Figure (4.10), $\mathrm{Sb}(\mathrm{OH})_{3}$ controls stibnite solubility for a wide range of sulfide concentrations at $250^{\circ} \mathrm{C}$. In contrast, for lower temperature fluids within power stations (Figure 4.11), antimony-sulfide complexes started to contribute significantly to the total dissolved antimony, and at $150^{\circ} \mathrm{C}, 10 \%$ of the total dissolved antimony in a near neutral fluid was comprised of antimony-sulfide moieties. For hydrothermal fluids with typical sulfide concentrations (i.e., $10^{-4}$ to $10^{-2} \mathrm{~mol} \mathrm{~kg}^{-1} \mathrm{~S}^{2-}$ total), $\mathrm{Sb}(\mathrm{OH})_{3}$ alone can be used to model antimony behavior at temperatures $>150^{\circ} \mathrm{C}$, but at temperatures $\leq 150^{\circ} \mathrm{C}$ antimony sulfide complexes must be included in geochemical modeling. In addition, at sulfide concentrations $\geq 0.01 \mathrm{~mol} \mathrm{~kg}^{-1}$, the two dimers $\mathrm{HSb}_{2} \mathrm{~S}_{4}{ }^{-}$and $\mathrm{Sb}_{2} \mathrm{~S}_{4}{ }^{2-}$ will be the species defining stibnite solubility at near neutral to alkaline pH's.

\subsection{References}

Akinifiyev, N.N., Zotov, A.V., Shikina, N.D., 1994. Experimental studies and self-consistent thermodynamic data in the $\mathrm{Sb}(\mathrm{III})-\mathrm{S}(\mathrm{II})-\mathrm{O}-\mathrm{H}$ system. Geochem. Internat. 31, 27-40.

Barnes, H.L., Seward, T.M., 1997. Geothermal systems and mercury deposits, in: Barnes, H.L. (Ed.), Geochemistry of Hydrothermal Ore Deposits, 3rd ed. Wiley Interscience, New York, pp. 699736.

Belevantsev, V.I., Gushchina, L.I., Obolenskii, A.A., 1998. Solubility of stibnite, $\mathrm{Sb}_{2} \mathrm{~S}_{3}$ (cr):A revision of proposed interpretations and refinements. Geochem. Internat. 36, 58-64.

Brown, K.L., Simmons, S.F., 2003. Precious metals in high-temperature geothermal systems in New Zealand. Geothermics 32, 619-625.

Chambefort, I., Dilles, J.H., 2015. Trace metals and volatiles zoning in active geothermal systems, Proceedings of the 37th New Zealand Geothermal Workshop, Taupo, New Zealand.

Dorrington, P., Brown, K., 2000. Management of stibnite deposition at Ngawha, Proceedings of the 22nd New Zealand Geothermal Workshop, Auckland, New Zealand. 
Ellis, A.J., McFadden, I.M., 1972. Partial molal volumes of ions in hydrothermal solutions. Geochim. Cosmochim. Acta 36, 413-426.

Fylstra, D., Lasdon, L., Watson, J., Warren, A., 1998. Design and use of the Microsoft Excel Solver. Interfaces 28, 29-55.

Gushchina, L.V., Borovikov, A.A., Shebanin, A.P., 2000. Formation of antimony(III) complexes in alkali sulfide solutions at high temperatures: An experimental Raman spectroscopic study. Geochem. Internat. 38, 510-513.

Hannington, M.D., Harðardóttir, V., Garbe-Schönberg, D., Brown, K.L., 2016. Gold enrichment in active geothermal systems by acculating colloidal suspensions. Nature Geoscience.

Hardardottir, V., Brown, K.L., Fridriksson, T., Hedenquist, J.W., Hannington, M.D., Thorhallsson, S., 2009. Metals in deep liquid of the Reykjanes geothermal system, southwest Iceland: Implications for the composition of seafloor black smoker fluids. Geology 37, 1103-1106.

Heinrich, C.A., Driesner, T., Stefánsson, A., Seward, T.M., 2004. Magmatic vapor contraction and the transport of gold from the porphyry environment to epithermal ore deposits. Geology 32, 761.

Helgeson, H.C., 1969. Thermodynamics of hydrothermal systems at elevated temperatues and pressures. American Journal of Science 267, 729-804.

Helgeson, H.C., Kirkham, D.H., 1974. Theoretical prediction of the thermodynamic behavoir of aqueous electolytes at high pressures and temperatures: II. Debye-Huckel parameters for activity coefficients and relative partial molal properties. American Journal of Science 274, 1199-1261.

Ho, P.C., Palmer, D.A., 1996. Ion association of dilute aqueous sodium hydroxide solutions to $600^{\circ} \mathrm{C}$ and $300 \mathrm{MPa}$ by conductance measurements. Journal of Solution Chemistry 25, 711-729.

Ho, P.C., Palmer, D.A., Grusckiewicz, M.S., 2001. Conductivity measurements of dilute aqueous HCl solutions to high temperatures and pressures using a flow-through cell. Journal of Physcial Chemistry B 105, 1260-1266.

Ho, P.C., Palmer, D.A., Mesmer, R.E., 1994. Electrical conductivity measurements of aqueous sodium chloride solutions to $600^{\circ} \mathrm{C}$ and $300 \mathrm{MPa}$. Journal of Solution Chemistry 23, 997-1018.

Hurtig, N.C., Williams-Jones, A.E., 2015. Porphyry-epithermal Au-Ag-Mo ore formation by vaporlike fluids: New insights from geochemical modeling. Geology 43, 587-590.

Kielland, J., 1937. Individual activity coefficients of ions in aqueous solutions. J. Am. Chem Soc. 59, $1675-1678$.

Kolpakova, N.N., 1971. On the speciation of antimony (III) in sulfide solutions (in Russian), Geochemistry of Hydrothermal Ore Deposition, Nauka, Moscow, pp. 197-209.

Kolpakova, N.N., 1982. Laboratory and field studies of ioinic equilibria in the $\mathrm{Sb}_{2} \mathrm{~S}_{3}-\mathrm{H}_{2} \mathrm{O}-\mathrm{H}_{2} \mathrm{~S}$ system. Geochem. Internat. 19, 46-54.

Krupp, R.E., 1988. Solubility of stibnite in hydrogen sulfide solutions, speciation, and equilibrium constants, from 25 to $350^{\circ} \mathrm{C}$. Geochim. Cosmochim. Acta 52, 3005-3015.

Krupp, R.E., Seward, T.M., 1990. Transport and deposition of metals in the Rotokawa geothermal system, New Zealand. Min. Dep. 25, 73-81.

Landrum, J.T., Bennett, P.C., Engel, A.S., Alsina, M.A., Pastén, P.A., Milliken, K., 2009. Partitioning geochemistry of arsenic and antimony, El Tatio Geyser Field, Chile. Appl. Geochem. 24, 664676.

Learned, R.E., 1966. The solubilities of quartz, quartz-cinnabar and cinnabar-stibnite in sodium sulfide solutions and their implications for ore genesis, Department of Geology. University of California, Riverside, Riverside, California.

Marshall, W.L., Franck, E.U., 1981. Ion product of water substance, $0-1000^{\circ} \mathrm{C}, 1-10,000$ bars. New international formulation and its background. Journal of Physcial Reference Data 10, 295304.

Mesmer, R.E., Marshall, W.L., Palmer, D.A., Simonson, J.M., Holmes, H.F., 1988. Thermodynamics of aqueous association and ionization reactions at high temperatures and pressures. Journal of Solution Chemistry 17, 699-718.

Migdisov, A.A., Bychkov, A.Y., 1998. The behaviour of metals and sulphur during the formation of hydrothermal mercury-antimony-arsenic mineralization, Uzon caldera, Kamchatka, Russia. $J$. Volcanol. Geotherm. Res. 84, 152-171.

Morteani, G., Ruggieri, G., Möller, P., Preinfalk, C., 2010. Geothermal mineralized scales in the pipe system of the geothermal Piancastagnaio power plant (Mt. Amiata geothermal area): a key to 
understand the stibnite, cinnabarite and gold mineralization of Tuscany (central Italy). Min. Dep. 46, 197-210.

Mosselmans, J.F.W., Helz, G.R., Pattrick, R.A.D., Charnock, J.M., Vaughan, D.J., 2000. A study of speciation of $\mathrm{Sb}$ in bisulfide solutions by X-ray absorption spectroscopy. Appl. Geochem. 15, 879-889.

Planer-Friedrich, B., Scheinost, A.C., 2011. Formation and structural characterization of thioantimony species and their natural occurrence in geothermal waters. Environ. Sci. Technol. 45, 68556863.

Pokrovski, G.S., Borisova, A.Y., Bychkov, A.Y., 2013. Speciation and transport of metals and metalloids in geological vapors. Reviews in Mineralogy and Geochemistry 76, 165-218.

Pope, J.G., Brown, K.L., McConchie, D.M., 2005. Gold Concentrations in Springs at Waiotapu, New Zealand: Implications for Precious Metal Deposition in Geothermal Systems. Econ. Geol. 100, 677-687.

Pope, J.G., McConchie, D.M., Clark, M.D., Brown, K.L., 2004. Diurnal variations in the chemistry of geothermal fluids after discharge, Champagne Pool, Waiotapu, New Zealand. Chem. Geol. 203, 253-272.

Raymond, J., Williams-Jones, A., Clark, J., 2005. Mineralization associated with scale and altered rock and pipe fragments from the Berlín geothermal field, El Salvador; implications for metal transport in natural systems. J. Volcanol. Geotherm. Res. 145, 81-96.

Ruaya, J.R., Seward, T.M., 1987. The ion-pair constant and other thermodynamic properties of $\mathrm{HCl}$ up to $350^{\circ}$ C. Geochim. Cosmochim. Acta 51, 121-130.

Sherman, D.M., Ragnarsdottir, K.V., Oelkers, E.H., 2000. Antimony transport in hydrothermal solutions: an EXAFS study of antimony(V) complexation in alkaline sulfide and sulfidechloride brines at temperatures from $25^{\circ} \mathrm{C}$ to $300^{\circ} \mathrm{C}$ at $\mathrm{P}_{\text {sat. }}$ Chem. Geol. 167, 161-167.

Shikina, N.D., Zotov, A.V., 1999. Solubility of stibnite $\left(\mathrm{Sb}_{2} \mathrm{~S}_{3}\right)$ in water and hydrogen sulfide solutions at temperature of $200-300^{\circ} \mathrm{C}$ under-vapor saturated conditions and a pressure of 500 bars. Geochem. Internat. 37, 82-86.

Simmons, S.F., Brown, K.L., 2007. The flux of gold and related metals through a volcanic arc, Taupo Volcanic Zone, New Zealand. Geology 35, 1099-1102.

Simmons, S.F., Brown, K.L., Tutolo, B.M., 2016. Hydrothermal transport of Ag, $\mathrm{Au}, \mathrm{Cu}, \mathrm{Pb}, \mathrm{Te}, \mathrm{Zn}$ and other metals and metalloids in New Zealand geothermal systems: Spatial patterns, fluidmineral equilibria, and implications for epithermal mineralization. Econ. Geol. 111, 589-618.

Simmons, S.F., Browne, P.R.L., 2000. Hydrothermal minerals and precious metals in the BroadlandsOhaaki geothermal system: Implications for understanding low-sulfidation epithermal environments. Econ. Geol. 95, 971-999.

Simpson, M.P., Palinkas, S.S., Mauk, J.L., Bodnar, R.J., 2015. Fluid inclusion chemistry of adulariasericite epithermal Au-Ag deposits of the Southern Hauraki Goldfield, New Zealand. Econ. Geol. 110, 763-786.

Sonney, R., Mountain, B.W., 2013. Experimental simulation of greywacke-fluid interaction under geothermal conditions. Geothermics 47, 27-39.

Spang, B., 2002. Water97_v13.xla, http://www.cheresources.com/staff.shtml.

Spycher, N.F., Reed, M.H., 1989. As(III) and Sb(III) sulfide complexes: An evaluation of stoichiometry and stability from existing experimental data. Geochim. Cosmochim. Acta 53, 2185-2194.

Stauffer, R.E., Thompson, J.M., 1984. Arsenic and antimony in geothermal waters of Yellowstone National Park, Wyoming, USA. Geochim. Cosmochim. Acta 48, 2547-2561.

Stefánsson, A., Seward, T.M., 2004. Gold(I) complexing in aqueous sulphide solutions to $500^{\circ} \mathrm{C}$ at 500 bar. Geochim. Cosmochim. Acta 68, 4121-4143.

Suleimenov, O.M., Seward, T.M., 1997. A spectrophotometric study of hydrogen sulphide ionisation in aqueous solutions to $350^{\circ} \mathrm{C}$. Geochim. Cosmochim. Acta 61, 5187-5198.

Tagirov, B.R., Suleimenov, O.M., Seward, T.M., 2007. Zinc complexation in aqueous sulfide solutions: Determination of the stoichiometry and stability of complexes via $\mathrm{ZnS}_{(\mathrm{cr})}$ solubility measurements at 100C and 150 bars. Geochim. Cosmochim. Acta 71, 4942-4953.

Tanger, J.C.I., Helgeson, H.C., 1988. Calculation of the thermodynamic and transport properties of aqueous species at high pressures and temperatures: Revised equations of state for the 
standard partial molal properties of ions and electrolytes. American Journal of Science

288, 19-98.

Ullrich, M.K., Pope, J.G., Seward, T.M., Wilson, N., Planer-Friedrich, B., 2013. Sulfur redox chemistry governs diurnal antimony and arsenic cycles at Champagne Pool, Waiotapu, New Zealand. J. Volcanol. Geotherm. Res. 262, 164-177.

Wagner, W., Cooper, J.R., Dittman, A., Kijima, J., Kretzschmar, H.-J., Kruse, A., Mareš, R., Oguchi, K., Sato, H., Stöcker, I., Šifner, O., Takaishi, Y., Trübenbach, J., Wilkommen, T., 2000. The IAPWS industrial formulation 1997 for the thermodynamic properties of water and steam. ASME Journal of Engineering for Gas Turbines and Power 122, 150-182.

Ward, K.T., Brown, K.L., Webster-Brown, J., 2006. Mineral precipitation in the Rotokawa geothermal power station, New Zealand. Proceedings 28th New Zealand Geothermal Workshop.

Weissberg, B.G., 1969. Gold-silver ore-grade precipiates from New Zealand thermal waters. Econ. Geol. 64, 95-108.

Weissberg, B.G., Browne, P.R.L., Seward, T.M., 1979. Ore metals in active geothermal systems, in: Barnes, H.L. (Ed.), Geochemistry of Hydrothermal Ore Deposits, 2nd ed. Wiley Interscience, New York, pp. 738-780.

Williams-Jones, A.E., Heinrich, C.A., 2005. Vapor transport of metals and the formation of magmatichydrothermal ore deposits. Econ. Geol. 100, 1287-1312.

Williams-Jones, A.E., Normand, C., 1997. Controls of mineral parageneses in the system Fe-Sb-S-O. Econ. Geol. 92, 308-324.

Wilson, N., Webster-Brown, J., Brown, K., 2007. Controls on stibnite precipitation at two New Zealand geothermal power stations. Geothermics 36, 330-347.

Wood, S.A., Crerar, D.A., Borcsik, M.P., 1987. Solubility of the assemblage pyrite-pyrrhotitemagnetite-sphalerite-galena-gold-stibnite-bismuthinite-argenitite-molybdenite in $\mathrm{H}_{2} \mathrm{O}-\mathrm{NaCl}$ $\mathrm{CO}_{2}$ solutions from 200 to $350^{\circ}$ C. Econ. Geol. 82, 1864-1887.

Zakaznova-Herzog, V.P., Seward, T., 2006. Antimonous acid protonation/deprotonation equilibria in hydrothermal solutions to $300^{\circ} \mathrm{C}$. Geochim. Cosmochim. Acta 70, 2298-2310.

Zotov, A.V., Shikina, N.D., Akinfiev, N.N., 2003. Thermodynamic properties of the Sb(III) hydroxide complex $\mathrm{Sb}(\mathrm{OH})_{3(\mathrm{aq})}$ at hydrothermal conditions. Geochim. Cosmochim. Acta 67, 1821-1836. 


\section{Chapter (5):}

\section{Antimony geochemistry in hydrothermal solutions: Concluding remarks}

\subsection{Summary of results}

The aim of this study was to determine the aqueous antimony species present at stibnite saturation in reducing solutions containing moderate to high concentrations of dissolved sulfide ( $\mathrm{S}^{2-}$ total $=0.001$ to $0.1 \mathrm{~mol} \mathrm{~kg}^{-1}$ ) from ambient to supercritical conditions and to obtain the heterogeneous equilibrium constants for stibnite dissolution in equilibrium with these antimony species. This was undertaken because these constants are needed to accurately predict antimony solubility in sulfidic fluids in natural hydrothermal systems. In addition, there is disagreement amongst previously published studies using various techniques (e.g., solubility, Raman spectroscopy, and X-ray absorption spectroscopy), and it was of interest to try to resolve these discrepancies. Thus, an additional aim of this study was to investigate the utility of using both solubility and spectroscopic experimental approaches to study complementary solutions. These objectives were accomplished by combining $30^{\circ} \mathrm{C}$ flow-through stibnite solubility experiments (Chapter 2), ambient temperature X-ray absorption spectroscopy measurements (Chapter 3), and high-temperature flow-through stibnite solubility experiments (Chapter 4). The main findings from these Chapters are:

Chapter (2): Stibnite solubility and antimony speciation in aqueous sulfide solutions at $30^{\circ} \mathrm{C}$ The aqueous antimony species present at ambient temperatures are $\mathrm{Sb}_{2} \mathrm{~S}_{4}{ }^{2-}, \mathrm{H}_{2} \mathrm{Sb}_{2} \mathrm{~S}_{5}{ }^{2-}, \mathrm{HSb}_{2} \mathrm{~S}_{4}^{-}$ , $\mathrm{H}_{3} \mathrm{SbS}_{2} \mathrm{O}, \mathrm{Sb}(\mathrm{OH})_{3}$, and $\mathrm{H}_{2} \mathrm{SbO}_{3}$. Stibnite solubility in moderately to strongly alkaline solutions is solely due to $\mathrm{Sb}_{2} \mathrm{~S}_{4}{ }^{2-}$ over a wide range of sulfide concentrations from 0.1 to $\sim 0.0005 \mathrm{~mol} \mathrm{~kg}^{-1}$. Between $\mathrm{pH} \sim 9$ and $\sim 5$, partially protonated antimony-sulfide dimers $\left(\mathrm{H}_{2} \mathrm{Sb}_{2} \mathrm{~S}_{5}{ }^{2-}\right.$ and/or $\mathrm{HSb}_{2} \mathrm{~S}_{4}{ }^{-}$ depending on sulfide concentrations) are the stable antimony species at sulfide concentrations from 0.001 to $0.01 \mathrm{~mol} \mathrm{~kg}^{-1}$. Neutral monomers $\left(\mathrm{H}_{3} \mathrm{SbS}_{2} \mathrm{O}\right.$ and/or $\mathrm{Sb}(\mathrm{OH})_{3}$ depending on sulfide concentration) make stibnite solubility independent of $\mathrm{pH}$ in moderately acidic solutions (i.e., at $\mathrm{pH}<$ $\sim 5$ ). At sulfide concentrations $\leq 0.0001 \mathrm{~mol} \mathrm{~kg}^{-1}, \mathrm{Sb}(\mathrm{OH})_{3}$ is a major species at $\mathrm{pH}<7$ and the predominant species at $\mathrm{pH}>8$. Equilibrium constants for the heterogeneous solubility reactions at $30^{\circ} \mathrm{C}$ were summarised in Table (2.8). 
Chapter (3): X-ray absorption spectroscopy measurements of antimony-sulfide andhydroxide complexes at stibnite saturation

Average first coordination shells in alkaline solutions are consistent with $\mathrm{Sb}_{2} \mathrm{~S}_{4}{ }^{2-}$ at moderate to high sulfide concentrations. At low sulfide concentrations, EXAFS are consistent with mixture of $\mathrm{Sb}_{2} \mathrm{~S}_{4}{ }^{2-}, \mathrm{Sb}(\mathrm{OH})_{3}$, and $\mathrm{H}_{2} \mathrm{SbO}_{3}{ }^{-}$. The quality of the XAS spectra produced by millimolar antimony concentrations $\left(\leq 0.005 \mathrm{~mol} \mathrm{~kg}^{-1}\right)$ in aqueous samples is too poor to enable detection of the first shell antimony atoms. However, the combination of XAS average coordination shells with the alkaline solubility curve enabled the elimination of the speciation model including antimony-sulfide monomers (i.e., $\mathrm{SbS}_{3}{ }^{3-}$ and $\mathrm{HSbS}_{2} \mathrm{O}^{2-}$ ) at high $\mathrm{pH}$.

Chapter (4): Stibnite solubility and antimony speciation in hydrosulfide solutions from 70 to $400^{\circ} \mathrm{C}$

The antimony species in aqueous sulfide solutions in equilibrium with stibnite at temperatures $>70^{\circ} \mathrm{C}$ are $\mathrm{Sb}_{2} \mathrm{~S}_{4}{ }^{2-}, \mathrm{HSb}_{2} \mathrm{~S}_{4}^{-}, \mathrm{H}_{3} \mathrm{SbS}_{2} \mathrm{O}$, and $\mathrm{Sb}(\mathrm{OH})_{3}$. With increasing temperature, the stability of neutral antimonous acid, $\mathrm{Sb}(\mathrm{OH})_{3}$, increases relative to the stability of the antimony-sulfide species. At temperatures $>300^{\circ} \mathrm{C}, \mathrm{Sb}(\mathrm{OH})_{3}$ is the only important species except at elevated sulfide concentrations (i.e., $\geq 0.05 \mathrm{~mol} \mathrm{~kg}^{-1}$ ). As a result, the relationship of stibnite solubility to changes in sulfide concentration changes with temperature. At $\mathrm{t}<\sim 150^{\circ} \mathrm{C}$ when antimony-sulfide complexes are stable, stibnite solubility increases with increasing sulfide concentration in near neutral fluids for the range of sulfide concentrations found in deep New Zealand geothermal fluids ( $\sim 0.0003$ to $\sim 0.007$ mol $\left.\mathrm{kg}^{-1}\right)$. In contrast, the relationship is reversed and stibnite solubility decreases with increasing sulfide concentration at $\mathrm{t}>200^{\circ} \mathrm{C}$. In supercritical fluids with vapour-like density between 390 and $406^{\circ} \mathrm{C}$, stibnite solubility was strongly dependent on fluid density, but the relationship to input $\mathrm{pH}, \mathrm{Cl}^{-}$, and sulfide concentration was consistent with the presence of $\mathrm{Sb}(\mathrm{OH})_{3}$. Equilibrium constants for the heterogeneous solubility reactions up to $350^{\circ} \mathrm{C}$ are summarised in Tables (4.9).

The thermodynamic data presented in this chapter were used to predict antimony saturation for conditions within the Rotokawa and Ngawha geothermal power stations in New Zealand (Figure 4.12) and highlighted the need for better thermodynamic data the heterogeneous stibnite- $\mathrm{Sb}(\mathrm{OH})_{3}$ equilibrium between 90 and $150^{\circ} \mathrm{C}$. This, however, was not the focus of the current study which was targeted at $\mathrm{Sb}$ (III)-sulfide complexes. The formation of stibnite scaling within these two stations was largely due to a temperature decrease from the geothermal well (temperatures 200 to $220^{\circ} \mathrm{C}$ ) to the exit of the heat-exchangers $\left(\sim 90^{\circ} \mathrm{C}\right.$ at Ngawha and $\sim 150^{\circ} \mathrm{C}$ at Rotokawa). In addition, a pH decrease from $\mathrm{pH}=7$ to $\sim 6$, resulting from the addition of condensed vapour, has the potential to decrease stibnite stability by $\sim 1 \mathrm{ppm}$ at $150^{\circ} \mathrm{C}$ or several hundred ppb at $100^{\circ} \mathrm{C}$. 


\subsection{Scope of current study and avenues for future research}

Stability of $\mathrm{Sb}(\mathrm{OH})_{3}$ at temperatures $<200^{\circ} \mathrm{C}$

This study was focused on the stoichiometry and stability of antimony-sulfide complexes in the $\mathrm{Sb}$ (III)-S(II)- $\mathrm{H}_{2} \mathrm{O}$ system and most experiments were conducted at sulfide concentrations between 0.01 and $0.1 \mathrm{~mol} \mathrm{~kg}^{-1}$, from $\mathrm{pH} 4$ to 12 , and from 30 to $350^{\circ} \mathrm{C}$. The thermodynamic equilibrium constants derived from these experiments can be applied to natural systems to gain insight into antimony transport chemistry and stibnite deposition. However, many reducing fluids in natural settings contain total reduced sulfur concentrations $<0.01 \mathrm{~mol} \mathrm{~kg}^{-1}$. This study has confirmed that $\mathrm{Sb}(\mathrm{OH})_{3}$ is major species at moderate to low sulfide concentrations and at elevated temperatures, particularly at $\mathrm{t}>200^{\circ} \mathrm{C}$. Thus, thermodynamic modeling of antimony geochemistry will still benefit from additional experimental data in the $\mathrm{Sb}$ (III)-S(II)-O-H system at sulfide concentrations $\leq 0.005$ mol kg-1. As noted in the introduction to Chapter (4), published values for heterogeneous equilibrium constant for $\mathrm{Sb}(\mathrm{OH})_{3}$ are based on antimony-oxide $\left(\mathrm{Sb}(\mathrm{III})_{2} \mathrm{O}_{3(\mathrm{~s})}\right)$ solubility experiments in the $\mathrm{Sb}$ (III)$\mathrm{O}-\mathrm{H}$ system at temperatures $<200^{\circ} \mathrm{C}$ and on stibnite solubility experiments at low sulfide concentrations and in pure water at temperatures $\geq 200^{\circ} \mathrm{C}$. The agreement between these high temperature stibnite solubility experiments is excellent (Figure 4.1). The current study has added to the available experimental data for $\mathrm{K}_{1033}$ at $30^{\circ} \mathrm{C}$ and at 150 through $400^{\circ} \mathrm{C}$. However, the variation in reported values within the current and previous studies suggests that more experimental solubility studies are needed from ambient temperature and up to at least $150^{\circ} \mathrm{C}$.

\section{XAS measurements in alkaline solutions at low sulfide concentrations}

$\mathrm{X}$-ray absorption spectroscopic measurements were completed on alkaline solutions containing 0.0003 to $0.005 \mathrm{~mol} \mathrm{~kg}^{-1} \mathrm{Sb}$. These experiments presented in Chapter (3) were able to quantify the average coordination environment of antimony, and partially delineate the change from sulfide to hydroxide ligands in decreasing sulfide concentration. The selection of solutions in the current study did not include enough solutions with $\mathrm{S}: \mathrm{Sb}$ ratios between approximately 1:3 and 6:1 in order to distinguished between various speciation models containing different antimony(III)-sulfidehydroxide complexes, such as $\mathrm{HSbS}_{2} \mathrm{O}^{2-}$ or $\mathrm{H}_{2} \mathrm{SbSO}_{2}{ }^{-}$. Combining XAS measurements of $\mathrm{Sb}$ (III) in strongly alkaline solutions with sulfide concentrations $\leq 0.001 \mathrm{~mol} \mathrm{~kg}^{-1}$ and stibnite solubility experiments in similar solutions could be used to investigate the transition between a strongly charged antimony-sulfide dimer (i.e., $\mathrm{Sb}_{2} \mathrm{~S}_{4}{ }^{2-}$ ) and a neutral antimony-hydroxide monomer (i.e., $\left.\mathrm{Sb}(\mathrm{OH})_{3}\right)$. The interpretation of the EXAFS results from such experiments could be assisted by including complementary suites of solutions with similar $\mathrm{S}: \mathrm{Sb}$ ratios buffered above and below the pKa of $\mathrm{Sb}(\mathrm{OH})_{3}$ (i.e., at $\mathrm{pH}=11.5$ and 12.5 ), so that the relative magnitude of the contributions of $\mathrm{Sb}(\mathrm{OH})_{3}$ and $\mathrm{H}_{2} \mathrm{SbO}_{3}{ }^{-}$could be constrained. 


\section{$X A S$ measurements at stibnite saturation at temperatures $\geq 150^{\circ} \mathrm{C}$}

Previous high temperature XAS are summarised in Figure (4.10) and were able to detect the change in predominate ligand complexing antimony beginning at $\sim 150^{\circ} \mathrm{C}$. The strongly alkaline $\mathrm{pH}$ conditions for most of these experiments make them difficult to quantitatively compare to the current study or to natural systems. The stibnite solubilities measured in this study indicate that in a solution with $\mathrm{pH}=8$ and a sulfide concentration of $0.02 \mathrm{~mol} \mathrm{~kg}^{-1}$, the antimony concentration would be at millimolar levels $\left(0.001 \mathrm{~mol} \mathrm{~kg}^{-1}\right)$ by $\sim 200^{\circ} \mathrm{C}$ and have comparable concentrations of $\mathrm{Sb}(\mathrm{OH})_{3}$ and $\mathrm{HSb}_{2} \mathrm{~S}_{4}{ }^{-}$between $\sim 230$ and $250^{\circ} \mathrm{C}$ (Figure 5.1). Measurements of antimony speciation in a hightemperature XAS cell might provide independent verification of the speciation model presented here or identify a transitional species present that was not identified in the current study due to the limited number of different input sulfide concentrations used.

Figure (5.1) Stibnite solubility and antimony species distribution from 300 to $80^{\circ} \mathrm{C}$ at $\mathrm{pH}=8$ and a sulfide concentration of $0.02 \mathbf{~ m o l ~ k g}^{-1}$ at swvp. The range of antimony concentrations used in this study for XAS analysis (Chapter 3) is indicated by gray shaded area $\left(0.0003\right.$ to $\left.0.005 \mathrm{~mol} \mathrm{~kg}^{-1}\right)$. Future XAS experiments could target total antimony concentrations $\sim 0.001 \mathrm{~mol} \mathrm{~kg}^{-1}$ where both $\mathrm{Sb}(\mathrm{OH})_{3}$ and antimony-sulfide species constitute a large proportion of the total dissolved antimony.

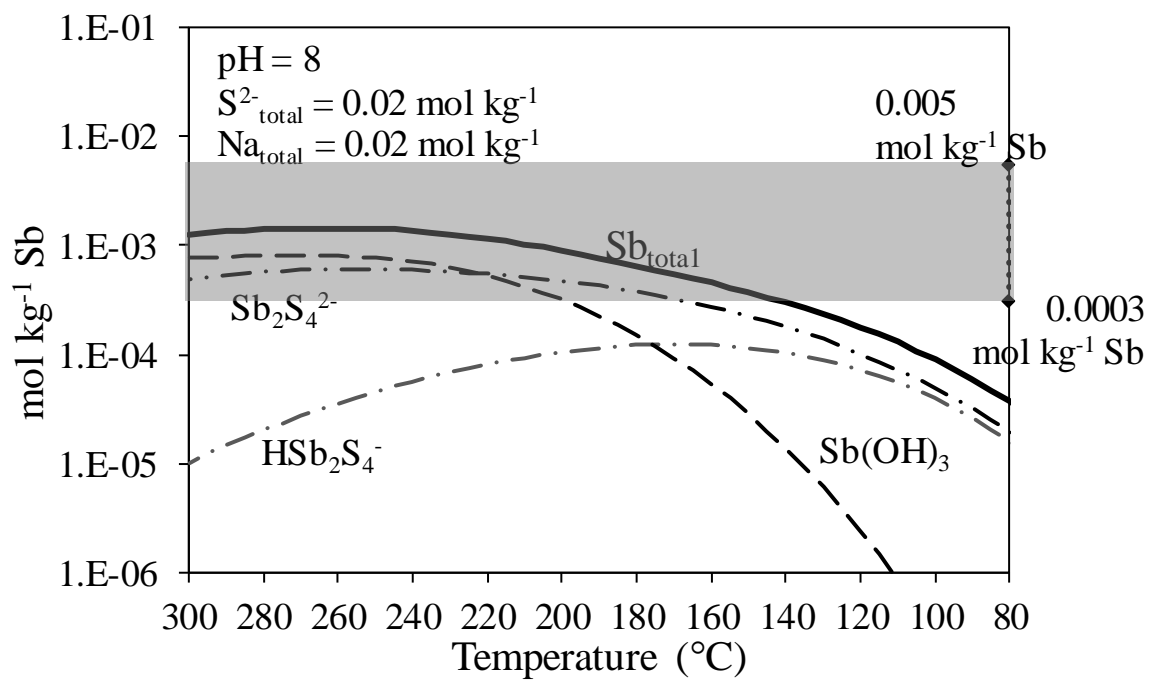

\section{Stibnite solubility in supercritical aqueous fluids}

Experiments were undertaken in this study which measured stibnite solubility in supercritical fluids at $\mathrm{t} \sim 400^{\circ} \mathrm{C}$. The $\mathrm{pH}$ and sulfide concentration of these solutions covered a limited range and the fluids were limited to fluids with vapour-like densities. The experiments were made challenging by the cooling of solutions between the back-pressure regulator (near $400^{\circ} \mathrm{C}$ ) and the sampling syringe, which is part of the basic setup of a continuous flow through system. In addition, there has been evidence that in aqueous vapor, antimony solubility is enhanced by the formation of volatile chloride complexes. The high stibnite solubilities measured in the few experiments in this study conducted in supercritical conditions indicated that antimony can be effectively transported in low salinity fluids (the chloride concentration in this study was $3 \times 10^{-4} \mathrm{~mol} \mathrm{~kg}^{-1}$ ) with vapour-like densities. Metal and 
metalloid transport in such fluids has been invoked in models for the formation of porphyry copper deposits (e.g., Pokrovski et al., 2013 and references therein). The extremely high stibnite solubilities in fluids approaching fluid-like densities make solubility experiments difficult to measure in a flow through experimental apparatus.

\section{Antimony(V)-sulfide complexation}

The current study was focused on $\mathrm{Sb}(\mathrm{III})-\mathrm{S}$ (II) interactions and atmospheric oxygen was eliminated from experimental solutions to prevent the formation of $\mathrm{Sb}(\mathrm{V})$ or more oxidized forms of sulfur. Evidence for $\mathrm{Sb}(\mathrm{V})$-sulfide interactions has been found by $\mathrm{UV}$-vis and $\mathrm{X}$-ray absorption spectroscopy (Kunkely and Vogler, 1995; Sherman et al., 2000), by stibnite solubility measurements in a system containing sulfide and elemental (i.e., zero valent) sulfur (Helz, 2002), and by LC-ICP-MS analysis of 20 to $90^{\circ} \mathrm{C}$ fluids from natural hot springs and their outflows (Planer-Friedrich and Scheinost, 2011; Ullrich et al., 2013).

Helz et al. (2002) measured stibnite solubility from $\mathrm{pH}=7.6$ to 10.1 in the presence of both sulfide and elemental sulfur and interpreted the results in terms a mixed-valence $\mathrm{Sb}(\mathrm{III}, \mathrm{V})$ dimer and a $\mathrm{Sb}(\mathrm{V})$ dimer, specifically $\mathrm{HSb}(\mathrm{III}, \mathrm{V})_{2} \mathrm{~S}_{5}{ }^{-}$and $\mathrm{Sb}(\mathrm{V})_{2} \mathrm{~S}_{6}{ }^{2-}$. The $\mathrm{Sb}-\mathrm{S}$ stoichiometry of the mixed-valence complex (HSb(III,V) $\left.{ }_{2} \mathrm{~S}_{5}^{-}\right)$proposed by Helz et al. (2002) was the same as for the $\mathrm{Sb}(\mathrm{III})$ dimer proposed in this study (i.e., $\mathrm{H}_{2} \mathrm{Sb}_{2} \mathrm{~S}_{5}{ }^{2-}$ ). However, the solubility measured by Helz et al. (2002) was generally $\sim 2$ orders of magnitude higher than the current study for comparable sulfide concentrations and $\mathrm{pH}$. In addition, the solubility curve measured by Helz et al. (2002) was not independent of $\mathrm{pH}$ between $\mathrm{pH}=7.5$ and 9.5, as it measured in the current study (Figure 2.5). Instead, stibnite solubility increased with decreasing $\mathrm{pH}$ when $\mathrm{pH}<9.5$. These findings and the later LC-ICP-MS studies suggest that $\mathrm{Sb}(\mathrm{V})-\mathrm{S}(\mathrm{II})$ interactions are an important part of antimony geochemistry at the interface between hydrothermal and surface environments.

Although reduced geothermal fluids can be modeled with the thermodynamic data presented in this study, accurate modeling of antimony geochemistry in environmental settings or in the outflow of hot springs will require thermodynamic data for antimony(V)-sulfide complexes, which is currently extremely limited (i.e., only available for $\mathrm{Sb}_{2} \mathrm{~S}_{6}{ }^{2-}(\mathrm{Helz}, 2002)$ and for $\mathrm{SbS}_{4}{ }^{3-}$ (Akeret, 1953; see compilation in Filella and May, 2003)). X-ray absorption spectroscopy (Sherman et al., 2000) and LCICP-MS studies (Planer-Friedrich and Scheinost, 2011; Ullrich et al., 2013) appear to confirm the $\mathrm{SbS}_{4}$ stoichiometry, but LC-ICP-MS also suggests the presence of an antimony(V) species with $\mathrm{SbS}_{3}$ stoichiometry (possibly $\mathrm{Sb}_{2} \mathrm{~S}_{6}{ }^{2-}$ ?). The UV-vis spectra of $\mathrm{Na}_{3}\left[\mathrm{SbS}_{4}\right] \cdot 9 \mathrm{H}_{2} \mathrm{O}$ (Schlippe's Salt) dissolved in a $0.001 \mathrm{M} \mathrm{NaOH}$ solution was consistent with $\mathrm{SbS}_{4}{ }^{3-}$ (Kunkely and Vogler, 1995). This experiment and the quantum chemical calculations of Tossell (2003a, b) who obtained the UV-vis spectra of $\mathrm{Sb}(\mathrm{V})$-sulfide complexes and their oxidation energetics and deprotonation energies could provide the starting point for $\mathrm{UV}$-vis measurements of $\mathrm{Sb}(\mathrm{V})$ in solutions with a wide range of $\mathrm{pH}$ and sulfide concentrations. 


\subsubsection{Ruminations on the value of combining solubility and spectroscopic experimental techniques}

The use of complementary solubility and XAS studies in this work demonstrated that XAS spectroscopy on its own did not identify the thermodynamically stable complex dimer, i.e., $\mathrm{Sb}_{2} \mathrm{~S}_{4}{ }^{2-}$, by detection of an $\mathrm{Sb}-\mathrm{Sb}$ interaction at the appropriate distance. Nevertheless, some speciation models (specifically $\mathrm{SbS}_{3}{ }^{3-}+\mathrm{HSbS}_{2} \mathrm{O}^{2-}$ ) could be eliminated when the average first shell coordination numbers derived from EXAFS were combined with the results from solubility experiments. This demonstrates that XAS results may be interpreted erroneously in this system if considered in isolation and that the interpretation of the solubility data can be enhanced by the inclusion of complimentary spectroscopic measurements. As only the fourth study to attempt to use XAS to study $\mathrm{Sb}$ (III)-S(II) interactions in solution, the current work emphasizes the importance of different techniques, in this case solubility and XAS, in elucidating reliable stoichiometries and stabilities of aqueous species in redox sensitive, heterogeneous systems involving sparingly soluble compounds (e.g., sulfides).

\subsection{Implications for antimony transport by hydrothermal fluids in the Earth's crust}

Multiple studies of antimony concentrations in hydrothermal fluids (Simmons et al., 2016), hydrothermally altered rocks (Simmons and Browne, 2000; Chambefort and Dilles, 2015), and ore deposits (Goldfarb et al., 2005) have demonstrated that antimony (along with arsenic and mercury) is an element that can be readily transported to the Earth's surface or the distal parts of a hydrothermal system. In light of the results from the current study, this occurs because appreciable concentrations of antimony (100 to $1000 \mathrm{ppb}$ ) can be dissolved in near neutral fluids at temperatures $>100^{\circ} \mathrm{C}$ due to the stability of $\mathrm{Sb}(\mathrm{OH})_{3}$ at higher temperatures (at $\mathrm{t}>\sim 120^{\circ} \mathrm{C}$ for $\mathrm{S}^{2-}{ }_{\text {total }}=0.001 \mathrm{~mol} \mathrm{~kg}^{-1}$ ) and due to the stability of $\mathrm{HSb}_{2} \mathrm{~S}_{4}{ }^{-}$at lower temperatures (at $\mathrm{t}<\sim 120^{\circ} \mathrm{C}_{\text {for }} \mathrm{S}^{2-}{ }_{\text {total }}=0.001 \mathrm{~mol} \mathrm{~kg}^{-1}$ ) for sulfide concentrations typical in crustal hydrothermal systems.

The stability of the $\mathrm{Sb}(\mathrm{OH})_{3}$ complex at higher temperatures means that, if boiling occurs at reservoir conditions with temperatures between 200 and $300^{\circ} \mathrm{C}$, the predominant aqueous antimony complex is not destabilized by the loss of $\mathrm{H}_{2} \mathrm{~S}_{\text {(aq) }}$ to the vapor phase (and resulting decrease of HSligands). This is the case in most developed New Zealand geothermal systems where the reservoirs are generally two-phase. Antimony's behavior during boiling is in contrast to gold ( $\mathrm{Au}$ ) and other "softer" metals that are transported as sulfide complexes at these temperatures (Seward, 1989; Stefánsson and Seward, 2004) and thus are sensitive to decreases in the activity of reduced sulfur. In addition, when $\mathrm{Sb}(\mathrm{OH})_{3}$ is the major aqueous species, stibnite solubility in slightly acidic fluids does not change if the $\mathrm{pH}$ is decreased during boiling, oxidation, fluid mixing, or reaction with wallrock because the stability of the $\mathrm{Sb}(\mathrm{OH})_{3}$ complex is independent of $\mathrm{pH}$ at $\mathrm{pH}<\mathrm{pKa}$ of $\mathrm{H}_{2} \mathrm{~S}$. This can be seen by comparing the left and right hand panels of Figure (5.2), which show the decrease in stibnite solubility from 270 to $70^{\circ} \mathrm{C}$ for two $\mathrm{pH}$ 's $(\mathrm{pH}=5.5$ and 6.5$)$ and three sulfide contents $(0.01,0.001$, and 0.0001 
Figure (5.2) Stibnite solubility and antimony species distribution from 270 to $70^{\circ} \mathrm{C}$ at $\mathrm{pH}=5.5(\mathrm{~A}, \mathrm{~B}$, and C) and $\mathrm{pH}=6.5\left(\mathrm{D}, \mathrm{E}\right.$, and F) for sulfide concentrations of $0.01,0.001$, and $0.0001 \mathrm{~mol} \mathrm{~kg}^{-1}$. Plots are at swvp. The range of antimony concentrations reported by Simmons et al. (2016) in reservoir fluids sampled from seven New Zealand geothermal systems is indicated by the gray region (i.e., 7 to $1230 \mu \mathrm{g} \mathrm{kg}^{-1}$ or $\sim 6 \times 10^{-8}$ to $\left.1 \times 10^{-5} \mathrm{~mol} \mathrm{~kg}^{-1}\right)$.
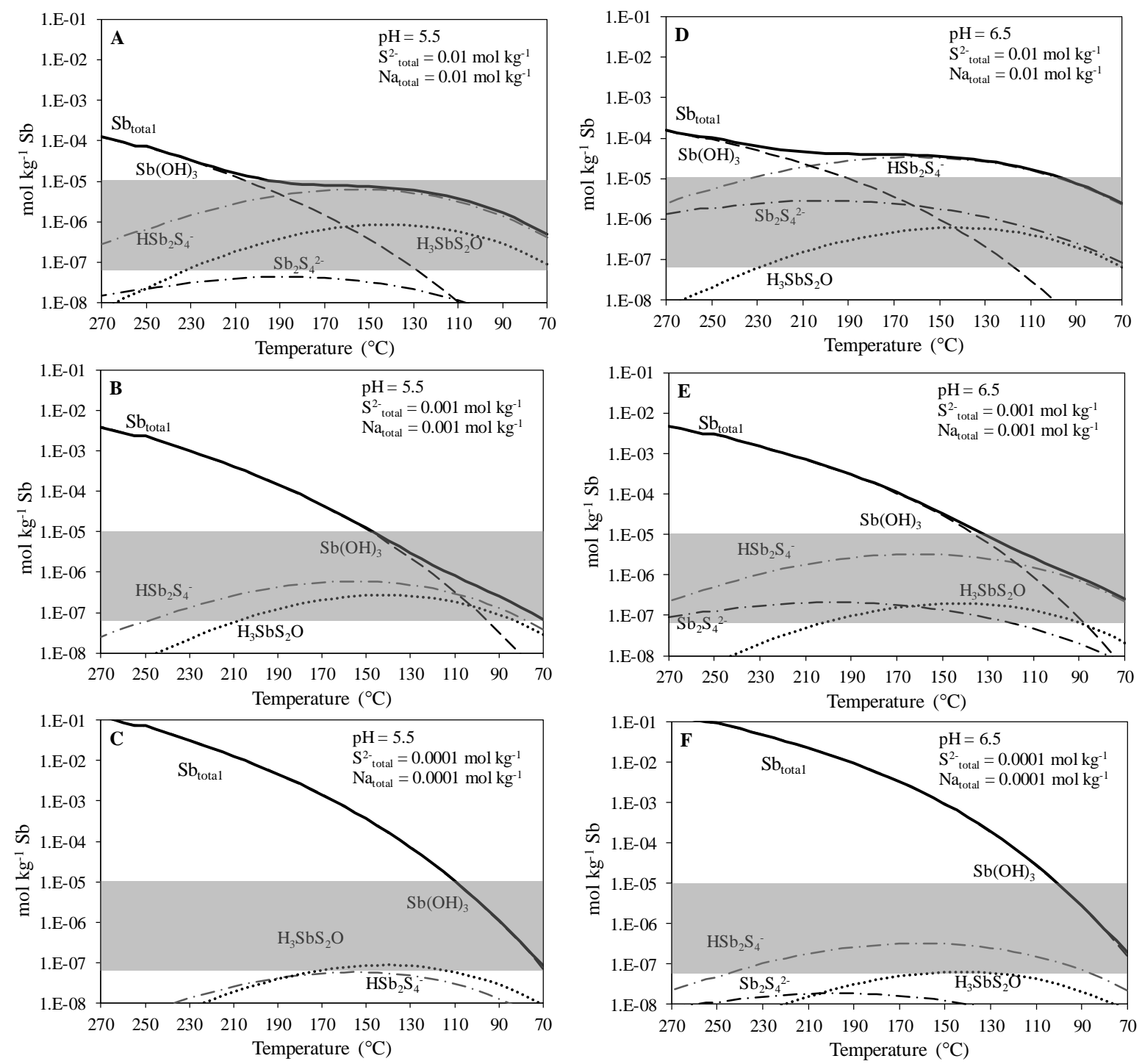

mol kg-1 ${ }^{-1}$. The $\mathrm{Sb}(\mathrm{OH})_{3}$ curve, which defines stibnite solubility in all plots at temperatures $>\sim 240^{\circ} \mathrm{C}$, is the same at $\mathrm{pH}=5.5$ (left panels) and at $\mathrm{pH}=6.5$ (right panels). The difference between the left and right plots is produced by antimony-sulfide species.

When antimony-sulfide complexes are predominant, specifically $\mathrm{HSb}_{2} \mathrm{~S}_{4}{ }^{-}$at the near neutral conditions used in Figure (5.2), stibnite solubility will decrease with decreases in temperature, $\mathrm{pH}$, and sulfide concentration. Such conditions might be encountered the lower-temperature peripheries of hydrothermal systems, particularly for systems with $\mathrm{pH}$ and sulfide concentrations at the, respectively, low and high ranges of what is observed in natural systems (i.e., Figure 5.2A). The gray shaded region (Figure 5.2) shows the range of antimony concentrations ( $10 \mathrm{ppb}$ to $\sim 1 \mathrm{ppm}$ ) reported by Simmons et al. (2016) in reservoir fluids sampled at depth from seven New Zealand geothermal systems and suggests that under certain conditions, namely $\mathrm{pH} \leq 5.5$, sulfide concentrations $\sim 0.01 \mathrm{~mol} \mathrm{~kg}^{-1}$, and antimony concentrations $\sim 1 \mathrm{ppm}$ (Figure 5.2A), geothermal fluids may reach saturation with stibnite 
at temperatures as high as $\sim 200^{\circ} \mathrm{C}$. However more commonly, stibnite will not become saturated until temperatures $<150^{\circ} \mathrm{C}$, especially considering that antimony concentrations are often $<500 \mathrm{ppb}(\sim$ $\left.4 \times 10^{-6} \mathrm{~mol} \mathrm{~kg}^{-1}\right)$. The most rapid decrease in stibnite solubility represented in Figure (5.2) occurs in fluids with the lowest sulfide concentration $\left(0.0001 \mathrm{~mol} \mathrm{~kg}^{-1}\right.$, Figures $5.2 \mathrm{C}$ and $\left.5.2 \mathrm{~F}\right)$ in response to a temperature decrease. For these conditions, stibnite solubility decreases by two orders of magnitude from $\sim 1 \times 10^{-5}$ to $\sim 1 \times 10^{-7} \mathrm{~mol} \mathrm{~kg}^{-1}(\sim 1 \mathrm{ppm}$ to $\sim 10 \mathrm{ppb})$ over a temperature decrease of $40^{\circ} \mathrm{C}$ from 110 to $70^{\circ} \mathrm{C}$ (Figures 5.1C and 5.1F). In natural hydrothermal systems, changes in $\mathrm{pH}$ and sulfide concentration will accompany temperature decreases, and thus the path of stibnite solubility will be more complicated than the curves represented in Figure (5.2).

Over the temperature range from ambient to hydrothermal, antimony-ligand interactions change from interactions that produce charged complexes with softer, more covalent bonding (i.e., with $\mathrm{HS}^{-}$and $\mathrm{S}^{2-}$ ) at lower temperatures to neutral complexes with harder, more ionic bonding at higher temperatures (i.e., $\mathrm{OH}^{-}$). This behavior means that the way in which stibnite solubility responds to changes in $\mathrm{pH}$ and sulfide ligand availability will vary with temperature. From a geothermal geochemistry perspective, the stability of $\mathrm{Sb}(\mathrm{OH})_{3}$ will link antimony behavior strongly to temperature, isolate it from changes in $\mathrm{pH}$, salinity, and sulfide concentration, and enable antimony to remain in solution (i.e., act conservatively) until the low temperature regions of a hydrothermal system. From an environmental perspective, the formation of antimony-sulfide complexes allows higher concentrations of antimony to remain in solution at temperatures $<90^{\circ} \mathrm{C}$ (i.e., Figure $5.2 \mathrm{~A}$ and 5.2D) and therefore facilitates the aqueous transport of antimony to the Earth's surface.

\subsection{References}

Akeret, R., 1953. Ueber die Löslichkeit von Antimon(3)sulfid. Dissertation (PhD thesis) ETH, Zurich, p. 77.

Chambefort, I., Dilles, J.H., 2015. Trace metals and volatiles zoning in active geothermal systems, Proceedings of the 37th New Zealand Geothermal Workshop, Taupo, New Zealand.

Filella, M., May, P.M., 2003. Computer simulation of the low-molecular-weight inorganic species distribution of antimony(III) and antimony(V) in natural waters. Geochim. Cosmochim. Acta 67, 4013-4031.

Goldfarb, R.J., Baker, T., Dubé, B., Groves, D.I., Hart, C.J.R., Gosselin, P., 2005. Distribution, character, and genesis of gold deposits in metamorphic terranes. Econ. Geol. 100, 407-450.

Helz, G.R., Valerio, Melissa S., Capps, Nathan E., 2002. Antimony speciation in alkaline sulfide solutions: Role of zerovalent sulfur. Environ. Sci. Technol. 36, 943-948.

Kunkely, H., Vogler, A., 1995. Photochemistry of Aqueous Tetrathioantimonate(V). Verlag der Zeitschrift fur Naturforschung 50B, 1155-1157.

Planer-Friedrich, B., Scheinost, A.C., 2011. Formation and structural characterization of thioantimony species and their natural occurrence in geothermal waters. Environ. Sci. Technol. 45, 68556863.

Pokrovski, G.S., Borisova, A.Y., Bychkov, A.Y., 2013. Speciation and transport of metals and metalloids in geological vapors. Reviews in Mineralogy and Geochemistry 76, 165-218.

Seward, T.M., 1989. The hydrothermal chemistry of gold and its implication for ore formation: boiling and conductive cooling as examples. Economic Geology Monograph 6, 390-396.

Sherman, D.M., Ragnarsdottir, K.V., Oelkers, E.H., 2000. Antimony transport in hydrothermal solutions: an EXAFS study of antimony(V) complexation in alkaline sulfide and sulfidechloride brines at temperatures from $25^{\circ} \mathrm{C}$ to $300^{\circ} \mathrm{C}$ at $\mathrm{P}_{\text {sat. }}$ Chem. Geol. 167, 161-167. 
Simmons, S.F., Brown, K.L., Tutolo, B.M., 2016. Hydrothermal transport of Ag, $\mathrm{Au}, \mathrm{Cu}, \mathrm{Pb}, \mathrm{Te}, \mathrm{Zn}$ and other metals and metalloids in New Zealand geothermal systems: Spatial patterns, fluidmineral equilibria, and implications for epithermal mineralization. Econ. Geol. 111, 589-618.

Simmons, S.F., Browne, P.R.L., 2000. Hydrothermal minerals and precious metals in the BroadlandsOhaaki geothermal system: Implications for understanding low-sulfidation epithermal environments. Econ. Geol. 95, 971-999.

Stefánsson, A., Seward, T.M., 2004. Gold(I) complexing in aqueous sulphide solutions to $500^{\circ} \mathrm{C}$ at 500 bar. Geochim. Cosmochim. Acta 68, 4121-4143.

Tossell, J.A., 2003a. Calculation of the energetics for the oxidation of Sb(III) sulfides by elemental $\mathrm{S}$ and polysulfides in aqueous solution. Geochim. Cosmochim. Acta 67, 3347-3354.

Tossell, J.A., 2003b. Calculation of the visible-UV absorption spectra of hydrogen sulfide, bisulfide, polysulfides, and As and Sb sulfides, in aqueous solution. Geochem. Trans. 4, 28-33.

Ullrich, M.K., Pope, J.G., Seward, T.M., Wilson, N., Planer-Friedrich, B., 2013. Sulfur redox chemistry governs diurnal antimony and arsenic cycles at Champagne Pool, Waiotapu, New Zealand. J. Volcanol. Geotherm. Res. 262, 164-177. 


\section{Appendix (A)}

Figure (A.1) XRD of Chinese stibnite used in experiments.

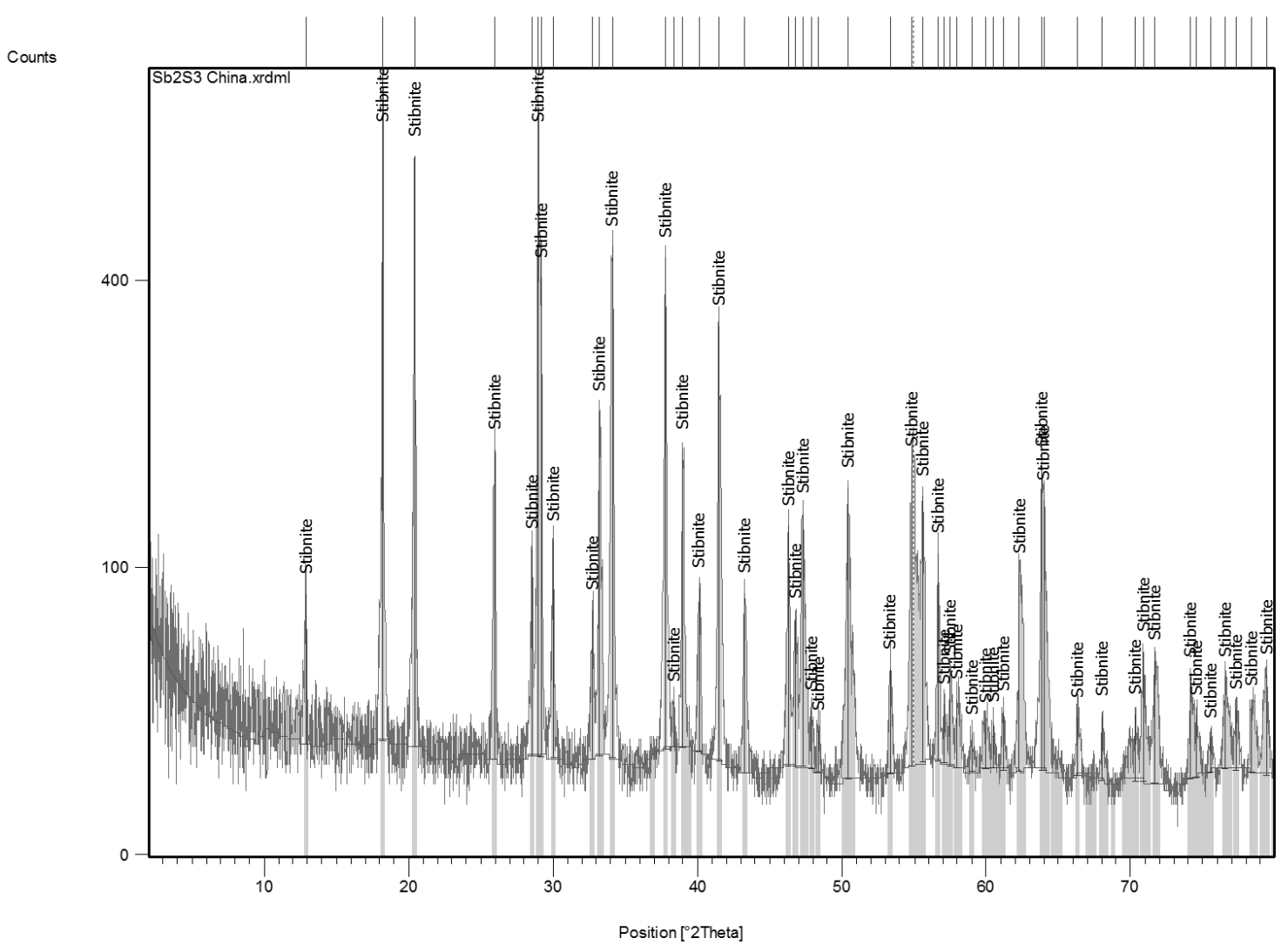


Table (A.1) Calculation of detection limits for antimony analyses by inductively-coupled plasmaoptical spectroscopy (ICP-OES) and hydride-generation atomic absorption spectroscopy (HG-AAS). Reference: Section 1030C of Standard Methods for the Examination of Water and Wastewater (20 ${ }^{\text {th }}$ Ed.).

\begin{tabular}{|c|c|c|c|c|}
\hline \multirow{3}{*}{$\begin{array}{l}\text { ICP-OES } \\
\text { QC }=0.05 \text { ppm } \\
\text { Date (year-month-day) }\end{array}$} & \multicolumn{2}{|c|}{$\mathrm{Sb}(\mathrm{ppm})$} & HG-AAS & \multirow{2}{*}{$\begin{array}{r}\text { Sb (ppb) } \\
\text { Wavelength }\end{array}$} \\
\hline & \multicolumn{2}{|c|}{ Wavelength } & $\mathrm{QC}=1 \mathrm{ppb}$ & \\
\hline & 206.8 & 217.5 & Date (year-month-day) & 206.8 \\
\hline 20150401 & 0.056296 & 0.056296 & 2013 & 1.1139 \\
\hline 20150401 & 0.060531 & 0.057411 & 20121214 & 1.2740 \\
\hline 20150401 & 0.058499 & 0.06082 & 20131214 & 1.0080 \\
\hline 20150401 & 0.059872 & 0.060033 & 20131220 & 1.0020 \\
\hline 20150401 & 0.058574 & 0.060076 & 20140525 & 1.0510 \\
\hline 20150401 & 0.06056 & 0.061021 & 20140425 & 1.0710 \\
\hline 20150401 & 0.057317 & 0.060496 & & \\
\hline 20150303 & 0.047998 & 0.051248 & & \\
\hline 20150303 & 0.049516 & 0.050458 & & \\
\hline 20150303 & 0.047842 & 0.050087 & & \\
\hline 20150319 & 0.051998 & 0.049988 & & \\
\hline 20150319 & 0.049785 & 0.04883 & & \\
\hline 20150319 & 0.050705 & 0.052451 & & \\
\hline 20150319 & 0.047968 & 0.047681 & & \\
\hline 20150309 & 0.050384 & 0.050901 & & \\
\hline 20150309 & 0.054772 & 0.05253 & & \\
\hline 20150309 & 0.050432 & 0.051506 & & \\
\hline 20150309 & 0.049748 & 0.048732 & & \\
\hline 20150319 & 0.048839 & 0.046409 & & \\
\hline 20150319 & 0.053555 & 0.054863 & & \\
\hline 20150319 & 0.04864 & 0.051843 & & \\
\hline 20150323 & 0.046297 & 0.04834 & & \\
\hline 20150324 & 0.045532 & 0.053087 & & \\
\hline 20150324 & 0.050885 & 0.054591 & & \\
\hline 20150324 & 0.046013 & 0.051498 & & \\
\hline 20150324 & 0.051218 & 0.053207 & & \\
\hline 20150324 & 0.048326 & 0.055029 & & \\
\hline 20150216 & 0.050467 & 0.052708 & & \\
\hline 20150216 & 0.049373 & 0.048922 & & \\
\hline 20150216 & 0.048109 & 0.051894 & & \\
\hline 20150216 & 0.049419 & 0.054595 & & \\
\hline 20150218 & 0.050447 & 0.052297 & & \\
\hline 20150225 & 0.052522 & 0.054516 & & \\
\hline 20150225 & 0.049906 & 0.051036 & & \\
\hline 20150225 & 0.053588 & 0.052031 & & \\
\hline 20150227 & 0.049071 & 0.048591 & & \\
\hline 20150227 & 0.046275 & 0.049557 & & \\
\hline 20150227 & 0.049165 & 0.047507 & & \\
\hline 20150227 & 0.057508 & 0.054068 & & \\
\hline 20150227 & 0.051789 & 0.0468 & & \\
\hline 20150227 & 0.051801 & 0.047682 & & \\
\hline 20150227 & 0.04951 & 0.049474 & & \\
\hline 20150227 & 0.049386 & 0.052828 & & \\
\hline 20150209 & 0.053088 & 0.054131 & & \\
\hline 20150209 & 0.058295 & 0.060538 & & \\
\hline 20150216 & 0.048694 & 0.05083 & & \\
\hline 20150216 & 0.050969 & 0.051425 & & \\
\hline 20150216 & 0.048127 & 0.052966 & & \\
\hline Average (ppm) & 0.05145 & 0.0525798 & Average (ppb) & 1.086651528 \\
\hline Stdev (ppm) & 0.004012 & 0.0039011 & Stdev (ppb) & 0.100707869 \\
\hline Detection limit (ppm) & 0.0132 & 0.012835 & Detection limit (ppb) & 0.3313289 \\
\hline (defined as $3.29 *$ stdev & andard) & & & \\
\hline$\%$ Uncertainty & 15.6 & 14.8 & & 18.5 \\
\hline
\end{tabular}


Table (A.2) Stibnite solubility data at $30^{\circ} \mathrm{C}$. Experiment number, $\mathrm{pH}$, antimony concentration, sulfide concentration, oven temperature, and sodium concentration for stibnite solubility experiments. Data is listed by increasing $\mathrm{pH}$. Concentrations, $\mathrm{pH}$, and temperatures are median values.

\begin{tabular}{|c|c|c|c|c|c|c|c|c|c|}
\hline Exp. & pH & $2 * \sigma$ & $\mathrm{Sb}\left(\mathrm{mol} \mathrm{kg}{ }^{-1}\right)$ & $2 * \sigma$ & $S_{\text {tot }}\left(\mathrm{mol} \mathrm{kg}^{-1}\right)$ & $2 * \sigma$ & $\mathbf{T}_{\text {oven }}\left({ }^{\circ} \mathbf{C}\right)$ & $2 * \sigma$ & $\mathrm{Na}\left(\mathrm{mol} \mathrm{kg}^{-1}\right)$ \\
\hline $\mathrm{Sb} 85$ & 4.56 & 0.002 & $4.34 \times 10^{\wedge}-9$ & $7.9 \times 10^{\wedge}-9$ & 0.020 & 0.0012 & 31.9 & 0.1 & 0 \\
\hline $\mathrm{Sb} 62$ & 4.66 & 0.23 & $3.21 \times 10^{\wedge}-9$ & $1.1 \times 10^{\wedge}-9$ & 0.021 & 0.0023 & 32.3 & 2.1 & 0.0001 \\
\hline $\mathrm{Sb} 63$ & 4.70 & 0.03 & $1.12 \times 10^{\wedge}-8$ & $1.7 \times 10^{\wedge}-9$ & 0.093 & 0.0077 & 32.8 & 0.5 & 0.0006 \\
\hline $\mathrm{Sb} 61$ & 4.92 & 0.03 & $4.23 \times 10^{\wedge}-9$ & $1.4 \times 10^{\wedge}-9$ & 0.021 & 0.0018 & 32.0 & 0.1 & 0.0001 \\
\hline $\mathrm{Sb} 60$ & 5.07 & 0.14 & $4.81 \times 10^{\wedge}-9$ & $1.3 \times 10^{\wedge}-9$ & 0.019 & 0.0011 & 31.9 & 0.6 & 0.0002 \\
\hline $\mathrm{Sb} 58$ & 5.59 & 0.11 & $1.74 \times 10^{\wedge}-8$ & $2.9 \times 10^{\wedge}-9$ & 0.020 & 0.0004 & 32.5 & 0.7 & 0.0009 \\
\hline $\mathrm{Sb} 64$ & 5.99 & 0.06 & $2.89 \times 10^{\wedge}-8$ & $6.0 \times 10^{\wedge}-9$ & 0.012 & 0.0027 & 31.8 & 0.4 & 0.0014 \\
\hline $\mathrm{Sb} 57$ & 6.06 & 0.06 & $1.58 \times 10^{\wedge}-7$ & $4.1 \times 10^{\wedge}-8$ & 0.020 & 0.0012 & 31.9 & 0.4 & 0.0026 \\
\hline $\mathrm{Sb} 96$ & 6.36 & 0.05 & $2.26 \times 10^{\wedge}-6$ & $1.2 \times 10^{\wedge}-7$ & 0.070 & 0.0013 & 30.4 & 0.2 & 0.0201 \\
\hline $\mathrm{Sb} 96$ & 6.43 & 0.05 & $2.20 \times 10^{\wedge}-6$ & $1.3 \times 10^{\wedge}-7$ & 0.063 & 0.0026 & 30.7 & 0.2 & 0.0201 \\
\hline $\mathrm{Sb} 96$ & 6.46 & 0.06 & $2.49 \times 10^{\wedge}-6$ & $2.1 \times 10^{\wedge}-7$ & 0.060 & 0.0017 & 31.3 & 0.3 & 0.0201 \\
\hline $\mathrm{Sb} 84$ & 6.47 & na & $2.31 \times 10^{\wedge}-7$ & $5.1 \times 10^{\wedge}-8$ & 0.024 & 0.0014 & 31.2 & 0.3 & 0.0065 \\
\hline $\mathrm{Sb} 83$ & 6.48 & 0.02 & $8.92 \times 10^{\wedge}-8$ & $8.8 \times 10^{\wedge}-9$ & 0.012 & 0.0004 & 32.4 & 0.4 & 0.0031 \\
\hline $\mathrm{Sb} 82$ & 6.84 & 0.02 & $4.47 \times 10^{\wedge}-7$ & $5.5 \times 10^{\wedge}-8$ & 0.015 & 0.0008 & 32.5 & 0.4 & 0.0068 \\
\hline $\mathrm{Sb} 56$ & 6.91 & 0.04 & $1.74 \times 10^{\wedge}-6$ & $5.6 \times 10^{\wedge}-7$ & 0.021 & 0.0026 & 32.0 & 0.8 & 0.0112 \\
\hline $\mathrm{Sb} 55$ & 7.10 & 0.02 & $2.74 \times 10^{\wedge}-6$ & $6.9 \times 10^{\wedge}-7$ & 0.026 & 0.0009 & 32.5 & 0.2 & 0 \\
\hline $\mathrm{Sb} 54$ & 7.11 & 0.04 & $1.12 \times 10^{\wedge}-5$ & $1.0 \times 10^{\wedge}-6$ & 0.053 & 0.0018 & 32.3 & 1.8 & 0.0352 \\
\hline Sb66 & 7.28 & 0.03 & $2.00 \times 10^{\wedge}-6$ & $3.6 \times 10^{\wedge}-7$ & 0.028 & 0.0010 & 31.8 & 0.5 & 0.0206 \\
\hline $\mathrm{Sb} 95$ & 7.40 & 0.02 & $1.68 \times 10^{\wedge}-6$ & $3.0 \times 10^{\wedge}-7$ & 0.013 & 0.0012 & 30.8 & 0.2 & 0.0104 \\
\hline $\mathrm{Sb} 68$ & 7.45 & 0.05 & $1.77 \times 10^{\wedge}-5$ & $3.2 \times 10^{\wedge}-7$ & 0.049 & 0.0018 & 31.9 & 0.6 & 0.0206 \\
\hline $\mathrm{Sb} 67$ & 7.56 & 0.04 & $1.84 \times 10^{\wedge}-5$ & $1.1 \times 10^{\wedge}-6$ & 0.051 & 0.0015 & 31.5 & 0.4 & 0.0429 \\
\hline $\mathrm{Sb} 95$ & 7.97 & 0.02 & $1.10 \times 10^{\wedge}-6$ & $3.3 \times 10^{\wedge}-8$ & 0.010 & 0.0003 & 31.6 & na & 0.0104 \\
\hline $\mathrm{Sb} 74$ & 8.06 & 0.00 & $1.21 \times 10^{\wedge}-6$ & $1.7 \times 10^{\wedge}-7$ & 0.010 & 0.0002 & 32.1 & 0.0 & 0.0100 \\
\hline $\mathrm{Sb} 73$ & 8.09 & 0.02 & $9.24 \times 10^{\wedge}-7$ & $1.3 \times 10^{\wedge}-8$ & 0.010 & 0.0004 & 31.5 & 0.2 & 0.0101 \\
\hline $\mathrm{Sb} 72$ & 8.11 & 0.16 & $1.76 \times 10^{\wedge}-6$ & $1.4 \times 10^{\wedge}-7$ & 0.010 & 0.0001 & 32.3 & 0.1 & 0.0099 \\
\hline $\mathrm{Sb} 65$ & 8.19 & na & $2.28 \times 10^{\wedge}-6$ & $2.2 \times 10^{\wedge}-7$ & 0.021 & 0.0005 & 31.6 & 0.7 & 0.0204 \\
\hline $\mathrm{Sb} 69$ & 8.25 & 0.01 & $3.05 \times 10^{\wedge}-5$ & $2.2 \times 10^{\wedge}-6$ & 0.049 & 0.0033 & 31.5 & 0.9 & 0.0514 \\
\hline $\mathrm{Sb} 95$ & 8.27 & 0.01 & $1.11 \times 10^{\wedge}-6$ & $2.7 \times 10^{\wedge}-8$ & 0.010 & 0.0004 & 31.3 & 0.5 & 0.0104 \\
\hline $\mathrm{Sb} 40$ & 8.57 & 0.11 & $3.57 \times 10^{\wedge}-5$ & $2.5 \times 10^{\wedge}-6$ & 0.050 & 0.0045 & 30.0 & na & 0.0520 \\
\hline $\mathrm{Sb} 42$ & 8.78 & 0.03 & $3.57 \times 10^{\wedge}-5$ & $2.9 \times 10^{\wedge}-6$ & 0.051 & 0.0045 & 27.6 & 1.2 & 0.0520 \\
\hline $\mathrm{Sb} 44$ & 9.05 & 0.04 & $3.65 \times 10^{\wedge}-5$ & $3.1 \times 10^{\wedge}-7$ & 0.054 & 0.0031 & 30.1 & 3.4 & 0.0534 \\
\hline $\mathrm{Sb} 71$ & 9.53 & 0.08 & $1.64 \times 10^{\wedge}-5$ & $8.6 \times 10^{\wedge}-7$ & 0.019 & 0.0001 & 31.8 & na & 0.0201 \\
\hline $\mathrm{Sb} 45$ & 9.57 & 0.02 & $4.96 \times 10^{\wedge}-5$ & $6.2 \times 10^{\wedge}-7$ & 0.053 & 0.0036 & 30.0 & 0.1 & 0.0533 \\
\hline $\mathrm{Sb} 78$ & 9.59 & 0.01 & $1.42 \times 10^{\wedge}-5$ & $5.2 \times 10^{\wedge}-7$ & 0.022 & 0.0005 & 31.9 & 0.0 & 0.0233 \\
\hline $\mathrm{Sb} 47$ & 9.79 & 0.06 & $6.91 \times 10^{\wedge}-5$ & $2.7 \times 10^{\wedge}-6$ & 0.051 & 0.0007 & 30.5 & 0.5 & 0.0531 \\
\hline $\mathrm{Sb} 78$ & 9.79 & 0.05 & $1.84 \times 10^{\wedge}-5$ & $2.7 \times 10^{\wedge}-6$ & 0.022 & 0.0005 & 32.0 & 0.8 & 0.0233 \\
\hline $\mathrm{Sb} 46$ & 9.83 & 0.11 & $6.62 \times 10^{\wedge}-5$ & $1.1 \times 10^{\wedge}-6$ & 0.051 & 0.0020 & 29.7 & 0.5 & 0.0535 \\
\hline $\mathrm{Sb} 46$ & 9.88 & 0.05 & $7.16 \times 10^{\wedge}-5$ & $2.3 \times 10^{\wedge}-6$ & 0.051 & 0.0020 & 30.2 & 0.5 & 0.0535 \\
\hline
\end{tabular}


Table (A.1) Stibnite solubility data at $30^{\circ}$ C. Continued

\begin{tabular}{|c|c|c|c|c|c|c|c|c|c|}
\hline Exp. & pH & $2 * \sigma$ & $\mathrm{Sb}\left(\mathrm{mol} \mathrm{kg}^{-1}\right)$ & $2 * \sigma$ & $S_{\text {tot }}\left(\mathrm{mol} \mathrm{kg}^{-1}\right)$ & $2 * \sigma$ & $\mathbf{T}_{\text {oven }}\left({ }^{\circ} \mathbf{C}\right)$ & $2 * \sigma$ & $\mathrm{Na}\left(\mathrm{mol} \mathrm{kg}^{-1}\right)$ \\
\hline Sb50 & 10.10 & 0.08 & $2.85 \times 10^{\wedge}-4$ & $2.4 \times 10^{\wedge}-6$ & 0.099 & 0.0058 & 30.7 & 0.1 & 0.0999 \\
\hline $\mathrm{Sb} 48$ & 10.25 & 0.05 & $1.21 \times 10^{\wedge}-4$ & $1.2 \times 10^{\wedge}-5$ & 0.052 & 0.0042 & 30.5 & 1.4 & 0.0530 \\
\hline $\mathrm{Sb} 49$ & 10.43 & 0.01 & $1.89 \times 10^{\wedge}-4$ & $2.4 \times 10^{\wedge}-6$ & 0.053 & 0.0043 & 30.7 & 0.5 & 0.0532 \\
\hline Sb90 & 10.57 & 0.03 & $1.47 \times 10^{\wedge}-5$ & $3.1 \times 10^{\wedge}-7$ & 2.2E-05 & $4.8 \mathrm{E}-07$ & 31.7 & 0.3 & 0.0005 \\
\hline Sb51 & 11.09 & 0.03 & $4.33 \times 10^{\wedge}-3$ & $3.8 \times 10^{\wedge}-4$ & 0.097 & 0.0059 & 30.7 & 0.4 & 0.1001 \\
\hline Sb51 & 11.17 & 0.05 & $3.98 \times 10^{\wedge}-3$ & $5.9 \times 10^{\wedge}-5$ & 0.097 & 0.0083 & 30.7 & 2.5 & 0.1001 \\
\hline Sb77 & 11.20 & 0.03 & $1.48 \times 10^{\wedge}-3$ & $1.8 \times 10^{\wedge}-4$ & 0.057 & 0.0009 & 31.7 & 0.2 & 0.0599 \\
\hline Sb77 & 11.29 & 0.07 & $1.73 \times 10^{\wedge}-3$ & $2.1 \times 10^{\wedge}-5$ & 0.057 & 0.0085 & 31.8 & na & 0.0599 \\
\hline Sb77 & 11.35 & 0.06 & $2.13 \times 10^{\wedge}-3$ & $1.9 \times 10^{\wedge}-4$ & 0.056 & 0.0008 & 31.8 & na & 0.0599 \\
\hline $\mathrm{Sb} 75$ & 11.38 & 0.06 & $3.70 \times 10^{\wedge}-4$ & $1.0 \times 10^{\wedge}-5$ & 0.009 & 0.0003 & 31.7 & 0.1 & 0.0116 \\
\hline $\mathrm{Sb} 75$ & 11.40 & 0.06 & $3.97 \times 10^{\wedge}-4$ & $1.1 \times 10^{\wedge}-5$ & 0.009 & $5.1 \mathrm{E}-05$ & 31.7 & 0.3 & 0.0116 \\
\hline Sb75 & 11.42 & 0.03 & $4.15 \times 10^{\wedge}-4$ & $5.6 \times 10^{\wedge}-6$ & 0.008 & 0.0003 & 32.0 & 0.3 & 0.0116 \\
\hline Sb80 & 11.81 & na & $1.75 \times 10^{\wedge}-3$ & $1.3 \times 10^{\wedge}-4$ & 0.018 & 0.0004 & 31.0 & 0.2 & 0.0237 \\
\hline $\mathrm{Sb} 80$ & 11.87 & 0.01 & $2.00 \times 10^{\wedge}-3$ & $5.6 \times 10^{\wedge}-5$ & 0.018 & 0.0003 & 31.3 & 0.2 & 0.0237 \\
\hline Sb91 & 11.98 & 0.02 & $9.27 \times 10^{\wedge}-4$ & $1.3 \times 10^{\wedge}-4$ & 0.001 & 0.0002 & 31.6 & 0.2 & 0.0102 \\
\hline
\end{tabular}


VisualBasic code to use DataFitX to run non-linear regression fits on solubility data in an Excel spreadsheet. Fits could be weighted or non-weighted and regression tolerances could be set in the "Fitting_Setup" sheet. Inputs were (a) antimony concentration, (b) activity of $\mathrm{H}^{+}\left(\mathrm{aH}^{+}\right)$, (c) activity of $\mathrm{HS}^{-}$, and (d) ionic strength. Variables were heterogeneous solubility constants that could be set to a constant value if desired. The parameters A, B, and B_Dot reference named ranges in "Fitting_Setup" spreadsheet. The equations used for these constants are the following:

$\mathrm{A}=0.00000000041775 *\left((\mathrm{Temp}+273.15)^{\wedge} 4\right)-0.00000069009 *\left((\mathrm{Temp}+273.15)^{\wedge} 3\right)+$ $0.00042737 *\left((\text { Temp }+273.15)^{\wedge} 2\right)-0.11558 *($ Temp +273.15$)+11.975$

$\mathrm{B}=(0.00025587 *(\mathrm{Temp}+273.15)+0.2487) * 10^{\wedge} 8$

Bdot $=\mathrm{IF}($ Temp $>299,0, \mathrm{IF}(\mathrm{Temp}<200,-0.00000030611 *$ Temp $*$ Temp $+0.0001027 *$ Temp + $0.038646,-0.0000028612 *$ Temp * Temp $+0.00094299 *$ Temp -0.026621$))$

\section{‘******** Debye-Huckel Equation for activity coefficient}

Function G(I As Double, z As Double, Optional Size As Variant) As Double

Dim A As Double, B As Double, B_Dot As Double

A $=$ Worksheets("Fitting_Setup").Range("A").Value

$\mathrm{B}=$ Worksheets("Fitting_Setup").Range("B").Value

B_Dot = Worksheets("Fitting_Setup").Range("Bdot").Value

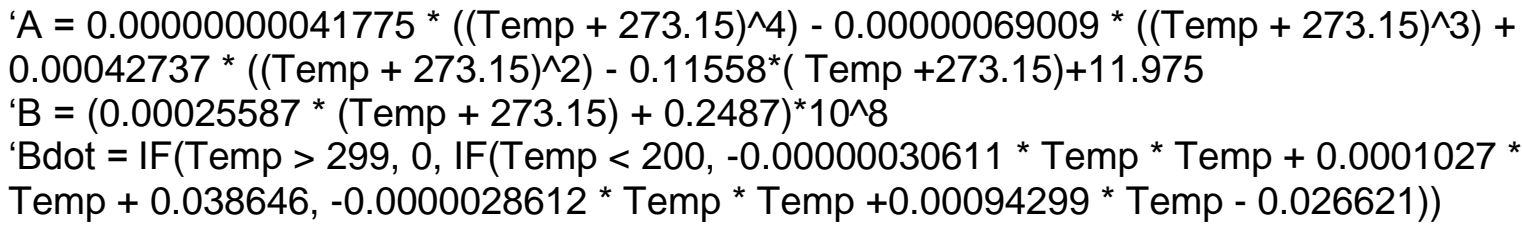

If $z=0$ Then

$\mathrm{G}=1 \#$

Else

If IsMissing(Size) Then

Select Case Abs(z)

Case 1

Size $=0.00000004$

Case 2

Size $=0.00000005$

Case 3

Size $=0.00000004$

Case Else

Size $=0.00000004$

End Select

End If

$G=10^{\wedge}\left(-A{ }^{*} z^{*} z^{*} \operatorname{Sqr}(I) /\left(1+B{ }^{*} \operatorname{Size}{ }^{*} \operatorname{Sqr}(I)\right)+B \_D o t * I\right)$

End If

End Function

‘***

‘***

*Fitting Function

Sub Fit_Solubility_Data()

Dim Found As Boolean, WeightedFit As Boolean

Dim OutputSheet As String, InputSheet As String, ExptSheetS As String, TheoreticalSheet

As String

Dim InputArray As Variant, Param_Array As Variant, Series As Variant, PredictArrayln() As Double, PredictArrayOut() As Double, Deviation() As Double

Dim DataArray() As Double 
Dim NumParams As Integer, NumDataRows As Integer, NumDataColumns As Integer, NumSeries As Integer, TotNumSeries As Integer

Dim SeriesNames() As String, Param_Names() As String, Param_Estimate() As Double Dim I As Integer, J As Integer, K As Integer, Lb As Integer, Lb_2 As Integer, Ub_2 As Integer, Ub As Integer, YSeriesColNum As Integer

Dim Rw As Integer, Cl As Integer, Failed As Boolean

Dim Cl As Double

Dim OutArray As Variant

Dim ModelString As String, Title As String, CurrentDir As String, LogDir As String,

ResultsFile As String, TimeStamp As String

Dim ResultsTable As Variant

'*** DataFitX declarations

Dim Model As MultipleNonlinearRegression

Dim Parameter As RegressionParameter

Dim SolubilityData As DataCollection

Dim ConstantArray As Variant

Dim ConstantKs As Variant

Application.ScreenUpdating $=$ False

$1 * * *$

'*** Setup output sheet

OutputSheet $=$ Worksheets("Fitting_Setup"). Range("OutputSheetName").Value

InputSheet = Worksheets("Fitting_Setup").Range("InputsheetName").Value

For Each sht In Worksheets

If sht.Name $=$ OutputSheet Then

Worksheets(sht.Name).Cells.Delete

Found $=$ True

End If

Exit For

Next sht

If Not Found Then

Worksheets.Add

ActiveSheet.Name $=$ OutputSheet

End If

‘***

،**** Read in fit parameters from setup sheet

Title = Worksheets("Fitting_Setup").Range("Title").Value

Param_Array $=$ Worksheets("Fitting_Setup").Range("Complex_Estimates").Value

ConstantArray = Worksheets("Fitting_Setup").Range("ConstantKs").Value

$\mathrm{Lb}=\mathrm{LBound}($ Param_Array, 1$)$

$\mathrm{Ub}=$ UBound(Param_Array, 1)

ReDim Param_Names(Lb To Ub)

ReDim Param_Estimate(Lb To Ub)

NumParams $=\mathrm{Ub}-\mathrm{Lb}+1$

For $\mathrm{J}=\mathrm{Lb}$ To Ub

If Len(Param_Array $(\mathrm{J}, 1))=0$ Then

NumParams $=\mathrm{J}-1$

Exit For

End If

Param_Names $(\mathrm{J})=$ Param_Array $(\mathrm{J}, 1)$

Param_Estimate $(\mathrm{J})=$ Param_Array $(\mathrm{J}, 2)$

Next

$1 * * *$

'*** Read in independent variables from the fit set up sheet and input data sheet

Series = Worksheets("Fitting_Setup").Range("Series").Value

$\mathrm{Lb}=\mathrm{LBound}($ Series, 1$)$

$\mathrm{Ub}=\mathrm{UBound}($ Series, 1$)$

NumSeries $=\mathrm{Ub}-\mathrm{Lb}+1$ 


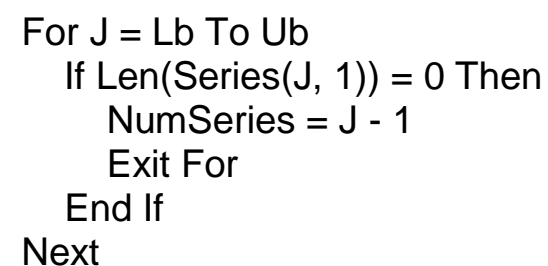

ReDim SeriesNames(0 To NumSeries)

For $\mathrm{J}=0$ To NumSeries -1

SeriesNames $(\mathrm{J})=\operatorname{Series}(\mathrm{J}+\mathrm{Lb}, 1)$

Next

NumDataRows $=$ Worksheets (InputSheet).Range("A1").CurrentRegion.Rows.Count

NumDataColumns = Worksheets(InputSheet).Range("A1").CurrentRegion. Columns. Count InputArray = Worksheets(InputSheet).Range("A1").CurrentRegion.Value

ReDim DataArray(0 To NumDataRows - 2, 0 To NumSeries)

On Error Resume Next

For I $=1$ To NumSeries

$\mathrm{J}=0$

$\mathrm{J}=$ Application.WorksheetFunction.Match(SeriesNames $(\mathrm{I}-1)$,

Worksheets(InputSheet).Rows(1), 0)

If $(\mathrm{J}=0)$ Then

MsgBox ("Can't find series name "' \& SeriesNames $(I-1)$ \& "' in first row of sheet " \& InputSheet)

End

End If

For $\mathrm{K}=0$ To NumDataRows - 1

DataArray $(K, I-1)=$ Worksheets (InputSheet).Cells $(K+2$, J).Value Next

Next

$1 * \star *$

'*** Read in the dependent variable name from fit setup sheet and values from input 'sheet

YSeriesCoINum = 0

SeriesNames(NumSeries) = Worksheets("Fitting_Setup").Range("Y").Value ' add onto the end of the series names; recall 0 is the first index

YSeriesCoINum = Application. WorksheetFunction.Match(SeriesNames(NumSeries),

Worksheets(InputSheet).Rows(1), 0)

If YSeriesCoINum $=0$ Then

MsgBox ("Can't find Yseries name "' \& SeriesNames(NumSeries) \& "' in first row of sheet " \& InputSheet)

End If

\section{End}

For $\mathrm{K}=0$ To NumDataRows -1

DataArray $(K$, NumSeries $)=$ Worksheets $($ InputSheet $)$.Cells $(K+2$, YSeriesColNum $) \cdot$ Value Next

'*** Now read in the weights (if any)

If Len(Worksheets("Fitting_Setup").Range("Weights").Value) $>0$ Then

WeightedFit $=$ True

YSeriesColNum $=0$

TotNumSeries $=$ NumSeries +1

ReDim Preserve SeriesNames(0 To TotNumSeries)

SeriesNames(TotNumSeries) = Worksheets("Fitting_Setup").Range("Weights").Value ' add onto the end of the series names +1 for weight; recall 0 is the first index

YSeriesColNum = Application.WorksheetFunction.Match(SeriesNames(TotNumSeries), Worksheets(InputSheet).Rows(1), 0)

If YSeriesColNum $=0$ Then

MsgBox ("Can't find Weights name "' \& SeriesNames(TotNumSeries) \& "' in first row of sheet " \& InputSheet) 
End

End If

ReDim Preserve DataArray(0 To NumDataRows - 2, 0 To TotNumSeries)

For $\mathrm{K}=0$ To NumDataRows - 1

DataArray $(\mathrm{K}$, TotNumSeries $)=$ Worksheets $($ InputSheet $) \cdot$ Cells $(K+2$,

YSeriesCoINum). Value ' Add Weights series to end of the data array

Next

Else

WeightedFit $=$ False

TotNumSeries $=$ NumSeries

End If

On Error GoTo 0

$1 * * *$

'*** Set up regression model from settings in fit setup sheet

Set Model = New MultipleNonlinearRegression

Set SolubilityData $=$ New DataCollection

Model.RegressionTolerance = Worksheets("Fitting_Setup").Range("RegTolerance").Value

Model.Maxlterations = Worksheets("Fitting_Setup").Range("Maxlterations").Value

Model.MaxUnchanged Iterations =

Worksheets("Fitting_Setup").Range("MaxUnchangedlterations").Value

SolubilityData.ImportSeriesFromArray DataArray, SeriesNames

ModelString = Worksheets("Fitting_Setup").Range("Model").Value

For I = 0 To NumSeries -1

SolubilityData(SeriesNames(I)).RegressionKey = "X" \& $(I+1)$

Next

ModelString $=$ Replace(ModelString, SeriesNames $(I)$, "X" \& $(I+1))$

SolubilityData(SeriesNames(NumSeries)).RegressionKey $=$ "Y" ' this is the $Y$ series

If WeightedFit Then

SolubilityData(SeriesNames(TotNumSeries)). RegressionKey = "SD" ' this is the Weights series

End If

1***

Model.DefineUserModel ModelString, dfxLocaleEnglish, Title

$\mathrm{Lb}=$ LBound(Param_Names)

For $\mathrm{J}=\mathrm{Lb}$ To NumParams $-\mathrm{Lb}+1$

If Not (IsNumeric(ConstantArray $(\mathrm{J}, 1))$ ) Then

Model.RegressionParameters.Item(Param_Names(J)).InitialEstimate = Param_Estimate(J)

End If

Next

$1 * * *$

'*** Fit data with model and write out results to text file and sheet if solution found

Model.FitCollection SolubilityData

$\mathrm{Rw}=1$

Worksheets(OutputSheet).Activate

LogDir = Worksheets("Fitting_Setup").Range("LogDir").Value

If Model.IsSolved Then

If WeightedFit And Not (Model.IsWeighted) Then

MsgBox ("Check SD column data; have been ignored in model fitting")

End If

ResultsFile $=$ Worksheets("Fitting_Setup"). Range("ResultsFile").Value

TimeStamp $=$ " " \& Year(Now) \& Month(Now) \& Hour(Now) \& Minute(Now) \&

Second(Now)

Open LogDir \& ResultsFile \& TimeStamp \& ".txt" For Output As \#1

Cells $(R w, 1) \cdot$ Offset $(0$, TotNumSeries +4$)=$ Title

Print \#1, DateTime.Now

Print \#1, Title

$\mathrm{Rw}=\mathrm{Rw}+1$ 
$\mathrm{Cl}=$ Worksheets("Fitting_Setup").Range("Cl").Value

Cells $(\mathrm{Rw}, 1)$.Offset $(0$, TotNumSeries +4$)=$ "Parameter"

Cells $(R w, 1)$. Offset $(0$, TotNumSeries +5$)=$ "Value"

Cells $(R w, 1)$. Offset $(0$, TotNumSeries +6$)=$ "Standard Error"

Cells $(\mathrm{Rw}, 1)$. Offset $(0$, TotNumSeries +7$)=$ "p Value"

Cells $(\mathrm{Rw}, 1)$. Offset $(0$, TotNumSeries + 8) = "Cl (" \& Cl \& "\%)"

$R w=R w+1$

For Each Parameter In Model.RegressionParameters

Cells $(R w, 1)$. Offset $(0$, TotNumSeries +4$)=$ Parameter.Name

Cells $(R w, 1)$. Offset $(0$, TotNumSeries +5$)=$ Parameter.Value

Cells $(\mathrm{Rw}, 1)$. Offset $(0$, TotNumSeries +6$)=$ Parameter.StandardError

Cells $(\mathrm{Rw}, 1)$. Offset $(0$, TotNumSeries +7$)=$ Parameter.ProbT

Cells $(\mathrm{Rw}, 1)$. Offset $(0$, TotNumSeries +8$)=$ Parameter .CalculateCIDelta $(\mathrm{Cl})$

Print \#1, "Parameter"; Tab(20); Parameter.Name

Print \#1, "Value"; Tab(20); Parameter.Value

Print \#1, "Standard Error"; Tab(20); Parameter.StandardError

Print \#1, "p Value"; Tab(20); Parameter.ProbT

Print \#1, "CI (" \& Cl \& "\%)"; Tab(20); Parameter.CalculateCIDelta(Cl)

$\mathrm{Rw}=\mathrm{Rw}+1$

Next Parameter

Cells $(\mathrm{Rw}, 1)$. Offset $(0$, TotNumSeries +4$)=$ "Error Sum of squares $=$ "

Cells $(R w, 1)$.Offset $(0$, TotNumSeries +5$)=$ Model.SST

Cells $(R w+1,1)$. Offset $(0$, TotNumSeries +4$)=$ "Regression sum of squares $="$

Cells $(R w+1,1) \cdot$ Offset $(0$, TotNumSeries +5$)=$ Model.SSR

Cells $(R w+2,1)$. Offset $(0$, TotNumSeries +4$)=$ "Total Sum of Squares $=$ "

Cells $(R w+2,1)$.Offset $(0$, TotNumSeries +5$)=$ Model.SST

Cells $(R w+3,1)$. Offset $(0$, TotNumSeries +4$)=$ "R^2 ="

Cells $(R w+3,1) \cdot$ Offset $(0$, TotNumSeries +5$)=$ Model.R2

Cells $(R w+4,1)$. Offset $(0$, TotNumSeries +4$)=$ "Standard Error $=$ "

Cell $s(R w+4,1)$.Offset $(0$, TotNumSeries +5$)=$ Model.StandardError

Cells $(R w+5,1)$. Offset $(0$, TotNumSeries +4$)=$ "ProbF $="$

Cells $(R w+5,1)$. Offset $(0$, TotNumSeries +5$)=$ Model.ProbF

Cells $(R w+6,1)$. Offset $(0$, TotNumSeries +4$)=$ "Y ="

Cells $(R w+6,1) \cdot$ Offset $(0$, TotNumSeries +9$)=$

Worksheets("Fitting_Setup").Range("Model").Value

Cells $(\mathrm{Rw}+7,1)$. Offset $(0$, TotNumSeries +4$)=$ "Model passed to DataFitX ="

Cells $(R w+7,1)$.Offset $(0$, TotNumSeries +9$)=$ ModelString

Print \#1, "Error Sum of squares = "; Tab(30); Model.SST

Print \#1, "Regression sum of squares = "; Tab(30); Model.SSR;

Print \#1, "Total Sum of Squares = "; Tab(30); Model.SST

Print \#1, "R^2 ="; Tab(30); Model.R2

Print \#1, "Standard Error = "; Tab(30); Model.StandardError

Print \#1, "ProbF = "; Tab(30); Model.ProbF

Print \#1, "Y ="; Tab(30); Worksheets("Fitting_Setup").Range("Model").Value

Print \#1, "Model passed to DataFitX ="; Tab(30); ModelString

Close \#1

ResultsTable $=$ Model.ResultTables. ExportSeriesToArrayAlt

$\mathrm{Lb}=\mathrm{LBound}($ ResultsTable, 1$)$

Lb_2 = LBound(ResultsTable, 2)

$\mathrm{Ub}=\mathrm{UBound}($ ResultsTable, 1$)$

Ub_2 = UBound(ResultsTable, 2)

Range(Cells (1, 1), Cells $\left.\left(U b-L b+1, U b \_2-L b \_2+1\right)\right)$.Offset $(1,0)=$ ResultsTable

For I = 0 To TotNumSeries

Range("A1").Offset(0, I).Value = SeriesNames(I)

Next

' more headings

Range("A1").Offset(0, TotNumSeries + 1).Value = "Predicted" 
Range("A1").Offset(0, TotNumSeries + 2).Value = "Residual"

Range("A1").CurrentRegion.Columns.AutoFit

Cells $(1$, TotNumSeries +5$)$. CurrentRegion.Columns.AutoFit

Columns(TotNumSeries +5 ). Font.Bold $=$ True

Range(Cells(2, TotNumSeries +5$)$, Cells(2, TotNumSeries +9$)$ ). Font.Bold $=$ True

Else

MsgBox Model.LastSolveError

MsgBox "Fit failed. See log file"

End If

Model.SaveLog LogDir \& Trim(Title) \& "_LOG.txt"

MsgBox Model.LastSolveError

MsgBox "log file written to " \& LogDir \& Trim(Title) \& "_LOG.txt"

If Model.IsSolved Then

ExptSheetS = Worksheets("Fitting_Setup").Range("ExptConstantS").Value

TheoreticalSheet = Worksheets("Fitting_Setup").Range("Theoretical").Value

If Not Prediction(TheoreticalSheet, NumSeries, SeriesNames, Model) Then End

If Not Prediction(ExptSheetS, NumSeries, SeriesNames, Model) Then

For $\mathrm{J}=1 \mathrm{To} \mathrm{Ub}-\mathrm{Lb}+1$

Worksheets (ExptSheetS).Cells $(\mathrm{J}+1,20) \cdot$ Value $=$ ResultsTable $(\mathrm{Lb}+\mathrm{J}-1$, Ub_2) /

ResultsTable $(\mathrm{Lb}+\mathrm{J}-1, \mathrm{Ub} 2$ - 1$)+1$

Worksheets $($ ExptSheetS $) \cdot$ Cells $(\mathrm{J}+1,24) \cdot$ Value $=$ ResultsTable $\left(\mathrm{Lb}+\mathrm{J}-1, \mathrm{Ub} \_2\right)$

Next

Worksheets(ExptSheetS).Cells(1, 20).Value = "Deviation"

Worksheets(ExptSheetS).Cells(1, 24).Value = "Residuals"

Worksheets(ExptSheetS).ChartObjects("DataPlot1").Activate

ActiveChart.ChartArea.Copy

Worksheets(ExptSheetS).ChartObjects("DataPlot1").Copy

Sheets(OutputSheet).Select

Range("M20").Select

ActiveSheet.Paste

End If

End Sub 
Table (A.3) Stibnite solubility data from 70 to $400^{\circ} \mathrm{C}$. Data listed by temperature. Two $\mathrm{pH}$ values are included: the $\mathrm{pH}$ measured at room temperature $\left(\mathrm{pH}_{\text {exit }}\right)$ and $\mathrm{pH}$ calculated by charge balance without antimony-sulfide species is included $\left(\mathrm{pH}_{\text {calc }}\right)$.

\begin{tabular}{|c|c|c|c|c|c|c|c|c|c|c|c|}
\hline Exp. & $\mathbf{T}\left({ }^{\circ} \mathbf{C}\right)$ & $2 * \sigma$ & $\mathbf{P}$ (bar) & $2 * \sigma$ & $\mathrm{pH}_{\text {exit }}$ & $2 * \sigma$ & $\begin{array}{c}\mathrm{pH}_{\text {calc with }} \\
\mathrm{Sb}(\mathrm{OH})_{3}\end{array}$ & $\begin{array}{c}\mathrm{Sb} \\
\left(\mathrm{mol} \mathrm{kg}^{-1}\right)\end{array}$ & $2 * \sigma$ & $\begin{array}{c}\mathrm{S}_{\mathrm{tot}} \\
\left(\mathrm{mol} \mathrm{kg}^{-1}\right)\end{array}$ & $2 * \sigma$ \\
\hline Sb107 & 66.6 & 0.4 & 25.9 & 1.3 & 8.51 & 0.01 & 8.19 & $3.31 \times 10^{\wedge}-5$ & $1.01 \times 10^{\wedge}-5$ & 0.011 & 0.0007 \\
\hline $\mathrm{Sb} 108$ & 68.8 & 0.3 & 23.0 & 0.3 & 8.44 & 0.10 & 7.97 & $3.38 \times 10^{\wedge}-4$ & $7.86 \times 10^{\wedge}-5$ & 0.055 & 0.005 \\
\hline $\mathrm{Sb} 109$ & 69.0 & 0.2 & 23.7 & 1.4 & 6.38 & 0.00 & 6.53 & $3.12 \times 10^{\wedge}-6$ & $1.01 \times 10^{\wedge}-6$ & 0.025 & 0.001 \\
\hline $\mathrm{Sb} 103$ & 70.4 & 0.0 & 23.4 & 0.0 & 3.59 & - & 3.52 & $1.20 \times 10^{\wedge}-7$ & $4.18 \times 10^{\wedge}-8$ & 0.032 & 0.000 \\
\hline $\mathrm{Sb} 102$ & 70.7 & 0.2 & 26.3 & 5.2 & 3.53 & 0.06 & 3.52 & $1.92 \times 10^{\wedge}-7$ & $1.54 \times 10^{\wedge}-7$ & 0.010 & 0.003 \\
\hline $\mathrm{Sb} 100$ & 71.1 & 0.3 & 38.0 & 5.7 & 6.49 & 0.01 & 6.51 & $9.35 \times 10^{\wedge}-6$ & $4.69 \times 10^{\wedge}-6$ & 0.012 & 0.001 \\
\hline $\mathrm{Sb} 101$ & 74.0 & 0.0 & 26.5 & 0.0 & 4.58 & 0.21 & 4.48 & $2.24 \times 10^{\wedge}-7$ & $1.10 \times 10^{\wedge}-7$ & 0.011 & 0.0003 \\
\hline Sb106 & 75.4 & 0.5 & 25.2 & 0.8 & 5.89 & 0.03 & 5.87 & $2.58 \times 10^{\wedge}-6$ & $6.21 \times 10^{\wedge}-7$ & 0.013 & 0.003 \\
\hline $\mathrm{Sb} 103$ & 98.0 & 0.0 & 27.6 & 0.0 & - & - & 3.52 & $1.41 \times 10^{\wedge}-6$ & $6.83 \times 10^{\wedge}-7$ & - & - \\
\hline $\mathrm{Sb} 105$ & 107.4 & 0.5 & 23.6 & 0.1 & 7.12 & 0.01 & 6.60 & $3.02 \times 10^{\wedge}-5$ & $2.15 \times 10^{\wedge}-6$ & 0.007 & 0.002 \\
\hline Sb99 & 108.7 & 0.4 & 63.1 & 17.5 & 7.22 & 0.03 & 7.38 & $7.74 \times 10^{\wedge}-5$ & $6.33 \times 10^{\wedge}-6$ & 0.028 & 0.001 \\
\hline $\mathrm{Sb} 105$ & 110.5 & 0.3 & 159.0 & 0.3 & - & - & 6.58 & $3.46 \times 10^{\wedge}-5$ & $4.76 \times 10^{\wedge}-6$ & 0.007 & 0.001 \\
\hline $\mathrm{Sb} 105$ & 111.2 & 0.8 & 43.9 & 4.0 & 7.28 & 0.01 & 6.52 & $3.82 \times 10^{\wedge}-5$ & $1.55 \times 10^{\wedge}-5$ & 0.008 & 0.003 \\
\hline $\mathrm{Sb} 104$ & 117.9 & 1.5 & 26.2 & 0.2 & 4.93 & 0.08 & 4.69 & $1.40 \times 10^{\wedge}-6$ & $5.06 \times 10^{\wedge}-7$ & 0.014 & 0.003 \\
\hline $\mathrm{Sb} 101$ & 146.0 & 0.0 & 20.7 & 0.0 & 4.73 & - & 4.50 & $2.23 \times 10^{\wedge}-6$ & $1.51 \times 10^{\wedge}-6$ & 0.010 & - \\
\hline $\mathrm{Sb} 106$ & 146.9 & 1.9 & 28.0 & 0.8 & 5.83 & 0.08 & 5.99 & $4.17 \times 10^{\wedge}-6$ & $1.14 \times 10^{\wedge}-6$ & 0.010 & 0.001 \\
\hline Sb109 & 148.5 & 1.2 & 32.2 & 1.1 & 6.38 & 0.00 & 6.51 & $1.33 \times 10^{\wedge}-5$ & $1.95 \times 10^{\wedge}-6$ & 0.025 & 0.002 \\
\hline $\mathrm{Sb} 100$ & 149.8 & 0.1 & 64.1 & 1.0 & - & - & 6.45 & $7.77 \times 10^{\wedge}-6$ & $1.09 \times 10^{\wedge}-6$ & 0.013 & $6.2 \mathrm{E}-05$ \\
\hline $\mathrm{Sb} 100$ & 150.1 & 0.9 & 29.6 & 0.8 & 6.52 & - & 6.37 & $1.68 \times 10^{\wedge}-5$ & $5.38 \times 10^{\wedge}-6$ & 0.015 & 0.003 \\
\hline $\mathrm{Sb} 103$ & 150.3 & 0.0 & 0.0 & 0.0 & - & - & 3.52 & $1.56 \times 10^{\wedge}-6$ & $5.56 \times 10^{\wedge}-7$ & - & - \\
\hline Sb98 & 152.5 & 10.3 & 82.6 & 51.8 & 7.02 & 0.05 & 7.25 & $5.16 \times 10^{\wedge}-5$ & $5.66 \times 10^{\wedge}-6$ & 0.030 & 0.004 \\
\hline Sb107 & 153.2 & 1.1 & 30.4 & 0.2 & 8.47 & 0.11 & 7.99 & $2.16 \times 10^{\wedge}-4$ & $1.82 \times 10^{\wedge}-5$ & 0.011 & 0.0004 \\
\hline Sb97 & 154.5 & 4.9 & 63.4 & 3.7 & 7.49 & 0.05 & 8.35 & $1.08 \times 10^{\wedge}-4$ & $2.90 \times 10^{\wedge}-5$ & 0.022 & 0.004 \\
\hline $\mathrm{Sb} 107$ & 193.1 & 0.4 & 39.1 & 0.7 & 8.41 & 0.07 & & $5.84 \times 10^{\wedge}-4$ & $2.64 \times 10^{\wedge}-4$ & 0.011 & 0.0009 \\
\hline $\mathrm{Sb} 106$ & 193.4 & 1.0 & 31.0 & 0.9 & - & - & 5.90 & $6.69 \times 10^{\wedge}-6$ & $1.37 \times 10^{\wedge}-6$ & 0.012 & $6.8 \mathrm{E}-05$ \\
\hline $\mathrm{Sb} 108$ & 193.5 & 0.6 & 39.4 & 18.5 & 10.80 & 0.01 & 7.87 & $4.02 \times 10^{\wedge}-3$ & $5.56 \times 10^{\wedge}-4$ & 0.053 & 0.003 \\
\hline $\mathrm{Sb} 102$ & 195.9 & 0.4 & 26.3 & 0.2 & - & - & & $4.63 \times 10^{\wedge}-6$ & $1.74 \times 10^{\wedge}-6$ & 0.011 & 0.001 \\
\hline $\mathrm{Sb} 109$ & 201.4 & 1.4 & 38.0 & 0.2 & 6.43 & - & 6.50 & $4.10 \times 10^{\wedge}-5$ & $1.38 \times 10^{\wedge}-5$ & 0.025 & 0.003 \\
\hline $\mathrm{Sb} 94$ & 203.0 & 2.0 & 45.1 & 3.8 & 7.54 & 0.17 & 8.14 & $1.87 \times 10^{\wedge}-4$ & $1.19 \times 10^{\wedge}-5$ & 0.020 & 0.001 \\
\hline Sb98 & 204.9 & 9.8 & 108.8 & 63.6 & 7.12 & 0.03 & 7.33 & $1.40 \times 10^{\wedge}-4$ & $9.70 \times 10^{\wedge}-6$ & 0.028 & 0.003 \\
\hline $\mathrm{Sb} 100$ & 205.1 & 2.7 & 30.0 & 0.7 & 6.57 & 0.14 & 6.44 & $3.22 \times 10^{\wedge}-5$ & $2.36 \times 10^{\wedge}-5$ & 0.013 & 0.0001 \\
\hline $\mathrm{Sb} 106$ & 246.8 & 0.4 & 61.9 & 0.7 & - & - & 5.93 & $3.30 \times 10^{\wedge}-5$ & $2.32 \times 10^{\wedge}-5$ & 0.011 & 0.011 \\
\hline Sb 107 & 248.2 & 1.9 & 85.2 & 0.3 & 8.94 & - & 7.34 & $1.34 \times 10^{\wedge}-3$ & $1.72 \times 10^{\wedge}-4$ & 0.015 & 0.001 \\
\hline Sb98 & 248.3 & 10.2 & 161.9 & 29.8 & - & - & 7.26 & $3.62 \times 10^{\wedge}-4$ & $2.71 \times 10^{\wedge}-5$ & 0.029 & 0.005 \\
\hline $\mathrm{Sb} 100$ & 251.5 & 2.2 & 55.4 & 0.7 & - & - & 6.45 & $2.07 \times 10^{\wedge}-4$ & $3.96 \times 10^{\wedge}-5$ & 0.013 & 0.0005 \\
\hline $\mathrm{Sb} 108$ & 251.6 & 0.8 & 84.0 & 0.3 & - & - & 7.94 & $3.43 \times 10^{\wedge}-3$ & $5.46 \times 10^{\wedge}-4$ & 0.056 & 0.013 \\
\hline $\mathrm{Sb} 109$ & 252.7 & 0.5 & 62.8 & 0.4 & - & - & 6.49 & $9.73 \times 10^{\wedge}-5$ & $3.45 \times 10^{\wedge}-5$ & 0.025 & 0.001 \\
\hline $\mathrm{Sb} 102$ & 252.7 & 1.5 & 52.2 & 0.2 & - & - & 3.54 & $5.44 \times 10^{\wedge}-5$ & $1.91 \times 10^{\wedge}-5$ & 0.011 & 0.0004 \\
\hline $\mathrm{Sb} 109$ & 253.0 & 0.5 & 117.4 & 2.0 & - & - & 6.45 & $7.50 \times 10^{\wedge}-5$ & $2.02 \times 10^{\wedge}-5$ & 0.027 & 0.001 \\
\hline Sb107 & 300.2 & 0.6 & 155.0 & 1.6 & - & - & 7.87 & $2.12 \times 10^{\wedge}-3$ & $5.97 \times 10^{\wedge}-5$ & 0.015 & 0.0005 \\
\hline $\mathrm{Sb} 106$ & 301.1 & 0.8 & 131.3 & 5.3 & - & - & 5.77 & $2.04 \times 10^{\wedge}-4$ & $2.47 \times 10^{\wedge}-5$ & 0.016 & 0.003 \\
\hline $\mathrm{Sb} 100$ & 302.8 & 3.0 & 111.3 & 4.7 & - & - & 6.38 & $1.15 \times 10^{\wedge}-3$ & $1.65 \times 10^{\wedge}-4$ & 0.016 & 0.001 \\
\hline $\mathrm{Sb} 102$ & 303.1 & 1.4 & 113.5 & 1.4 & - & - & 3.54 & $3.17 \times 10^{\wedge}-4$ & $5.09 \times 10^{\wedge}-5$ & 0.012 & 0.004 \\
\hline Sb98 & 303.7 & 8.8 & 186.5 & 56.1 & - & - & 7.10 & $8.76 \times 10^{\wedge}-4$ & $9.53 \times 10^{\wedge}-5$ & 0.031 & 0.001 \\
\hline Sb109 & 304.1 & 0.8 & 137.7 & 0.2 & - & - & 6.39 & $1.92 \times 10^{\wedge}-4$ & $2.12 \times 10^{\wedge}-5$ & 0.028 & 0.002 \\
\hline $\mathrm{Sb} 108$ & 304.5 & 1.0 & 178.1 & 1.3 & - & - & 7.85 & $5.98 \times 10^{\wedge}-3$ & $4.79 \times 10^{\wedge}-4$ & 0.062 & 0.003 \\
\hline $\mathrm{Sb} 102$ & 307.7 & 1.1 & 201.2 & 0.6 & - & - & 3.55 & $2.74 \times 10^{\wedge}-4$ & $4.90 \times 10^{\wedge}-5$ & 0.012 & 0.002 \\
\hline Sb99 & 308.6 & 2.5 & 115.1 & 21.4 & - & - & 7.08 & $9.10 \times 10^{\wedge}-4$ & $2.16 \times 10^{\wedge}-4$ & 0.031 & 0.003 \\
\hline
\end{tabular}


Table (A.3) Stibnite solubility data from 70 to $400^{\circ} \mathrm{C}$. Continued

\begin{tabular}{|c|c|c|c|c|c|c|c|c|c|c|c|}
\hline Exp. & $\mathbf{T}\left({ }^{\circ} \mathbf{C}\right)$ & $2 * \sigma$ & $\mathbf{P}$ (bar) & $2 * \sigma$ & $\mathbf{p H}_{\text {exit }}$ & $2 * \sigma$ & $\begin{array}{c}\mathrm{pH}_{\text {calc with }} \\
\mathrm{Sb}(\mathrm{OH})_{3}\end{array}$ & $\begin{array}{c}\mathrm{Sb} \\
\left(\mathrm{mol} \mathrm{kg}^{-1}\right)\end{array}$ & $2 * \sigma$ & $\begin{array}{c}\mathrm{S}_{\mathrm{tot}} \\
\left(\mathrm{mol} \mathrm{kg}^{-1}\right)\end{array}$ & $2 * \sigma$ \\
\hline$\overline{\mathrm{Sb} 106}$ & 343.2 & 1.8 & 192.2 & 57.6 & - & - & 5.85 & $2.01 \times 10^{\wedge}-3$ & $2.33 \times 10^{\wedge}-4$ & 0.016 & 0.0004 \\
\hline $\mathrm{Sb} 107$ & 344.6 & 1.0 & 249.1 & 0.4 & - & - & 8.19 & $3.31 \times 10^{\wedge}-3$ & $3.61 \times 10^{\wedge}-4$ & 0.018 & 0.002 \\
\hline $\mathrm{Sb} 109$ & 347.0 & 0.7 & 250.0 & 0.2 & - & - & 6.33 & $8.84 \times 10^{\wedge}-4$ & $1.13 \times 10^{\wedge}-4$ & 0.028 & 0.003 \\
\hline $\mathrm{Sb} 109$ & 347.1 & 0.5 & 192.9 & 0.2 & - & - & 6.33 & $7.09 \times 10^{\wedge}-4$ & $2.33 \times 10^{\wedge}-5$ & 0.027 & 0.0004 \\
\hline $\mathrm{Sb} 109$ & 348.1 & 1.5 & 215.1 & 0.2 & - & - & 6.33 & $7.63 \times 10^{\wedge}-4$ & $1.95 \times 10^{\wedge}-4$ & 0.027 & 0.003 \\
\hline Sb99 & 350.2 & 1.5 & 203.6 & 0.6 & - & - & 6.81 & $2.91 \times 10^{\wedge}-3$ & $7.04 \times 10^{\wedge}-5$ & 0.036 & 0.0002 \\
\hline $\mathrm{Sb} 100$ & 351.1 & 3.5 & 168.3 & 1.3 & - & - & 6.14 & $3.63 \times 10^{\wedge}-3$ & $1.22 \times 10^{\wedge}-3$ & 0.022 & 0.006 \\
\hline $\mathrm{Sb} 102$ & 352.7 & 1.7 & 201.0 & 0.7 & - & - & 3.55 & $1.76 \times 10^{\wedge}-3$ & $2.23 \times 10^{\wedge}-4$ & 0.016 & 0.001 \\
\hline $\mathrm{Sb} 100$ & 389.7 & 7.5 & 203.1 & 9.9 & - & - & 14.45 & $2.46 \times 10^{\wedge}-3$ & $8.57 \times 10^{\wedge}-4$ & 0.042 & 0.026 \\
\hline Sb107 & 395.8 & 7.9 & 197.2 & 15.5 & - & - & 13.83 & $9.16 \times 10^{\wedge}-4$ & $3.80 \times 10^{\wedge}-4$ & 0.038 & 0.007 \\
\hline $\mathrm{Sb} 100$ & 395.9 & 1.4 & 303.6 & 51.1 & - & - & 9.21 & $1.57 \times 10^{\wedge}-2$ & $3.08 \times 10^{\wedge}-3$ & 0.035 & 0.073 \\
\hline $\mathrm{Sb} 100$ & 396.0 & 3.0 & 252.7 & 16.5 & - & - & 12.65 & $3.78 \times 10^{\wedge}-3$ & $1.21 \times 10^{\wedge}-3$ & 0.029 & 0.009 \\
\hline $\mathrm{Sb} 104$ & 398.4 & 0.2 & 170.2 & 1.4 & - & - & 12.99 & $3.45 \times 10^{\wedge}-4$ & $1.77 \times 10^{\wedge}-4$ & - & - \\
\hline $\mathrm{Sb} 105$ & 400.5 & 0.0 & 228.2 & 0.0 & - & - & 12.65 & $2.77 \times 10^{\wedge}-3$ & $8.50 \times 10^{\wedge}-4$ & 0.039 & 0.030 \\
\hline $\mathrm{Sb} 105$ & 400.6 & 0.0 & 291.0 & 0.0 & - & - & 10.44 & $1.46 \times 10^{\wedge}-2$ & $4.69 \times 10^{\wedge}-3$ & 0.035 & 0.009 \\
\hline Sb107 & 401.1 & 0.4 & 158.8 & 3.8 & - & - & 14.60 & $2.43 \times 10^{\wedge}-4$ & $7.08 \times 10^{\wedge}-5$ & 0.036 & 0.008 \\
\hline $\mathrm{Sb} 102$ & 401.4 & 2.6 & 190.3 & 5.0 & - & - & 6.05 & $4.79 \times 10^{\wedge}-4$ & $2.94 \times 10^{\wedge}-4$ & 0.025 & 0.005 \\
\hline $\mathrm{Sb} 104$ & 404.3 & 0.9 & 233.6 & 1.2 & - & - & 11.59 & $1.21 \times 10^{\wedge}-3$ & $4.65 \times 10^{\wedge}-4$ & - & - \\
\hline $\mathrm{Sb} 102$ & 405.9 & 0.2 & 245.6 & 0.7 & - & - & 5.80 & $2.43 \times 10^{\wedge}-3$ & $4.30 \times 10^{\wedge}-4$ & 0.027 & 0.013 \\
\hline
\end{tabular}


Speciation above $25^{\circ} \mathrm{C}$ involved two loops:

1. Speciation of solution using guessed $\mathrm{pH}$ and ionic strength using the following equations and the iterative capacity of Excel.

2. $\mathrm{pH}$ iterative calculated from the solution charge balance using the Solver add-in to Excel, including iteration of ionic strength in macro. Iterated until ionic strength and $\mathrm{pH}$ no longer changed.

Activity coefficients $(\gamma)$ were defined in Equation (2.23) and ionic strength in Equation (2.24). $K_{\mathrm{NaOH}}$, $K_{\text {NaHS }}$, and $K_{H 2 S}$ were defined in Equations (2.18) through (2.20).

\section{pH balance equation:}

Fit equation:

$$
0=m_{H^{+}}+m_{N a^{+}}-m_{H S^{-}}-m_{O H^{-}}+\sum_{i}^{x y z w} m S b_{x y z w} *(3 x-2 y-2 z+w)
$$

" $3 \mathrm{x}-2 \mathrm{y}-2 \mathrm{z}+\mathrm{w}$ " is the charge of the antimony complex (see Equation (2.3))

Components of fit equation:

$$
\begin{gathered}
m_{H^{+}}=\frac{m_{H^{+}}}{\gamma_{H^{+}}} \\
m_{O H^{-}}=\frac{K_{w}}{a_{H^{+}} \gamma_{O H^{-}}} \\
m_{N a^{+}}=m_{N a_{\text {total }}} * \text { fraction }_{\mathrm{Na}^{+}} \\
m_{\mathrm{HS}^{-}}=m_{S_{\text {total }}} * \text { fraction }_{\mathrm{HS}^{-}}
\end{gathered}
$$

\section{Derivation of fraction $_{\mathrm{Na}+}$ and fraction $_{\mathrm{HS}-}$ :}

\section{Sulfide species:}

$$
\text { fraction }_{H S^{-}}=\frac{m_{H S^{-}}}{m_{S_{\text {total }}}}=\frac{m_{H S^{-}}}{m_{H_{2} S}+m_{N a H S^{\circ}}+m_{H S^{-}}}
$$

Concentration of HS- combining $\mathrm{H}_{2} \mathrm{~S}$ disassociation reaction and sulfide balance:

$$
m_{H S^{-}}=\frac{K_{H_{2} S} * m_{H_{2} S}}{\gamma_{H S^{-}} * a_{H^{+}}}=\frac{K_{H_{2} S}\left(m_{S_{\text {total }}}-m_{H S^{-}}-m_{N a S H^{\circ}}\right)}{\gamma_{H S^{-}} * a_{H^{+}}}
$$

Expanded and with $\mathrm{mNaSH}^{\circ}$ in terms of the association reaction:

$$
m_{H S^{-}}=\frac{K_{H_{2} S} * m_{S_{\text {total }}}-K_{H_{2} S} * m_{H S^{-}}-K_{H_{2} S} \frac{\gamma_{N a^{+}} m_{N a^{+}} m_{H S^{-}} \gamma_{H S^{-}}}{K_{N a H S^{o}}}}{\gamma_{H S^{-}} * a_{H^{+}}}
$$

Write as individual quotients

$$
m_{H S^{-}}=\frac{K_{\mathrm{H}_{2} S} * m_{S_{\text {total }}}}{\gamma_{\mathrm{HS}^{-}} * a_{\mathrm{H}^{+}}}-\frac{K_{\mathrm{H}_{2} S} * m_{\mathrm{HS}^{-}}}{\gamma_{H S^{-}} * a_{\mathrm{H}^{+}}}-\frac{K_{\mathrm{H}_{2} S} * \gamma_{\mathrm{Na}^{+}} * m_{\mathrm{Na}^{+}} * m_{\mathrm{HS}^{-}}}{a_{\mathrm{H}^{+}} * K_{N a S H^{\circ}}}
$$

and divide through by $1 / \mathrm{mHS}$ - so that $\mathrm{mHS}$ - is only in one term: 


$$
1=\frac{K_{\mathrm{H}_{2} S} * m_{S_{\text {total }}}}{\gamma_{H S^{-}} * a_{H^{+}} * m_{H S^{-}}}-\frac{K_{\mathrm{H}_{2} S}}{\gamma_{H S^{-}} * a_{H^{+}}}-\frac{K_{\mathrm{H}_{2} S} * \gamma_{\mathrm{Na}^{+}} * m_{\mathrm{Na}^{+}}}{a_{\mathrm{H}^{+}} * K_{\mathrm{NaSH}^{\circ}}}
$$

Rearrange to isolate term including mHS- on one side of the equation:

$$
\frac{K_{\mathrm{H}_{2} S} * m_{S_{\text {total }}}}{\gamma_{\mathrm{HS}^{-}} * a_{\mathrm{H}^{+}} * m_{\mathrm{HS}^{-}}}=1+\frac{K_{\mathrm{H}_{2} S}}{\gamma_{\mathrm{HS}^{-}} * a_{\mathrm{H}^{+}}}+\frac{K_{\mathrm{H}_{2} S} * \gamma_{\mathrm{Na}^{+}} * m_{\mathrm{Na}}}{a_{\mathrm{H}^{+}} * K_{\mathrm{NaSH}^{\circ}}}
$$

Divide through by quotient to isolate mHS-:

$$
\frac{1}{m_{H S^{-}}}=\frac{\gamma_{H S^{-}} * a_{H^{+}}}{K_{H_{2} S} * m_{S_{\text {total }}}}+\frac{1}{m_{S_{\text {total }}}}+\frac{\gamma_{N a^{+}} * m_{N a^{+}} * \gamma_{H S^{-}}}{K_{N a S H^{\circ}} * m_{S_{\text {total }}}}
$$

Invert above and divide through by $1 / \mathrm{mStotal}$ to obtain equation for fraction of HS- to get final equation:

$$
\text { fraction }_{H S^{-}}=\frac{1}{\frac{a_{H^{+} \gamma_{H S^{-}}}}{K_{H_{2} S}}+1+\frac{\gamma_{H S^{-}} \gamma_{N a^{+}} m_{N a^{+}}}{K_{N a H S^{o}}}}
$$

Note that $m_{\text {Stotal }}$ was replaced with $m_{\text {Sfree }}$ when antimony-sulfide complexes were present, as developed with Equations (2.22) and (4.9).

\section{Sodium species:}

$$
\text { fraction }_{\mathrm{Na}^{+}}=\frac{m_{\mathrm{Na}}}{m_{\mathrm{Na} a_{\text {total }}}}=\frac{m_{N a^{+}}}{m_{N a^{+}}+m_{N a H S^{\circ}}+m_{N a O H}{ }^{\circ}}
$$

Divide left side by $\mathrm{mNa}+\mathrm{mNa}+$

$$
\text { fraction }_{\mathrm{Na}^{+}}=\frac{1}{1+\frac{m_{\mathrm{NaHS}}{ }^{\circ}}{m_{\mathrm{Na}^{+}}}+\frac{m_{\mathrm{NaOH}}}{m_{\mathrm{Na}^{+}}}}
$$

Write $\mathrm{m}_{\mathrm{NaOH}^{\circ}}$ in terms of $\mathrm{NaOH}$ dissociation reaction and water reaction. Similar treatment for NaHS

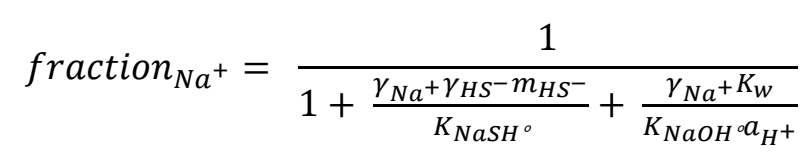




\section{VisualBasic Charge Balance Macro}

Macro uses the generalized reduced gradient (GRG) method to minimize the charge balance equation by adjusting the $\mathrm{pH}$. Then the new ionic strength is used and the optimization is repeated.

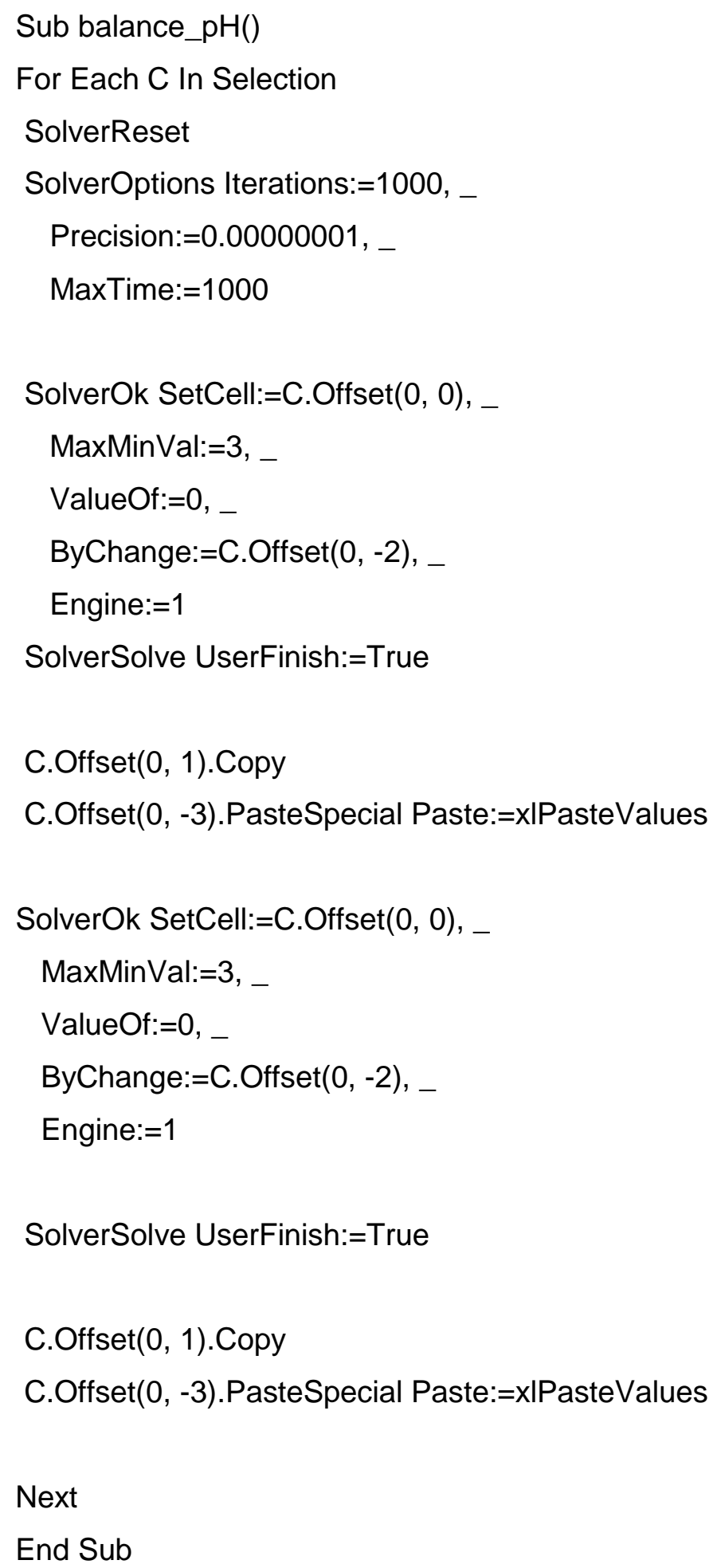


Figure (A.2) SEM images of reacted stibnite from high temperature experiments. Images demonstrate grain-size distribution and embayed surfaces of reacted grains, including preferential dissolution parallel to the c-axis.
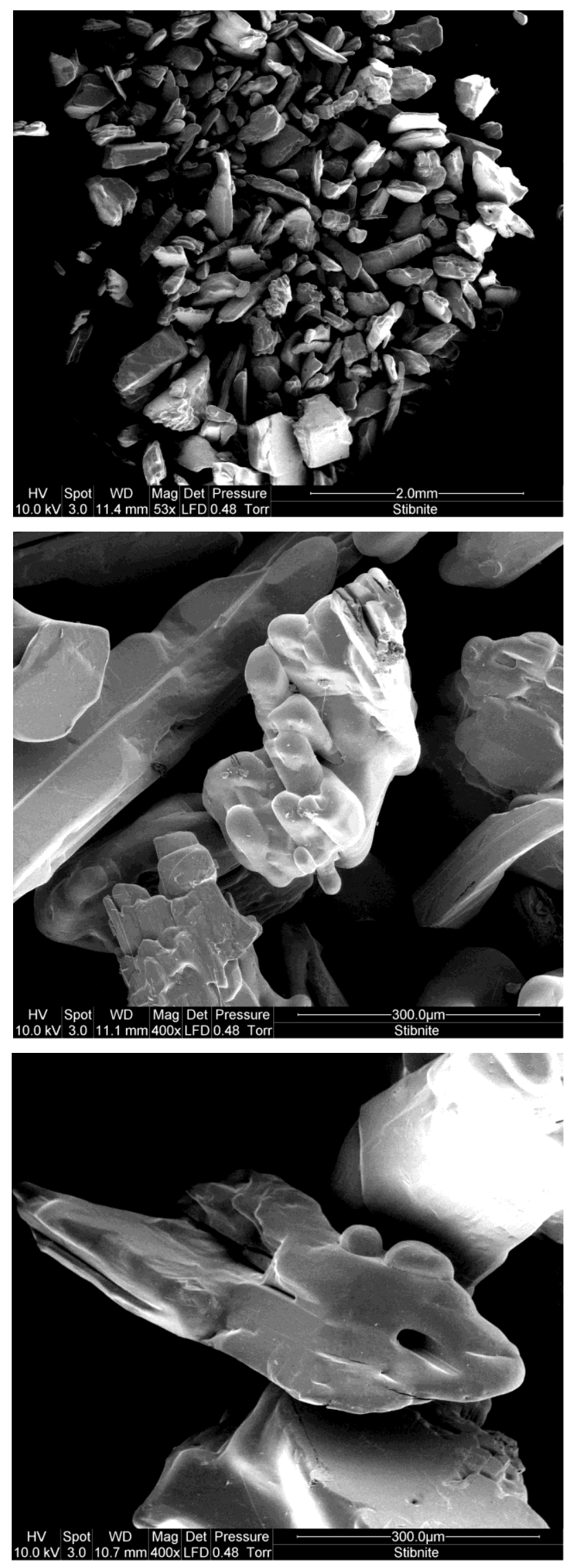
